*ak RMIS View/Frint Document Cover Sheet tow

This document was retrieved from the Documentation and Records Manaqement (DRM) ISEARCH System. It is intended for Information only and may not be the most recent or updated version. Contact a Document Service Center (see Hanford Info for locations) if you need additional retrieval information.

Accession \#: D196040515

Document \#: SD-WM-ER-525

Title/Desc:

THERMAL HYDRAULIC FEASIBILITY ASSESSMENT FOR THE SNF PROJECT

Pages: 251 


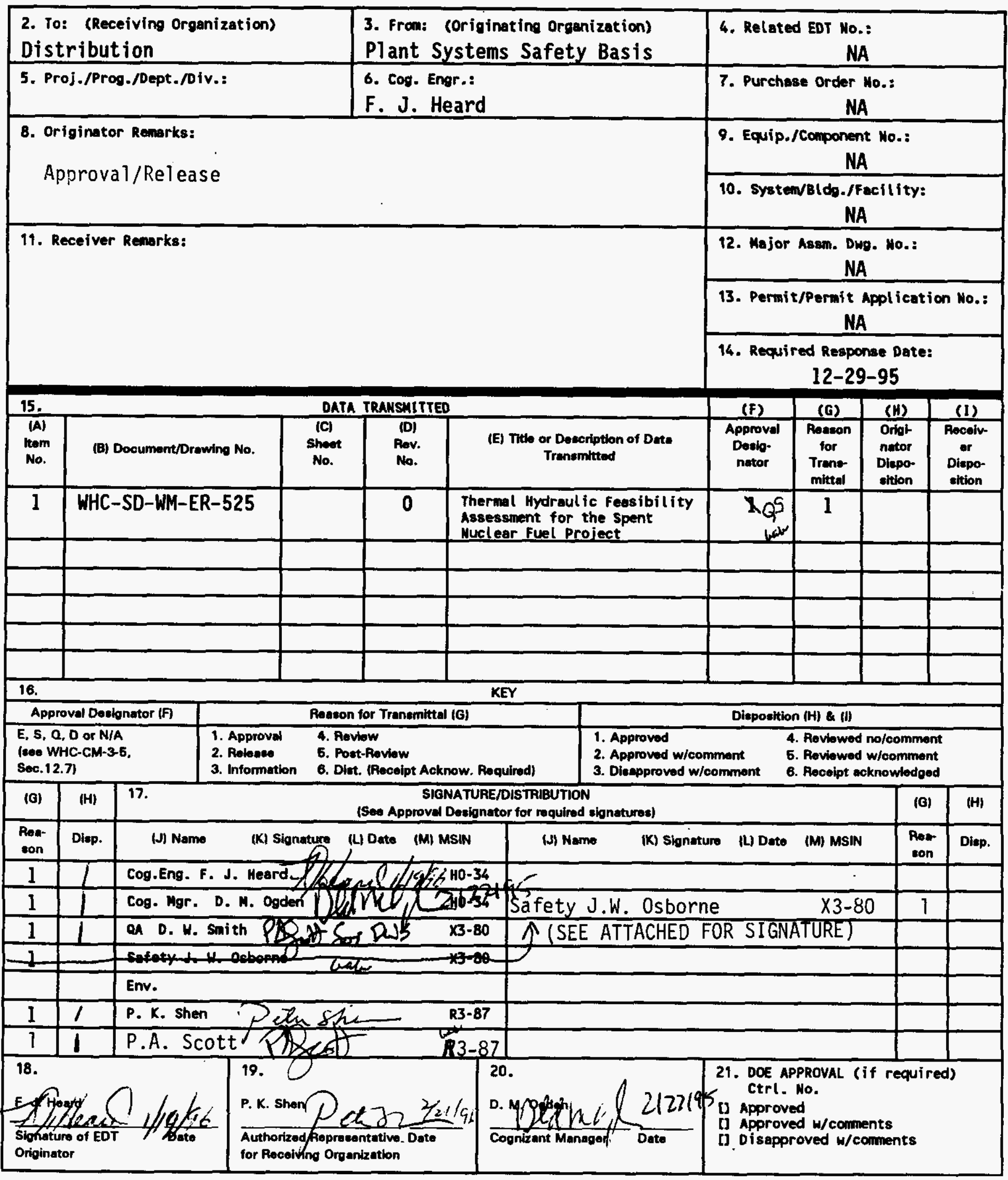




\section{ENGINEERING DATA TRANSMITTAL}

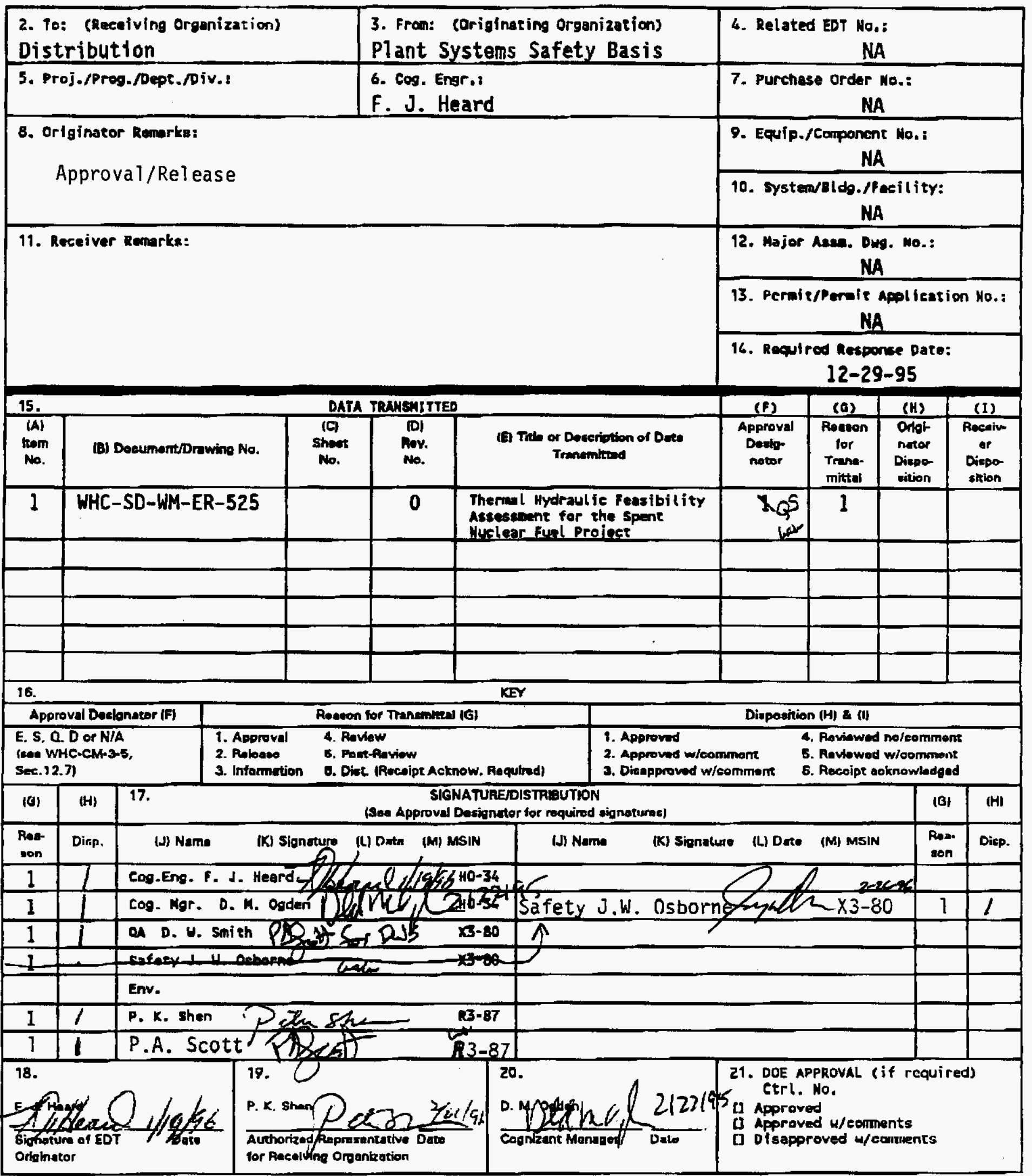




\title{
Thermal Hydraulic Feasibility Assessment for the Spent Nuclear Fuel Project
}

\author{
F. J. Heard \\ Westinghouse Hanford Company, Richland, WA 99352 \\ U.S. Department of Energy Contract DE-AC06-87RL10930

$\begin{array}{lll}\text { EDT/ECN: } & 613539 & \text { UC: } 2020 \\ \text { Org Code: } & 74 A 50 & \text { Charge Code: } \\ \text { B\&R Code: } & \text { E23135040 }\end{array}$

Key Words: Spent Nuclear Fuel, K Basins, Thermal Hydraulic, Chemical Reactions, Corrosion, Finite Element Methods, Models, Temperature Control, Canister Storage Building, Multi-Canister Overpak, Technical Acquisition Progran, Scoping Analyses, Path Forward, Integrated Process Strategy

Abstract: A series of scoping analyses have been completed investigating the thermal-hydraulic performance and feasibility of the Spent Nuclear Fuel Project (SWFP) Integrated Process Strategy (IPS). The SWFP was establ ished to develop engineered solutions for the expedited removal, stabilization, and storage of spent muclear fuel from the $X$ Basins at the U.S. Department of Energy's Hanford site in Richland, Washington. The subject efforts focused on independently investigating, quantifying, and establishing the governing hest production and removal mechanisms for each of the IPS operations and configurations, obtaining preliminary results for comparison with and verification of other analyses, and providing technology-based recommendations for consideration and incorporation into the design bases for the SNFP. The goal was to develop a series of thermalhydraulic models that could respond to all process and safety-related issues that may arise pertaining to the SNFP. A series of sensitivity analyses were also performed to help identify those parameters that have the greatest impact on energy transfer and, hence, temperature control. It is anticipated that the subject thermal-hydraulic models will form the basis for a series of advanced and more detailed models that will more accurately reflect the thermal performance of the IPS and alleviate the necessity for some of the more conservative assumptions and oversimplifications, as well as form the basis for the final process and safety analyses.

TRADEMARK DISCLAIMER. Reference herein to any specific commercial product, process, or service by trade name, trademark, manufacturer, or otherwise, does not necessarily constitute or imoly its endorsement, recommendation, or favoring by the United States Goverment or any agency thereof or its contractors or subcontractors.

Printed in the United States of America. To obtain copies of this document, contact: UHC/BCS Document Control Services, P.O. Box 1970, Mailstop H6-08, Richland WA 99352 Phone (509) 372-2420. Fax (509) 376-4989.

$\frac{\operatorname{lomit} \text { dosideng } 2-29-96}{\text { Date }}$

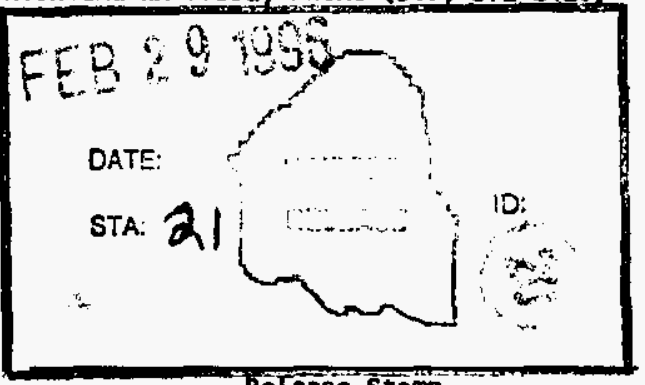

Approved for Public Release 
WHC-SD-WM-ER-525

Rev. 0

\title{
Thermal Hydraulic Feasibility Assessment for the Spent Nuclear Fuel Project
}

\author{
F. J. Heard \\ E. R. Cramer \\ T. R. Beaver \\ Westinghouse Hanford Company
}

M. J. Thurgood

John Marvin, Inc.

January 1996

Issued by

WESTINGHOUSE HANFORD COMPANY

for the

U.S. DEPARTMENT OF ENERGY

RICHLAND OPERATIONS OFFICE

RICHLAND, WASHINGTON 
WHC-SD-WM-ER-525

Rev. 0

THERMAL HYDRAULIC FEASIBILITY ASSESSMENT FOR THE

SPENT NUCLEAR FUEL PROJECT

\author{
F. J. Heard \\ E. R. Cramer \\ T. R. Beaver \\ Westinghouse Hanford Company \\ M. J. Thurgood \\ John Marvin, Inc.
}

\title{
ABSTRACT
}

A series of scoping analyses have been completed investigating the thermal-hydraulic performance and feasibility of the Spent Nuclear Project (SNP) Integrated Process Strategy (IPS). The SNFP was established to develop engineered solutions for the expedited removal, stabilization, and storage of spent nuclear fuel from the $K$ Basins at the U.S. Department of Energy's Hanford Site in Richland, Washington. The subject efforts focused on independently investigating, quantifying, and establishing the governing heat production and removal mechanisms for each of the IPS operations and configurations, obtaining preliminary results for comparison with and verification of other analyses, and providing technology-based recommendations for consideration and incorporation into the design bases for the SNFP. The goal was to develop a series of thermal-hydraulic models that could respond to all process and safety-related issues that may arise pertaining to the SNFP. A series of sensitivity analyses were also performed to help identify those parameters that have the greatest impact on energy transfer and, hence, temperature control. It is anticipated that the subject thermal-hydraulic models will form the basis for a series of advanced and more detailed models that will more accurately reflect the thermal performance of the IPS and 
WHC-SD-WM-ER-525

Rev. 0

alleviate the necessity for some of the more conservative assumptions and oversimplifications, as well as form the basis for adding refinements prior to performing the final process and safety analyses. 
WHC-SD-WM-ER-525

Rev. 0

\section{EXECUTIVE SUMMARY}

A series of scoping analyses have been completed investigating the thermal hydraulic performance and feasibility of the Spent Nuclear Fuel Project (SNFP) Integrated Process Strategy (IPS). The SNF Project was established to develop engineered solutions for the expedited removal, stabilization, and storage of spent nuclear fuel from the $K$ Basins at the U.S. Department of Energy's Hanford Site in Richland, Washington.

The subject efforts focused on investigating, quantifying, and establishing the governing heat production and removal mechanisms for each of the individual IPS operations and configurations, obtaining preliminary results for comparison with and verification of other analyses, and providing technology based recommendations for consideration and incorporation into the design bases for the SNFP. The goal was to develop a series of thermalhydraulic models that could respond to all process and safety related issues that may arise pertaining to the SNFP. A series of sensitivity analyses were also performed to help identify those parameters that have the greatest impact on energy transfer and, hence, temperature control. It is anticipated that the subject thermal-hydraulic models will form the basis for a series of advanced and more detailed models that will more accurately reflect the thermal performance of the IPS and alleviate the necessity for some of the more conservative assumptions and over simplifications, as well form the basis for adding refinements prior to performing the final process and safety analyses.

By necessity the level of thermal analysis documented within this report was scoping in nature. This was driven by the general complexity of the IPS, 
WHC-SD-WM-ER-525

Rev. 0

the preliminary realization of the extent of fuel corrosion, the large number of possible geometrical configurations, the rapidly evolving Multi-Canister Overpak (MCO) and transportation shipping cask designs, the incredible demand for thermal hydraulic information, and the limited time to preform the analyses.

The thermal-hydraulic models that were developed are considered "generic" in nature, in the sense that extensive flexibility was build into the treatment of the individual fuel assemblies. The thermal models considered the spent nuclear fuel types, physical condition of the fuel, potential chemical reactions, the various packing configurations for loading, and the ambient environmental conditions including solar heating associated with the transportation of the fuel to the Canister Storage Building (CSB) for interim storage. The user has complete control to specify the type of chemical reaction, reactive surface area, reactant mass limits, and nuclear decay heat generation values for groups of elements, single elements, or down to the nodal level.

Four Arrhenius Rate Law based relationships involving reactions between unirradiated uranium, liquid water, and water vapor with or without oxygen were also modeled. These reactions are referred to by the name of the author that published the results; i.e, Tyfield (1988), McGillivary (1994), Ritchie (1981), and Condon (1983). The McGillivary and Ritchie reactions can be subdivided further on the basis of having an oxygenated or oxygen free environment. The fourth reaction relationship (Condon), which is based on thermodynamic principles, is still being investigated, but is mentioned for completeness. It must be emphasized that these reaction rate relationships 
WHC-SD-WM-ER-525

Rev. 0

were developed using unirradiated uranium metal samples. Reaction rate correlations remain to be confirmed or developed for corroded and irradiated uranium metal. It is expected that a reaction rate relationship(s) for irradiated uranium fuel will be developed from data scheduled to be obtained by Pacific Northwest National Laboratory (PNNL) personnel from chemical kinetic reaction studies of irradiated K-West fuel samples. The corroded and irradiated uranium reaction rate relationship(s) will be added to the above thermal models when they are made available.

For most conditions within a MCO, shipping cask, or storage tube, the reaction rate will be limited by the availability of reactants such as water vapor and oxygen. The chemical reaction can proceed no faster than the rate at which water vapor is generated by evaporation (or oxygen can be supplied) and transported to the reaction surface. The present analyses are considered conservative in this sense by assuming that no energy is required to evaporate water and no time delay occurs in transporting the chemical species to the reacting surface. The current thermal models have the capability to limit the reactions based on an assumed mass of residual reactants or the total amount of chemical energy produced, but do not account for mass transfer delays. Other mass transport effects that may need to be accounted for are the rate limiting effects of hydrogen production and blanketing, an inert gas purge, and the buildup of a diffusion limiting oxide or scale layer.

Additional thermal-hydraulic models, representative of the axial configuration of a MCO within shipping cask and storage tube containing up to six levels of fuel, are currently in development and will be used to quantify internal natural convection patterns, mass transfer, potential hot spots, and the extent and duration of surface chemical reactions under various normal 
WHC-SD-WM-ER-525

Rev. 0

operating and off-normal scenarios. It is expected that these models will have the capability to model an evaporative source of water vapor, the transport of the reacting species throughout the system by diffusion or internal convection flows, and the removal of mass from the system by the vacuum pump.

The results of preliminary thermal analyses do not preclude any of the current path options given nominal material properties, representative environmental conditions, and the anticipated process timeline sequences. However, uncertainties in the material properties, definition of the multiple and competing chemical reactions, concerns about residual reactants within the MCO after vacuum drying, and the reactive surface area for corroded fuel elements presently make definitive statements difficult.

The preliminary thermal analyses have shown that natural convection within the MCO will provide a significant mechanism for axial and radial heat redistribution and mass transport just prior to vacuum drying and during transportation to the CSB. To maximize the thermal performance of the MCO and, hence, temperature control, it is recommended that the MCO be designed to enhance natural circulation by providing enough uniformly spaced parallel flow paths around and through each tier of individual fuel assemblies, upper and lower plenums, and tier-to-tier alignment (i.e, to enhance the "chimney effect" for mass transport). The recommendation for tier-to-tier alignment should be balanced with the need to promote mixing and prevent flow channeling during the hot conditioning process.

A series of sensitivity analyses have also shown that radiative heat transfer is a significant mechanism for heat transfer, especially under vacuum 
WHC-SD-WM-ER-525

Rev. 0

conditions when natural convection is not possible. Consideration must be given to special coatings or passivation treatments to enhance the emissivity and, hence, radiative heat transfer. It is strongly recommended that the emissivities of the fuel baskets and the MCO inner and outer surfaces be maximized to achieve surface emissivities in the range of 0.7 to 0.8 , regardless of the fill gas. The emissivity of the CSB storage tube surfaces and the inner surface of the transportation shipping cask should also be held to similar high values. In addition, the emissivity of the zircaloy cladding surface must be confirmed to be equal or greater than 0.4 .

The use of helium as a back fill or inerting cover gas in the MCO is very effective in reducing the temperature of the fuel and is strongly recommended, but leakage issues and cost considerations may limit the effectiveness of this option. However, because of the potential off-normal event concerning the loss-of-helium fill gas and higher fuel temperatures if nitrogen or argon are used as the back fill gas, the recommendation for enhanced fuel basket and MCO emissivities remains.

The above recommendations for enhanced emissivities and helium as the fill gas become non-issues, if the proposed MCO temperature profile, corresponding to a peak fuel temperature of $400{ }^{\circ} \mathrm{F}$ and a maximum MCO surface temperature of $270^{\circ} \mathrm{F}$, provides an acceptable pre-condition (i.e., basis) for the required safety analyses.

Current analyses have also shown that the proposed $50^{\circ} \mathrm{C}\left(122{ }^{\circ} \mathrm{F}\right) \mathrm{MCO}-$ shipping cask gap cooling/heating water system is an important means to supply 
WHC-SD-WM-ER-525

Rev. 0

enough energy to evaporate any residual water and achieve higher fuel temperatures in a timely manner, but low enough to prevent rapid uranium metal reaction rates.

During vacuum drying, the supply of oxidants will be limited to the amount of residual water remaining in the cask and the amount of air that could flow through the cask through broken inlet and outlet vacuum lines. Current estimates show that for nominal conditions the amount of air flow or the amount of residual water expected to remain in the MCO after draining and vacuum drying will not be sufficient to sustain a runaway oxidation reaction, even if temperatures are high enough to reach such a condition.

Ignition and runaway oxidation reactions in the CSB storage tubes are unlikely because most of the moisture will have been removed by vacuum drying. Air inleakage through failed ports will not be sufficient to sustain a runaway oxidation reaction and, normally, the fuel is expected to be stored in an inert atmosphere. However, the highest fuel temperatures will occur within the CSB storage tubes due to reduced heat transfer. Any residual reactants, such as frozen water, will react quite rapidly given the high temperature conditions within the CSB.

Since maximum fuel temperatures are likely for high decay heat MCOs, gas generation, especially hydrogen, and the ability to vent these gases are likely to be an issue. Large concentrations of hydrogen in the MCO and/or storage tube could be hazardous if an air ingress incident occurs. High pressures caused by gas generation could also become an issue if they are sufficiently high and the MCOs and/or storage tubes are sealed. 
WHC-SD-WM-ER-525

Rev. 0

CONTENTS

1.0 INTRODUCTION . . . . . . . . . . . . . . . . 1-1

1.1 PURPOSE AND SCOPE ................. . . . .

1.2 BACKGROUND AND OBJECTIVES ...............

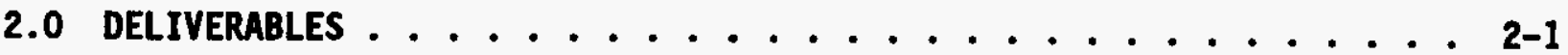

3.0 THERMAL PERFORMANCE FACTORS .............. 3-1

3.1 STATUS OF THERMAL MODELING .............. 3-1

3.2 CODE DESCRIPTIONS .................. 3-3

3.2.1 FIDAP . . . . . . . . . . . . . 3-3

3.2 .2 HUB $\ldots \ldots \ldots . \ldots . \ldots . \ldots 3$

3.3 TECHNICAL ISSUES ....................... 3-4

3.3.1 Reaction Rates . . . . . . . . . . . 3-4

3.3.1.1 Reaction Rate Relationships. . . . . . . . 3-7

3.3.1.2 Modeling of Hot and Cold Spots . . . . . 3-9

3.3.2 Thermo-physical Properties and Convective Heat Transfer Coefficients ............. 3-11

3.3.3 Mass Transport . . . . . . . . . . . .

4.0 MODEL DEVELOPMENT, METHODOLOGY, AND ASSUMPTIONS . . . . . . 4-1

4.1 FIDAP MODELS ...................... 4-1

4.1.1 Quarter Symmetric Fuel Encapsulation Canister (FEC)

Model .................. 4-4

4.1.2 MCO and Cask 30 Degree Sector, 2-D Mode1 . . . . . 4-5

4.1.2.1 Mark IV Fuel .............. 4-5

4.1.2.2 Mark Ia Fuel. . . . . . . . . . . . . 4-5

4.1.3 Ignition Model ............. 4-5

4.1.4 MCO and Storage Tube 30 Degree Sector, 2-D Mode1 . . 4-6

4.1.5 Porous Rubble Bed ............... 4-6

4.1.6 Chemical Reaction Sensitivity - Plate Model . . . . 4-7

4.1.7 Storage Tube - MCO Gap Circulation Model . . . . . . . 4-8

4.2 HUB ANALYTICAL SOLUTIONS . . . . . . . . . . 4-9

4.2.2 Analytical Solution for Annular Ring Model . . . . 4-9

4.2.2.1 Internal MCO Convective Heat Transfer. . . . 4-10

4.2.2.2 Incident Solar Heat flux. . . . . . . . 4-11

4.2.2.3 Decay Heat Rate . . . . . . . . . 4-11

4.2.2.4 Heat Due to Metal oxidation ....... 4-11

4.2.2.5 External Convective Heat Transfer Coefficient . 4-12

4.2.2.6 Outer Cask (or Storage Tube Wall Temperature . 4-13

4.2.2.7 Inner Cask (or Storage Tube) Wall Temperature . 4-13

4.2.2.8 Outer MCO Wall Temperature ......... 4-13

4.2.2.9 Outer (Fourth) Fuel Ring Temperature . . . . . 4-14

4.2.2.10 Third Fuel Ring Temperature ....... 4-15

4.2.2.11 Second Fuel Ring Temperature ........ . 4-16

4.2.2.12 First Fuel Ring Temperature . . . . . . . 4-17

4.2.2.13 Solution ............... 4-18

4.2.3 Analytical Solution for Rubble Basket ...... 4-18

4.2.3.1 Analytical Solution for the 10th (Outermost)

Ring of Fuel ............ 4-18

4.2.3.2 Analytical Solution for the Nine outer Rings . 4-20

4.2.3.3 Analytical Solution for the Fuel Basket Center Region. 
4.2.4 Normalization ............. 4-22

4.2 .5 Technical Notebook . . . . . . . . . 4-22

5.0 RESULTS . . . . . . . . . . . . . 5-1

5.1 FIDAP FINITE ELEMENT RESULTS ........

5.1.1 TH2-1: Thermal Performance of Basel ine $\mathrm{MCO}$, Transportation Cask, and MCO/Storage Tube Models . . . 5-2

5.1.2 TH2-3: Thermal Performance for Initial MCO Loading, Removal from Basin and Transportation to Drying Station 5-5

5.1.3 TH2-4: Thermal Performance During Dewatering and Vacuum Drying ................ 5-8

5.1.4 TH2-5: Thermal Performance in a Transportation Shipping Cask .............. 5-11

5.1.5 TH2-7: Thermal Performance in a Canister Storage

5.2 HUB ANALYTICAL SOLUTIONS Tube ........... . . 5-13

5.2.1 TH2-2: NCO Natural Convection Assessment .... 5-16

5.2.2 TH2-3: MCO Thermal Performance During Reracking/Dewatering . . . . . . . . . . . 5-17

5.2.2.1 Water Temperature Required to Reach Ignition Temperature ............ 5-17

5.2.3 TH2-5: MCO Thermal Performance in Shipping Cask . 5-19

5.2.4 TH2-5a: Thermal Performance of Rubble Basket ...5-19

5.2.5 TH2-7: MCO Thermal Performance in CSB Storage Tube . 5-20

5.2.6 Parameter Sensitivities .......... 5-21

5.3 SEMI-INFINITE PLATE MODEL - CHEMICAL REACTION SENSITIVITIES : 5-24

5.4 STORAGE TUBE MCO GAP CIRCULATION MODEL ......... 5-25

6.0 CONCLUSIONS AND RECOMMENDATIONS .............. 6-. . . .

7.0 REFERENCES .......................... . . .

\section{LIST OF FIGURES}

1-1. Spent Nuclear Fuel Project Process Flow ............ 1-3

3-1. Quarter Symmetric Model of MCO and Shipping Cask With

Fuel Encapsulation Canister ............ . . 3-13

3-2. $30^{\circ}$ Sector Model of MCO and Shipping Cask With

Mark IV Fuel Assemblies . . . . . . . . . . . . . 3-14

3-3. $30^{\circ}$ Sector Model of MCO and Shipping Cask With

Mark Ia Fuel Assemblies ............... . . . .15

3-4. $30^{\circ}$ Sector Model of NCO and Storage Tube With

Mark IV Fuel Assemblies ............ . . . . . . . . . .

3-5. Volumetric Heat Rate Versus Temperature for the Tyfieid,

Ritchie, and McGillivary Reaction Rate Relationships...... . 3-17

3-6. Volumetric Heat Rate for McGillivary Reaction Rate Relationship

Versus Temperature and Water Vapor Pressure ......... 3-18

3-7. Volumetric Heat Rate for McGillivary Reaction Rate Reiationship

Versus Water Vapor Pressure and Temperature ......... 3-19

4-1. Cross Section View of a Mark IV Fuel Assembly ........ 4-23

4-2. Isometric View of a Mark IV Fuel Assembly . . . . . . 4-24

4-3. Top and Side Views of a Sealed Fueled Encapsulation Canister . . 4-25 
4-4. Top View of an Open Fuel Encapsulation Canister Barre1 with Seven Fuel Assemblies . . . . . . . . . . . . . 4-26

4-5. Planar Cross Section View of MCO Within a Shipping Cask Containing Fuel Encapsulation Canisters With

Fuel Assemblies ................... 4-27

4-6. MCO Axial Tier Location .................. 4-28

4-7. Representative Basket Designs ............ 4-29

4-8. Finite Element Nodalization for Quarter Symmetric Model . . . . 4-30

4-9. Finite Element Nodalization for $30^{\circ}$ Sector Model

With Mark IV Fuel Assemblies . . . . . . . . . . . . . 4-31

4-10. Finite Element Nodalization for $30^{\circ}$ Sector Model

With Mark Ia Fuel Assemblies. . . . . . . . . . 4-32

4-11. Finite Element Nodalization for $30^{\circ}$ Sector Model of Storage Tube

With Mark IV Fuel Assemblies .............. 4-33

4-12. Finite Element Nodalization for Quarter Symmetric Model of a Porous Rubble Bed ................ . . 4-34

4-13. Finite Element Nodalization for the Chemical Reaction

Sensitivity Plate Model .............. 4-35

4-14. Canister Storage Building and Representative View of

MCO Locations and Storage Tubes ............ 4-36

4-15. Finite Element Nodalization for MCO-Storage Tube Gap

Circulation Model (Lower End) ........... 4-37

4-16. Finite Element Nodalization for MCO-Storage Tube Gap

Circulation Model (Upper End) .............. 4-38

4-17. Ring Model of Fuel Basket Inside of MCO . . . . . . . . . . 4-39

4-18. Ring Model of Fuel Rubble Basket . . . . . . . . . . . . . . . . 4-40

4-19. Comparison of Radial Temperature Profiles Between the Simple HUB

and Detailed FIDAP Models for Conduction Only and

Conduction + Radiation ................... 4-41

5-1. Center and Peak Fuel Temperature Node Numbers and Locations for $30^{\circ}$ Sector Model of MCO and Shipping Cask With

Mark Ia Fuel Assemblies . . . . . . . . . . . . . . 5-26

5-2. Peak Fuel Temperature Versus Time for a MCO and Shipping Cask

With Mark Ia Fuel (Decay Heat Only) ... . . . . . . . . 5-27

5-3. Radial Temperature Contour Plot for a MCO and Shipping Cask With

Mark Ia Fuel After 15 Days (Decay Heat Only) . . . . . . . . 5-28

5-4. Temperature Surface Plot for a MCO and Shipping Cask with

Mark Ia Fuel After 15 Days (Decay Heat Only) . . . . . . . . . 5-29

5-5. Center and Peak Fuel Temperature Node Numbers and Locations for $30^{\circ}$ Sector Model of MCO and Shipping Cask With

Mark IV Fuel Assemblies ......... . . . . . . 5-30

5-6. Peak Fuel Temperature Versus Time for a MCO and Shipping Cask

With Mark IV Fuel (Decay Heat Only) . . . . . . . . . . 5-31

5-7. Radial Temperature Contour Plot for a MCO and Shipping Cask With

Mark IV Fuel After 15 Days (Decay Heat Only) . . . . . . . . 5-32

5-8. Temperature Surface PIot for a MCO and Shipping Cask With

Mark IV Fuel After 15 Days (Decay Heat Only) . . . . . . . . . . 5-33

5-9. Center and Peak Fuel Temperature Node Numbers and Locations for $30^{\circ}$ Sector Model of MCO and Storage Tube With

Mark IV Fuel Assemblies ................ . 5-34

5-10. Peak Fuel Temperature Versus Time for a MCO and Storage Tube

With Mark IV Fuel (Decay Heat Only) ............ . 5-35

5-11. Radial Temperature Contour Plot for a MCO and Storage Tube With

Mark IV Fuel After 15 Days (Decay Heat Only) . . . . . . . 5-36 
5-12. Temperature Surface Plot for a MCO and Storage Tube With Mark IV Fuel After 15 Days (Decay Heat Only) . . . . . . . . . . . . 5-37

5-13. Peak Fuel Temperature Versus Time for Initial Fuel Loading for $\mathrm{K}$ Basin Ambient Water Temperature of $10^{\circ} \mathrm{C}\left(50^{\circ} \mathrm{F}\right)$ (Nomina) Decay Heat + Chemical Heat (Tyfield Oxygen Free)) . . . . . . 5-38

5-14. Peak Fuel Temperature Versus Time for Fully Loaded MCO With Water for an Ambient Air Temperature of $37.8{ }^{\circ} \mathrm{C}\left(100^{\circ} \mathrm{F}\right)$

(Nominal Decay Heat + Chemical Heat (Tyfield Oxygen Free)) . . . . 5-39

5-15. Peak Fuel Temperature Versus Time for Fully Loaded MCo With Water for an Ambient Air Temperature of $37.8^{\circ} \mathrm{C}\left(100^{\circ} \mathrm{F}\right)$ (Nominal Decay Heat + Chemical Heat (Ritchie Oxygen Free)) . . . . 5-40

5-16. Peak Fuel Temperature Versus Time for Initial Fuel Loading for $K$ Basin Ambient Water Temperature of $100^{\circ} \mathrm{C}\left(50^{\circ} \mathrm{F}\right.$ ) (Nominal Decay Heat + Chemical Heat (Ritchie with 0xygen)) ...... . 5-41

5-17. Peak Fuel Temperature Versus Time for Fully Loaded MCO With Water for an Ambient Air Temperature of $37.8^{\circ} \mathrm{C}\left(100^{\circ} \mathrm{F}\right)$ (Nominal Decay Heat + Chemical Heat (Ritchie with Oxygen)) . . . - 5-42

5-18. Peak Fuel Temperature Versus Time for Fully Loaded MCO With Water for an Ambient Air Temperatures of $37.8^{\circ} \mathrm{C}\left(100^{\circ} \mathrm{F}\right)$ (Normal Decay Heat + Solar Heat + Chemical Heat (Ritchie with Oxygen)) ..................... 5-43

5-19. Peak Fuel Temperature Versus Time for Initial Fuel Loading for $K$ Basin Ambient Water Temperature of $100^{\circ} \mathrm{C}\left(50^{\circ} \mathrm{F}\right.$ ) (Maximum Decay Heat + Chemical Heat (Ritchie with Oxygen)) . . . . . . 5-44

5-20. Peak Fuel Temperature Versus Time for Fully Loaded MCO With Water for an Ambient Air Temperature of $37.8^{\circ} \mathrm{C}\left(100^{\circ} \mathrm{F}\right)$ (Maximum Decay Heat + Chemical Heat (Ritchie with Oxygen)) . . . . 5-45

5-21. Peak Fuel Temperature Versus Time for Fully Loaded MCO With Water for an Ambient Air Temperature of $37.8^{\circ} \mathrm{C}\left(100^{\circ} \mathrm{F}\right)$ (Maximum Decay Heat + Solar Heat + Chemical Heat (Ritchie

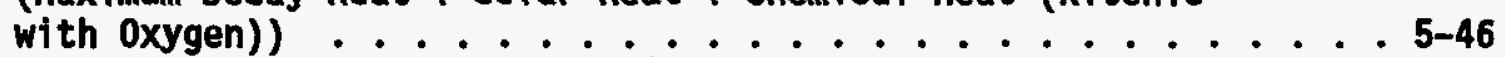

5-22. Peak Fuel Temperature Versus Time for MCO During Dewatering and Vacuum Drying with Helium Fill Gas and Water Gap Heating at $50{ }^{\circ} \mathrm{C}$ (122 ${ }^{\circ} \mathrm{F}$ ) (Nominal Decay Heat + Chemical Heat (McGillivary with Oxygen, 2kPa Hater Vapor Pressure)) 5-47

5-23. Peak Fuel Temperature Versus Time for MCO During Dewatering and Vacuum Drying with Helium Fill Gas, Air Gap, and Ambient Temperature of $37.8{ }^{\circ} \mathrm{C}\left(100^{\circ} \mathrm{F}\right)$ (Nominal Decay Heat + Chemical Heat (McGillivary with Oxygen, 2kPa Water Vapor Pressure)) . . . . 5-48

5-24. Peak Fuel Temperature Versus Time for MCO $\left(\epsilon_{\mathrm{ss} 304}=0.75\right)$ During Dewatering and Vacuum Drying with Helium Fill Gas, Air Gap, and Ambient Temperature of $37.8^{\circ} \mathrm{C}\left(100^{\circ} \mathrm{F}\right)$ (Nominal Decay Heat + Chemical Heat (McGillivary with Oxygen, 2kPa Water Vapor Pressure)) ......................... 5-49

5-25. Peak Fuel Temperature Versus Time for MCO During Dewatering and Vacuum Drying With Air Fill Gas and Water Gap Heating at $50^{\circ} \mathrm{C}$ $\left(122{ }^{\circ} \mathrm{F}\right.$ ) (Nominal Decay Heat + Chemical Heat (McGillivary With Oxygen, 2kPa Water Pressure)) . . . . . . . . . . . 5-50

5-26. Peak Fuel Temperature Versus Time for MCO During Dewatering and Vacuum Drying with Air Fill Gas, Air Gap, and Ambient Air Temperature of $37.8^{\circ} \mathrm{C}\left(100^{\circ} \mathrm{F}\right)$ (Nominal Decay Heat + Chemical Heat (MCGillivary with Oxygen, 2kPa Water Pressure)) . . . . . 5-5l 
WHC-SD-WM-ER-525

Rev. 0

5-27. Peak Fuel Temperature Versus Time for MCO $\left(\epsilon_{\mathrm{ss} 304}=0.75\right)$ During Dewatering and Vacuum Drying with Air Fill Gas, Air Gap, and Ambient Air Temperature of $37.8^{\circ} \mathrm{C}\left(100^{\circ} \mathrm{F}\right)$ (Nominal Decay Heat + Chemical Heat (McGillivary with Oxygen, 2kPa Water Pressure)) . . 5-52

5-28. Peak Fuel Temperature Versus Time for MCO During Dewatering and Vacuum Drying with Helium Fill Gas, and Water Gap Heating at $50{ }^{\circ} \mathrm{C}\left(122{ }^{\circ} \mathrm{F}\right)$ (Maximum Decay Heat + Chemical Heat (McGillivary with 0xygen, 2kPa Nater Pressure)) . . . . . . . . . . . . 5-53

5-29. Peak Fuel Temperature Versus Time for MCO During Dewatering and Vacuum Drying with Helium Fill Gas, Air Gap, and Ambient Air Temperature of $37.8^{\circ} \mathrm{C}\left(100^{\circ} \mathrm{F}\right)$ (Maximum Decay Heat + Chemical Heat (McGillivary with 0xygen, 2kPa Water Pressure)) . . . . . . 5-54

5-30. Peak Fuel Temperature Versus Time for $\operatorname{MCO}\left(\epsilon_{s 8304}=0.75\right)$ Dewatering and Vacuum Drying with Helium Fil153as, Air Gap, and Ambient Air Temperature of $37.8^{\circ} \mathrm{C}\left(100{ }^{\circ} \mathrm{F}\right.$ ) (Maximum Decay Heat + Chemical Heat (McGillivary with Oxygen, $2 \mathrm{kPa}$ Water Pressure)) - 5-55

5-31. Peak Fuel Temperatures Versus Time for MCO During Dewatering and Vacuum Drying With Air Fill Gas and Water Gap Heating at $50^{\circ} \mathrm{C}$ $\left(122^{\circ} \mathrm{F}\right.$ ) (Maximum Decay Heat + Chemical Heat (McGillivary With 0xygen, 2kPa Water Pressure)) . . . . . . . . . . . 5-56

5-32. Peak Fuel Temperature Versus Time for MCO During Dewatering and Vacuum Drying with Air Fill Gas, Air Gap, and Ambient Air Temperature of $37.8^{\circ} \mathrm{C}\left(100^{\circ} \mathrm{F}\right.$ ) (Maximum Decay Heat + Chemical Heat (HcGillivary with 0xygen, 2kPa Water Pressure)) . . . . . . 5-57

5-33. Peak Fuel Temperature Versus Time for $\mathrm{MCO}\left(\epsilon_{\mathrm{ss} 304}=0.75\right)$ During Dewatering and Vacuum Drying with Air Fill GaS, Air Gap, and Ambient Air Temperature of $37.8^{\circ} \mathrm{C}\left(100^{\circ} \mathrm{F}\right.$ ) (Maximum Decay Heat + Chemical Heat (WcGillivary with 0xygen, 2kPa Water Pressure)) . . 5-58

5-34. Peak Fuel Temperature Versus Time for a MCO and Shipping Cask With Mark IV Fuel with Helium Fill Gas for Various Ambient Temperature (Nominal Decay Heat, Solar Heating, $2.5 \mathrm{Kg}$ Residual Water, Ritchie Oxygen Free) ................. 5-59

5-35. Peak fuel Temperature Versus Time for a MCO and Shipping Cask With Mark IV Fuel Within a Shipping Cask with Moist Air for Varying Ambient Temperatures (Nominal Decay Heat, Solar Heating, $2.5 \mathrm{Kg}$ Residual Water, McGillivary with Oxygen, $2 \mathrm{kPa}$ Water Vapor Pressure)

5-36. Peak Fuel Temperature Versus Time for NCO and Storage Tube With Mark IV Fuel, Helium Fill Gas, Various Amounts of

Residual Water, and $140^{\circ} \mathrm{F}$ Ambient Vault Air Temperature (Nominal

Decay Heat + Chemical Heat (Ritchie Oxygen Free) . . . . . . . . 5-61

5-37. Peak Fuel Temperature Versus Time for MCO and Storage Tube With

Mark IV Fuel, Nitrogen Fill Gas, Various Amounts of Residual

Water, and $140^{\circ} \mathrm{F}$ Amblent Vault Air Temperature (Nominal Decay Heat + Chemical Heat (Ritchie Oxygen Free) . . . . . . . . . 5-62

5-38. Peak Fuel Temperature Versus Time for MCO and Storage Tube With Mark IV Fuel, Argon Fill Gas, Various Amounts of Residual Water, and $140^{\circ} \mathrm{F}$ Ambient Vault Air Temperature (Nominal Decay Heat + Chemical Heat (Ritchie Oxygen Free)) . . . . . . . . 5-63

5-39. A Comparison Between the Analytical HUB and FIDAP Models With and Without Convection . . . . . . . . . . . . . . 5-64

5-40. Radial Temperature Profile Near the Ignition Temperature (10 ${ }^{\circ} \mathrm{C}$ Water MCO-Shipping Cask Gap . . . . . . . . . . 5-65

5-41. Radial Temperature Profile for MCO Within a Shipping Cask (50 ${ }^{\circ} \mathrm{C}$ Water $\mathrm{MCO}$-Shipping Cask Gap) ............ . . 5-66 
5-42. Radial Temperature Profile Due to Conduction, Radiation and Convection for NCO Within a Shipping Cask ........... 5-67

5-43. Radial Temperature Profile for Rubble .......... . 5-68

5-44. Radial Temperature Profile in MCO Stored in CSB Storage Tube . . 5-69

\section{LIST OF TABLES}

2-1. Deliverables Associated with the Thermal-Hydraulic Feasibility Assessment ................... 2-1

4-1. N Reactor Fuel Type Dimensions . . . . . . . . . . . . 4-2

4-2. Solar Insolation Values for Average July Day at Hanford .... 4-3

5-1. Peak Fuel Temperatures for Baseline Models and Representative Conditions (Decay Heat only) . . . . . . . . . . . 5-4

5-2. Peak Fuel Temperatures for Initial Fuel Loading, Removal from Basin, and Transportation to Vacuum Drying Station (Decay

Heat only) ................ . . . . . . . .

5-3. Peak Fuel Temperatures for Initial Fuel Loading, Removal from Basin, and Transportation to Vacuum Drying (Decay + Chemical Heat) .................. . . . . . .

5-4. Peak Fuel Temperatures for Dewatering and Vacuum Drying ... 5-11

5-5. Peak Fuel Temperature for Transportation Shipping Cask. . . . . 5-13

5-6. Peak Fuel Temperature and Energy Balance for incO Within A CSB Storage Tube Versus Fill Gas and Decay Heat (No Chemical Reactions) ............... 5-14

5-7. Peak Fuel Temperatures for Interim Storage in the Canister Storage Building Versus Fill Gas and Residual Water (Nominal Decay + Chemical Reactions . . . . . . . . . . 5-16

5-8. Ignition Temperature $\left(T_{\infty}\right)$ Sensitivity for Various Cases ... 5-23 5-9. Ignition Temperature (To) Versus Storage Tube Geometry Variations . . . . . . . . . . . 5-24

\section{APPENDIXES}

APPENDIX A SURFACE HEAT FLUX - USER SUBROUTINE (USRBCF) . . . . . . . A-1 APPENDIX B VOLUMETRIC HEAT SOURCE - USER SUBROUTIN (USRSRC) . . . . . . B-1 APPENDIX CLISTING OF COMPUTER PROGRAM (SOLAR.F) TO CALCULATE SOLAR INSOLATION . . . . . . . . . . . C-1 APPENDIX D ASSUMPTIONS FOR $30^{\circ}$ SECTOR MARK IV MODEL AND REPRESENTATIVE FIDAP INPUT . . . . . . . . . . . . . D-1 APPENDIX E FIDAP MODEL SIZES ................. . . E-1 
WHC-SD-WM-ER-525

Rev. 0

Nomenclature

(SI Units)

\begin{tabular}{|c|c|}
\hline Quantity & SI \\
\hline Length & meter $(m)$ \\
\hline Time $(t)$ & second $(s)$ \\
\hline Mass & Kilogram $(\mathrm{Kg})$ \\
\hline Temperature $(T)$ & Kelvin $(K)$ \\
\hline Force $(F)$ & Newton (N) \\
\hline Energy & Joules $(\mathrm{J})$ or $(\mathrm{N}-\mathrm{m})$ \\
\hline Gravitational Acceleration (a) & $\mathrm{m} / \mathrm{s}^{2}$ \\
\hline Density $(\rho)$ & $\mathrm{kg} / \mathrm{m}^{3}$ \\
\hline Velocity (v) & $\mathrm{m} / \mathrm{s}$ \\
\hline Pressure $(P)$ & Pascal $\left(\mathrm{N} / \mathrm{m}^{2}\right)$ \\
\hline Dynamic Viscosity $(\mu)$ & Pascal-s (Kg/m-s) \\
\hline Kinematic Viscosity $(r)$ & $\mathrm{m}^{2} / \mathrm{s}$ \\
\hline Specific Heat $(C p)$ & $\mathrm{J} / \mathrm{kg}-\mathrm{K}$ \\
\hline Power & Watt $(\mathrm{J} / \mathrm{s})$ \\
\hline Heat Flux & $\mathrm{J} / \mathrm{m}^{2} \mathrm{~s}$ \\
\hline Volumetric Heat Source & $\mathrm{J} / \mathrm{m}^{3}-\mathrm{s}$ \\
\hline Heat Transfer Coefficient $\left(h_{c}\right)$ & $\mathrm{J} / \mathrm{m}^{2}-\mathrm{s}-\mathrm{K}$ \\
\hline Thermal Conductivity $(k)$ & $\mathrm{J} / \mathrm{m}-\mathrm{s}-\mathrm{K}$ \\
\hline Thermal Diffusivity & $\mathrm{m}^{2} / \mathrm{s}$ \\
\hline Mass Diffusivity & $\mathrm{m}^{2} / \mathrm{s}$ \\
\hline Volume Expansion Coefficient (B) & $1 / \mathrm{K}$ \\
\hline Surface Reaction Rate (mass units) & $\mathrm{Kg} / \mathrm{m}^{2}-\mathrm{s}$ \\
\hline Volumetric Reaction Rate (mass units) & $\mathrm{Kg} / \mathrm{m}^{3}-\mathrm{s}$ \\
\hline Heat of Reaction (mass units) & $\mathrm{J} / \mathrm{Kg}$ \\
\hline$g_{c}$ & $1 \mathrm{Kg}-\mathrm{m} / \mathrm{N}-\mathrm{s}^{2}$ \\
\hline Stefan-Boltzman Constant $(\sigma)$ & $5.6667 E-8 \mathrm{~J} / \mathrm{s}-\mathrm{m}^{2}-\mathrm{K}^{4}$ \\
\hline Universal Gas Constant (R) & $8314.34 \mathrm{~J} /$ Kgmole-K \\
\hline
\end{tabular}


WHC-SD-WM-ER-525

Rev. 0

THERMAL HYDRAULIC FEASIBILITY ASSESSMENT FOR THE

SPENT NUCLEAR FUEL PROJECT

\subsection{INTRODUCTION}

\subsection{PURPOSE AND SCOPE}

This report documents the results of the thermal hydraulic and chemical reaction models that were developed in support of the Spent Nuclear Fuel Project (SNFP) Integrated Process Strategy (IPS). Figure 1-1 presents the SNF project process flow.

The subject analysis efforts focused on investigating, quantifying, and establishing the governing heat production and removal mechanisms for the various process operations and configurations, obtaining preliminary results for comparison with and verification of other analyses, as well as, independently investigating each of the process steps, and providing technology based recommendations for consideration and incorporation into the design bases for the IPS. The goal was to develop a series of thermalhydraulic models that could respond to all process and safety related issues that may arise pertaining to the SNFP.

These models were developed to perform an early assessment of the thermal hydraulic technical issues associated with the SNF Project. By necessity, these models are considered scoping in nature, but sufficiently advanced to independently assess results from other thermal analysts, as well as provide clarification, identification and resolution of technical issues as they arise. This was driven by the general complexity of the IPS, the preliminary realization of the extent of fuel corrosion, the rapidly evolving MultiCanister Overpak (MCO) and shipping cask designs, and the immediate need for thermal-hydraulic information.

It is anticipated that the subject thermal-hydraulic models will form the basis for a series of advanced and more detailed models that will more accurately reflect the thermal performance of the IPS and alleviate the necessity for some of the more conservative assumptions and over simplifications, as well form the basis for the final process and safety analyses.

\subsection{BACKGROUND AND OBJECTIVES}

The SNF Project was established to develop engineered solutions to the expedited removal, stabilization, and storage of spent nuclear fuel and sludge from the K Basins at the U.S. Department of Energy's Hanford Site.

The SNF Project has an aggressive schedule to retrieve all fuel currently residing in the two $K$ Basins (i.e, $K W-105$ and $K E-105$ ) and provide transport to the Canister Storage Building (CSB) for short/long term storage options. The 
WHC-SD-WM-ER-525

Rev. 0

retrieval efforts also include both removing the residual sludge from the fuel assemblies, basin floors and process pits, and disposal of the existing Fuel Encapsulation Canisters (FEC) and support racks.

The primary objectives of the subject model development and thermal analyses are as follows:

- Investigate, quantify, and establish the governing heat production and removal mechanisms for the various IPS operations and configurations.

- Evaluate each the various process steps within the IPS for feasibility from a safety and thermal-hydraulic viewpoint.

- Provide technology-based recommendations for consideration and incorporation into the design bases for the IPS processes.

A secondary objective was as follows:

- Independentiy review and assess results from other thermal analysts or outside consultants working on specific issues. 
WHC-SD-WM-ER-525

Rev. 0

Figure 1-1 Spent Nuclear Fuel Project Process Flow.

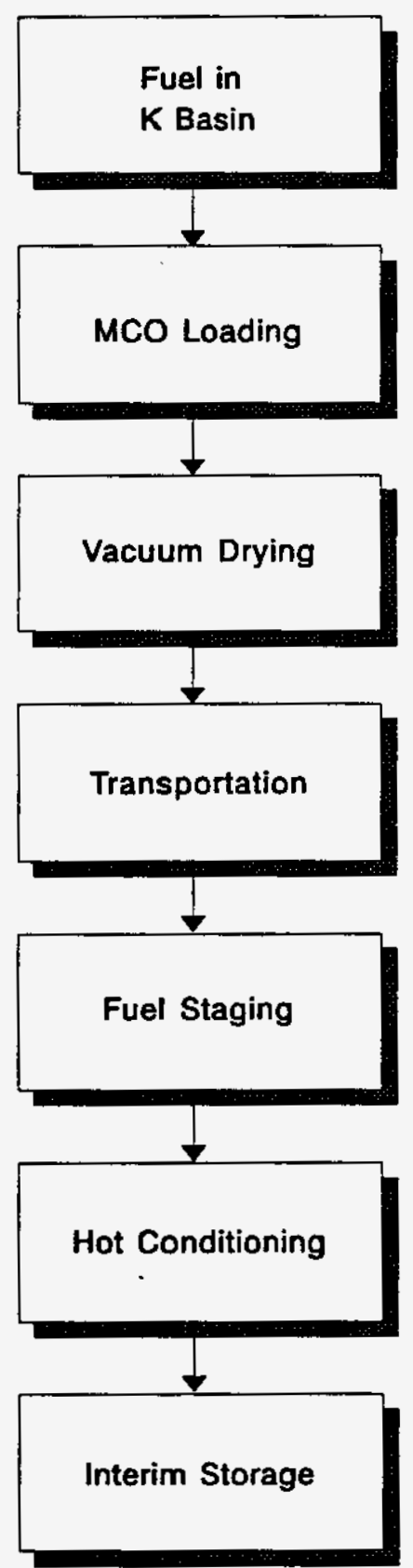


WHC-SD-WM-ER-525

Rev. 0

\subsection{DELIVERABLES}

The deliverables associated with the thermal-hydraulic feasibility assessment associated with the SNF Project Integrated Process Strategy (IPS) are presented in Table 2-1.

These deliverables require that the appropriate thermal, fluid, and chemical reaction models of a scoping nature be developed, verified, and used to perform an early assessment of the thermal hydraulic technical issues for the IPS. These efforts are also expected to provide clarification and identification of technical issues. The feasibility studies will develop models capable, when necessary, of performing parametric analyses for various fuel types, nuclear decay heat loads, degrees of fuel damage, and other variables such as thermal emissivities deemed important to the SNF Project.

Deliverables TH2-1 and TH2-2 refer to preliminary scoping models and some "back-of-the-envelope" calculations to assess natural convection.

Deliverables TH2-3, TH2-4, and TH2-5 address thermal performance during the MCO loading, vacuum drying, transportation, and initial fuel staging process steps shown in Figure 1-1, respectively. (The models which were developed for deliverable TH2-4 will be used at a later date to investigate the thermal performance during hot vacuum conditioning.)

Deliverable TH2-7, which was deleted, addresses the thermal performance of the MCO within the CSB and is presented for completeness.

Table 2-1. Deliverables Associated with the Thermal-Hydraulic Feasibility Assessment.

\begin{tabular}{||l|l||}
\hline TH2-1 & Develop MCO, MCO/Transfer Cask and MCO/Storage Tube Scoping Models \\
\hline TH2-2 & MCO Natural Convection Flow Assessment \\
\hline TH2-3 & MCO Thermal Performance During Reracking and Dewatering \\
\hline TH2-4 & MCO Thermal Performance During Vacuum Drying \\
\hline TH2-5 & MCO Thermal Performance in the Shipping Cask \\
\hline TH2-7 & $\begin{array}{l}\text { MCO Thermal Performance in Canister Storage Building (CSB) Storage } \\
\text { Tube }\end{array}$ \\
\hline
\end{tabular}


WHC-SD-WM-ER-525

Rev. 0

\subsection{THERMAL PERFORMANCE FACTORS}

To prevent rapid temperature excursions associated with "runaway" chemical reactions, temperatures must be maintained at less than the "threshold" temperature limit.

Temperature control involves maintaining an energy balance where the energy gains to the system equal the energy losses from the system. If the energy gains exceed the losses, the system temperatures will increase until the energy losses increase to balance the system. If the energy gains far exceed the capability of the system to reject energy, the temperature will continue to increase. The mechanisms for temperature control must be based on analytical studies that qualify the design and/or process operating limits necessary to prevent a runaway chemical reaction.

The following sections discuss the current status of the thermalhydraulic modeling efforts, the various computer programs that are being used to perform the analyses and assessments, as well as the various technical issues associated with the thermal analyses. Model development, methodology, and assumptions are discussed in Section 4.0.

\subsection{STATUS OF THERMAL MODELING}

Numerous steady-state one-dimensional and transient two-dimensional finite-element thermal models of various combinations involving a MultiCanister Overpak (MCO), transportation shipping cask, Fuel Encapsulation Canisters (FEC), fuel assemblies (FA), and the Canister Storage Building (CSB) storage tubes have been developed using the HUB engineering spreadsheet and FIDAPl computer code. [FIDAP has been validated and verified for use at Hanford (Heard 1994). The corresponding HUB models have been normalized against FIDAP results.]

These models were developed to perform an early assessment of the thermal hydraulic technical issues associated with the SNF Project. By necessity, these models are considered scoping in nature, but sufficiently advanced to independently assess results from other thermal analysts, as well as provide clarification, identification and resolution of technical issues as they arise. This was driven by the general complexity of the IPS, the preliminary realization of the extent of fuel corrosion, the rapidly evolving MultiCanister Overpak (MCO) and shipping cask designs, and the immediate need for thermal-hydraul ic information.

The inherent assumption in all of the following discussions and analysis results is that by ignoring axial effects the resulting temperatures represent conservative values. It is anticipated that the subject thermal-hydraulic models will form the basis for a series of advanced and more detailed models, including sub-channel and three-dimensional analyses, that will more accurately reflect the thermal performance of the IPS and alleviate the necessity for some of the more conservative assumptions and over simplifications, as well form the basis for the final process and safety analyses.

FIDAP (Fluid Dynamic Analysis Package) is a registered trademark of Fluid Dynamics, Inc., Evanston, IL 
WHC-SD-WM-ER-525

Rev. 0

Figures 3-1, 3-2, 3-3 and 3-4 present the four fundamental geometries that were utilized to derive the FIDAP models. (A simple 2-D plate model was developed for use with a series of sensitivity analyses with chemical reactions, but is not considered representative of the actual SNF geometries and as such is not discussed within this section. See Section 4.1.6 for a more detailed discussion of the plate model.) The four fundamental geometries consist of the following:

- A 90-degree sector (quarter symmetric) containing seven fuel assemblies within a Fuel Encapsulation Canister (FEC) within a Multi-Canister Overpak (MCO) - Figure 3-1

- A 30-degree sector (one-twelfth symmetric) containing densely packed Mark IV fuel assemblies within a MCO within a shipping cask - Figure 3-2

- A 30-degree sector (one-twelfth symmetric) containing densely packed Mark Ia fuel assemblies within a MCO within a shipping cask - Figure 3-3

- A 30-degree sector (one-twelfth symmetric) containing densely packed Mark IV fuel assemblies within a MCO within a storage tube Figure 3-4

The FIDAP models that have been developed from these four fundamental geometries are as follows.

- A 90-degree sector model of a fuel encapsulation canister (FEC) containing seven fuel assemblies within a MCO and shipping cask

- A 30-degree sector model containing the equivalent of 54 Mark IV fuel assemblies within a MCO and shipping cask

- A 30-degree sector model containing the equivalent of 48 Mark Ia fuel assemblies within a MCO and shipping cask

- A 90-degree 8 inch diameter rubble canister (porous media) within a MCO and shipping cask

- A 30-degree sector ignition model containing the equivalent of 54 Mark IV fuel assemblies within a MCO and shipping cask with variable ambient temperatures and user selected chemical reaction kinetics

- A 30-degree sector model containing the equivalent of 54 Mark IV fuel assemblies within a MCO and storage tube.

Two other FIDAP models were developed for a series of specialized analyses. They are as follows.

- A 2-D plate model for use with chemical reaction sensitivity analyses

- A 2-D axi-symmetric full length storage tube - MCO gap model to investigate natural circulation flows and hydrogen transport. 
WHC-SD-WM-ER-525

Rev. 0

The above FIDAP models required several user subroutines to be written to evaluate and return either the surface heat flux. or volumetric heat source for the various kinetics associated with the uranium-steam and/or oxygen

reactions. These reactions are discussed further in Section 3.3, and the user subroutines that were developed for the surface reaction heat fluxes or volumetric heat sources are documented in Appendixes $A$ and $B$, respectively.

\subsection{CODE DESCRIPTIONS}

The FIDAP and HUB ${ }^{2}$ computer programs were used to develop the thermalhydraulic models of the IPS. The following sections provide a brief description of the subject programs.

\subsubsection{FIDAP}

The Fluid Dynamic Analysis Package (FIDAP) is a commercially available general purpose computer package that uses finite element methods (FEM) to simulate many classes of single or multi-phase compressible or incompressible flows, including heat transfer, and mass transport of chemical species (< 15) in both non-reacting and reacting flows as discussed below. The simulation can be either steady-state or transient and can model flows in complex arbitrary geometries that are 2-D, axi-symmetric, or 3-0. Mixed coordinate or moving/rotating systems are supported.

FIDAP can be thought of as a single-integrated environment for the simulation of thermal-hydraulic problems. The program can be viewed as an integrated set of components and program modules designed to perform all aspects of model generation and automatic meshing or paving, problem setup including view factor calculations, solution, and post-processing of a flow and/or thermal analysis.

FIDAP supports reactions based on both chemical kinetic-controlled models, such as the Arrhenius Rate Law, where the reaction rate is determined from chemical kinetic considerations or mixing-controlled reactions where the mixing action of a turbulent velocity field determines the rate of reaction. Both mass fraction and molar concentration forms for the reaction models are supported. Simple one-step, competing, controlling, and multi-step chemical models are also supported.

\section{2 .2 HUB}

HUB is an integrated "spreadsheet like" computational notebook, intended primarily for engineers and scientists who routinely require well-documented calculations as a record of their work. Calculations are based on equations that can be written to the document and imbedded in tables and graphs. The equations are integrated in that they are computationally linked throughout a document. Equations for the heat transfer from the fuel to the environment

\footnotetext{
${ }^{2}$ HJS is a trademark of Numerical Applications, Inc., of Richland, iiA
} 
Rev. 0

through the MCO and tube or cask walls are entered into HUB, along with the chemical and decay heat generation rates, convective heat transfer coefficients and the thermal properties of the materials, and the solution for the temperatures of each surface is obtained.

\subsection{TECHNICAL ISSUES}

Three major issues will effect thermal performance. These are: (1) fully defining the multiple and competing chemical reactions that will occur between water, water vapor, oxygen and uranium as a function of relative humidity, and oxygenated or oxygen free conditions, (2) determining the reaction surface area associated with corroded or breached fuel assemblies and the modeling of highly reactive "hot" or inactive "cold" spots, and (3) quantifying the difference between the relative rates of water vapor production and rate at which the reacting mass (i.e, water vapor or oxygen) can be transferred to the reacting surface. This last issue involves assessing the effects of convective and diffusive mass transport on the thermal pefromance of the MCO. Three secondary issues involve the uncertainties associated with various material properties. These are: (1) determining the thermal conductivity of various gases under low pressure conditions, (2) defining the effective thermal conductivity of porous, corroded and/or declad fuel, and (3) determining the emissivities of materials (including corroded fuel) as a function of surface condition and temperature.

All of the above major issues must be thoroughly investigated and understood such that conditions within the MCO can be maintained to prevent chemical reactions from occurring to such an extent that a temperature excursion will occur, possibly compromising the mechanical integrity of the fuel encapsulation canisters, MCO, shipping cask, and CSB storage tube.

The following paragraphs discuss the issues associated with the chemical reactions rates and surface reaction areas, thermophysical properties, and mass transport.

\subsubsection{Reaction Rates}

The chemical reactions proceed at different rates depending on the individual reaction, activation energy, temperature of the fuel, the amount and form of reactant media involved; such as water, moist air, and for low pressure conditions the partial pressures of water vapor and the presence or not of oxygen. (Readers are referred to Section 3.0 of Puigh 1995, for a detailed discussion of the chemical reactions of Uranium with liquid water, water vapor and/or oxygen.) Section 3.3.1.1 presents a brief discussion of the reaction rate models that have been incorparated into the FIDAP and HUB models.

The rate of reaction of a particular reaction is usually presented in terms of milligrams (mg) of uranium (U), oxygen $\left(\mathrm{O}_{2}\right)$, or water $\left(\mathrm{H}_{2} \mathrm{O}\right)$ reacted per $\mathrm{cm}^{2}$ per hour and is highly dependent on the surface area available for reactions, temperature of the fuel, and amount of reactants (i.e., water, water vapor or uranium metal) to drive the reactions. The functional form of the above reactions are usually expressed in terms of a generalized Arrhenius Rate Law as shown by Equation 3-1, where the temperature dependence is usually 
Rev. 0

treated as an exponential function. In addition, most Arrhenius Rate based chemical reactions are mass limited or depend on the near surface concentrations of the reactants.

The mass fraction form of the Arrhenius Rate Law is shown by the following equation

$$
R_{i f}=K_{i f} \operatorname{EXP}\left[\frac{E_{j}}{\left(T+T_{R \theta f}\right)}\right] \prod_{i=1}^{N} C_{i}^{n_{i j}}
$$

where

$R_{i j}=$ Reaction rate for species $i$ in reaction $j\left(\mathrm{~kg} / \mathrm{m}^{3}-\mathrm{s}\right)$

$K_{i j}=$ Reaction rate constant for species $i$ in reaction $j\left(\mathrm{~kg} / \mathrm{m}^{3}-\mathrm{s}\right)$.

$E_{j} \quad=$ Activation energy for reaction $j$ divided by the Universal Gas Constant $\left({ }^{\circ} \mathrm{K}\right)$

$n_{i j}=$ Power index of reacting species $i$ in reaction $j$.

$N \quad=$ Number of reacting species in reaction $j(N \leq 15)$

$T_{\text {Ref }}=$ Reference temperature $\left({ }^{\circ} \mathrm{K}\right)$. Where $\left(T+T_{\text {Ref }}\right)$ is an absolute temperature. If the analyses are already based on an absolute temperature scale (j.e., ${ }^{\circ}$ or ${ }^{\circ} \mathrm{K}$ ), then $T_{\text {Ref }}$ can be set to zero.

$C_{i}=$ Mass fraction of species $i$ (dimensionaless).

Subject to the constraint

$$
\sum_{i=1}^{N} c_{i}=1.0
$$

Similarly, the energy produced by the reaction $j$ is shown by the following equation

$$
q_{j}=\sum_{i=1}^{N} \Delta H_{j} R_{i j}
$$

where

$$
\begin{aligned}
& q_{j}=\text { Chemical heat for reaction } j\left(\mathrm{~J} / \mathrm{m}^{3}-\mathrm{s}\right) \\
& \Delta H_{j}=\text { Heat of reaction for reaction } \mathrm{j}(\mathrm{J} / \mathrm{Kg}) \\
& R_{i j}=\text { Reaction rate for species } i \text { in reaction } j\left(\mathrm{~kg} / \mathrm{m}^{3}-s\right)
\end{aligned}
$$

The heat of reaction those cases involving uranium with water or water

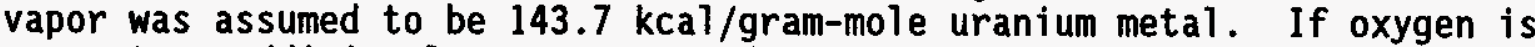
present an additional energy term of $57.3 \mathrm{kcal} / \mathrm{gram}$ mole of $\mathrm{H}_{2}$ was assumed for the reaction between the hydrogen released through the uranium - water vapor reaction and oxygen. For those cases involving uranium reactions with oxygen, a heat of reaction of $259.3 \mathrm{kcal} / \mathrm{gram}-\mathrm{mole}$ uranium metal was assumed. 
Since the reaction rate constant and activation energy are physical constants dependent on the reaction, the only mechanisms for reducing the rate of reaction are reducing the system temperature and/or reducing the relative mass fractions associated with the reactants.

For multiple surface reactions the general form of the Arrhenius Rate Law remains, but subject to the following surface (boundary) constraints, including the rate at which mass can be transported to the reacting surface.

$$
-\rho \alpha_{1} \frac{\partial C_{i}}{\partial n}+c_{1} s=s_{1} ; i=1, \ldots, n_{s}
$$

Together with the normal velocity condition

$$
\rho \vec{U} \cdot \vec{N}=S
$$

and,

$$
S=\sum_{1=1}^{N} S_{1} ; N=n_{s}+1
$$

where

$$
\begin{array}{ll}
\rho & =\text { Density of reacting media }\left(\mathrm{Kg} / \mathrm{m}^{3}\right) \\
\alpha_{i} & =\text { Mass diffusivity of species } i\left(\mathrm{~m}^{2} / \mathrm{S}\right) \\
C_{i} & =\text { Mass Fraction of species i dimensionaless) } \\
S_{i} & =\text { Surface reaction term }\left(\mathrm{Kg} / \mathrm{m}^{2}-S\right) \\
\vec{U} \cdot \vec{n} & =\text { Velocity }(\mathrm{m} / \mathrm{s}) \text { normal to surface } \\
\mathrm{S} & =\text { Sum of all reaction terms including any reaction term for } \\
N & \text { the carrier gas } \\
N & =\text { Number of reacting species }\left(\mathrm{n}_{\mathrm{s}}\right)+\text { carrier. }
\end{array}
$$

The subject thermal analyses, because of their one- or two-dimensional nature, initially assumed unlimited amounts of reactants and zero mass flow resistance. This effectively sets the multiplicative summation term for the species mass fractions in Equation 3-1 to 1.0, sets the concentration gradients for each species in Equation 3-4 to zero, and provides no information with regards to the non-uniform depletion of a given chemical species at any point.

A user subroutine to limit the chemical reactions based on total energy equivalent to a given mass of reactant was written, debugged, and successfully incorporated into the volumetric heat source subroutine USRSRC and has been used to determine the peak fuel temperatures as a result of chemical reactions for various amounts of residual water and oxygen. This subroutine assumes that a given mass of reactants is uniformly distributed throughout the MCO internal volume. This mass, when fully reacted, will result in a given amount of energy. Since, the heat rate is proportional to the reaction rate, the energy produced is proportional to the amount of mass reacted. By suming the chemical energy produced by each individual element over each timestep, the depletion of a given amount of reaction mass can be simulated. This was 
judged to be a conservative estimate of the resulting temperatures, since the reaction rate is actually dependent on the concentrations of the reactants and the transport of the reactants to the reacting surfaces.

In addition, is is assumed that the chemical reactions are not 1 imited by the buildup of a oxide layer, the difference in the relative rates at which water vapor can be produced versus the rate at which water vapor can be transported to the reacting surfaces, or hydrogen blanketing near the reacting surfaces. (Hydrogen is produced by the water or water vapor reactions with uranium metal and is assumed to be expelled from the reaction surface. This hydrogen is concentrated near the surface and effectively reduces the mass flux of the water or water vapor transported towards the reacting surface; hence, the term hydrogen blanketing.) Information regarding the spatial distribution of the reacting species is subject to the development of a threedimensional model coupling all aspects of energy, momentum, and mass transport.

\subsubsection{Reaction Rate Relationships. Four Arrhenius Rate Law based} relationships involving reactions between unirradiated uranium, liquid water, and water vapor with or without oxygen were modeled with FIDAP through two user subroutines (USRBCF and USRSRC). These reactions are referred to by the name of the author that published the results; i.e, Tyfield (1988), McGillivary (1994), Ritchie (1981), and Condon (1983). (These reactions are discussed in greater detail in Section 3.0 of Puigh 1995.) The McGillivary and Ritchie reactions can be subdivided further on the basis of having an oxygenated or oxygen free environment. The fourth reaction relationship based on Condon, which is based on thermodynamic principles, is still being investigated, but is mentioned for completeness. It is anticipated that an appendix to this report will be issued when the Condon Model is judged complete and available for use by the SNF Project. In addition, reaction rate correlations must be developed for irradiated fuel. It is expected that a reaction rate relationship(s) will be developed from reaction data obtained by Pacific Northwest National Laboratory (PNNL) personnel using the data quality objectives (DQO) that have been developed for chemical kinetic studies of $K$ West fuel samples (Lawrence 1995).

The heat generation source term for chemical reactions is a function of the extent of fuel damage (i.e., reactive surface area), the temperature of the fuel, and the supply of water vapor and/or oxygen to drive the reaction. For most conditions within a MCO, the reaction rate will be 1 imited by the availability of reactants such as water vapor and oxygen to drive the reactions. A comparison of the volumetric heat generation rates $\left(\mathrm{J} / \mathrm{m}^{3}-\mathrm{s}\right)$ for the Tyfield, Ritchie and McGillivary Reaction rate relationships are presented in Figures $3-5,3-6$, and 3-7. Figure 3-5 presents a comparison of the volumetric heat generation rates for the Tyfield, Ritchie (oxygen free), Ritchie (oxygenated), and McGillivary reaction rate relationships. The presence of oxygen clearly poisions the reaction, which results in reduced reaction rates and a reduced volumetric heat generation rate.

Figures 3-6 and 3-7 present the volumetric heat generation rate for the McGillivary reaction rate relationship cross parametrized as a function of temperature and water vapor pressure. 
Rev. 0

Figures 3-5, 3-6, and 3-7 were derived from reaction heat fluxes $\left(\mathrm{J} / \mathrm{m}^{2}-\mathrm{s}\right)$ and assumed a surface area/volume ratio of $220 \mathrm{~m}^{-1}$, which corresponds to completely decladd fuel.

The chemical heat generation will be especially important during the vacuum drying portion of the IPS when the fuel temperatures begin to rise as the convective heat transfer is reduced in a low pressure environment and in the CSB storage tubes, which have reduced heat transfer capabilities.

The above reaction models required several user subroutines to be written to evaluate and return either the surface heat flux (USRBCF) or volumetric heat source (USRSRC) for the various kinetics associated with the different uranium water vapor and/or oxygen reaction relationships. The user subroutines that were developed for the surface reaction heat fluxes or volumetric heat sources are documented in Appendixes A and B, respectively.

The Tyfield and Ritchie relationships address immersion in oxygen depleted water and are applicable for those conditions in the IPS where either the partial pressure of water vapor is very high or where liquid water is in direct contact with the fuel. Such an environment is associated with the current storage within the $K$ Basins and reracking of the fuel in water filled MCOs prior to draining and vacuum drying. The Ritchie relationship was specifically developed from reaction data in environments at or near $100 \%$ relative humidity and at standard atmospheric pressure.

An additional relationship was developed (Puigh 1995) for use with reactions in oxygen saturated water using the general form of Ritchie. The reaction rate in oxygen-saturated water is lower than that for oxygen depleted water. The presence of oxygen acts as a poison and reduces the reaction rate by several orders of magnitude, as shown within Figure 3-5.

The MCGillivary relationship examined uranium reactions in environments with reduced pressure and relative humidities ranging from 2 to $90 \%$. The McGillivary relationship accounts for two simultaneous reactions; water vapor with uranium and oxygen with uranium. The McGillivary relationship results in reaction rates generally less than Tyfield or Ritchie. This is due to the diffusion of water vapor to the reactive fuel surface and the poisoning effect of oxygen.

Each of the above reaction rate relationships is user selectable, along with other required input parameters, given the environmental conditions associated with each analysis. For example, the volumetric heat source (USRSRC) subroutine, returns the value of the volumetric heat source $(\mathrm{J} / \mathrm{m} 3-\mathrm{s})$ based on a reaction relationship, which was in turn derived from a surface reaction heat flux $(\mathrm{J} / \mathrm{m} 2-\mathrm{s})$ using the Gaussian Divergence Theorem or the Area/Volume ratio $(1 / \mathrm{m})$ for deposition within the designated cladding elements. The surface heat flux (USRBCF) subroutine, which does not allow user input, returns a value of surface heat flux $(\mathrm{J} / \mathrm{m} 2-\mathrm{s})$ based on a reaction relationship that is applied to a fuel or cladding surface. For thin volumes, such as the cladding surrounding the fuel elements, the results approach each other. Agreement between the two methodologies was confirmed by performing duplicate analyses; one with a volumetric heat source deposited within the cladding and the other with a surface heat flux deposited on the surface of the fuel element. The maximum temperature difference between the above two methods was $0.009{ }^{\circ} \mathrm{K}$. 
Rev. 0

Because of the versatility associated with passing user input to the USRSRC subroutine, the USRSRC rather than the USRBCF subroutine was used for analyses within this report involving chemical reactions.

3.3.1.2 Modeling of Hot and Cold Spots. The source term for chemical reactions is a function of the extent of fuel damage (i.e., reactive surface area), the temperature of the fuel, and the supply of water vapor and/or oxygen to drive the reaction. The thermal analyses discussed in Section 5.0 incorporate heat sources from both nuclear decay heat and chemical reactions.

The potential effects of degraded, badly damaged, or missing cladding or fuel on the thermal performance of the MCO were accommodated within the various models and can be easliy simulated by multiplying the reactive surface area by a factor such as $0.5,1,2,5,10$, etc. Multipliers greater than 1.0 simulate the effects of highly corroded fuel with a reactive surface area greater than the geometrical surface area. Multipliers less than 1.0 simulate reduced reactions that may be associated with fuel loss or oxide layers that might reduce the chemical reaction rate. Currently all the analyses performed to date have assumed a surface area multipler of 1.0 .

The affect of "hot or cold spots" can be investigated as necessary with FIDAP as described within the following paragraphs. The results of the "hot or cold spot" analyses will be provided at a later date as an addendum to this report.

The conservation of energy equation, as programmed within FIDAP, assumes that the total volumetric heat generation term $Q(\mathrm{~J} / \mathrm{m} 3-\mathrm{s})$ is a combination of several factors, as shown within the following equation:

$Q \quad=q_{s}+q_{d}+q_{r}+q_{j}+q_{p}$

where $q_{s}=$ The total heat generation rate due to the applied sources or sinks per unit volume

$q_{d} \quad=$ The total heat generation due to viscous dissipation

$q_{r} \quad=$ The total heat generation due to chemical reactions

$q_{j}=$ The total heat generation rate due to electrical (Joule) heating

$q_{p} \quad=$ The total heat generation rate due to participating media radiation.

Not all of the above. terms are used for each analysis. The user has complete control over the number of heat generation terms and the degree of detail used.

Each of the above terms is based on the total (i.e., cumulative) heat generation rates as determined from user entries for groups of elements, individual elements, or individual nodes. It must be emphasized that the above terms are cumulative. Localized "hot spots" can be accommodated by the application of multiple positive heat generation source terms to individual nodes within an element or an element within a group of elements, etc. Localized "cold spots" can be accommodated by the application of negative 
(i.e., sinks) volumetric heat generation rates or the non-application of additional source terms.

The nuclear decay heats, which were treated as constant values, can be applied on a global elemental, individual element, and nodal basis. The user has complete control to specify heat generation values down to the nodal level. The nuclear decay heat values for each individual fuel element with in the subject models were applied as constant volumetric heat sources (i.e., SOURCE $(\mathrm{J} / \mathrm{m} 3-\mathrm{s})$ ) separate from the surface heat fluxes or volumetric heat sources produced by chemical reactions. This allows for the potential of model ing separate distributions of both nuclear decay and/or chemical heats, subject to symmetry considerations, that may or may not be dependent on local conditions. If necessary, a user supplied subroutine can be compiled and linked with the main program to return volumetric heat generation values for a set of nodal points at a specified time.

The values used for the nuclear decay heat where obtained from an inventory of the fuel stored in the K Basins (Willis 1985). The nominal and maximum values of 1.58 and 3.44 watts per fuel assembly were used to derive estimates of the nominal and maximum MCO heat generations rates of 426 and 929 watts per MCO, respectively. These estimates were derived for a loading of Mark IV fuel assemblies and are assumed to remain valid for the Mark Ia fuel assemblies. A mimimun decay heat value of 0.53 watts per fuel assembly was derived assuming one-third of the nominal value. A MCO entirely comprised of minimum decay heat fuel assemblies would result in a total heat generation value of 142 watts per MCO.

The chemical reaction heat sources can be applied in several different ways :

- Applied as a reaction volumetric heat source (REACTION) term, $q_{r}$ $(\mathrm{J} / \mathrm{m} 3-\mathrm{s})$, where the local reaction rate depends on utilizing local conditions (i.e., temperatures, mass concentrations, and reactive surface area).

- Applied at the outer surface of the cladding as a heat flux (BCFLUX) term (J/m2-s), which may or may not be subject to a user supplied subroutine using an iterative process and the local conditions (i.e., temperatures, mass concentrations, and reactive surface area) to determine the local chemical reaction rate and, hence, applied heat flux.

- Applied as a separate volumetric heat source (SOURCE) term, $q_{s}$ $(\mathrm{J} / \mathrm{m} 3-\mathrm{s})$ deposited within the four thin rings of cladding surrounding the fuel elements, subject to a user supplied subroutine and the local conditions (i.e., temperatures, mass concentrations, and reactive surface area).

Both hot and cold spots can be modeled by changing the thermo-physical properties of the elements that may be associated with degraded fuel or the absence of fuel. Thermo-physical property sets (i.e., density, specific heat, thermal conductivity, emissivity) representative of degraded or reacted fuel and/or cladding can be applied on an individual elemental basis. The absence of fuel can be modeled by changing the subject fuel elements to some other material, such as water, air or helium. Some iteration with the geometrical 
Rev. 0

setup, subject to symmetry considerations, may be necessary to accommodate irregular degraded fuel.

\subsubsection{Thermo-physical Properties and Convective Heat Transfer Coefficients}

A11 three modes of heat transfer are used: conductive, convective, and radiative. Radiative heat transfer is particularly noteworthy, since it involves a series of highly detailed but automated view-factor calculations involving a series of full or partially obstructing surfaces.

The thermophysical properties for density, specific heat, thermal conductivity, as well as viscosities and emissivities, as necessary, were obtained for the various materials from a series of handbooks; such as the Nuclear Systems Material Handbook (NSMH), various engineering texts (Holman 1990, El-Wakil 1971, and Bird 1960), and reference documents such as the Spent Nuclear Fuel Technical notebook (Short and Beary 1995). Currently, the following "solid" material properties are available for use; uranium metal (U), uranium oxide $\left(\mathrm{UO}_{2}\right)$, Zircaloy-4 (ZIRC), Alumimum (Al), stainless steel 304 (SS304), stainless steel 316 (SS316), mild carbon stee1 (MCS), and silicon oxide $\left(\mathrm{SiO}_{2}\right)$. The following liquid and gaseous "fluid" material properties are available; water $\left(\mathrm{H}_{2} \mathrm{O}\right)$, water vapor (VAPOR), air (AIR), nitrogen $\left(\mathrm{N}_{2}\right)$, oxygen $\left(\mathrm{O}_{2}\right)$, helium $(\mathrm{He})$, Argon $(\mathrm{Ar})$, and hydrogen $\left(\mathrm{H}_{2}\right)$.

Estimates of the convective heat transfer coefficients on the outside surface of the transportation shipping cask and storage tube within the CSB were made using well known empirical treatments for free convection from vertical flat or cylindrical surfaces (McAdams 1954) and are documented within Section 4.2.2.5. Free convection heat transfer coefficients for vertical plates or vertical cylindrical surfaces are some of the best known correlations and represent a small uncertainty to the energy balance. The assumption is that the shipping cask and MCO remain in a vertical position during shipping. The convective heat transfer coefficients and, hence, energy transfer, are dependent on material properties, which are temperature dependent, as well as the temperature difference between the surface of the shipping cask and the ambient atmospheric temperature or the surface of the storage tube and the local temperature within the Canister Storage Building (CSB) vault.

Energy transfer between the interior surfaces and the MCO and between the MCO and the shipping cask or storage tube involve a combination of all three modes of heat transfer: conduction, convection, and radiation. At low pressures or for small gaps it is expected that convective heat transfer will be insignificant. Thermal radiation and conduction will remain. The thermal conductivity of gases and gas mixtures at low pressure conditions is not well known and represents another source of uncertainty that may have an impact on the thermal performance of the proposed system during vacuum drying.

Radiative losses from the cask surface depend on the surface area of the shipping cask, the difference between the temperature of the cask surface to the fourth power and the ambient temperature to the fourth power, and the emissivity of the cask's surface. Emissivities for most materials as a function of temperature are rather sparse. Usually a single value at some temperature and surface condition (i.e., polished, pitted, oxidized, etc.) is quoted. The lack of emissivity data represents a significant uncertainty in 
Rev. 0

the energy removal capabilities of the system. Emissivities provide the an option for maximizing heat transfer by specifying that the inner and outer surfaces of the MCO, the inner surface of the Shipping Cask, and the inner and outer surfaces of the storage tube be passiviated or chemically treated to achieve an emissivity near 0.8, and that the outer surface of the shipping cask be painted with a material such UNIFLEX or Azted 100 white paint which have known low solar absorptivity values ranging from approximately 0.15 to 0.18 and a relatively high normal emissivity value of 0.85 .

\subsubsection{Mass Transport}

None of the current thermal models employing chemical reaction heat generation rates model the rate limiting mass transport of reacting species (water, water vapor or oxygen), the rate limiting effects of hydrogen dilution or an inert gas purge dilution, or the buildup of diffusion limiting oxide or scale layers. The source term for chemical reactions is a function of the extent of fuel damage (i.e., reactive surface area), the temperature of the fuel, and the supply of water vapor and/or oxygen to drive the reaction. For most conditions within a $M C O$, the reaction rate will be limited by the availability of reactants such as water vapor and oxygen.

The reaction rate and, hence, chemical energy will be especially important during the vacuum drying portion of the IPS where fuel temperatures begin to rise as the convective heat transfer is reduced in a low pressure or vacuum environment. The chemical reaction can proceed no faster than the rate at which water vapor is generated by evaporation and transported to the reaction surface. The present analyses are considered conservative in this sense by assuming that there is no energy required to evaporate water and no mass transport delay to the reacting surface. The thermal models do have the capability to limit the reactions based on a total energy equivalent to a uniformly distributed mass of reactants within the symmetry of the model, but do not account for mass transfer. However, in the prediction of peak temperatures for a sustained reaction, the introduction of some modeling describing the rate of specie transport to a reacting surface will be desirable.

A series of additional thermal-hydraulic and mass transport models representative of the axial configuration of a shipping cask and storage tube containing a MCO are currently in development and will be used to quantify the extent of the internal natural circulation patterns, mass transfer, potential hot spots, and the extent and duration of surface chemical reactions under various operating and off-normal scenarios.

The fundamental geometries presented by Figures $3-1,3-2,3-3$, and 3-4 show the additional noding necessary to resolve the flows fields and various specie concentrations throughout the given model. It is anticipated that the next generation of models, as discussed above, will be three-dimensional (3-D) and have the capability to model a source of reacting species as well as the transport of the reacting mass throughout the system, either by diffusion or natural circulation flows.

$3 \& 4$ UNIFLEX and Aztec are trademarks of American Floor Products Company, Inc. 
WHC-SD-WM-ER-525

Rev. 0

Figure 3-1. Quarter Symmetric Model of MCO and Shipping Cask With Fuel Encapsulation Canister.

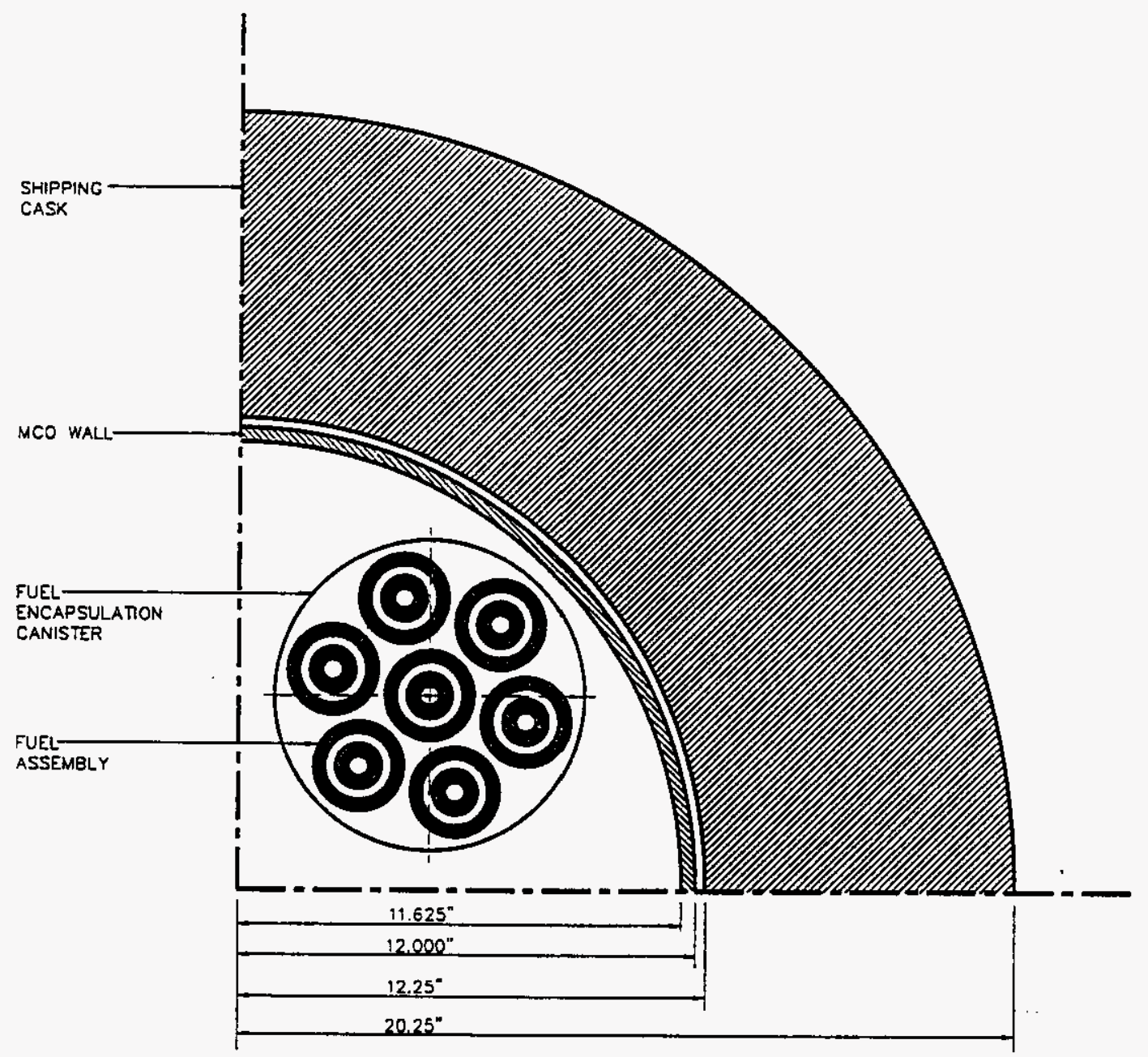


WHC-SD-WM-ER-525
Rev. 0

Figure 3-2. $30^{\circ}$ Sector Model of MCO and Shipping Cask With Mark IV Fuel Assemblies.

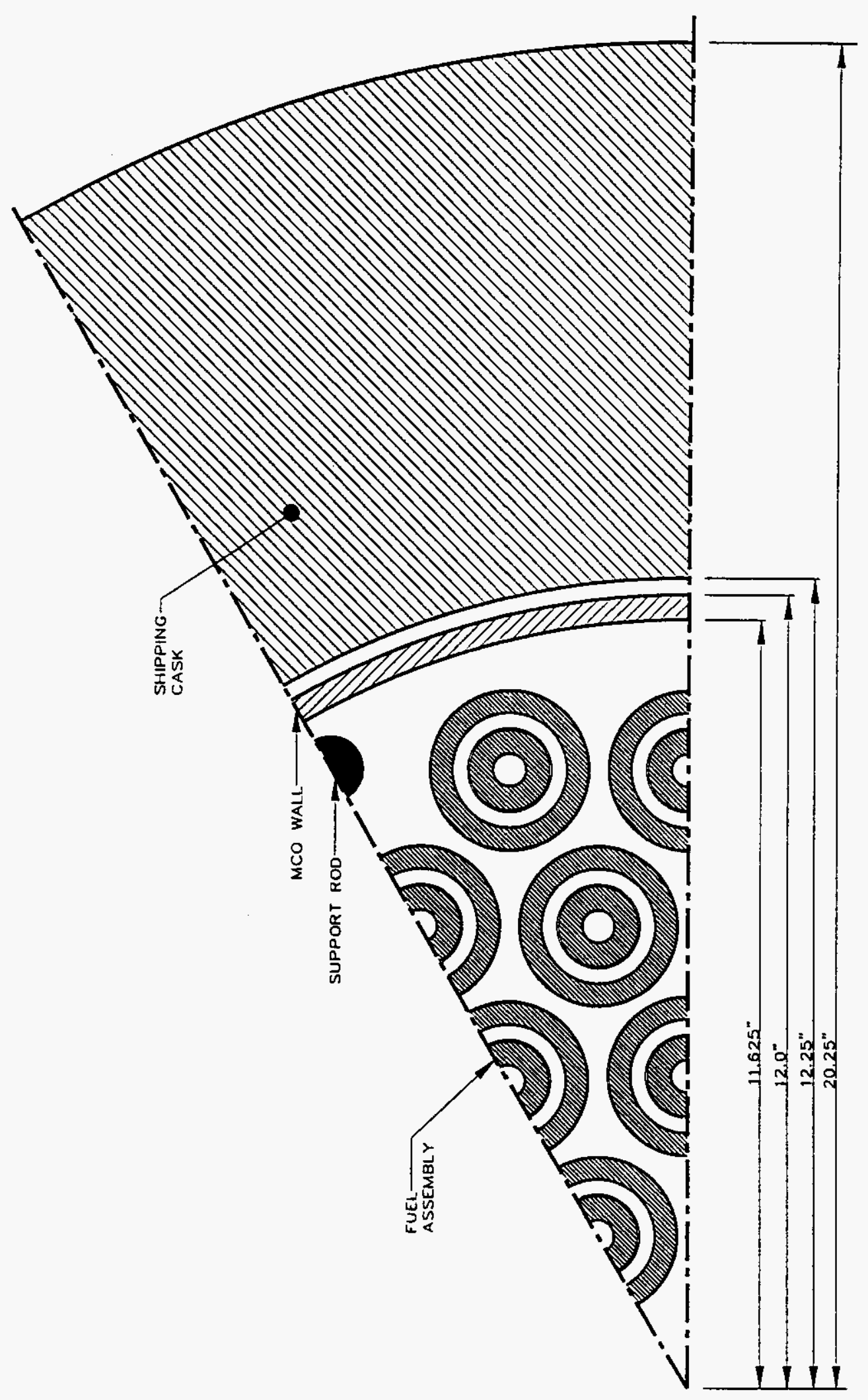

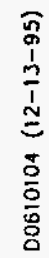


WHC-SD-WM-ER-525

Rev. 0

Figure 3-3. $30^{\circ}$ Sector Model of MCO and Shipping Cask With Mark Ia Fuel Assemblies.

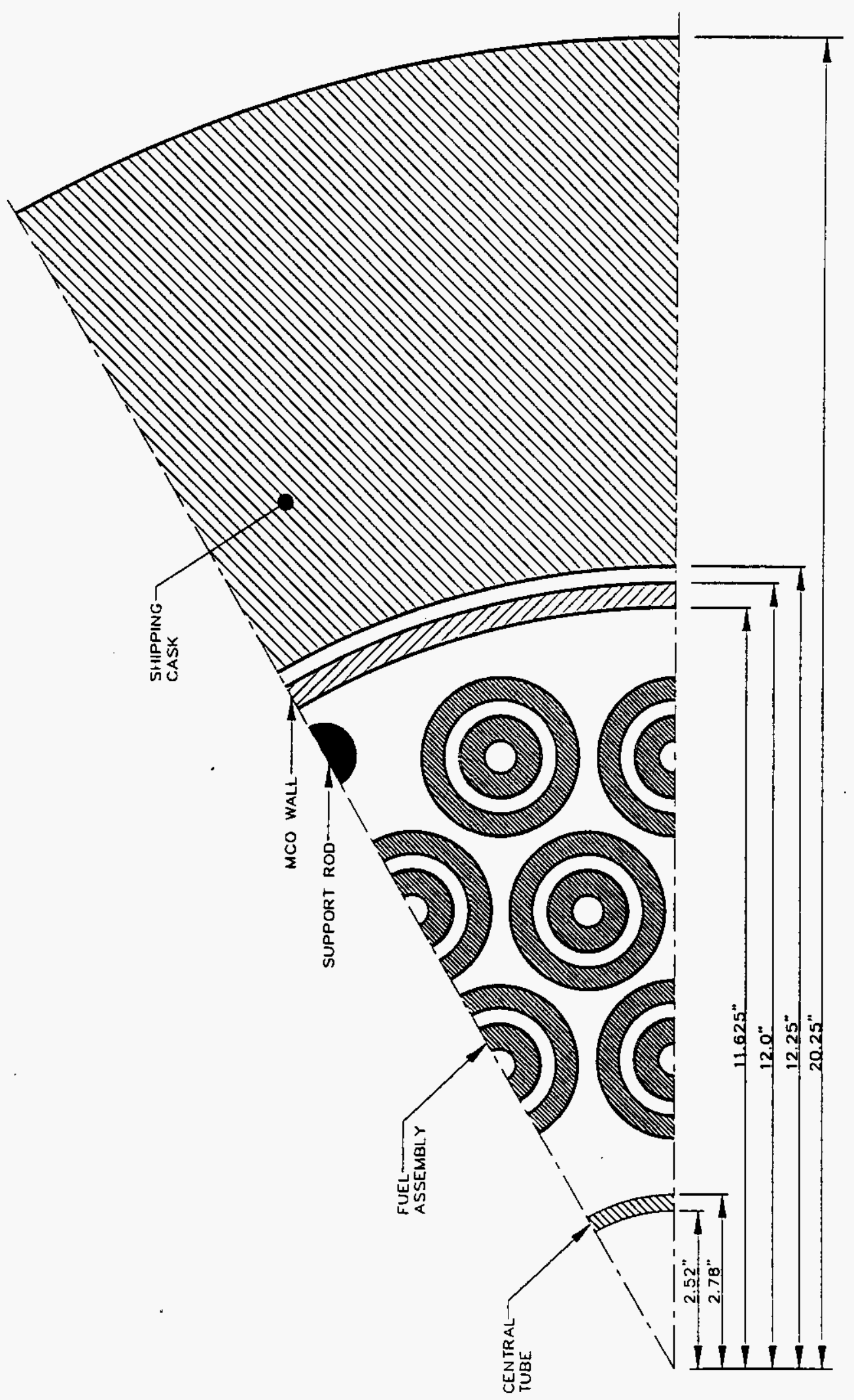

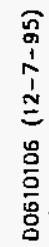


WHC-SD-WM-ER-525

Rev. 0

Figure 3-4. $30^{\circ}$ Sector Model of MCO and Storage Tube With Mark IV Fuel Assemblies.

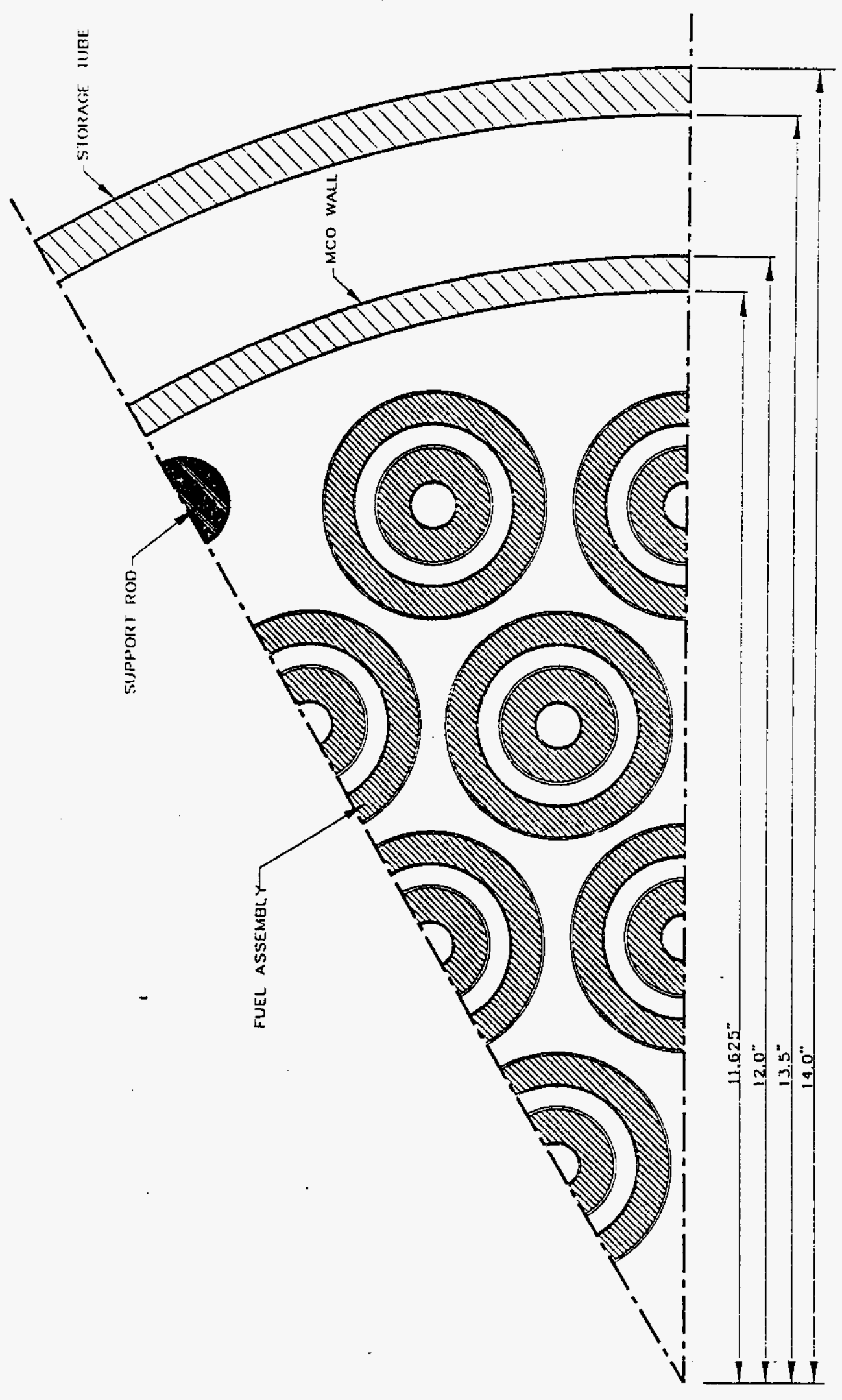


Figure 3-5. Volumetric Heat Rate Versus Temperature for the Tyfield, Ritchie, and McGillivary Reaction Rate Relationships.

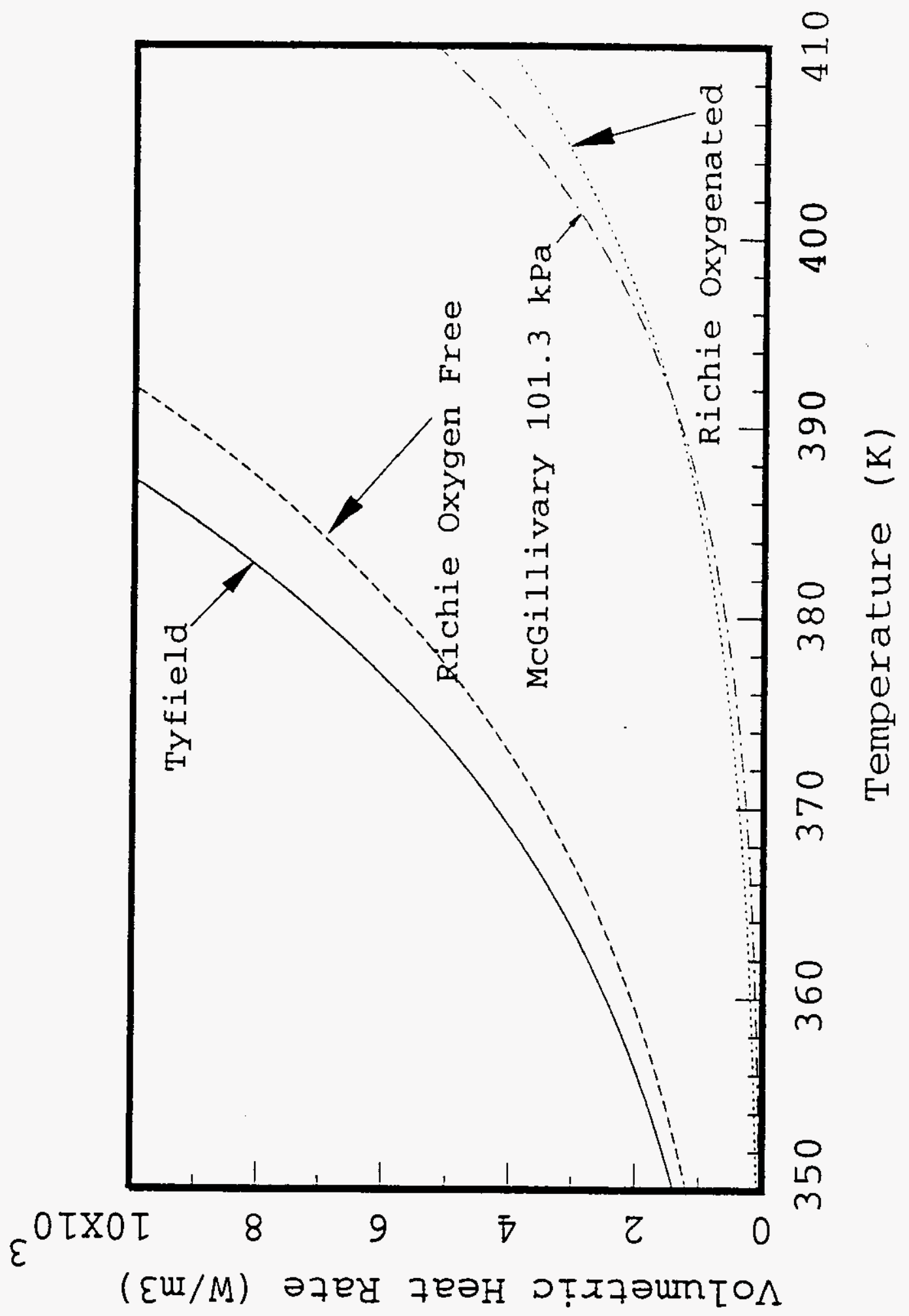


Figure 3-6. Volumetric Heat Rate for McGillivary Reaction Rate Relationship Versus Temperature and Water Vapor Pressure.

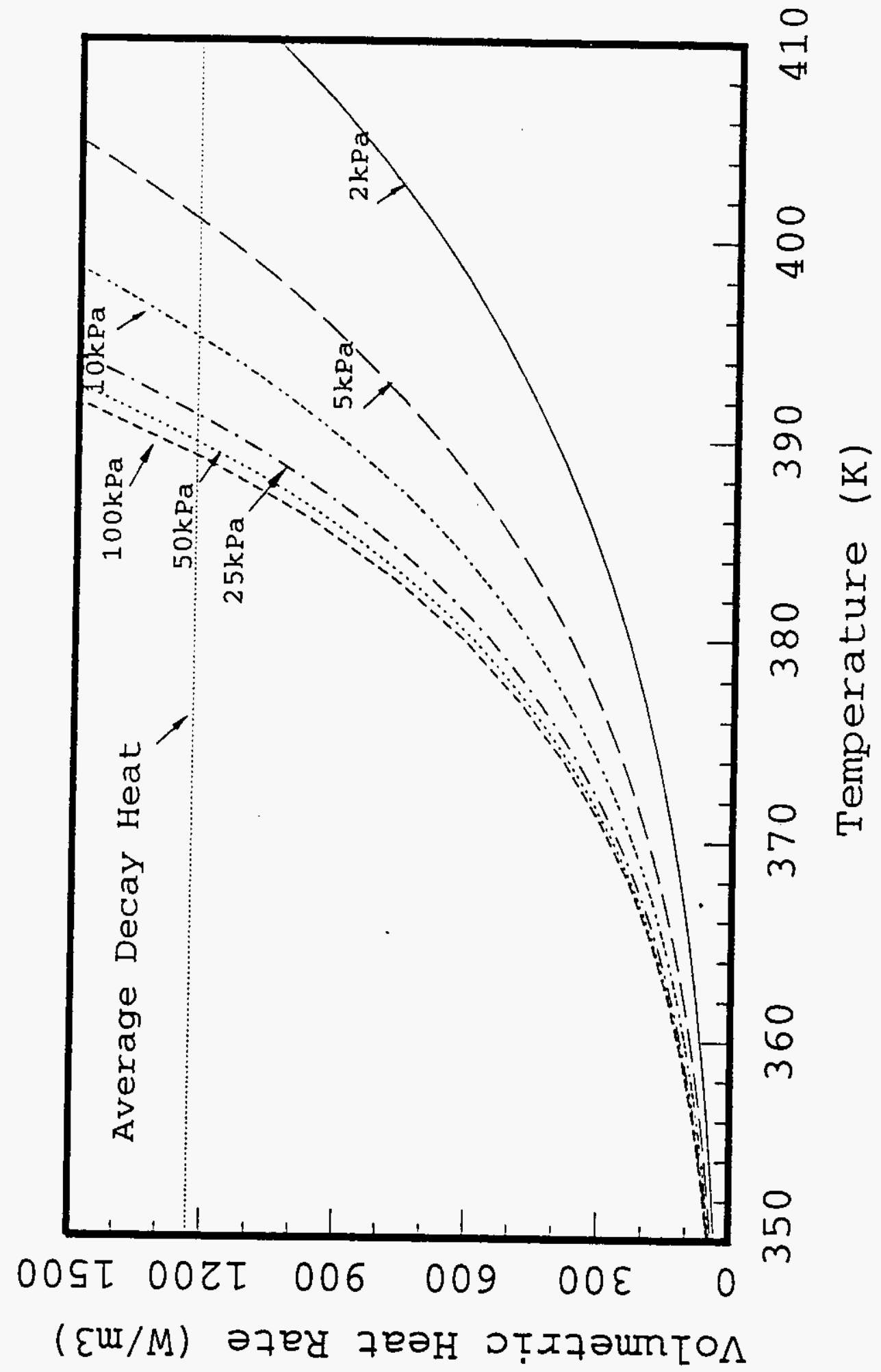


Figure 3-7. Volumetric Heat Rate for McGillivary Reaction Rate Relationship Versus Water Vapor Pressure and Temperature.

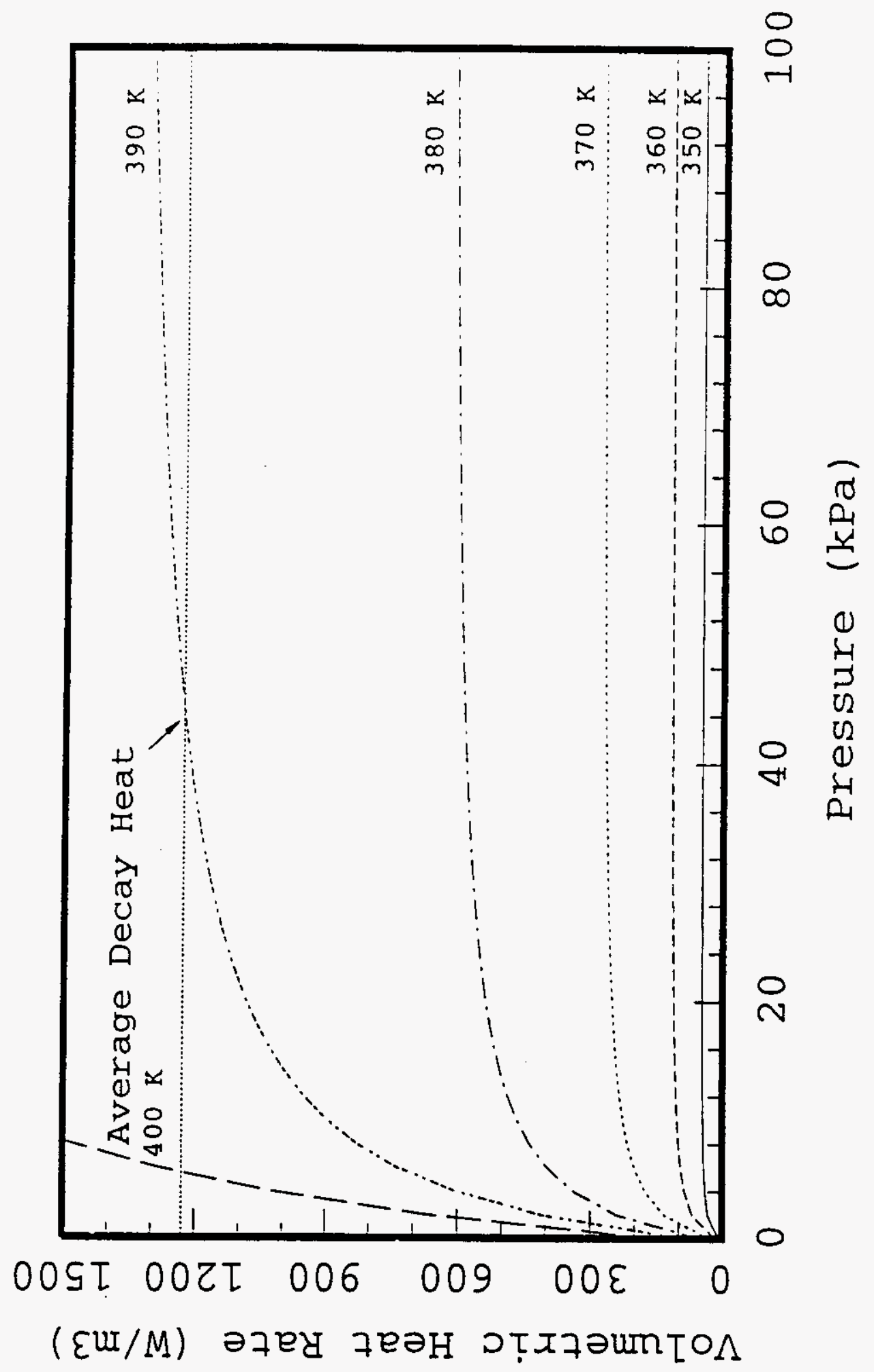


WHC-SD-WM-ER-525

Rev. 0

\subsection{MODEL DEVELOPMENT, METHODOLOGY, AND ASSUMPTIONS}

The purpose of this section is to document the development, methodology, and assumptions behind each of the initial thermal models and to show how the existing thermal models are versatile enough to provide detailed technical support in defining and resolving IPS issues.

\subsection{FIDAP MODELS}

As summarized in Section 3.1, eight separate two-dimensional (2-D) FIDAP models where constructed. The 2-D models neglected axial effects and are assumed to result in conservative temperature estimates. Each of the subject thermal-hydraulic models provided a mechanism to investigate the range of temperatures and heat up rates associated with each of the proposed IPS options and engineering alternatives; such as fuel type, wet versus dry shipping, hot versus cold vacuum drying scenarios, dense packing, as well as providing an analytical base for investigating the chemical reactions and preforming the required safety analyses. Several specialized models were also developed such as the semi-infinite plate model for chemical reaction sensitivity studies and the storage tube gap circulation model. The following sections describe each of the eight models. Appendix $E$ summarizes the resulting model sizes.

In most cases the model definition data, material property sets and simulation control information remain identical from one model to another, only the geometry differs. Table 4-1 presents the N Reactor Fuel dimensions that were used for the two-dimensional models. The overall axial length of the Mark IV fuel elements range from 17.4 to to a maximum of 26.1 inches. The overall axial length of the Mark Ia fuel elements range from 14.3 to a maximum of 20.9 inches. For the purposes of the two-dimensional radial models a unit depth of one meter was assumed. Figures 4-1 and 4-2 present a cross section and isometric view of a Mark IV fuel assembly, respectively.

The MCO outer diameter was assumed to be 24 inches with a wall thickness of 0.375 inches. A 0.50 inch diametrical gap was assumed between the MCO outer diameter and the shipping cask inner diameter. The shipping cask was assumed to be 40.5 inches with a wall thickness of 8 inches. For the models involving the CSB and storage tube, a 3 inch diametrical gap between the MCO outer diameter and the storage tube inner diameter. The storage tube was assumed to be 28 inches in diameter with a 0.50 inch wall thickness.

Energy gains and losses from the system involve heat transfer from the inner fuel elements to the outer surface of the shipping cask to ambient conditions via conductive, convective, and radiative heat transfer mechanisms. clearly the correct treatment of the energy gains and system boundary loss mechanisms is very important. For the following models all three modes (i.e., conduction, convective, and radiative) of heat transfer were incorporated via specialized surface or continuum elements and are available for use.

Radiative heat transfer is particularly noteworthy, since it involves a series of highly detailed automated view-factor calculations performed by FIDAP involving a series of full or partially obstructing surfaces. The view factors were calculated on an individual element basis for all elements 
WHC-SD-WM-ER-525

Rev. 0

comprising radiative surfaces. Radiative heat transfer has been found to be a very significant, especially under vacuum conditions when natural circulation is not possible and the thermal conductivity of gases is reduced. A grey body approach without participating media was assumed for each of the radiating surfaces within the mode1. The outer surface of the system is assumed to be radiating to a user determined black body temperature.

Convective heat transfer coefficients can be applied separately to each of the interior surfaces and the external cask surface to account for convective heat transfer and convective heat losses to the surrounding ambient conditions. Convective losses from the cask surface involve a combination of both forced convection from wind affects and natural circulation losses due to axial temperature differences. This is further complicated by the cylindrical curved outer surface of the shipping cask, which under forced convection result in increased losses from the "upwind" side and reduced losses on the "downwind" side. The standard methodology usually employed in this situation is to ignore the effects of forced convection and take credit only for natural circulation. The convective heat transfer coefficients for the external surface of the shipping cask have been derived for 10 degree (and some five degree) intervals from 50 to $210^{\circ} \mathrm{F}$.

Table 4-1. N Reactor Fuel Type Dimensions.

\begin{tabular}{||c|c|c||}
\hline Fuel Type & Mark-IA & Mark-IV \\
\hline Overall Nominal Dimensions (inches) & & \\
\hline Outer element 0D & 2.404 & 2.425 \\
\hline Outer element ID & 1.767 & 1.701 \\
\hline Inner, element 0D & 1.246 & 1.279 \\
\hline Inner element ID & 0.440 & 0.479 \\
\hline Cladding Thickness (mils) & & \\
\hline Outer element, outer clad & 25 & 25 \\
\hline Outer element, inner clad & 25 & 20 \\
\hline Inner element, outer clad & 40 & 30 \\
\hline Inner element, inner clad & 25 & 20 \\
\hline Nominal Maximum Length (inches) & & \\
\hline Outer element & 20.88 & 26.10 \\
\hline Inner element & 20.82 & 26.04 \\
\hline Assumed End Cap Thickness (inches) & & \\
\hline Outer element & 0.200 & 0.200 \\
\hline Inner element & 0.200 & 0.200 \\
\hline
\end{tabular}


Besides nuclear decay heat and chemical reactions, solar insolation (incident surface heat flux) corresponding to the latitude of Hanford was treated as an energy gain. The solar insolation values were obtained from Irwin 1994 and are presented in Table 4-2. The values associated with the

Table 4-2. Solar Insolation Values for Average July Day at Hanford.

\begin{tabular}{|c|c|c|c|c|c|c|c|c|}
\hline \multirow[b]{2}{*}{ Hour-PST } & \multicolumn{2}{|c|}{ PNL $-4622^{\circ}$} & \multicolumn{2}{|c|}{ 10CFR71 ${ }^{b}$} & \multicolumn{2}{|c|}{ CosINE } & \multicolumn{2}{|c|}{ ASHRAE OFF-SITE ${ }^{c}$} \\
\hline & Langleys ${ }^{d}$ & Btu/fte ${ }^{2, e}$ & Longleys & $B t u / f t^{2}$ & Langleys & $B t u / f t^{2}$ & Langleys & Btu/ft ${ }^{2}$ \\
\hline $12.04 \mathrm{am}$ & 0 & 0 & 0 & 0 & 0 & 0 & 0 & 0 \\
\hline 04-05 an & 2.5 & 9.2 & 3.1 & 11.4 & 13.6 & 50.1 & 0 & 0 \\
\hline $05-06 \mathrm{em}$ & 9.8 & 36.1 & 12.1 & 44.7 & 26.8 & 98.8 & 0 & 0 \\
\hline $06-07 \mathrm{em}$ & 22.1 & 81.5 & 27.3 & 100.7 & 39.0 & 143.8 & 18.3 & 67.3 \\
\hline 07-08 am & 36.6 & 134.9 & 45.2 & 166.8 & 49.9 & 184.0 & 42.3 & 156.0 \\
\hline 08-09 an & 49.9 & 184.0 & 61.7 & 227.5 & 59.2 & 218.3 & 63.9 & 235.5 \\
\hline $09-10 \mathrm{am}$ & 60.7 & 223.8 & 75.0 & 276.7 & 66.4 & 244.8 & 81.5 & 300.4 \\
\hline $10-11 \mathrm{em}$ & 68.3 & 251.8 & 84.4 & 311.3 & 71.3 & 262.9 & 93.9 & 346.0 \\
\hline $11-12 \mathrm{am}$ & 72.1 & 265.8 & 89.1 & 328.6 & 73.8 & 272.1 & 100.4 & 370.0 \\
\hline 12-01 pm & 71.9 & 265.1 & 88.9 & 327.7 & 73.8 & 272.1 & 100.4 & 370.0 \\
\hline 01-02 pm & 67.8 & 250.0 & 83.8 & 309.0 & 71.3 & 262.9 & 93.9 & 346.0 \\
\hline 02-03 pm & 60.5 & 223.1 & 74.8 & 275.8 & 66.4 & 244.8 & 81.5 & 300.4 \\
\hline 03-04 pm & 49.9 & 184.0 & 61.7 & 227.5 & 59.2 & 218.3 & 63.9 & 235.5 \\
\hline $04-05 \mathrm{pm}$ & 37.2 & 137.2 & 46.0 & 169.6 & 49.9 & 184.0 & 42.3 & 156.0 \\
\hline $05-06 \mathrm{pm}$ & 23.6 & 87.0 & 29.2 & 107.6 & 39.0 & 143.8 & 18.3 & 67.3 \\
\hline $06-07 \mathrm{pm}$ & 11.3 & 41.7 & 14.0 & 51.5 & 26.8 & 98.8 & 0 & 0 \\
\hline $07-08 \mathrm{~mm}$ & 2.9 & 10.7 & 3.6 & 13.2 & 13.6 & 50.1 & 0 & 0 \\
\hline 08-12 pm & 0 & 0 & 0 & 0 & 0 & 0 & 0 & 0 \\
\hline SUM & 647.1 & 2386.0 & 800.0 & 2950.0 & $800.0^{\circ}$ & 2950.0 & 800.0 & 2950.0 \\
\hline
\end{tabular}

a. Recommended for Hanford Sito

b. Hanford Site Insolation Normalized to 10CFR71 Requirements

c. Recommended off-eite case, meets 10CFR71 Requirements

d. A Langley is defined as 1 gram calorie per square centimeter

-. Conversion to SI Unite

1 Langley $=41870.0 \mathrm{~J} / \mathrm{m}^{2}$

$1 \mathrm{Btu} / \mathrm{ft}^{2}=11355.9 \mathrm{~J} / \mathrm{m}^{2}$ 
Rev. 0

first column are recommended for use on the Hanford site and reflect measured values. However, the values in the second column reflect Hanford specific values that have been normalized to 10CFR71 requirements and, as such, represent a conservative total heat input. The 10CFR71 values used for the analyses were derived assuming a geometrical factor of 0.5 and a solar absorption coefficient of $\mathbf{0 . 3}$ for the outer surface of the shipping cask.

Solar insolation was applied to the outer diameter of the shipping cask via a time dependent surface heat flux that can simulate up to 30 daily cycles of solar heating.

\subsubsection{Quarter Symmetric Fuel Encapsulation Canister (FEC) Model}

The thermal model developed from Figure 3-1 and shown in progression from Figures 4-5 through 4-8 represents a two-dimensional quarter symmetric radial cross section of a MCO within a shipping cask, containing a one Fuel Encapsulation Canister (FEC) barrel and seven fuel assemblies each consisting of a outer element ring and inner element. (Each FEC consists of two barrels each containing seven fuel assemblies.) Figures 4-3 and 4-4 present representative top and side views of a fuel encapsulation canister and a barrel with seven fuel assemblies. Figure 4-5 presents a cross sectional view of a MCO showing the location of the two FECs (i.e., four barrels) at each tier. Figures 4-6 and 4-7 present an axial view of the tiers proposed for Mark IV and Mark Ia fuel, and the baskets to contain the fuel assembijes. Figure 4-8 presents the resulting two-dimensional finite element nodalization pattern that has been developed. The quarter symmetry allows for the expansion of the model to half or ful1 symmetry at a later date.

The model as presented by Figure 4-8 was originally developed to reflect the concept of direct loading of the FECs into the MCO with minimum fuel handling and reflects the additional noding required to resolve the expected flow fields and chemical specie concentrations. However, for the purposes of this report the above model was run in the thermal mode only, which solves only the conservation of energy equation.

The two-dimensional radial modeling approach was to treat each of the seven fuel assemblies separately, each with an inner and outer fuel element and cladding, within a single Fuel Encapsulation Canister (FEC) barrel, within a MCO, within a shipping cask. This was done to maximize the thermal resistance and, hence, the maximum temperatures. As shown in Figures 3-1 and 4-8, three of the seven fuel assemblies were assumed to be orientated along a 45 degree line relative to the center point and external surface of the shipping cask. Again this was done to maximize the thermal resistance. The remaining four fuel assemblies were located two above and two below the 45 degree line. The natural configuration of the seven fuel assemblies within an $\mathrm{FEC}$ is that of a hexagon.

Packing configurations other than loading a FEC with seven fuel assemblies have been investigated and are discussed in Section 4.1.2 and are referred to as the dense pack option. The remaining packing option involving fuel debris and sludge (i.e., porous media) is discussed in Section 4.1.4. 


\subsubsection{MCO and Cask 30 Degree Sector, 2-D Model}

Packing configurations other than direct loading of FECs into a MCO have been investigated and are discussed in the following sections and are referred to as the dense pack option.

Because of the large number of MCOs that would be required to completely load out the FECs, the loading concept was changed to a densely packed array that would allow up to 270 or 288 fuel assemblies per MCO (48 to 54 fuel assemblies depending on the type of fuel with five or six tiers per MCO). Mark Ia fuel, because of criticality concerns associated with the higher initial enrichment and the shorter length, would be limited to 48 fuel assemblies per tier with six tiers per MCO. Mark IV fuel, which does not have a criticality concern and has a longer maximum length, would be loaded to 54 fuel assemblies per tier with five tiers per MCO.

The dense pack option significantly increases both the decay heat and surface area available for reactions relative to the FEC loading option discussed in Section 4.1.1.

4.1.2.1 Mark IV Fuel. The thermal model developed from Figure 3-2 and shown in Figure 4-9 represents a two dimensional one-twelfth symmetric radial cross section of MCO within a shipping cask, containing 4.5 Mark IV fuel assemblies (2 full and 5 half) each consisting of a outer annular ring and inner annular ring. This is equivalent to 54 Mark IV fuel assemblies at any given elevation within a MCO. The one-twelfth symmetry allows for the expansion of the model to, one-sixth, one-third, half or full symmetry at a later date.

4.1.2.2 Mark Ia Fuel. The thermal model developed from Figure 3-3 and shown in Figure 4-10 represents a two-dimensional one-twelfth symmetric radial cross section of a MCO within a shipping cask, containing 4 Mark Ia fuel assemblies (2 full and 4 half) each consisting of a outer annular ring and inner annular ring. This is equivalent to 48 Mark Ia fuel assemblies at any given elevation within a MCO. The one-twelfth symmetry allows for the expansion of the model to one-sixth, one-third, half or full symmetry at a later date.

Because of criticality concerns associated with Mark Ia fuel, the center fuel assembly was excluded from each tier. A 6 -inch Schedule 40 pipe centered within each tier provides a mechanical mechanism to prevent loading more than 48 Mark Ia fuel assemblies.

\subsubsection{Ignition Model}

The thermal model described in Section 4.1.2.1 was modified to investigate fuel pyrophoricity. In particular, the convective heat transfer coefficients for the external surface of the system were derived for 10 degree and some five degree $F$ intervals, from 50 to 210 degrees $F$, and the analysis execution sequence was automated such that a sequence of runs could be performed for different ambient conditions. The resulting peak fuel or cladding temperature profiles were plotted and numerically differentiated. The goal was to determine when the second derivative of temperature with respect to time went positive. This was judged to be a prime indication of the ignition temperature necessary to start a "runaway" chemical reaction. 
This model was developed based on preliminary design basis accident descriptions and safety analys is issues regarding the minimum threshold temperature that would initiate the rapid temperature excursions associated with "runaway" chemical reactions. The goal was to determine these temperatures and develop strategies to maintain peak temperatures less than the "threshold" temperature limit.

A user subroutine to limit the chemical reactions based on total energy equivalent to a given mass of residual reactants was used to determine the peak fuel temperatures as a result of chemical reactions for various amounts of residual water. (Given unlimited reactants and a high enough ambient temperatures, the system would "runaway" in every case.) By investigating the effects of 7 imited amounts of residual reactants, processing criteria can be developed for the cold vacuum drying facility.

\subsubsection{MCO and Storage Tube 30 Degree Sector, 2-D Model}

The thermal model developed from Figure 3-4 and shown in Figure 4-11 represents a two dimensional one-twelfth symmetric radial cross section of MCO within a storage tube within the Canister Storage Building (CSB), containing a 4.5 Mark IV fuel assemblies ( 2 full and 5 half) each consisting of a outer annular ring and inner annular ring. This is equivalent to 54 Mark IV fuel assemblies at any given elevation within the MCO. The one-twelfth symmetry allows for the expansion of the model to one-sixth, one-third, half or fult symmetry at a later date. A MCO and storage tube model containing Mark Ia fuel assemblies has not yet been developed.

The MCO and storage tube model differs from the earlier one-twelfth models in several ways: (1) the diametrical gap is 3.0 inches rather than 0.50 inches, and (2) only convective heat transfer losses are allowed from the outer surface of the storage tube. Thermal radiation was not allowed from the outer surface of the storage tube. This was done to conservatively approximate a single storage tube within an array of storage tubes each at the same temperature. The subject storage tube would lose as much energy by thermal radiation as it would gain from the surrounding tubes.

The 3.0 inch diametrical gap is large enough to establish a weak natural circulation flow pattern as discussed in Section 4.1.7. However, the MCO Storage Tube model discussed above only assumed conductive and radiative heat transfer across the MCO - Storage Tube gap. Additional, work is necessary to determine an effective conductivity that will approximate the combined effects of conduction and convection.

\subsubsection{Porous Rubble Bed}

A porous rubble bed thermal model was developed from Figure 3-1 and the thermal model discussed in Section 4.1.1. The resulting porous bed finite element nodalization pattern, as presented by Figure 4-12, represents a twodimensional quarter symmetric radial cross section of $M C O$ within a shipping cask, containing a homogenized area representative of an 8 -inch wire mesh basket containing fuel debris and sludge (i.e., porous media). 
The porous rubble bed model requires both fluid and solid properties. The amount of solid and fluid material are related via the porositry of the porous media. The solid properties are assumed to be those of uranium metal, but can be changed to uranium oxide or any other material mix as desired. The fluid properties are assumed to be either water or mixes of various gases such as oxygen, water vapor, hydrogen, argon, etc. For the finite elements within the porous entity the volume average porous media momentum, continuity, species, and energy equations are solved.

The geometry for this model is complete, but the input necessary to describe the porous material has not yet been established. In particular, the effective conductivity and viscosity to be used, the type of permeability model to be used, and the porosity of the porous media remains to be defined.

\subsubsection{Chemical Reaction Sensitivity - Plate Mode1}

A two-dimensional FIDAP model of a semi-infinite flat $p l a t e$ of uranium metal was developed to perform parametric studies of uranium oxidation models. The plate has a thickness of $1.0 \mathrm{~cm}$ (Figure 4-13). Although not intended to be a precise model of the fuel in a $M C O, 1.1 \mathrm{~cm}$ is close to the thickness of an actual Mark IV fuel element. An outer Mark IV fuel element has a thickness of $0.919 \mathrm{~cm}$, and an inner Mark IV fuel element has a thickness of $1.016 \mathrm{~cm}$.

Radiative and conductive heat transfer from one side of the plate are modeled. The other side of the plate is assumed to be an adiabatic surface. Heat is transferred from the uranium plate across a gas gap to a steel wall. There is conduction through the steel wall and then radiative and conduction heat transfer from the steel wall to a heat sink that is at a specified boundary condition temperature representative of ambient conditions.

A constant nuclear decay heat load is distributed throughout the uranium and a heat load to simulate chemical oxidation is applied at the edge of the uranium. This chemical source term is actually modeled as a uniformly distributed heat load over $0.1 \mathrm{~cm}$ at the edge of the uranium plate.

The chemical heat source terms can also be applied to just one element in the model. This can be used to simulate the effect of scraping the oxide scale off along a thin line across the uranium plate and allowing the uranium hydroxide to burn quickly.

Four different choices of equations for the uranium oxidation heat are included in the model. These are: (1) the Tyfield equation, (2) the McGillivary equation, (3) Ritchie equation, and (4) the Condon model. These are the same reaction rate relationships that were utilized for the more detail two-dimensional models discussed above in Sections 4.1.1 through 4.1.4.

Hydrogen pressure over the uranium is required for the condon model. If an oxygenated atmosphere is being modeled, the calculation of the equilibrium hydrogen pressure is calculated as a function of uranium temperature by an equation given in Condon (1983). If an oxygen-free atmosphere is being modeled, the equilibrium hydrogen pressure is calculated from an empirical 
equation for the ratio of hydrogen concentration to water vapor concentration as a function of the uranium temperature (Cooper 1995). This ratio is equal to

$$
\begin{aligned}
\frac{P_{H_{2}}}{P_{H_{2} \mathrm{O}}} & =2.76 \times 10^{-13}+3.735 \times 10^{-11} \mathrm{~T}+3.07134 \times 10^{-9} \mathrm{~T}^{2} \\
& -2.127 \times 10^{-11} \mathrm{~T}^{3}+2.2409 \times 10^{-14} \mathrm{~T}^{4} \\
& +8.2456 \times 10^{-17} \mathrm{~T}^{5}-8.7232 \times 10^{-20} \mathrm{~T}^{6}
\end{aligned}
$$
Kelvin.

Where $T$ is the temperature of the local uranium metal node in degrees

The atmosphere is considered to be oxygen free if the oxygen partial pressure is less than one torr.

If the uranium temperature is higher than the temperature of the adjacent atmosphere, the water vapor pressure is assumed to be the water vapor pressure in the $M C O$.

If the uranium temperature is less than the atmosphere temperature, water vapor will condense on the uranium, so the water vapor pressure is calculated to be the saturation pressure at the uranium temperature.

\subsubsection{Storage Tube - MCO Gap Circulation Model}

A full length Computational Fluid Dynamics (CFD) model of the gas space or gap between the MCO overpack and the Canister Storage Building (CSB) Storage Tube (ST) was constructed and is shown in Figures 4-14, 4-15, and 4-16. This model was developed to evaluate the degree of natural convection within this gas space and how it effects heat transfer across this gap given a axial temperature gradient typical of CSB conditions. In addition, the mode] was later modified to investigate the mixing of contaminant species, such as hydrogen if released from the $M C O$, within the gap and the potential for hydrogen pocketing at the top of the storage tube.

Because of the relatively small width of the radial gap ( 1.5 inches) in comparison to the diameter of the MCOs (24 inches) a two-dimensional axisymmetric (RZ) model of the gas space was considered adequate for these scoping calculations. The resulting geometry for the gas space consists of a very thin rectangle 1.5 inches wide and 320 inches long as shown on Figure 4-14. The inner and outer sides of this rectangular flow field represents the outer surface of two stacked MCO's and the surrounding canister storage tube respectively. Top and bottom surfaces represent the vertical extent of the canister storage tube.

Boundary conditions for this model consist of a uniform heat flux from the outside surface of the MCO's equivalent to a decay heat loading of

426 watts per MCO. Heat transfer from the outside surface of the storage tube to the CSB cooling system was simulated by applying a linear temperature 
distribution ranging from $115^{\circ} \mathrm{F}$ at the baseplate to $140^{\circ} \mathrm{F}$ at the upper deck along the vertical outside wall of the storage tube. Radiation heat transfer across the air gap between the MCOs and the storage tube is included in the model. The radiating surfaces are assumed to be gray and the intervening gas (air) transparent (nonparticipating media). The MCOs and storage tube were assumed to be constructed of polished stainless steel with a total emmittance of 0.25. Gas flow within gap was assumed to be buoyancy driven and any convective heat transfer was determined by the CFD code from solution of the coupled momentum and energy equations.

\subsection{HUB ANALYTICAL SOLUTIONS}

The model used for obtaining an analytical solution for heat transfer within the MCO is shown in the Figure 4-17. This model assumes that the fue region can be modeled as alternating rings of fuel and air gaps. The volume of air in the gaps is equal to the volume of air surrounding the actual fuel rods. The annular fuel rings of the model are superimposed on the actual fuel arrangement in the Figure 4-17. The MCO wall and the cask or tube walls are modeled as cylinders. Heat transfer between each of the fuel solid surfaces and between the outer ring of fuel and the MCO wall occurs due to conduction and radiant heat transfer for the condition when the MCO is at a vacuum and by conduction, convection and radiation when air is present. The temperatures solved for are shown in Figure 4-17.

The definition of these temperatures is as follows:

1. T1: Temperature on outer radial side of the innermost row of fuel elements.

2. T2: Temperature on the outer radial side of second row of fuel elements from the center.

3. T3: Temperature on the outer radial side of the third row of fuel elements from the MCO centerline.

4. T4: Temperature on the outer radial side of the fourth row of fuel elements from the MCO centerline.

5. T5: Temperature on the outer surface of the MCO wall.

6. T6: Temperature on the inner surface of the cask (tube) wall.

7. T7: Temperature on the outer surface of the cask (tube) wa11.

8. T8: The ambient temperature.

\subsubsection{Analytical Solution for Annular Ring Model}

A discussion of the analytical solution for the annular ring model is provided in the following paragraphs. 
WHC-SD-WM-ER-525

Rev. 0

4.2.2.1 Internal MCO Convective Heat Transfer. The heat removal rate within the interior of the MCO due to convection around and through the fuel assemblies is given by:

$$
\operatorname{Qconv}(\Delta T)=0.393 \cdot(\Delta T)^{2}
$$

where, the heat transferred is in watts $(\mathrm{J} / \mathrm{s})$ and the temperature gradient, $\Delta T$ is in ${ }^{\circ} \mathrm{C}$.

This equation was derived assuming the fuel elements are uniformly spaced with a pitch of 2.75 inches, the flow is laminar, and that the characteristic length of the circulating flow was the equivalent of three times the fuel element length; i.e., one fuel element length for upward flow, one fuel element length for downward flow, and one fuel element length for cross flow.

It was also assumed that the upward flow occupies one-half of the available flow area, the downward flow occupies the other half, and that the flow circulates due to a difference in density. The total path length of the circulating air was assumed to be the equivalent of three times the fuel element length, i.e., one fuel element length for the upward flow, one length for the down flow, and the equivalent of one fuel element length for the cross flow.

The driving head due to the density difference was set equal to the equation for laminar pressure drop and solved as a function of temperature. This is a reasonable approximation for natural circulation at this stage of the MCO design. A more rigorous analysis will be required when the design becomes better defined.

It is assumed that all of the convective heat removal occurs from the inner three rows of fuel and is deposited within the outer row of fuel. The convective heat removal is partitioned between the inner three rows based on the number of fuel elements in each row.

The convective heat removal from the inner row of fuel is

$$
Q \operatorname{conv1a}=\frac{Q \operatorname{conv}(T 1-T 5)}{6}
$$

The convective heat removal from the second row of fuel is

$$
\text { Qconv2a }=\frac{Q \operatorname{conv}(T 1-T 5)}{3}
$$


WHC-SD-WM-ER-525

Rev. 0

The convective heat removal from the third row of fuel is

$$
Q \operatorname{conv} 3 a=\frac{Q \operatorname{conv}(T 1-T 5)}{2}
$$

The total heat removed from the inner three rows of fuel by convection can be derived by summing equations $4-3,4-4$, and 4-5;

$$
Q \operatorname{conv} 4 a=Q \operatorname{conv}(T 1-T 5)
$$

4.2.2.2 Incident Solar Heat Flux. The average incident solar heat flux on the external outer surface of the shipping cask was assumed to be

$$
\text { gsolar }=47.04 \frac{J}{m^{2}-s}
$$

This value is based on a 24 hour average of the 10CFR71 values presented by Table 4-2 assuming a 0.5 geometrical factor and a surface absorption coefficeint of 0.3 .

4.2.2.3 Decay Heat Rate. The decay heat rate is assumed to be $1228 \mathrm{~W} / \mathrm{m}^{3}$ of fuel and corresponds to a total MCO heat genration rate of 426 watts or 1.58 watts per fuel assembly.

4.2.2.4 Heat Due to Metal 0xidation. The McGillivary oxidation rate equation has been used to obtain heat rate due to metal oxidation.

$$
q I(T)=\Delta h_{s}\left(\frac{0.4196 p e^{-\frac{6432}{T}}}{1+2.48 \times 10^{-7} p e^{\frac{5236}{T}}}\right)+\Delta h_{o 2}\left(10.95 e^{-\frac{8077}{T}}\right)
$$

where

$$
\begin{aligned}
\Delta h_{s} & =3.4 \times 10^{7} \mathrm{~J} / \mathrm{kg} \text { in the presence of oxygen. } \\
& =1.67 \times 10^{7} \mathrm{~J} / \mathrm{kg} \text { in the absence of oxygen. } \\
\Delta h_{02} & =3.4 \times 10^{7} \mathrm{~J} / \mathrm{kg} \\
\mathrm{p} & =\text { Water vapor pressure in } \mathrm{kPa} \\
\mathrm{T} & =\text { Temperature in }{ }^{\circ} \mathrm{K} \\
\mathrm{q}_{r} & =\text { Heat rate in } \mathrm{J} / \mathrm{m}^{2}-\mathrm{s}
\end{aligned}
$$

The heat rate for the inner ring of fuel is

$$
q r l a=6 q_{x}(T 1) \cdot \text { Area }
$$


The heat rate for the second ring of fuel is

$$
q r 2 a=6 q_{r}(T 2) \cdot 2 \cdot \text { Area }
$$

The heat rate for the third ring of fuel is

$$
q r 3 a=6 \text { gr }(T 3) \cdot 3 \cdot \text { Area }
$$

The heat rate for the fourth ring of fuel is

$$
\text { gr4a }=6 \operatorname{qr}(T 4) \cdot 3 \cdot \text { Area }
$$

The total heat rate for the entire fuel basket is

$$
\text { qrtot }=q r l a+q r 2 a+q r 3 a+q r 4 a
$$

where

Area $=$ Total surface area of inside and outside surface of both the inside and outside elements of a single fuel assembly.

4.2.2.5 External Convective Heat Transfer Coefficient. The convection coefficient on the external outer surface of the shipping cask is given by [McAdams 1954] for free convection from vertical surfaces as

$$
h_{c}=\frac{K_{f}}{L}(.13)\left(L^{3}\left(t_{7}-t_{8}\right) \Psi\right)^{1 / 3}
$$

where

$$
\Psi=\left(\frac{\rho_{f}^{2} g B_{f}}{\mu_{f}^{2}}\left(\frac{C P_{f} \mu_{f}}{k_{t}}\right)\right)
$$

$k_{f}=$ Thermal conductivity of the air evaluated at the film temperature

$t_{7}=$ Cask (tube) wall temperature

$t_{B}=$ Ambient temperature

$\rho_{\mathrm{f}}=$ Air density at film temperature

$B_{f} \quad=\quad$ Volume coefficient of expansion of air

g = Acceleration of gravity

$\mu_{f}=$ Air dynamic viscosity at film temperature

$\mathrm{CP}_{\mathrm{f}}=$ Air specific heat at film temperature 
Rev. 0

4.2.2.6 Outer Cask (or Storage Tube Wall Temperature. The temperature (TT) of the outer surface of the shipping cask (or storage tube) wall can be derived by the following equation;

$$
h_{c} A 7(T 7-T 8)+\sigma A 7 e_{c}\left(T 7^{4}-T 8^{4}\right)=q 7+\text { gsolar*A7+qxtot }
$$

where, the energy losses due to convective and radiative heat transfer equal the energy gains from incident solar, chemical reaction heat, and nuclear decay heat and

$$
\begin{aligned}
& \text { A7 } \quad=\quad \begin{array}{l}
\text { Outside surface area of cask (tube) over the length of one } \\
\text { fuel element }
\end{array} \\
& \sigma \quad=\text { Stefan-Boltzmann constant }=0.1715 \mathrm{E}-8 \mathrm{Btu} / \mathrm{hr}-\mathrm{ft}^{2}-\mathrm{R}^{4} \\
& \epsilon_{c} \quad=\text { Emissivity of cask (tube) wall } 0.55 \text { to } 0.7 \\
& q 7 \quad=\quad \begin{array}{l}
\text { Total decay heat of fuel assemblies stored in one tier or a } \\
\text { single fuel basket }
\end{array}
\end{aligned}
$$

4.2.2.7 Inner Cask (or Storage Tube) Wall Temperature. The temperature drop across the shipping cask or storage wall can be derived and used to obtain the inner wall temperature. The following equation is obtained by applying Fourier's Law to an infinitely long cylinder with an outer and inner diameter of ODcask and IDcask, respectively.

$$
T 6=(q 7+q r \operatorname{tot}) \frac{\ln \left(\frac{O D \text { cask }}{I D C a s k}\right)}{2 \pi K s I i c I V}+T 7
$$

where

$\begin{array}{ll}\text { ODcask } & =\text { Outside diameter of cask (tube) } \\ \text { IDcask } & =\text { Inside diameter of cask (tube) } \\ \text { Ks } & =\text { Thermal conductivity of mild carbon steel } \\ \text { licIV } & =\quad \text { Length of fuel element }\end{array}$

4.2.2.8 Outer MCO Wall Temperature. The temperature of the outer MCO can be derived by performing an energy balance across the gap between the outer diameter of the MCO wall and the inner diameter of the shipping cask or storage tube wall. Energy losses due to conduction and radiative heat transfer across the gap must equal the gains from nuclear decay heat and 
Rev. 0

chemcial reactions. The energy balance is presented by the following equation;

$$
\begin{aligned}
\frac{K_{\mathrm{a}}}{x 6-I 5} & 0.5(A 5+A 6)(T 5-T 6) \\
& +\frac{0 A 5\left(T 5^{4}-T 6^{4}\right)}{\frac{1}{\epsilon_{\text {mco }}}+\frac{A 5}{A 6}\left(\frac{1}{\epsilon_{\text {IDcask }}}-1\right)}=q 7+q r \operatorname{tot}
\end{aligned}
$$

where

$$
\begin{aligned}
& \mathrm{K}_{\mathrm{a}}=\quad \text { Thermal conductivity of air in the gap between the } \\
& \text { MCO and Cask (or storage tube) based on average of MCO } \\
& \text { and inner cask (or storage tube) wall temperatures } \\
& \text { r6 = Inside radius of cask (tube) } \\
& \text { r5 }=\text { Outside radius of the mco } \\
& \text { A5 }=\text { Surface area of MCO outer wall over the length of one } \\
& \text { fuel element } \\
& \text { A6 = Surface area of Cask (tube) inner wall over the length } \\
& \text { of one fuel element } \\
& \epsilon_{\text {meo }}=\text { Emissivity of the mco wall } 0.2 \text { to } 0.7 \\
& \epsilon_{\text {IDcask }}=\text { Emissivity of the cask liner (or tube wal1) } 0.2 \text { to } 0.7
\end{aligned}
$$

4.2.2.9 Outer (Fourth) Fuel Ring Temperature. The temperature of the outermost fuel ring can be derived by perfroming an energy balance across the gap between the outer ring of fuel and the inner diameter of the MCO wall. Energy losses due to conduction, radiative heat, and convective transfer across the gap must equal the energy gains from nuclear decay heat and chemical reactions. The energy balance is given by the following equation

$$
\begin{aligned}
& \frac{K_{a}}{I g a p} 0.5(A 4 a+A 5 i a)(T 4-T 5) \\
& +\frac{A f a c t 10 A 4\left(T 4^{4}-T 5^{4}\right)}{\frac{1}{\varepsilon_{\text {fuel }}}+\frac{A 4}{A 5 i}\left(\frac{1}{\epsilon_{\text {mco }}}-1\right)}+\text { Oconv4a }=q 7+\text { grtot }
\end{aligned}
$$


where

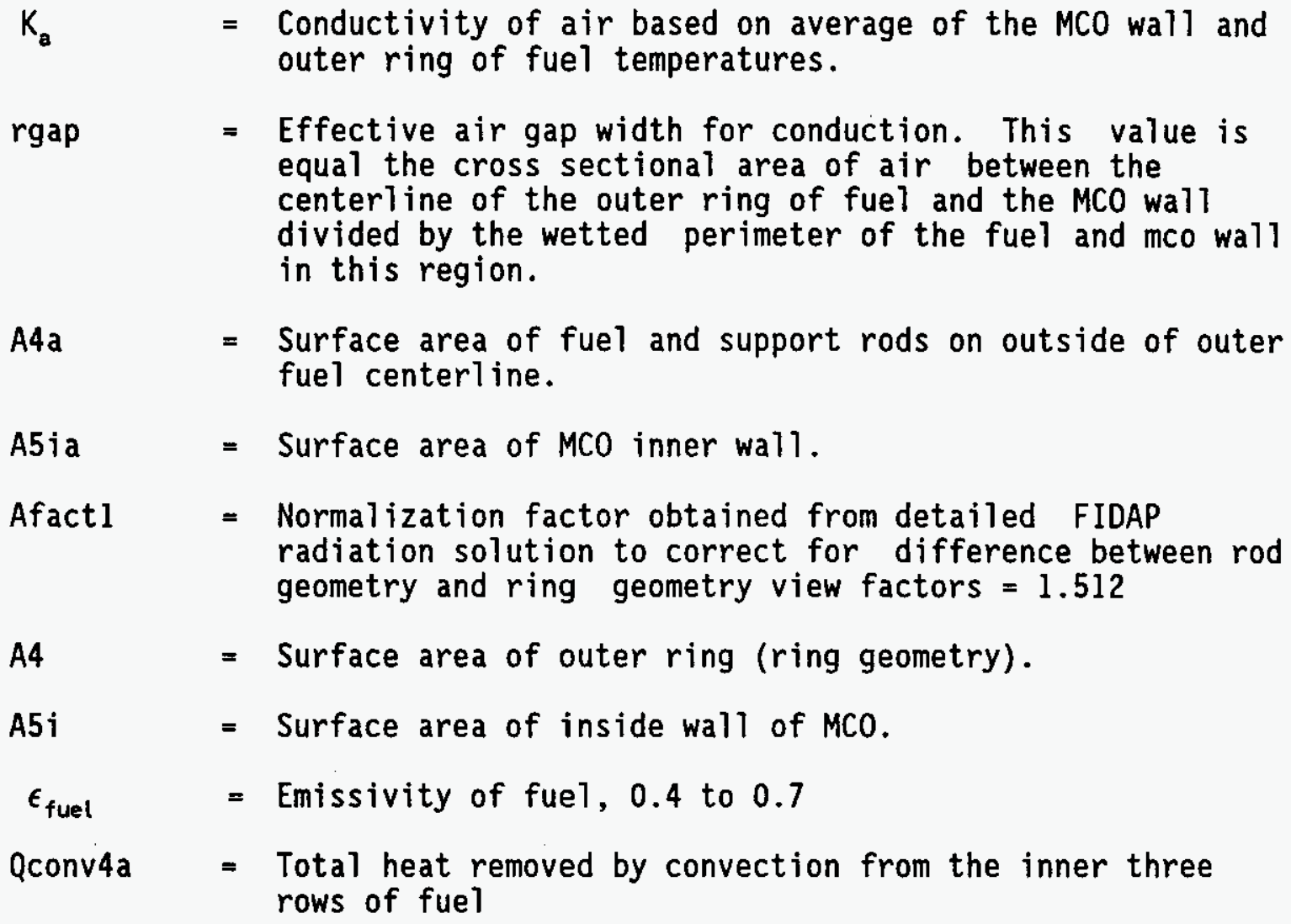

4.2.2.10 Third Fuel Ring Temperature. The temperature of the third fuel ring can be determined by perfroming an energy balance across the gap between the third and fourth rings of fuel. Energy losses due to conduction, radiative heat, and convective transfer across the gap must equal the energy gains from nuclear decay heat and chemical reactions. The form of the energy balance is presented by the following equation where

$$
\begin{aligned}
\frac{K_{a}}{0.70 r g a p} & 0.5(A 3 a+A 4 i a) \\
(T 3 a-T 4 a)+ & \frac{A f a c t 30 A 3\left(T 3 a^{4}-T 4 a^{4}\right)}{\frac{1}{\epsilon_{f u e l}}+\frac{A 3}{A 4 i}\left(\frac{1}{\epsilon_{f u e l}}-1\right)} \\
& + \text { Qconv3a+Qconv2a+ Qconv1a= g3 + Qr } 1 a \\
& + \text { qr } 2 a+q r 3 a
\end{aligned}
$$

where

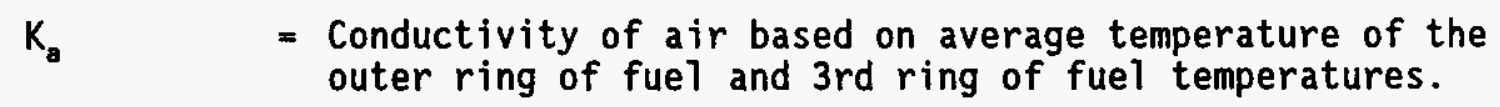


rgap

A4ia

A3a

Afact3

A4 $\mathbf{i}$

A3

Qconv3a

Qconv2a

Qconvla

= Effective air gap width for conduction. This value is equal the cross sectional area of air between the centerline of the outer ring of fuel and the center line of the third ring of fuel divided by the wetted perimeter of the fuel on both sides of the air gap. The factor of 0.7 is a normalization factor obtained from comparison with the detailed FIDAP model to correct for the nonuniform thickness of the air gap in the rod geometry.

= Surface area of fuel and support rods on inside of outer fuel centerline.

= Surface area of fuel on outside of third ring of fuel.

= Normalization factor obtained from detailed FIDAP radiation solution to correct for difference between rod geometry and ring geometry view factors $=1.75$.

= Inner surface area of outer ring (ring geometry).

= Outer surface area of third ring (ring geometry).

$=$ Heat removed from the third ring of fuel by convection.

= Heat removed from the second ring of fuel by convection.

= Heat removed from the first ring of fuel by convection.

4.2.2.11 Second Fuel Ring Temperature. The temperature of the second ring of fuel can be determined by perfroming an energy balance across the gap between the second and third rings of fuel. Energy losses due to conduction, radiative heat, and convective transfer across the subject gap must equal the energy gains from nuclear decay heat and chemical reactions. The energy balance is given by the following equation

$$
\begin{aligned}
\frac{K_{\mathrm{a}}}{0.91 \text { rgap }} & 0.5(A 2 a+A 3 i a)(T 2 a-T 3 a) \\
& +\frac{A f a c t 20 A 2\left(T 2 a^{4}-T 3 a^{4}\right)}{\frac{1}{\epsilon_{\text {fuel }}}+\frac{A 2}{A 3 i}\left(\frac{1}{\epsilon_{\text {fuel }}}-1\right)} \\
& + \text { Qconv2a }+ \text { Qconv1a }=q 2+g r 1 a+g r 2 a
\end{aligned}
$$

where

$$
\begin{aligned}
& \mathrm{K}_{\mathrm{a}}=\begin{array}{l}
\text { Conductivity of air based on average of the third and } \\
\text { second ring of fuet temperatures. }
\end{array} \\
& \text { rgap } \quad=\begin{array}{l}
\text { Effective air gap width for conduction. This value is } \\
\text { equal the cross sectional area of air between the } \\
\text { centerline of the third ring of fuel and the center line of }
\end{array}
\end{aligned}
$$


WHC-SD-WM-ER-525

Rev. 0

the second ring of fuel divided by the wetted perimeter of the fuel on both sides of the air gap. The factor of 0.91 is a normalization factor obtained from comparison with the detailed FIDAP model to correct for the nonuniform thickness of the air gap in the rod geometry.

A3ia = Surface area of fuel and support rods on inside of third ring of fuel centerline.

A2a = Surface area of fuel on outside of second ring of fuel.

Afact2 = Normalization factor obtained from detailed FIDAP radiation solution to correct for difference between rod geometry and ring geometry view factors $=1.476$

A3i = Inner surface area of third ring of fuel (ring geometry).

A2 = Outer surface area of second ring of fuel (ring geometry).

Qconv2a = Heat removed from the second ring of fuel by convection.

Qconvla = Heat removed from the first ring of fuel by convection.

4.2.2.12 First Fuel Ring Temperature. The temperature of the innermost ring of fuel can be determined by performing an energy balance across the gap between the first and second rings of fuel. Energy losses due to conduction, radiative heat, and convective transfer across the gap must equal the energy gains from nuclear decay heat and chemical reactions. The energy balance is given by the following equation

$$
\begin{aligned}
& \frac{K_{d}}{0.74 \text { rgap }} 0.5(A 1 a+A 2 i a)(T 1 A-T 2 A) \\
& +\frac{\text { Afact1 OAI }\left(T 1 a^{4}-T 2 a^{4}\right)}{\frac{1}{\epsilon_{\text {fuel }}}+\frac{A 1}{A 2 i}\left(\frac{1}{\epsilon_{\text {fuel }}}-1\right)}+Q \text { conv1a }=q 1+q I 1 a
\end{aligned}
$$

where

$\mathrm{K}_{\mathrm{a}}=$ Conductivity of air based on average of the second ring of fuel and first ring of fuel temperatures.

rgap = Effective air gap width for conduction. This value is equal the cross sectional area of air between the centerline of the second ring of fuel and the center line of the third ring of fuel divided by the wetted perimeter of the fuel on both sides of the air gap. The factor of 0.7418 is a normalization factor obtained from comparison with the detailed FIDAP model to correct for the nonuniform thickness of the air gap in the rod geometry.

A2ia = Surface area of fuel and support rods on inside of second ring of fuel centerline. 
WHC-SD-WM-ER-525

Rev. 0

Ala = Surface area of fuel on outside of first ring of fuel.

Afactl = Normalization factor obtained from detailed FIDAP radiation solution to correct for difference between rod geometry and ring geometry view factors $=2.011$

A2i = Inner surface area of second ring of fuel (ring geometry).

Al = Outer surface area of first ring of fuel (ring geometry).

Qconvla = Heat removed from the first ring of fuel by convection.

4.2.2.13 Solution. The above set of equations are solved simultaneously to obtain a solution for each of the fuel ring surface temperatures given a specified ambient temperature. The equations are solved by guessing an initial value for each of the temperatures and then using successive substitution until the error in each equation is reduced to zero. It is assumed that the thermal resistances due to conduction across the fuel and mco wall are small and can be neglected.

That this is the case has been verified by detailed FIDAP analysis which show that the temperature drop across the fuel elements are less than a degree, while the temperature drop across the MCO wall is at most a few degrees.

\subsubsection{Analytical Solution for Rubble Basket}

In this analysis, it is assumed that a fuel rubble basket is sitting in the interior centerline position of a MCO and that the decay heat generation rate and surface to volume ratio is the same as that for declad fuel elements. The rubble basket will be divided into 10 annular rings and the analytical solution for the temperature of each annular ring will be derived and solved. The analytical results are presented in Section 5.2.4.

The model must be divided into 10 annular rings because the heat generation rate is not uniform but is a function of temperature because of the heat of reaction due to fuel oxidation. The model for the fuel basket is shown in Figure 4-17. In the model, it is assumed that the surface temperature is held constant and that the decay heat per unit volume is constant. The heat released due to chemical reaction is temperature dependent so it is different for each region of fuel in the basket, however, it is assumed that the temperature of each region is uniform so that the chemical reaction heat release is constant within that region.

4.2.3.1 Analytical Solution for the 10th (Outermost) Ring of Fuel. The analytical solution for the outermost fuel ring is obtained as follows. For a uniform volumetric heat generation. rate within the region

$$
\frac{\partial}{\partial r}\left(r \frac{\partial T}{\partial r}\right)=r \frac{q^{\prime}}{k}
$$


Rev. 0

where

$r=$ Radial distance

$\mathrm{T}=$ Temperature

$q^{*}=$ Volumetric heat rate $\left(B t u / h r-\mathrm{ft}^{3}\right)$

$k$ = Composite thermal conductivity of the rubble bed

$=K_{\text {air }}(T) /\left(1-\alpha^{0.33}\right)$

$\alpha=$ Solids volume fraction (assumed to be 0.62 for maximum packing of spheres).

at $r=r g$

$$
\frac{\partial T}{\partial r}=\frac{-q_{b g}}{2 \pi k r L}
$$

where

$\mathrm{q}_{\mathrm{bg}}=$ Total heat rate into region 10 from the inner regions of the rubble basket (Btu/hr).

$\mathrm{L} \quad=$ Length of rubble basket.

at $r=r 10$

$$
\mathrm{T}=\text { Tsurf }=366 \mathrm{~K}=199.1^{\circ} \mathrm{F} .
$$

where

Tsurf = Temperature of the rubble basket surface, from the analysis in the previous section, this temperature is taken to be $99.1{ }^{\circ} \mathrm{F}$. have

Integrating the above equation and applying the boundary conditions we

$$
r \frac{\partial T}{\partial r}=-\frac{r^{2} q^{\prime}}{2 k}+C 1
$$

apply boundary condition

$$
C 1=\frac{r g^{2} q^{\prime} 10-q_{b 9}}{2 k}
$$


WHC-SD-WM-ER-525

Rev. 0

therefore

$$
\frac{\partial T}{\partial r}=\frac{r^{2} q_{10}^{\prime}}{2 k}+\frac{r g^{2} q_{10}-\frac{q_{b g}}{\pi L}}{2 k r}
$$

Integrating

$$
T=\frac{-r^{2} q_{10}^{\prime}}{4 k}+\frac{r g^{2} q_{10}^{\prime}-\frac{q_{b g}}{\pi L}}{2 k} \log _{e}(r)+C 2
$$

Applying the second boundary condition

$$
C 2=T \operatorname{surf}+\frac{r 10^{2} q_{10}^{\prime}}{4 k}-\frac{r 9^{2} q_{10}^{\prime}-\frac{q_{b 9}}{\pi L}}{2 k} \log _{e}(r 10)
$$

and substituting

where

$$
T 10(r)=\left(r 10^{2}-r^{2}\right) \frac{q_{10}^{\prime}}{4 k}+\frac{r 9^{2} q_{10}^{\prime}-\frac{q_{b 9}}{\pi k}}{2 k} \log _{0}\left(\frac{r}{r_{10}}\right)+\text { Tsurf }
$$

where

$q^{\prime}{ }_{10}=\alpha^{*}\left(q_{O H}^{\prime}+q_{C R}^{\prime}\right) * V_{01}$

$\alpha=$ Solids volume fraction (assumed to be 0.62 for maximum packing of spheres)

$q_{D H}^{\prime}=$ Volumetric decay heat rate $1228 \mathrm{~W} / \mathrm{m}^{3}$ (118.7 Btu $\left./ \mathrm{hr}^{\prime}-\mathrm{ft}^{3}\right)$

$q^{\prime}{ }_{C R}=$ Volumetric chemical reaction heat $\left(B t u / h r-\mathrm{ft}^{3}\right)$

$q_{b 9} \quad=\quad \Sigma_{i} q_{i} * V_{01} 1_{i}$ for $i=1,9$

4.2.3.2 Analytical Solution for the Nine Outer Rings. The above equation gives the solution for each of the outer 9 rings of fuel if Tsurf is replaced with the temperature of the inner surface of the previous outer ring and the appropriate subscripts are used for each of the variables. 
4.2.3.3 Analytical Solution for the Fuel Basket Center Region. For a uniform volumetric heat generation rate, the conduction solution for the center region is

$$
\frac{\partial}{\partial r}\left(r \frac{\partial T}{\partial r}\right)=-r \frac{g^{\prime}}{\dot{k}}
$$

Integrating we have

$$
r \frac{\partial T}{\partial r}=\frac{-r^{2} q_{1}^{\prime}}{2 k}+C 1
$$

and integrating again we have

$$
T=-r^{2} \frac{q_{1}^{\prime}}{4 k}+c 1 \log _{e}(r)+c 2
$$

The boundary conditions are

at $r=0, \partial T / \partial r=0$

at $r=\mathrm{Rl}, \mathrm{T}=\mathrm{Tl}$

$\mathrm{Tl}$ is the temperature at the boundary between region 1 and region 2 and is obtained by solving the equation given in the section above.

Applying the first boundary condition, $\mathrm{Cl}=0$ so

$$
T=\frac{-r^{2} q_{1}^{\prime}}{4 k}+C 2
$$

Applying the second boundary condition gives

$$
C 2=T 1+\frac{r 1^{2} q_{1}^{\prime}}{4 k}
$$

substituting we get

$$
T=\frac{\left.I I^{2}-r^{2}\right) q_{1}^{\prime}}{4 k_{u}}+T 1
$$

where

$k_{u}=\begin{aligned} & \text { Thermal conductivity of uranium since the center ring contains a } \\ & \text { single fuel chunk. }\end{aligned}$ 
WHC-SD-WM-ER-525

ReV. 0

\subsubsection{Normalization}

To determine the accuracy of the simplified analytical solution, the results of the analytical solution with no correction factors, have been compared with detailed steady-state FIDAP calculations that were performed using the 30 degree sector model with Mark IV fuel within an MCO with a decay heat of 426 watts without chemical reactions within a shipping cask for a ambient temperature of $100^{\circ} \mathrm{F}$. These comparisons were perfromed for two cases: (1) conduction only, and (2) combined conduction and radiation. $A$ comparison of the two cases is shown in the Figure 4-19. The surface emissivities used in the calculation are: $\epsilon_{c l a d}=0.4, \epsilon_{\text {mco }}=0.2$, $\epsilon_{\text {IDcask }}=0.2$, and $\epsilon_{\text {cocask }}=0.55$.

The analytical solution for the conduction only case with no correction factors, deviates from the detailed FIDAP calculation by about $15^{\circ} \mathrm{K}$. The accuracy of the analytical solution for conduction has been increased by multiplying the conduction length for each air gap by an appropriate factor to match the FIDAP solution. The case with conduction and radiation again shows about a $15^{\circ} \mathrm{K}$ conservatism in the analytical solution without correction factors, compared to the FIDAP solution. This conservatism can be removed by applying an appropriate factor to the radiation surface area to cause the analytical solution to match the detailed FIDAP solution. These correction factors have been applied in all of the HUB analyses and subsequent results (Section 5.2 and Figures 5-37 through 5-42) contained in this report. The reasonably close agreement between the annular ring analytical solution with no correction factors and the FIDAP solutions provides additional confidence that the FIDAP model input for geometry and view factors is correct.

\subsubsection{Technical Notebook}

Detailed documentation of all of the calculations that have been performed using the analytical solution are documented in a notebook which is filed under the task specifcation SFM-95-011. Readers interested in the details of the solution for any particular case should refer to this notebook. The main results of these calculations and the conclusions that can be drawn from these calculations are presented in this report. 
WHC-SD-WM-ER-525

Rev. 0

Figure 4-1. Cross Section View of a Mark IV Fuel Assembly.

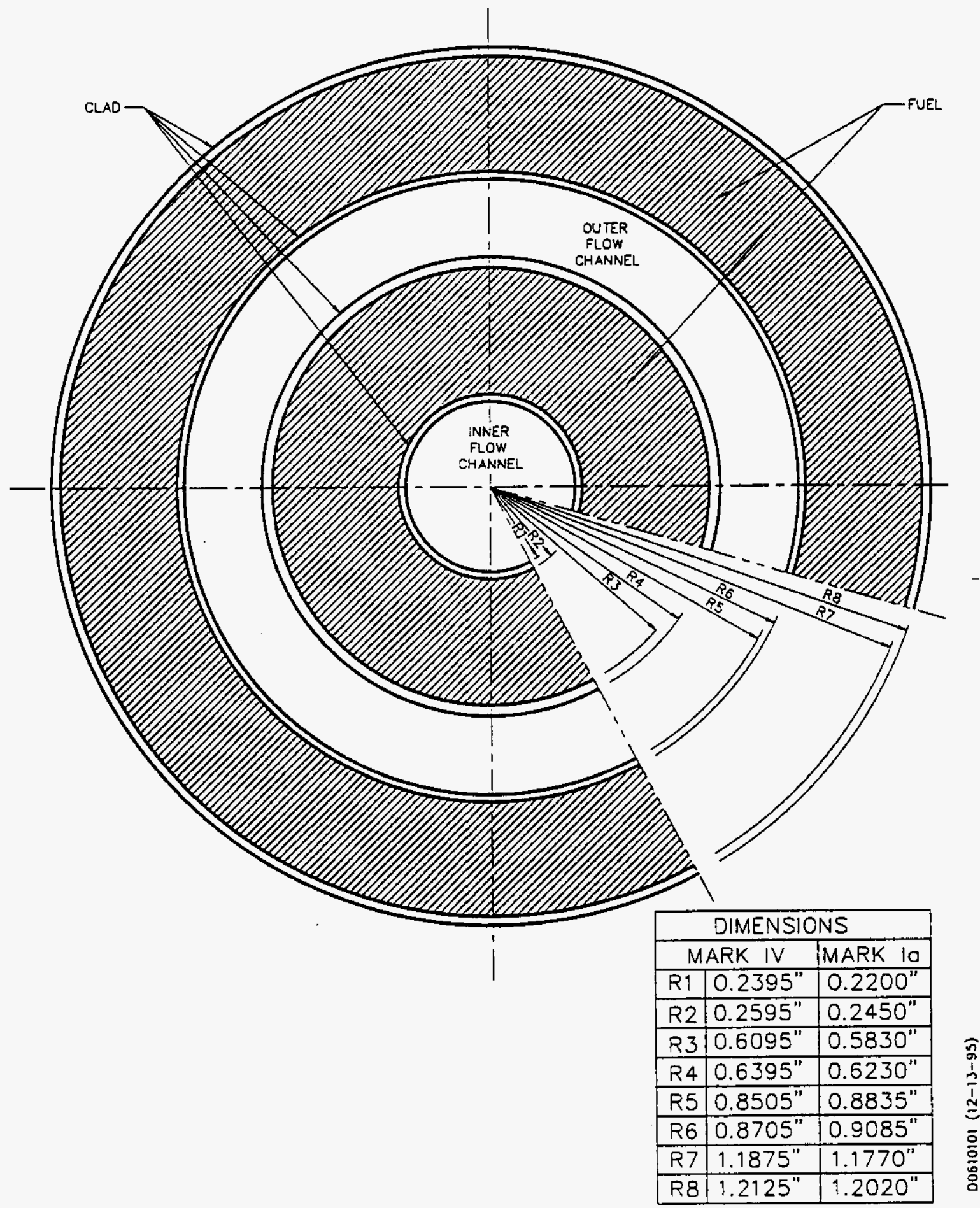


WHC-SD-WM-ER-525

Rev. 0

Figure 4-2. Isometric View of a Mark IV Fuel Assembly.

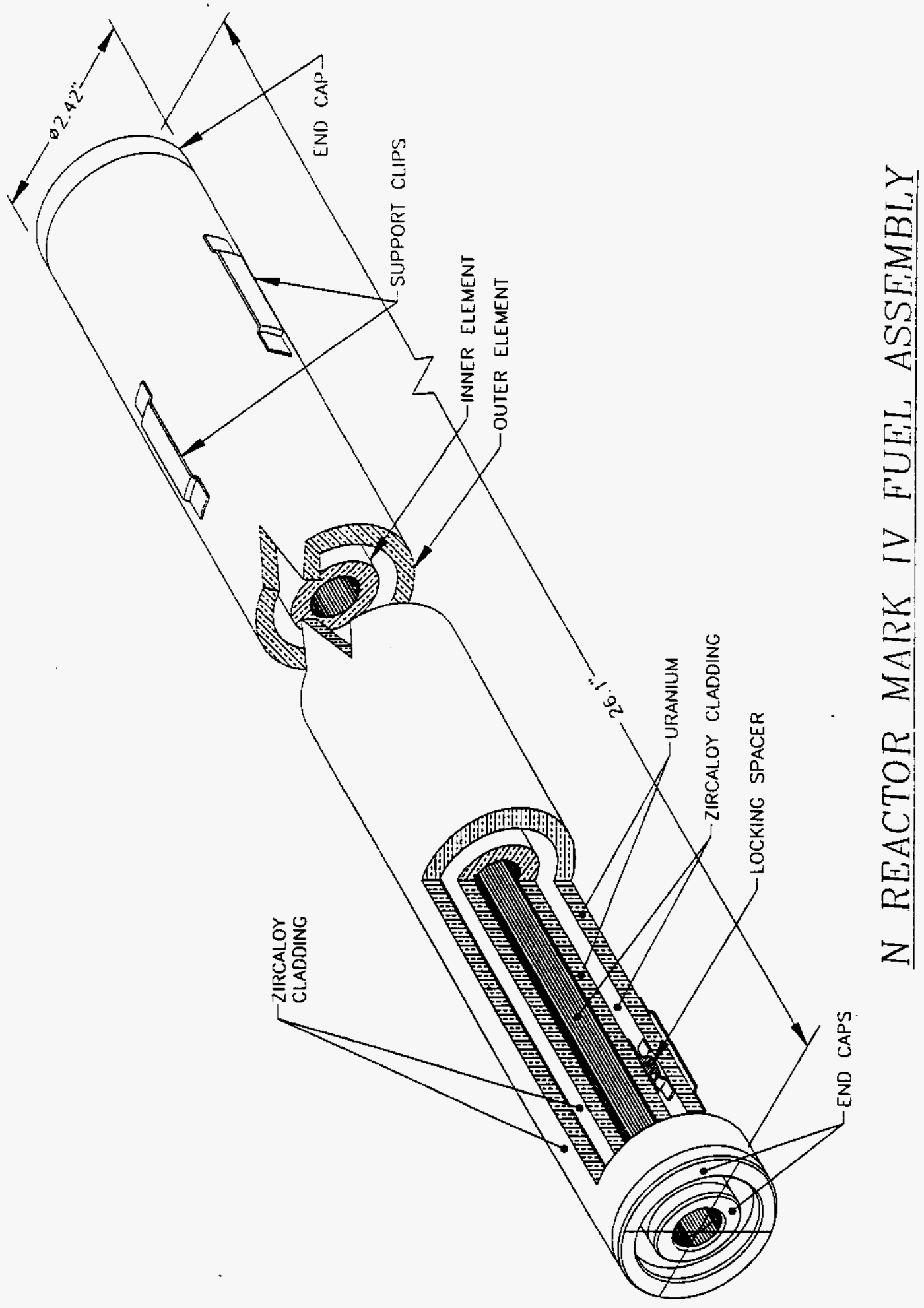


WHC-SD-WM-ER-525

Rev. 0

Figure 4-3. Top and Side Views of a Sealed Fueled Encapsulation Canister.

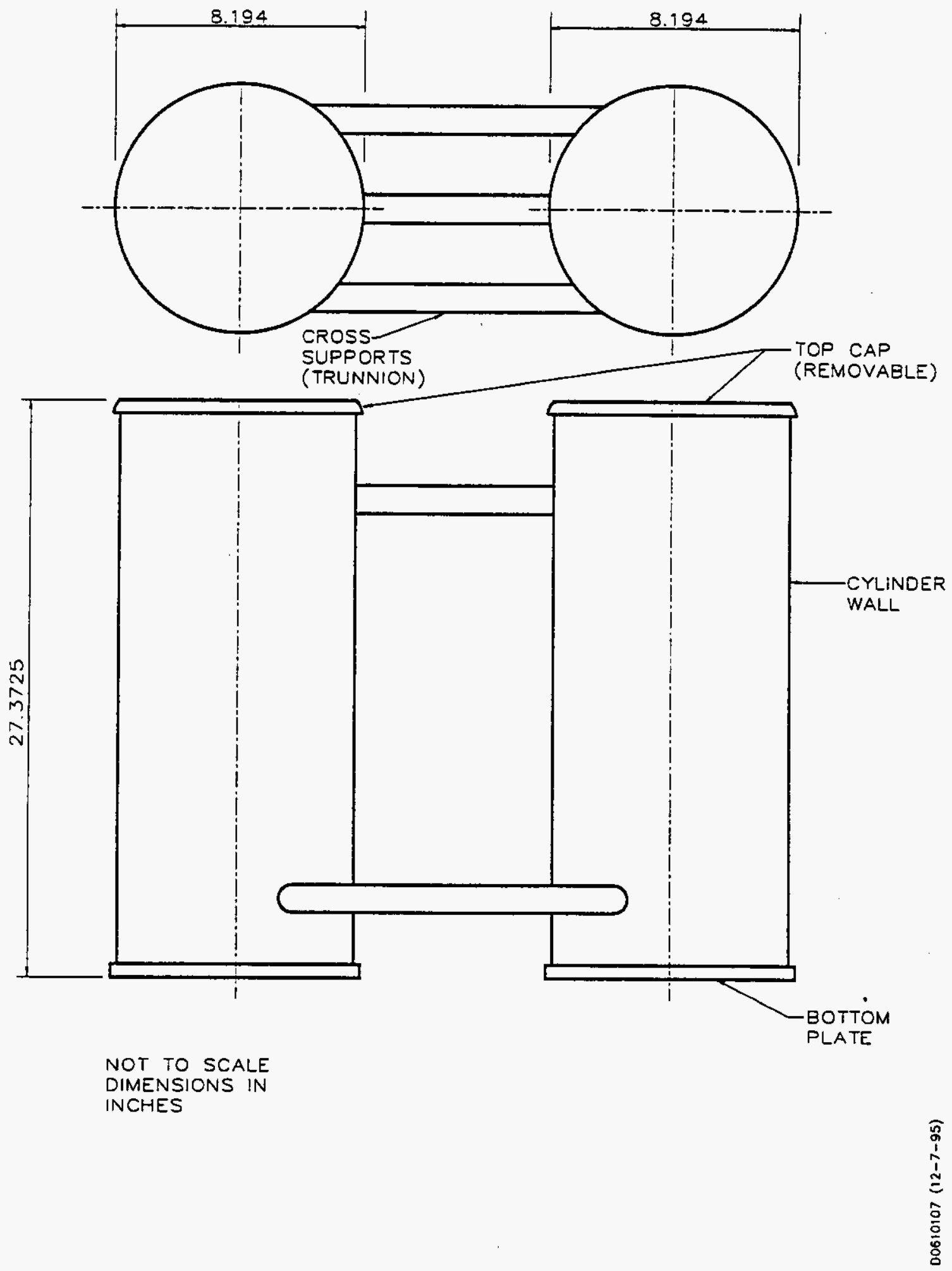


WHC-SD-WM-ER-525

Rev. 0

Figure 4-4. Top View of an Open Fuel Encapsulation Canister Barrel with Seven Fuel Assemblies.

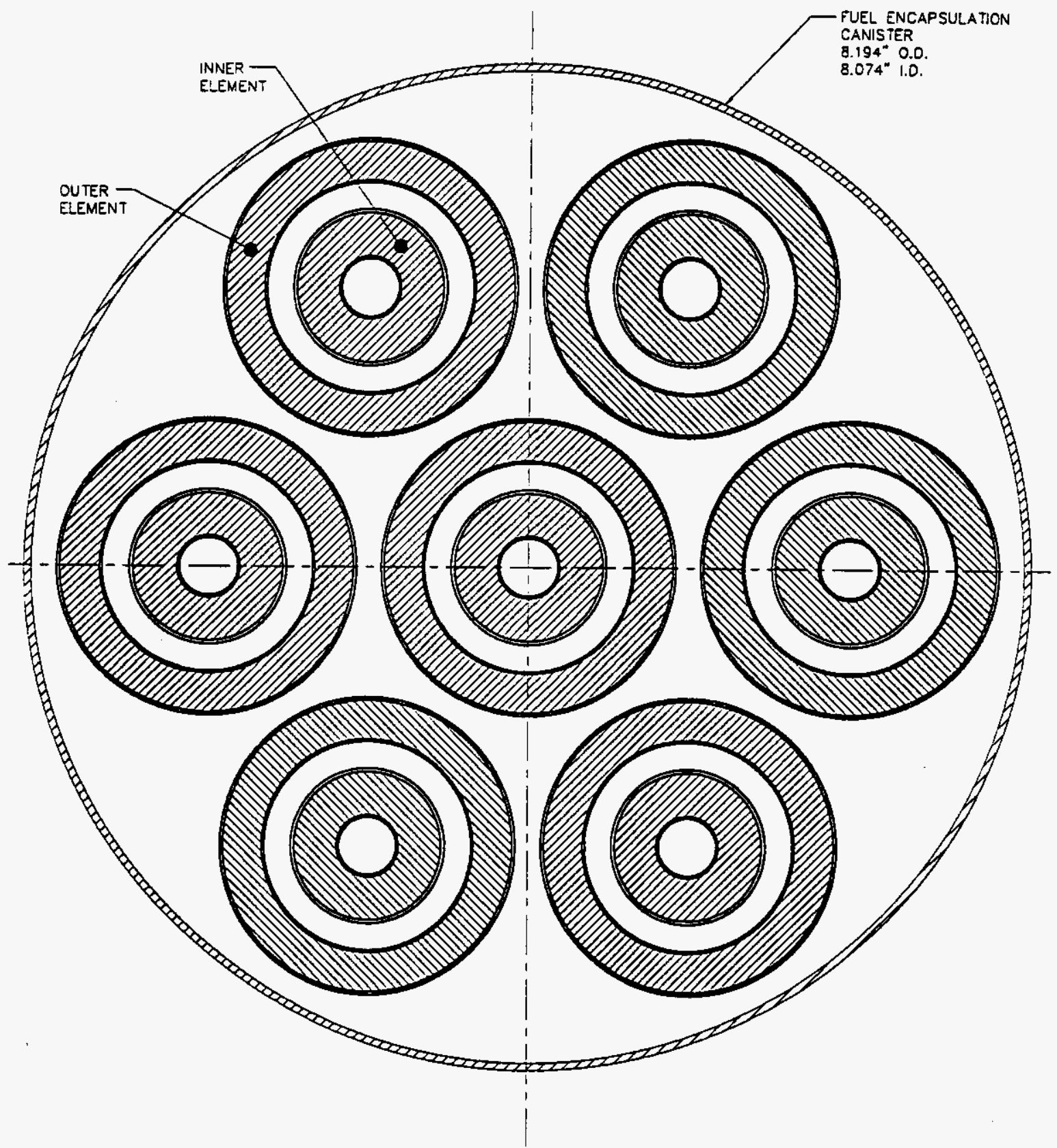

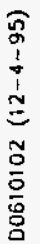




$$
\begin{gathered}
\text { WHC-SD-WM-ER-525 } \\
\text { Rev. } 0
\end{gathered}
$$

Figure 4-5. Planar Cross Section View of MCO Within a Shipping Cask Containing Fuel Encapsulation Canisters With

Fuel Assemblies.

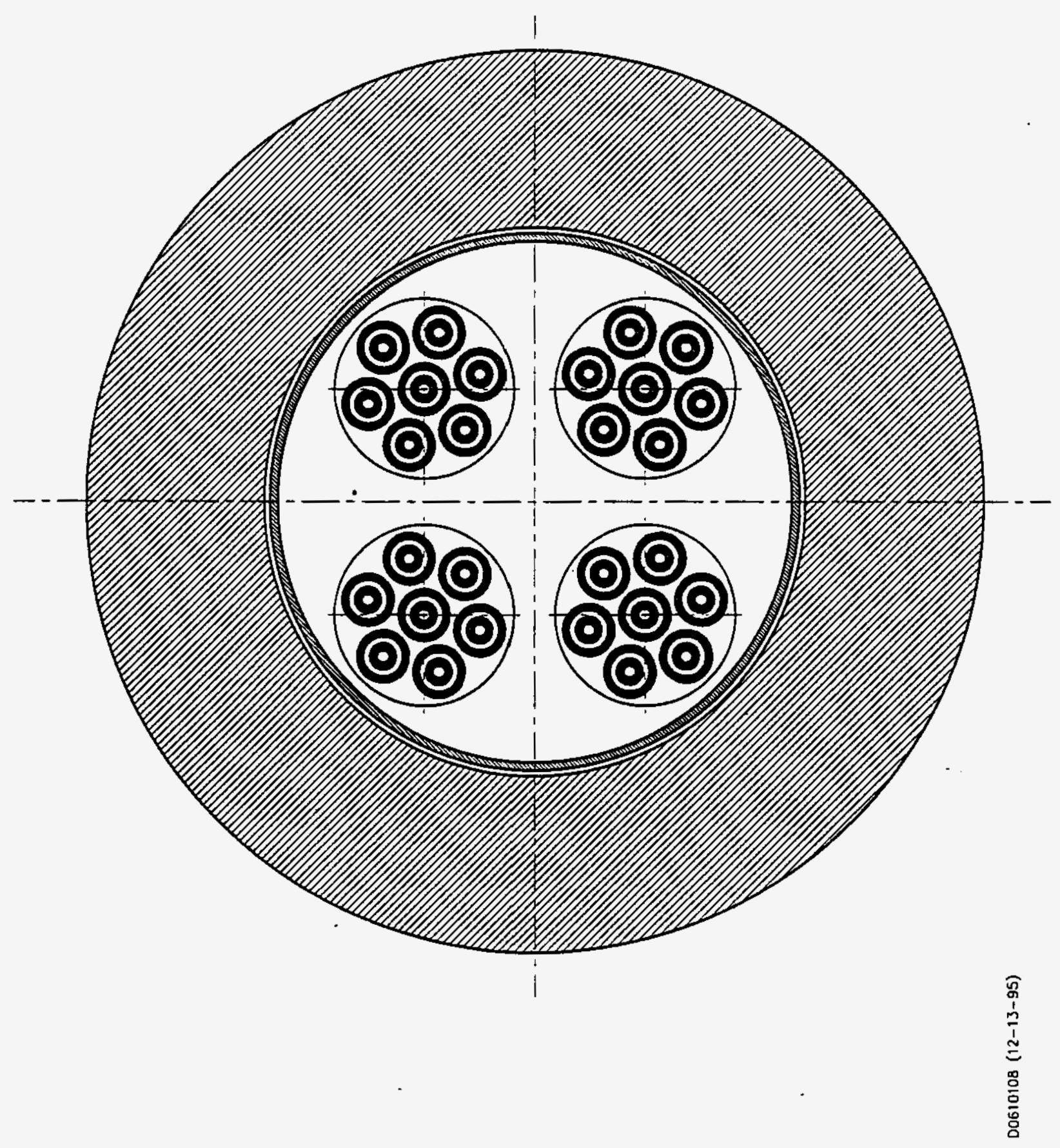




\section{WHC-SD-WM-ER-525 \\ Rev. 0}

Figure 4-6. MCO Axial Tier Location.

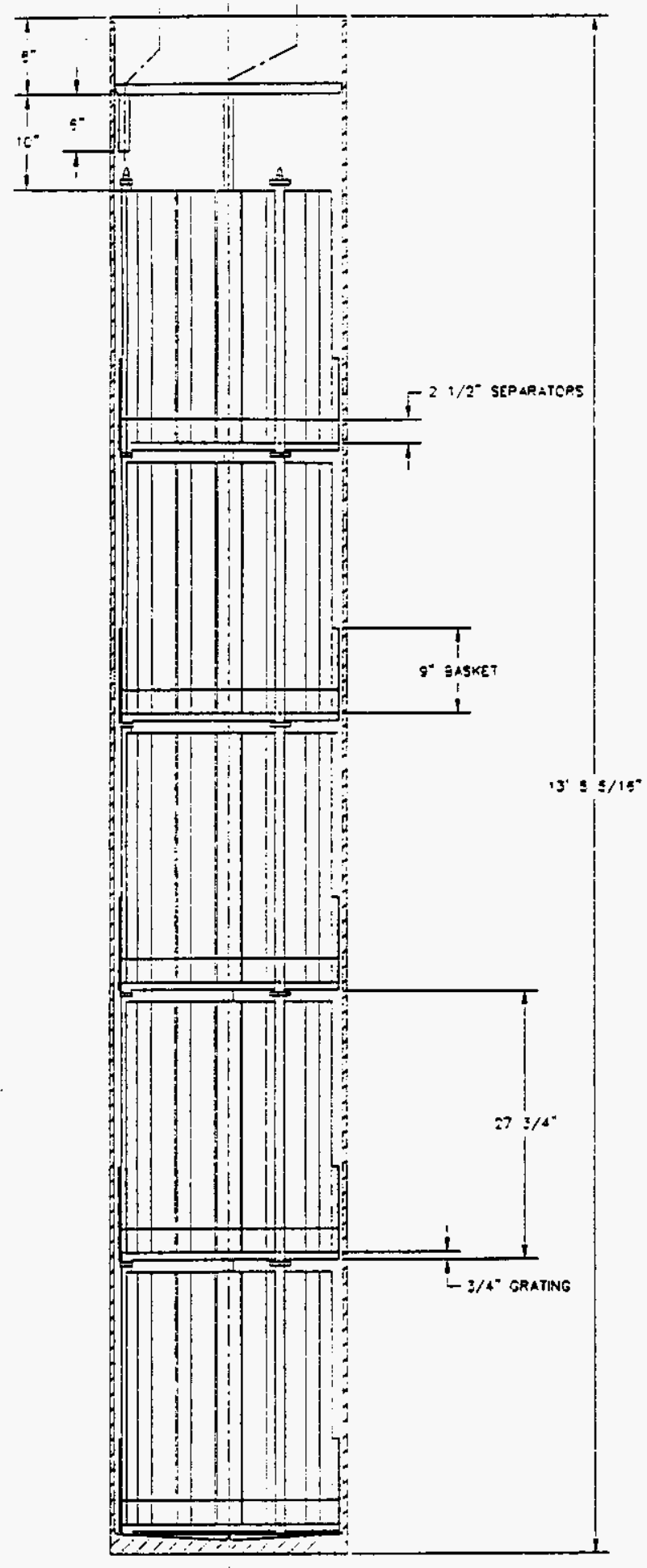

$M I=K \quad=U E$

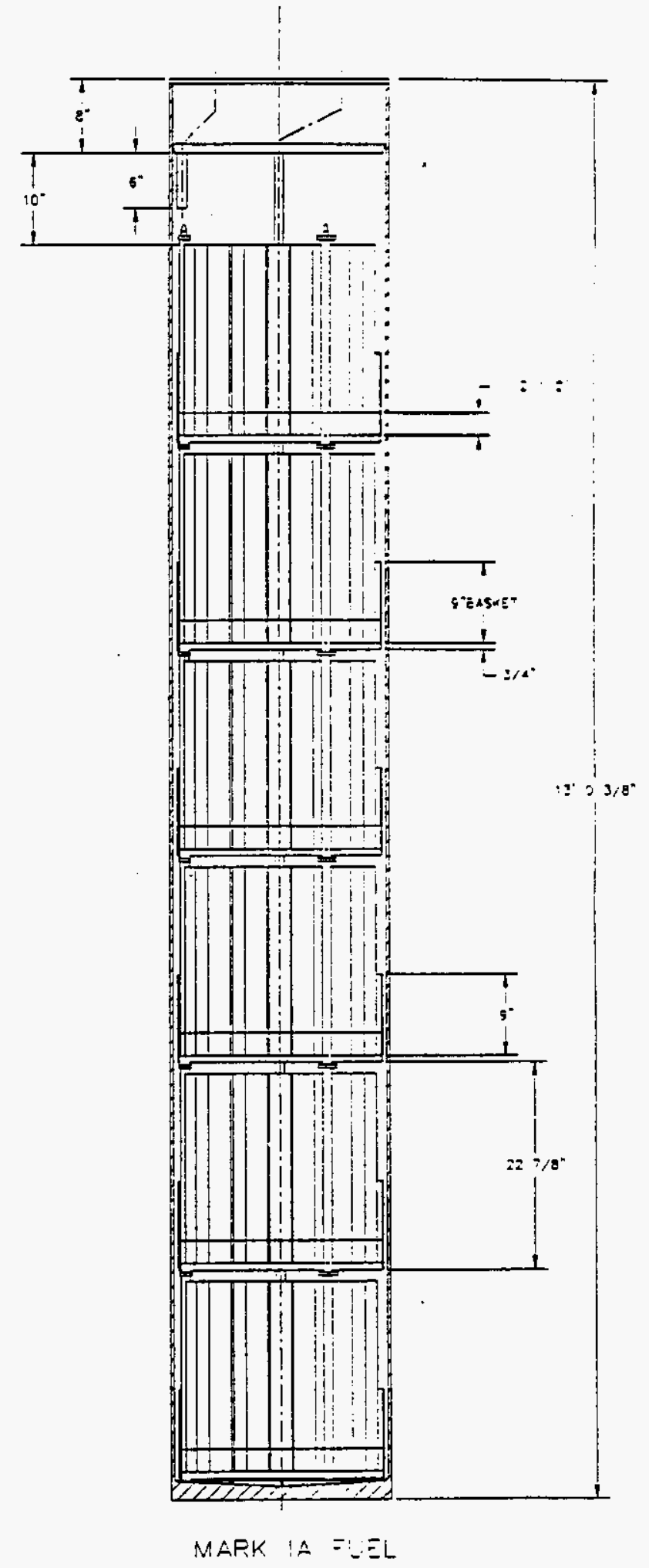


WHC-SD-WM-ER-525

Rev. 0

Figure 4-7. Representative Basket Designs.

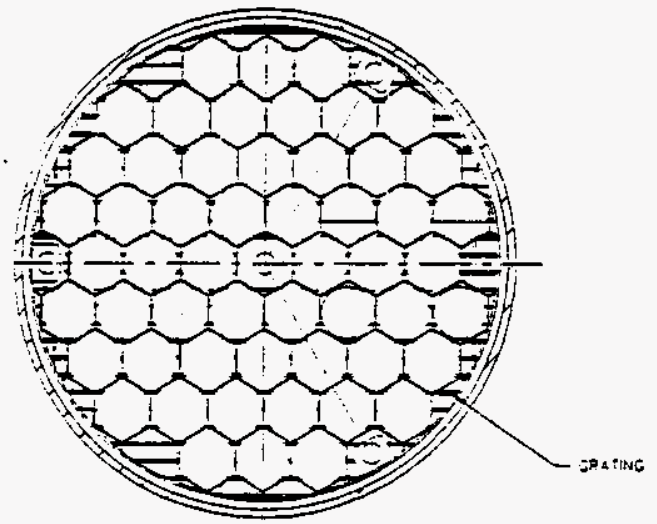

$M A=K \quad \because \quad=-E$
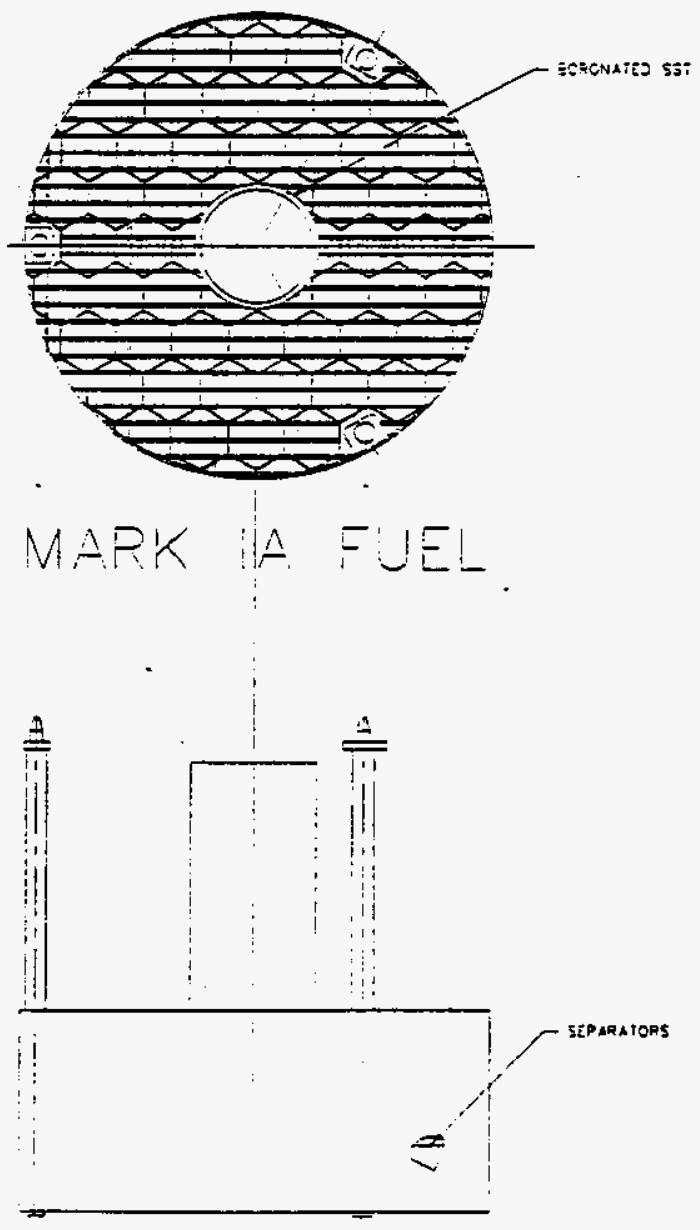

$\Xi-\subseteq r \equiv-$ 
WHC-SD-WM-ER-525

Rev. 0

Figure 4-8. Finite Element Nodalization for Quarter Symmetric Model.

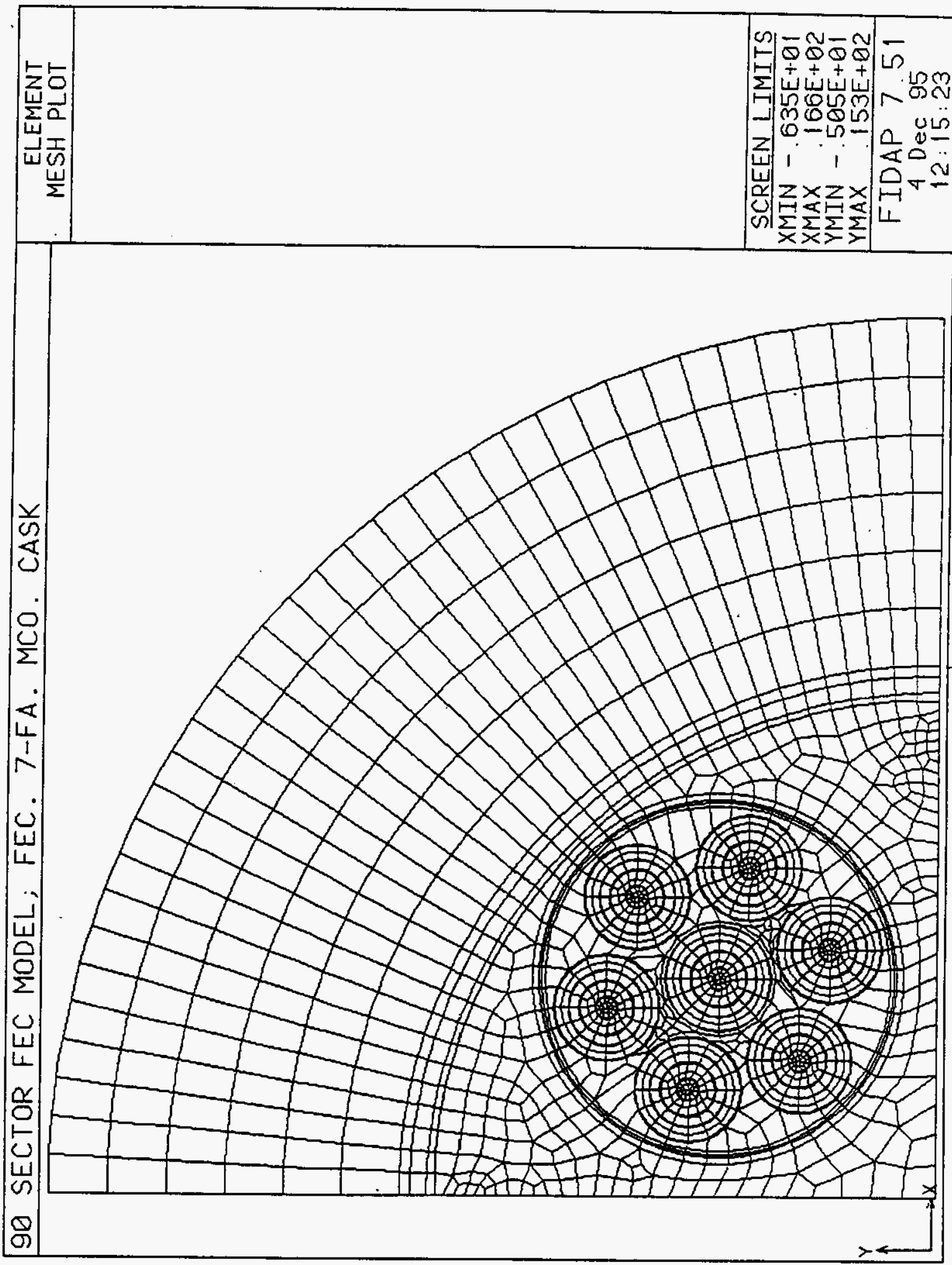


WHC-SD-WM-ER-525

Rev. 0

Figure 4-9. Finite Element Nodalization for $30^{\circ}$ Sector Model With Mark IV Fuel Assemblies.

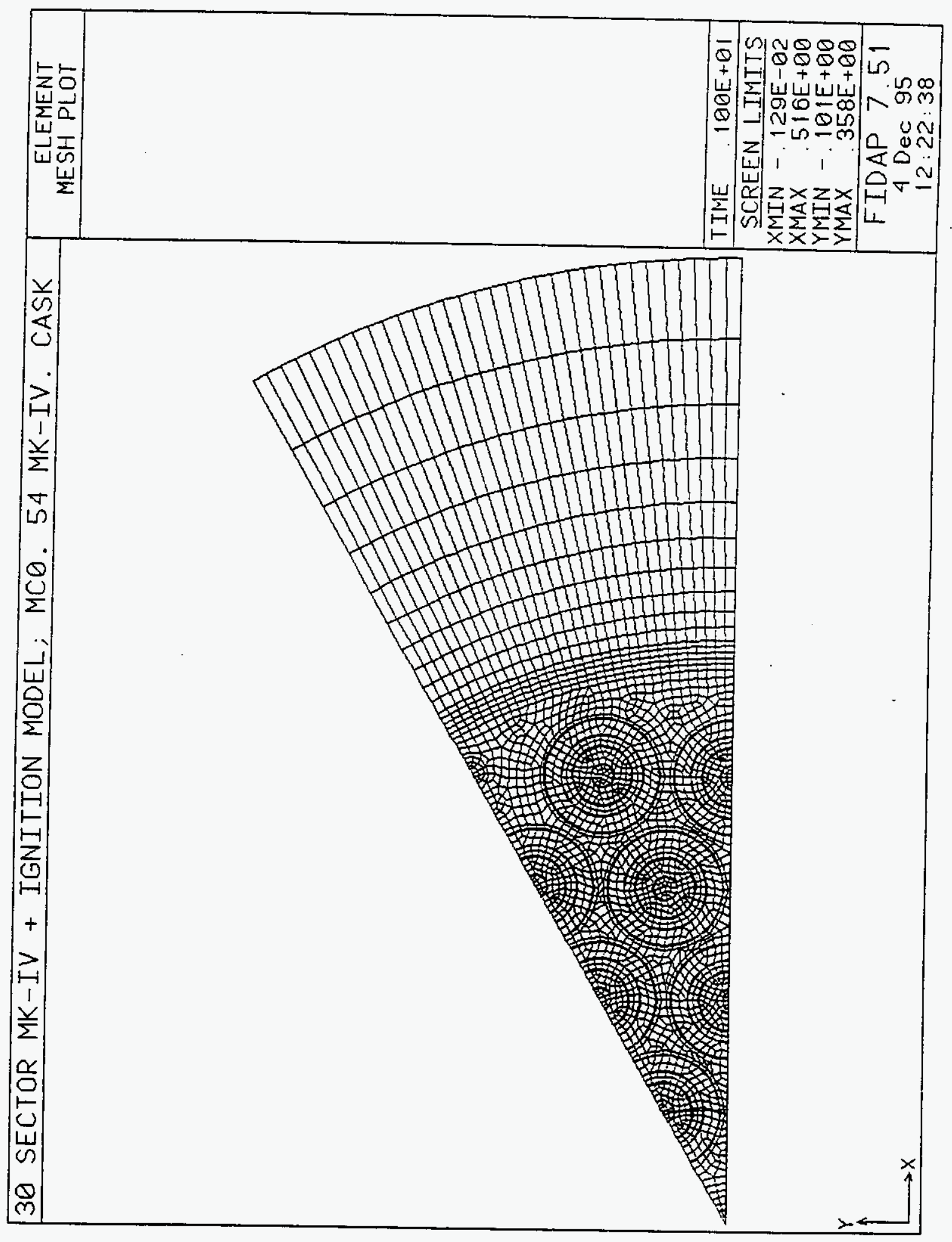


WHC-SD-WM-ER-525

Rev. 0

Figure 4-10. Finite Element Nodalization for $30^{\circ}$ Sector Model With Mark Ia Fuel Assemblies.

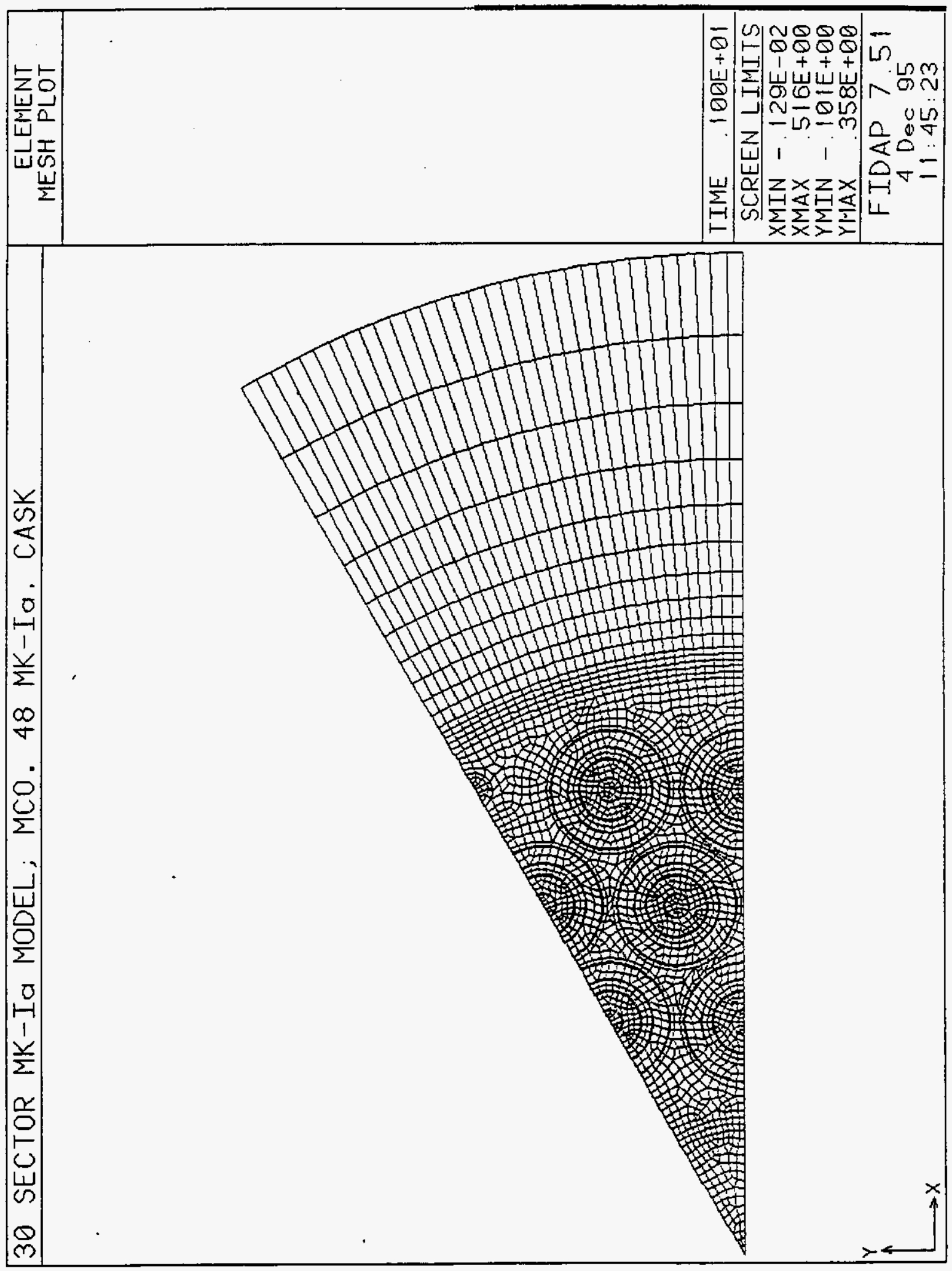


WHC-SD-WM-ER-525

Rev. 0

Figure 4-11. Finite Element Nodalization for $30^{\circ}$ Sector Model of Storage Tube With Mark IV Fuel Assemblies.

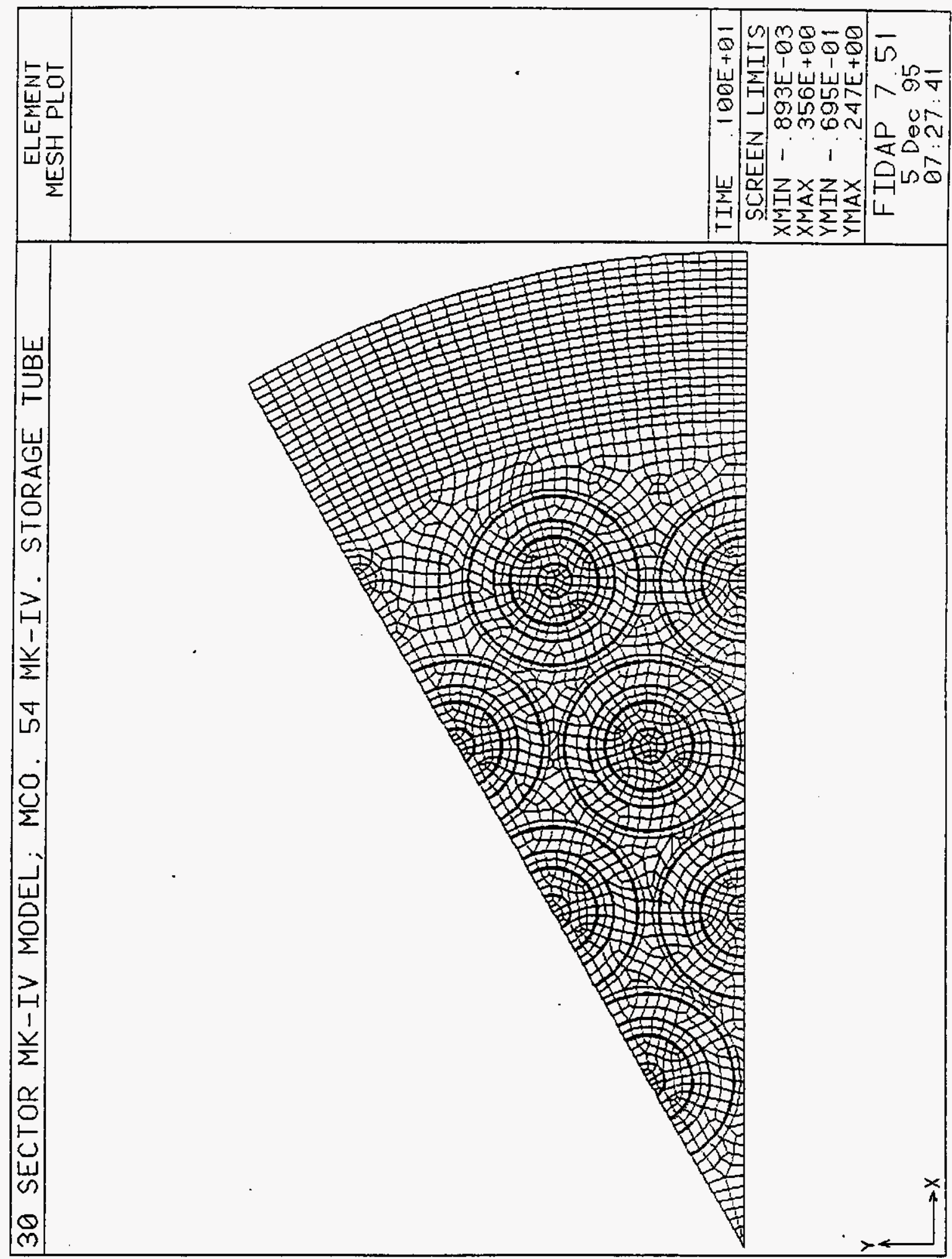



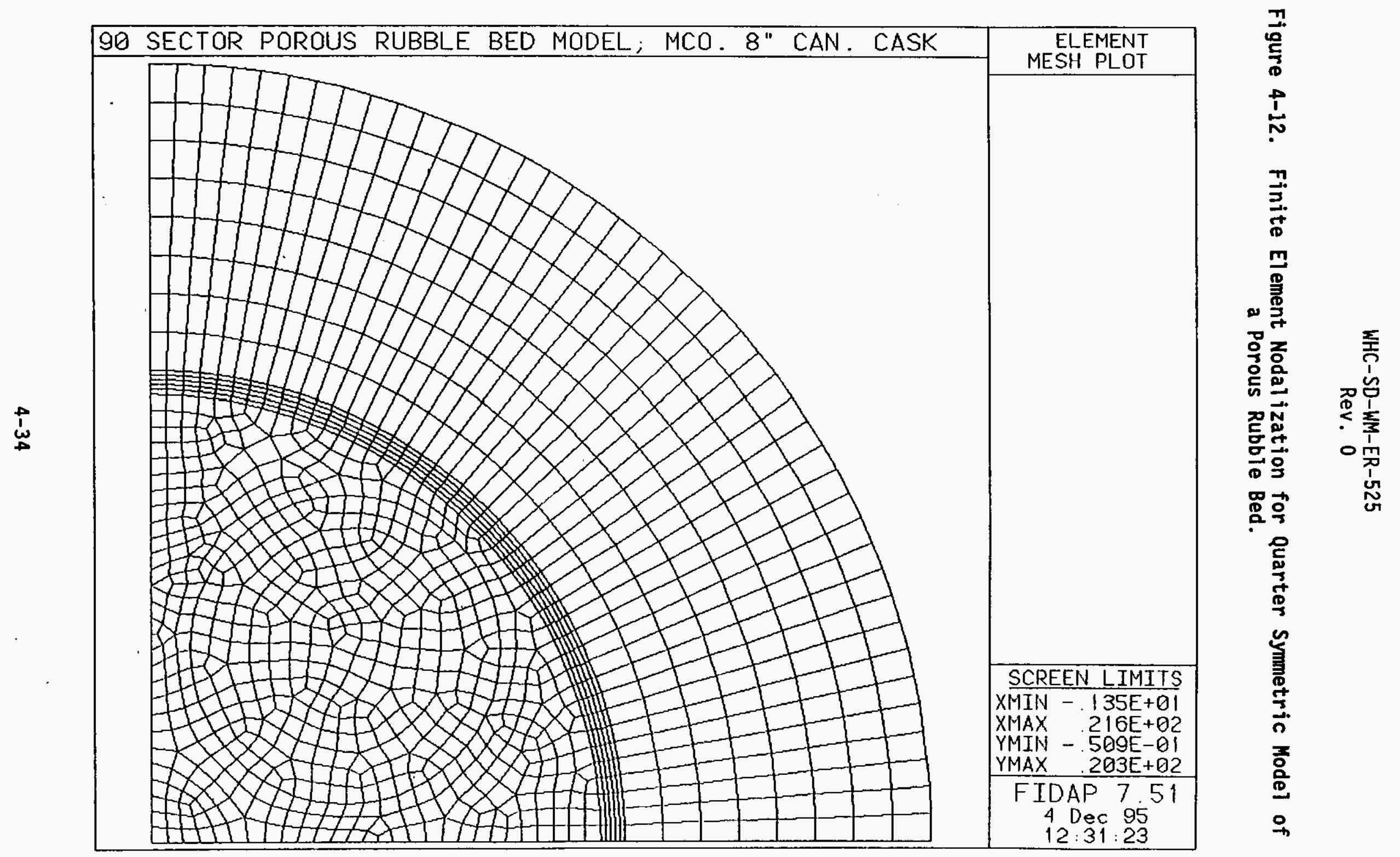
WHC-SD-WM-ER-525

Rev. 0

Figure 4-13. Finite Element Nodalization for the Chemical Reaction Sensitivity Plate Model.

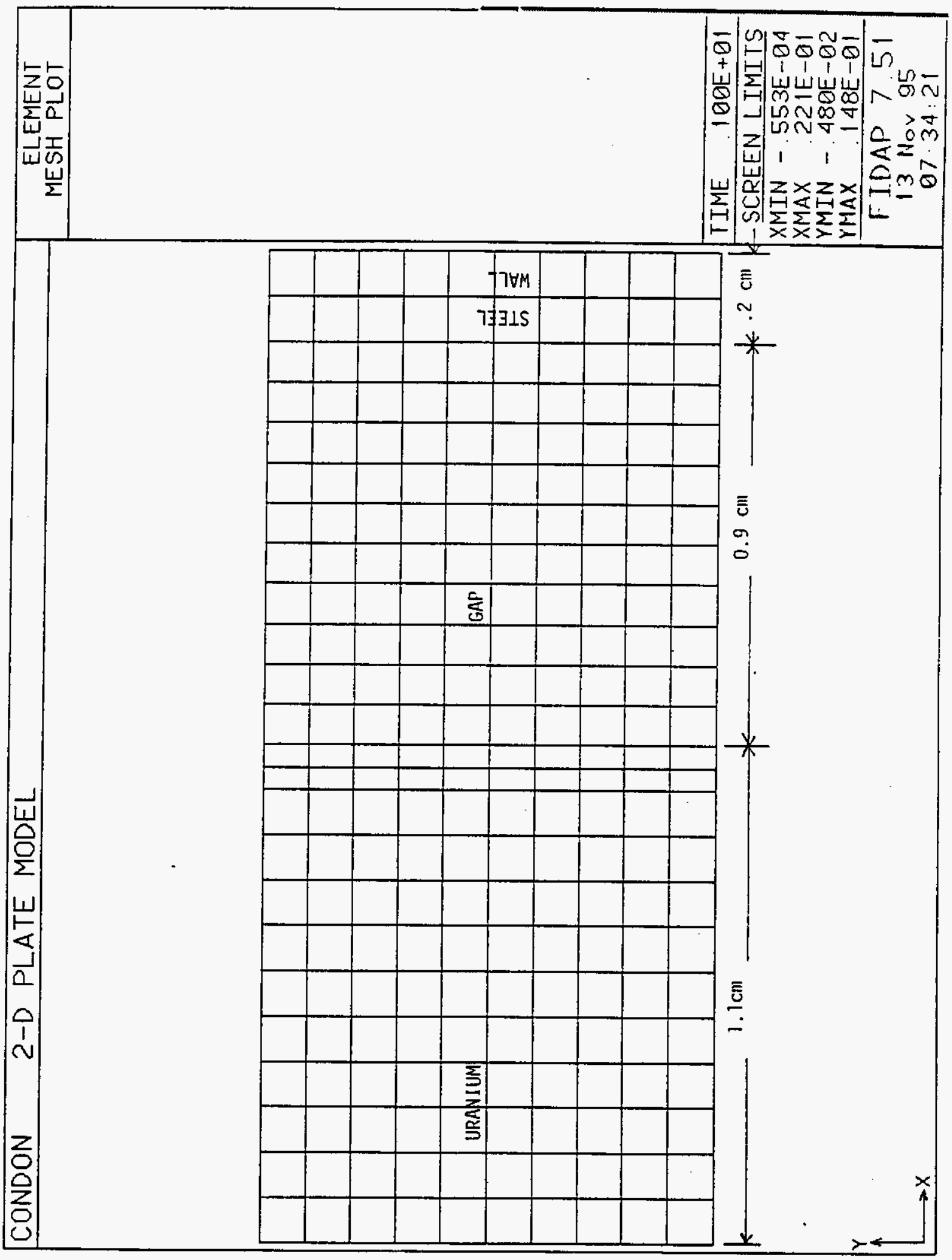


Figure 4-14. Canister Storage Building and Representative View of MCO Locations and Storage Tubes.

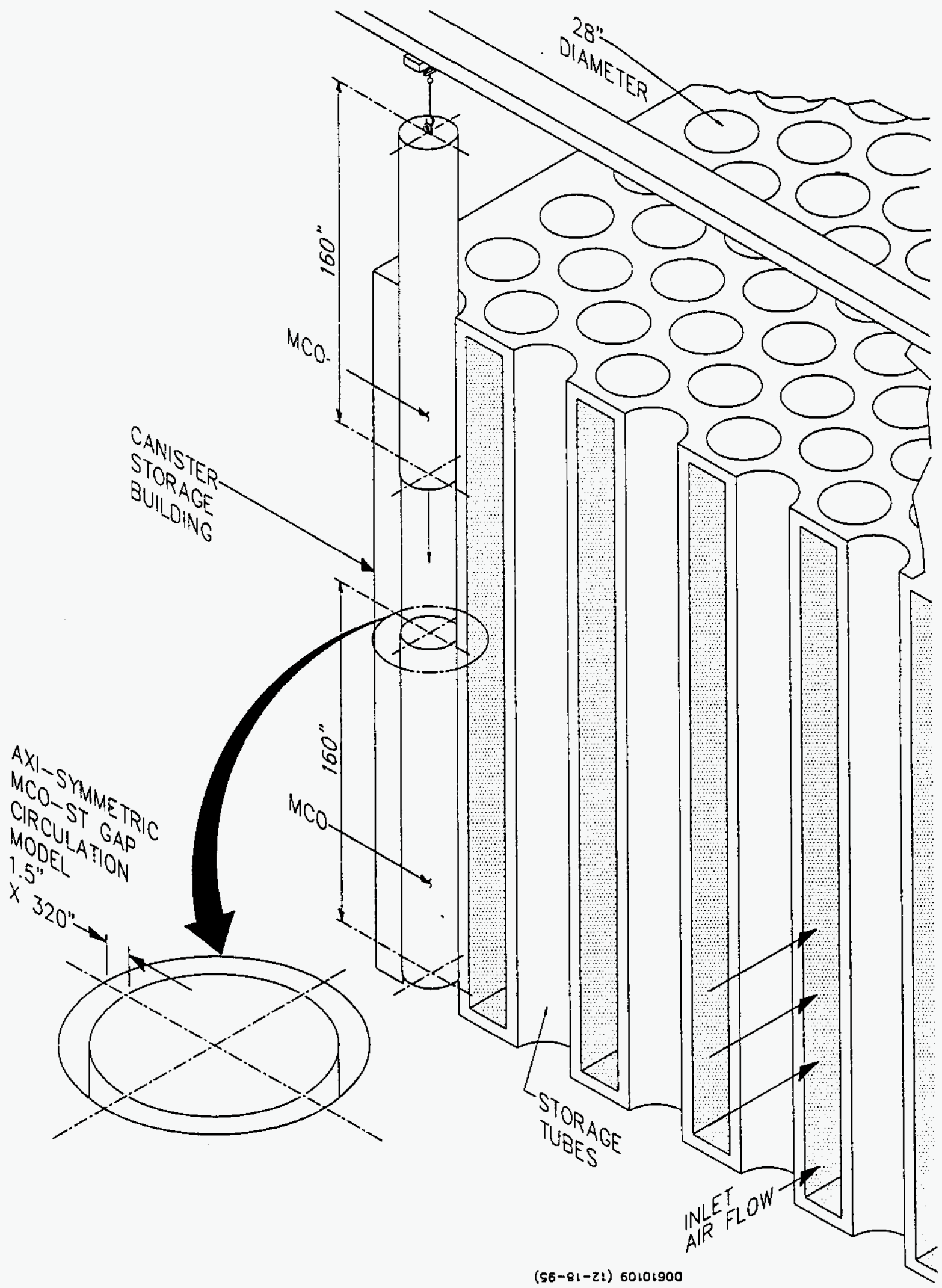




\section{WHC-SD-WM-ER-525 \\ Rev. 0}

Figure 4-15. Finite Element Nodalization for MCO-Storage Tube Gap Circulation Model (Lower End).

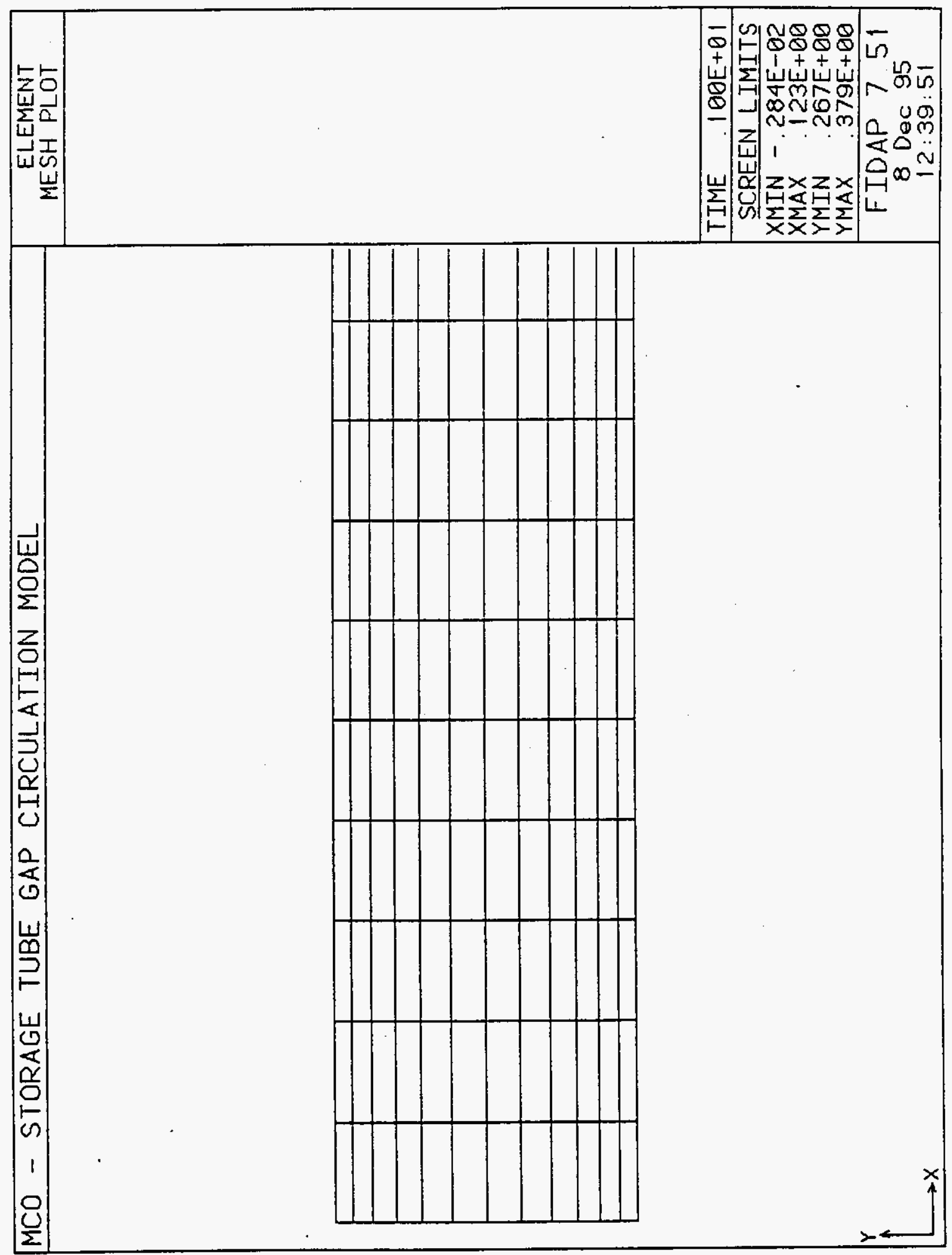


WHC-SD-WM-ER-525

Rev. 0

Figure 4-16. Finite Element Nodalization for MCO-Storage Tube Gap Circulation Model (Upper End).

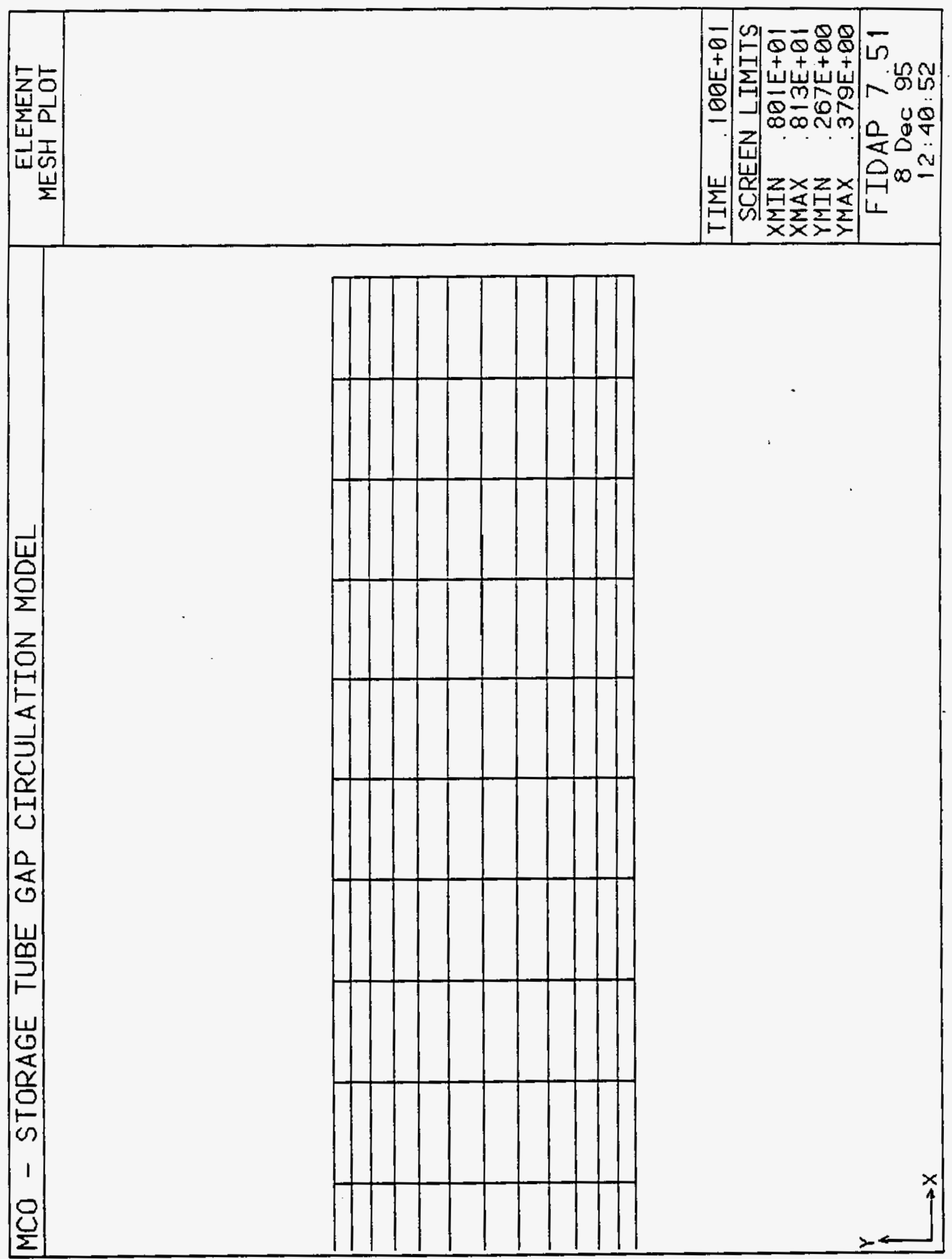


WHC-SD-WM-ER-525

Rev. 0

Figure 4-17. Ring Model of Fuel Basket Inside of MCO.

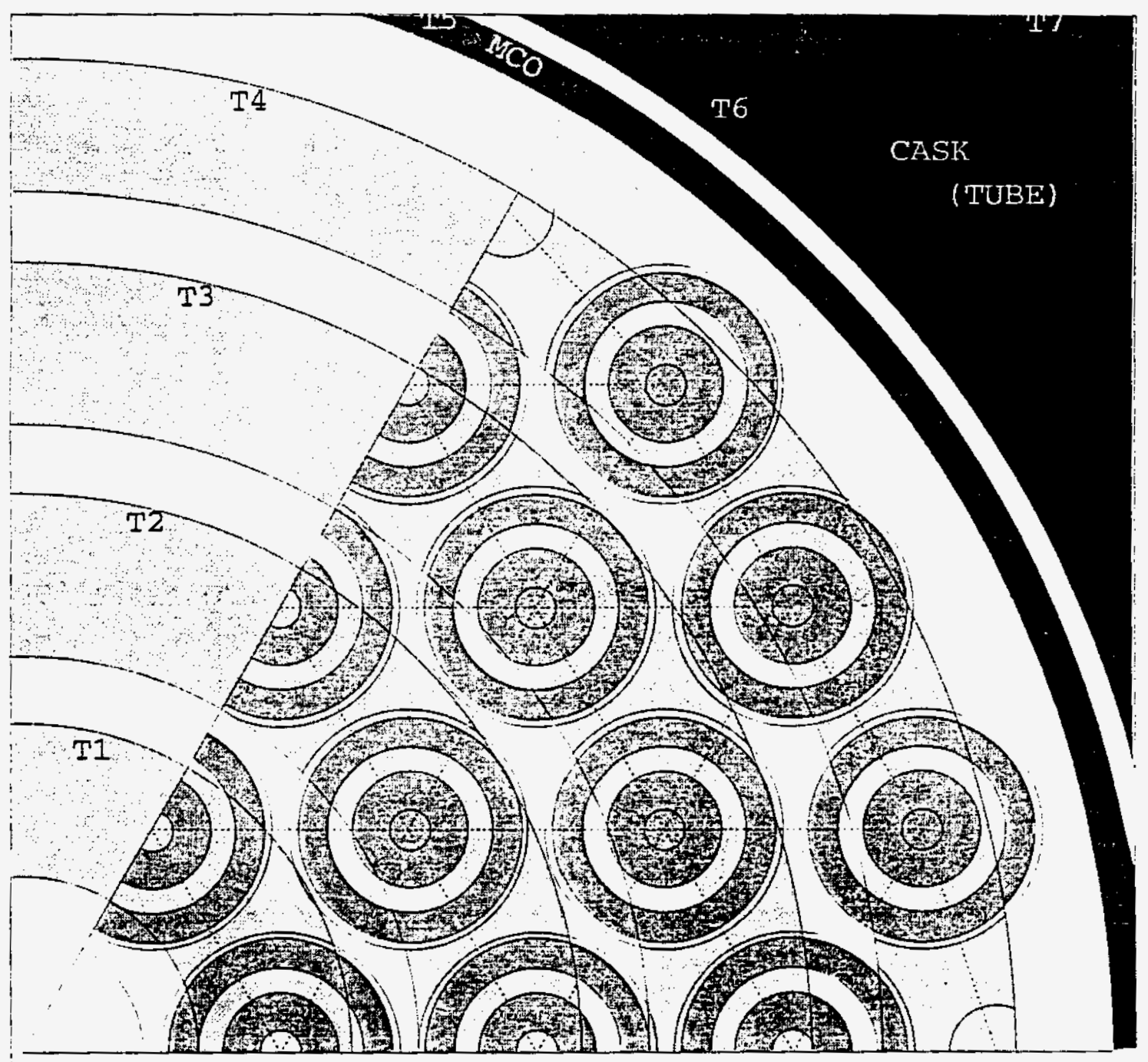


WHC-SD-WM-ER-525

Rev. 0

Figure 4-18. Ring Model of Fuel Rubble Basket.

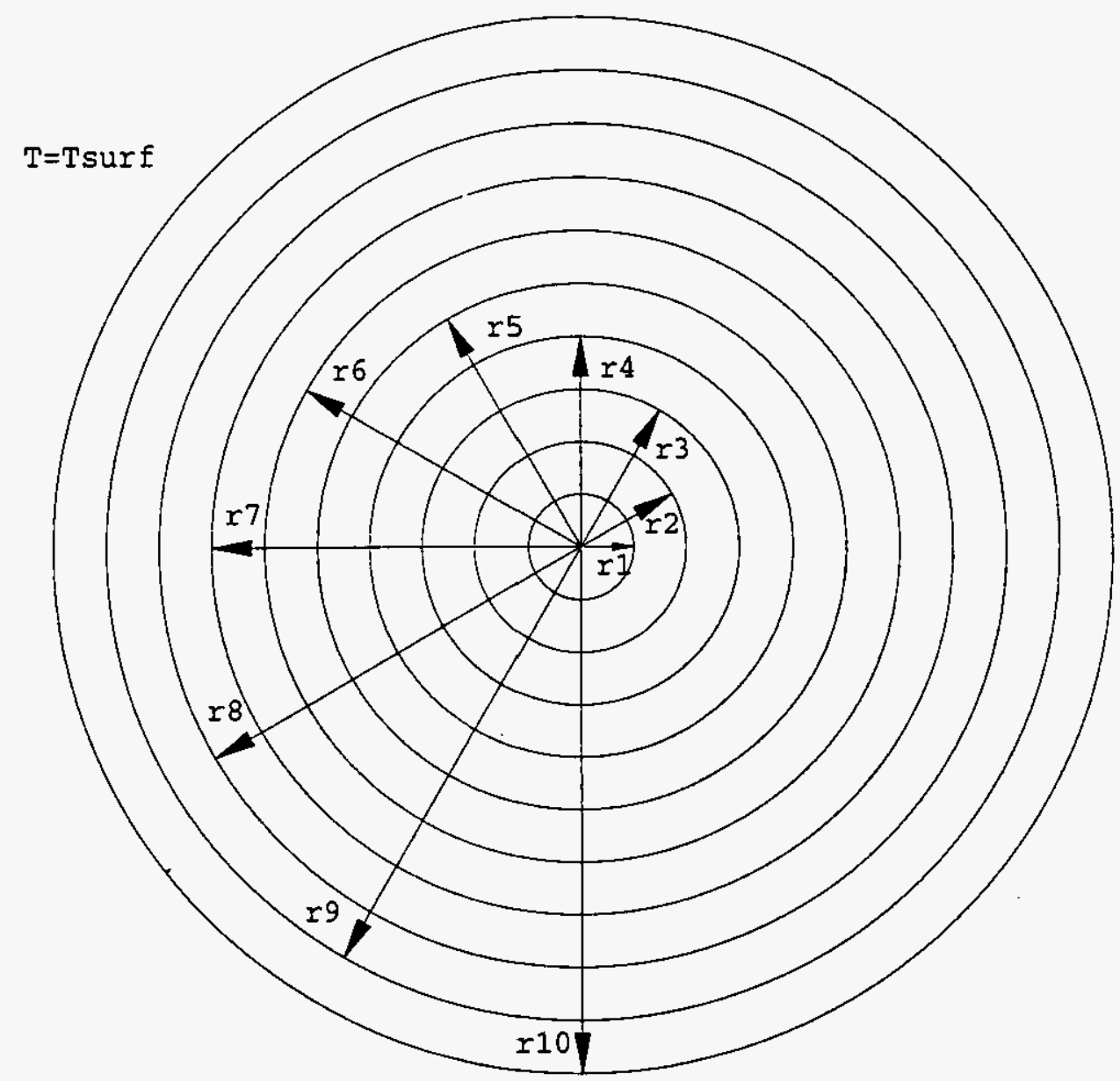


Rev. 0

Figure 4-19. Comparison of Radial Temperature Profiles Between the Simple HUB and Detailed FIDAP Models for Conduction Oniy and Conduction + Radiation.

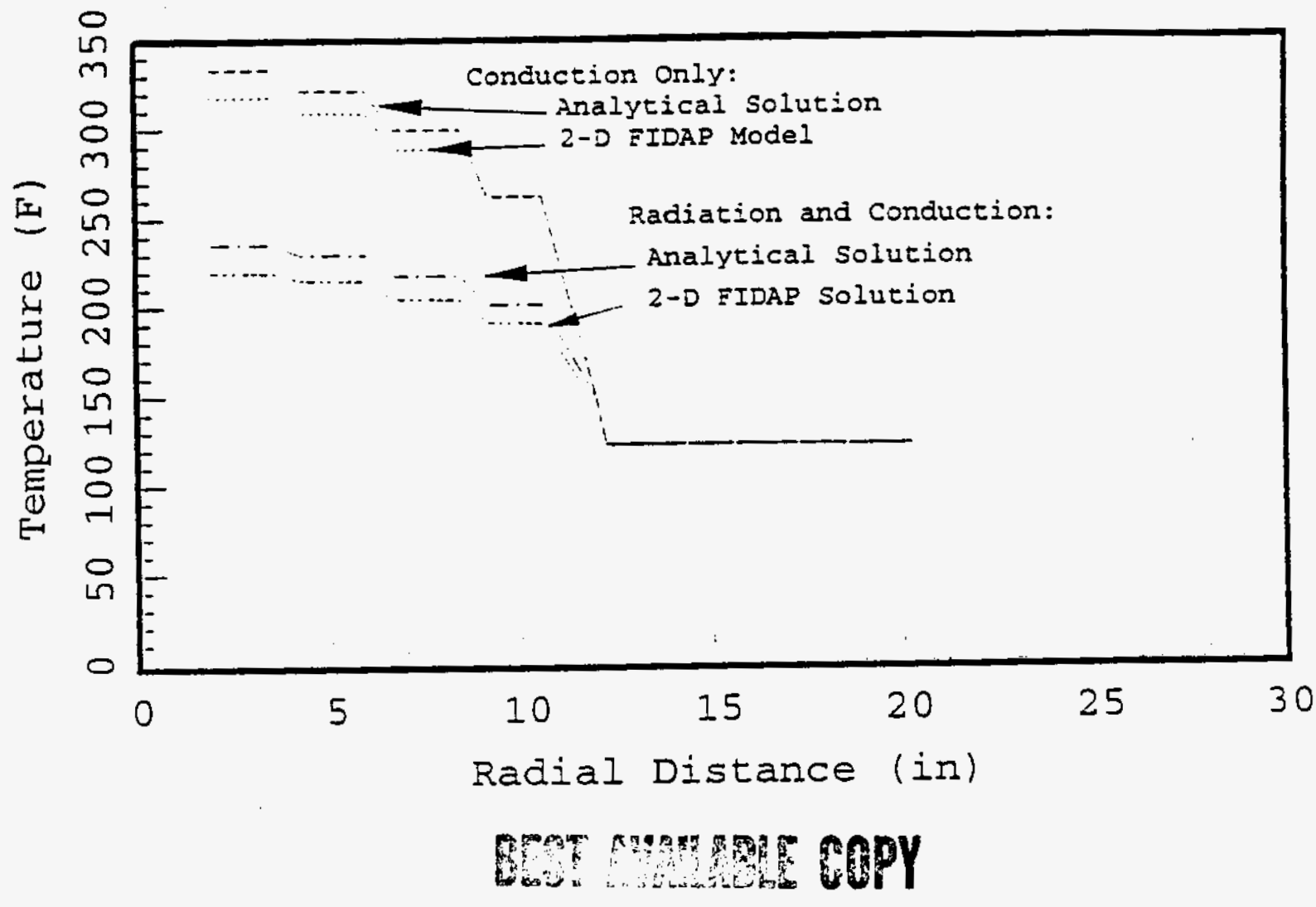


WHC-SD-WM-ER-525

Rev. 0

\subsection{RESULTS}

Section 5.0 presents the results from series of analyses that were performed using the FIDAP and HUB computer codes to assess the Integrated Process Strategy (IPS) as illustrated by Figure 1-1.

The models discussed in Section 4.0 and the results as presented in Section 5.0 are judged to have satisfied deliverable TH2-1; Develop MCO, MCO/Transfer Cask and MCO/Storage Tube Scoping Models. The results presented in Sections 5.1 and 5.2 satisfy the remaining thermal-hydraulic deliverables TH2-2 through TH2-7, as presented in Table 2-1. Section 5.3 presents some preliminary results and conclusions from the semi-infinite plate chemical sensitivity model. Section 5.4 presents the results from the axi-symmetric gap circulation model that was developed to investigate circulation flow patterns within the CSB Storage Tube - MCO gap.

\subsection{FIDAP FINITE ELEMENT RESULTS}

The results of the two-dimensional finite element models that were developed for the SNFP integrated process strategy, as shown in Figure 2-1, are presented in the following sections. The analyses that were performed focused on presenting the peak fuel temperatures. Other component (i.e., clad, MCO, shipping cask, storage tube, etc.) temperatures were determined as part of the subject analyses, but are not presented within this report. If necessary, these temperatures can be extracted from the various result files and reported as an addendum to this report.

Section 5.1.1 presents an overview of the thermal performance of the baseline models that were developed, per deliverable TH2-1 from Table 2-1. Section 5.1.2 presents the thermal performance of the fuel during the initial MCO and cask, K Basin submersion, loading, withdrawal, and transport to the vacuum drying station per deliverable TH2-3. Section 5.1.3 presents the thermal performance of the $M C O$ and shipping cask during draining (i.e., dewatering) and warm vacuum drying, per deliverable TH2-4. Section 5.1.4 presents the thermal performance of the MCO and shipping cask during transportation to the Canister Storage Building (CSB). Section 5.1 .5 presents the anticipated thermal performance of the MCO within a storage tube for an assumed CSB ambient air temperature of $140^{\circ} \mathrm{F}$.

All of the results presented in Tables 5-1 through 5-7 and Figures 5-1 through 5-38 were obtained from 15-day transient simulations using a variable time stepping algorithm. However, not all of the figures show results for the entire 15 days $(1,296,000 \mathrm{~s})$. This is due to the variable time stepping algorithm employed by FIDAP. If the increase in the predicted time increment from one time step to the next is greater than 100, FIDAP terminates execution on the assumption that steady-state has been reached. 
WHC-SD-WM-ER-525

Rev. 0

\subsubsection{TH2-1: Thermal Performance of Basel ine MCO, Transportation Cask, and MCO/Storage Tube Models}

The results of the baseline models developed to investigate the thermal performance of the MCO within a transportation shipping cask and CSB storage tube are presented in Table 5-1 and Figures 5-1 through 5-9.

The analyses were performed for assumed maximum, nominal, and minimum decay heat loads of 929,462 , and 142 watts per MCO, respectively. No chemical reactions were modeled for the baseline analyses. The analyses assumed solar heating on the outside surface of the shipping cask as derived from the 10CFR71 values reported in Table 4-2 assuming a geometrical factor of 0.5 and a conservatively high solar adsorption coefficient of 0.3 . This is equivalent to assuming that the outer surface of the cask is painted with a material such as UNIFLEX or AZTEC 100 white paint, which have low solar absorption values ranging from approximately 0.15 to 0.18 and a relatively high normal emissivity values ranging from 0.55 to of 0.85 . All of the simulations were performed for a 15-day transient simulation starting from initial temperatures of either $100^{\circ} \mathrm{F}\left(37.8^{\circ} \mathrm{C}, 310.9^{\circ} \mathrm{K}\right)$ or $140^{\circ} \mathrm{F}\left(60^{\circ} \mathrm{C}\right.$, $\left.333.2^{\circ} \mathrm{K}\right)$. The same initial temperatures were also used as the ambient temperatures for boundary conditions.

Both convective and radiative heat transfer were assumed from the outer surface of the shipping cask. Only convective heat transfer was assumed from the outer surface of the storage tube.

The results from Table 1 indicate that the storage tube configuration obtains a maximum fuel temperature of $384.2{ }^{\circ} \mathrm{F}\left(195.6^{\circ} \mathrm{C}, 468.8{ }^{\circ} \mathrm{K}\right)$. This is due to the reduced heat transfer (i.e., no radiative heat losses) from the outer surface of the storage tube, argon fill gas, and the high ambient temperature $\left(140^{\circ} \mathrm{F}\right)$ assumed to represent the outlet temperature from the CSB.

The results from Table 1 indicate that variations in the decay heat load and the assumed fill gas (i.e., helium, nitrogen, argon) can almost offset each other for the MCO/storage tube configuration. The use of helium as the fill gas significantly reduces peak fuel temperatures. Further reductions in peak fuel temperatures can be achieved if the emissivity of the MCO stainless steel surfaces and the shipping cask liner are chemically treated or passivated to obtain a normal emissivity in the range of 0.7 to 0.8 . The effects of high emissivities are discussed in Sections 5.1.3 and 5.1.4.

Figures 5-1, 5-2, 5-3, and 5-4 present a finite element mesh diagram showing the locations of nodal points of interest, the peak fuel temperature versus time, a radial temperature plot at the same time of maximum peak fuel temperature, and a surface plot of the radial temperature distribution, respectively. The following assumptions were made for this analysis:

1. Nominal dimensions, as shown in Figure 3-3 and Table 4-1

2. Mark Ia fuel, 288 fuel assemblies per MCO

3. Nominal decay heat, no chemical reactions

4. Fifteen day transient simulation, including solar heating (10CFR71) 
WHC-SD-WM-ER-525

Rev. 0

5. Convective and radiative heat losses from $O D$ of shipping cask

6. Air was assumed to reside both internal to $M C O$ and within the 0.25 in. gap between the MCO and shipping cask ID

7. MCO $/$ cask; $\epsilon_{\text {ss } 304}=0.25, \epsilon_{\text {ZIRC }}=0.40, \epsilon_{\text {CASKID }}=0.25, \epsilon_{\text {CASKOD }}=0.55$

8. Ambient temperature $100{ }^{\circ} \mathrm{F}\left(37.8{ }^{\circ} \mathrm{C}, 310.9^{\circ} \mathrm{K}\right)$

The results from Figure 5-2 indicate that a maximum equilibrium peak fuel temperature of $213.8^{\circ} \mathrm{F}\left(101.0^{\circ} \mathrm{C}, 374.2^{\circ} \mathrm{K}\right)$ is reached after approximately 6 days $(518,400$ seconds). Figure $5-2$ al so shows very small oscillations in the peak fuel temperature. This is due to the daily solar heating cycles (sinusoidal) that are applied to the outer surface of the cask. The solar heating effect propagates through the system, but is nearly damped out at node 1000 .

Figures $5-5,5-6,5-7$, and 5-8 present the same plots as Figures 5-1 through 5-4, but for Mark IV fuel. The same assumptions as the Mark Ia results were used for the Mark IV analyses except that the nominal dimensions corresponding to Mark IV fuel were used (Figure 3-2, and Table 4-1) resulting in 270 fuel assemblies per MCO.

The results indicate a peak fuel temperature of $218.9^{\circ} \mathrm{F}\left(103.8^{\circ} \mathrm{C}\right.$, $377.0^{\circ} \mathrm{K}$ ), slightly greater than that of the Mark Ia results. This is due to the greater thermal resistance associated with one additional row of fuel, as shown by Figure 3-2.

Figures 5-9, 5-10, 5-11, and 5-12 present the same plots as Figures 5-1 through 5-4 and 5-5 through 5-8, but for an MCO containing Mark IV fuel within a CSB storage tube. The following assumptions were made for this analysis:

1. Nominal dimensions, as shown in Figure 3-4, and Table 4-1

2. Mark IV fuel, 270 fuel assemblies per MCO

3. Nominal decay heat, no chemical reactions

4. Fifteen day transient simulation, no solar heating

5. Convective heat losses from the $O D$ of the storage tube

6. No radiative heat losses from the 00 of the storage tube

7. Argon fill gas was assumed to reside within the MCO and the 1.5 in. gap between the MCO and storage tube ID

8. Ambient temperature, $140^{\circ} \mathrm{F}$

9. $\mathrm{MCO} /$ storage tube; $\epsilon_{\mathrm{ss} 304}=0.25, \epsilon_{\mathrm{ZIRC}}=0.40, \epsilon_{\mathrm{STID}}=0.55$

The results indicated a peak fuel temperature of $279.0^{\circ} \mathrm{F}\left(173.2^{\circ} \mathrm{C}\right.$, $\left.410.4^{\circ} \mathrm{K}\right)$. 
WHC-SD-WM-ER-525

Rev. 0

Table 5-1 summarizes the peak fuel temperatures for the baseline models for representative conditions. The peak fuel temperatures for a MCO within a shipping cask range from $307.2^{\circ} \mathrm{F}\left(152.9^{\circ} \mathrm{C}, 426.1^{\circ} \mathrm{K}\right)$ to $151.7^{\circ} \mathrm{F}\left(66.5^{\circ} \mathrm{C}\right.$, $\left.339.7^{\circ} \mathrm{K}\right)$.

The peak fuel temperatures for a MCO containing Mark IV fuel assemblies within a storage tube for an ambient temperature of $140^{\circ} \mathrm{F}$ range from a maximum of $384.2{ }^{\circ} \mathrm{F}\left(195.6^{\circ} \mathrm{C}, 468.8^{\circ} \mathrm{K}\right)$ for maximum decay heat and argon fill gas to $168.3^{\circ} \mathrm{F}\left(75.7^{\circ} \mathrm{C}, 348.9^{\circ} \mathrm{K}\right)$ for minimum decay heat and helium fill gas. Additional calculations were performed for a MCO containing Mark IV fuel assemblies at nominal decay heat within a storage tube, but with an ambient temperature of $100^{\circ} \mathrm{F}$. The results range from $252.6^{\circ} \mathrm{F}$ to $176.3^{\circ} \mathrm{F}$.

A close inspection of Table 5-1 indicates that the higher temperature associated with using argon as the fill gas for nominal and maximum decay heat loads can be nearly offset by using helium.

Table 5-1. Peak Fuel Temperatures for Baseline Models and Representative Conditions (Decay Heat Only).

\begin{tabular}{|c|c|c|c|c|c|c|}
\hline & & \multicolumn{5}{|c|}{ Peak Fuel Temperatures, ${ }^{\circ} \mathrm{F}\left({ }^{\circ} \mathrm{K}\right)$} \\
\hline & & \multicolumn{2}{|c|}{$\begin{array}{l}\frac{\text { MCO }+ \text { Shipping Cask }}{\text { (VR Fuel Type and }} \\
\text { Fill Gas) }\end{array}$} & \multicolumn{3}{|c|}{ (VR Fuel Type and Fill Gas) } \\
\hline $\begin{array}{l}\text { Decay } \\
\text { Heat } \\
\text { per MCo } \\
\text { (W) }\end{array}$ & $\begin{array}{l}\text { Ambient Air } \\
\text { Temperature } \\
\left.{ }_{F(}{ }^{\circ} K\right)\end{array}$ & $\begin{array}{l}\text { Mark Ia } \\
\text { Fuel and } \\
\text { Air }\end{array}$ & $\begin{array}{l}\text { Mark IV } \\
\text { Fuel and } \\
\text { Air }\end{array}$ & $\begin{array}{l}\text { Mark IV } \\
\text { Fuel and } \\
\text { Hel ium }\end{array}$ & $\begin{array}{l}\text { Mark IV } \\
\text { Fuel and } \\
\text { Air }\end{array}$ & $\begin{array}{l}\text { Mark IV } \\
\text { Fuel and } \\
\text { Argon }\end{array}$ \\
\hline 142 & $100(310.2)$ & $151.7(339.7)$ & $153.5(340.7)$ & - & - & -- \\
\hline 426 & $100(310.2)$ & $213.8(374.2)$ & $218.9(377.0)$ & $176.3(353.3)$ & $240.8(389.2)$ & $252.6(395.7)$ \\
\hline 929 & $100(310.2)$ & $298.9(421.5)$ & $307.2(426.1)$ & 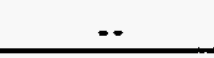 & - & $\cdots$ \\
\hline 142 & $140(333.2)$ & $\cdots$ & - & $168.3(348.9)$ & $191.7(361.9)$ & $196.5(364.6)$ \\
\hline 426 & $140(333.2)$ & $\cdots$ & $\cdots$ & $213.3(373.9)$ & $268.5(404.6)$ & $279.0(410.4)$ \\
\hline 929 & $140(333.2)$ & $\cdots$ & -- & $279.7(410.8)$ & $369.0(460.4)$ & $384.2(468.8)$ \\
\hline
\end{tabular}

${ }^{*} \epsilon_{\mathrm{ss} 304}=0.25, \epsilon_{\text {ZIRC }}=0.40, \epsilon_{\text {CASKID }}=0.25, \epsilon_{\text {CASKOD }}=0.55$

** $\epsilon_{\mathrm{ss} 304}=0.25, \epsilon_{\mathrm{ZIRC}}=0.40, \epsilon_{\mathrm{STID}}=0.55$

The following thermal-hydraulic information will allow the MCO and CSB design efforts to be decoupled and allow the CSB designer to proceed independently with their definitive design efforts.

1. MCO Radial Heat Flux

The nominal (average) and maximum MCO powers should be used with a heated MCO length of 130.5 inches for Mark IV fuel and 125.3 inches for Mark Ia fuel to calculate the MCO radial heat flux using a MCO outer diameter of 24 inches. 
WHC-SD-WM-ER-525

Rev. 0

2. MCO External Surface Maximum Temperature

The maximum external surface temperature of the MCO should not exceed $270{ }^{\circ} \mathrm{F}\left(405.4{ }^{\circ} \mathrm{K}\right)$, which corresponds to an estimated maximum fuel temperature of $400^{\circ} \mathrm{F}\left(477.6{ }^{\circ} \mathrm{K}\right)$. As shown in Table 5-1, the maximum MCO surface and peak fuel temperatures can be achieved, with any of the three fuel gases under consideration. The maximum peak fuel temperature within the CSB is $384.2^{\circ} \mathrm{F}\left(468.8^{\circ} \mathrm{K}\right)$ for Argon as the fill gas. The corresponding maximum MCO surface temperature is $263.7^{\circ} \mathrm{F}\left(401.9^{\circ} \mathrm{K}\right)$. Increasing the MCO surface temperature by $6.3^{\circ} \mathrm{F}$ to $270^{\circ} \mathrm{F}$, results in an estimated peak fuel temperature of $390{ }^{\circ} \mathrm{F}$, which is slightly less than the $400{ }^{\circ} \mathrm{F}$ peak fuel temperature limit. For helium the corresponding maximum MCO surface temperature is $224.3^{\circ} \mathrm{F}\left(380^{\circ} \mathrm{K}\right)$.

\section{MCO External Surface Emissivity}

No special emissivity coating is required for the MCO external surface. However, the current MCO design specifications call for a minimum surface emissivity of 0.25 , which was assumed for the results presented in Table 5-1. This value which corrdsponds to bright stainless steel, should be used by the CSB designers for the MCO outer surface. The emissivity of the CSB storage tube will be determined by the CSB design.

The $400{ }^{\circ} \mathrm{F}$ maximum peak fuel temperature was assumed to be a valid safe temperature, but has not yet been confirmed. It is anticipated that the above MCO temperature profile, corresponding to a peak fuel temperature of $400{ }^{\circ} \mathrm{F}$ and a maximum MCO surface temperature of $270^{\circ} \mathrm{F}$, will now form the basis for the CSB safety analyses.

\subsubsection{TH2-3: Thermal Performance for Initial MCO Loading, Removal from Basin and Transportation to Drying Station}

Table 5-2 and Figures 5-13 through 5-21 present the results of the analyses that were performed investigating the thermal performance of the MCO and shipping cask for initial fuel loading, removal from the $K$ Basins(s), and transportation to the vacuum drying station.

The analyses were performed assuming decay heat loads of 142, 426, and 929 watts per MCO, corresponding to the minimum, nominal, and maximum values expected. Table 5-2 presents the thermal performance results for decay heat only (no chemical reactions); whereas, Table 5-3 presents the same thermal performance results for decay heat and chemical reactions. The analyses assumed solar heating during transportation to the vacuum drying station.

The analyses were performed assuming the following scenario:

1. The fuel and MCO internals (i.e., fuel baskets) were assumed to be pre-positioned within the $K$ Basin at a uniform equilibrium temperature of $50^{\circ} \mathrm{F}\left(283.2^{\circ} \mathrm{K}\right)$

2. The empty MCO and shipping cask are assumed to have been in dry storage at a uniform equilibrium temperature of $100^{\circ} \mathrm{F}\left(310.9^{\circ} \mathrm{K}\right)$ 
Rev. 0

3. The 0.25 in. gap between the MCO and shipping cask is assumed to remain dry. (To prevent contamination of the outer surface of the MCO and inner surface of the cask, the gap is assumed to be sealed by an inflatable bladder.)

4. Phase 1 - The MCO and cask are assumed to be instanteously submerged, fully loaded with fuel, and allowed to reach an equilibrium temperature.

5. Phase 2 - The loaded MCO with water and cask are removed from the basin and allowed to stand in air exposed to an ambient temperature of $100^{\circ} \mathrm{F}$, and allowed to reach an equilibrium temperature.

6. Phase 3 - The loaded MCO with water and cask are transported to the dewatering and vacuum drying station, during which the cask subject to solar heating, and allowed to reach an equilibrium temperature.

The following assumptions were made for this analysis:

1. Mark IV fuel, 270 fuel assemblies per MCO

2. Decay heat only, with and without chemical reactions

3. Three consecutive 15-day transient simulations (15 days for each of the three process phases). The 15-day transients were designed to allow the MCO to reach either thermal equilibrium or exhibit a thermal "runaway." If thermal equilibrium was achieved, the proposed process timeline is independent of potential delays. If a thermal "runaway" occurs, then the proposed process timeline is not independent of potential delays, and additional care is required not to exceed the process timelines or an auxilliary cooling mechanism must be developed.

4. No internal convective or radiative heat transfer for water filled MCO (conduction only)

5. Conduction and radiative heat transfer across dry gap

6. Convective heat losses only from OD of cask during Phase 1

7. Convective and radiative heat losses from OD of cask during Phases 2 and 3

8. Basin ambient temperature $=50^{\circ} \mathrm{F}\left(10^{\circ} \mathrm{C}, 283.2^{\circ} \mathrm{K}\right)$ for Phase 1 , $100{ }^{\circ} \mathrm{F}\left(37.8{ }^{\circ} \mathrm{C}, 310.9^{\circ} \mathrm{K}\right)$ for Phases 2 and 3

9. The temperature endpoints from the previous process phase were used as the initial temperatures for the next phase

10. Node 1207 corresponds to the location of the peak fuel temperature.

The results presented in Table 5-2 indicate that for decay heat only (no chemical reactions) the maximum predicted peak temperatures range from $62.4^{\circ} \mathrm{F}$ $\left(290.1^{\circ} \mathrm{K}\right)$ for Phase 1 to $199.9^{\circ} \mathrm{F}\left(366.5^{\circ} \mathrm{K}\right)$ for Phase 3 . The results indicate that for Phase 1 with the basin water at $50^{\circ} \mathrm{F}$ results in a maximum 
WHC-SD-WM-ER-525

Rev. 0

equilibrium peak fuel temperature of $127.4^{\circ} \mathrm{F}\left(326.2^{\circ} \mathrm{K}\right)$. Once the loaded MCO and shipping cask are removed from the basin, the ambient temperature changes and an additional thermal heatup commences. The maximum equilibrium peak fuel temperature for Phase 2 is $189.1^{\circ} \mathrm{F}\left(360.5^{\circ} \mathrm{K}\right)$. Solar heating during Phase 3 adds approximately $11^{\circ} \mathrm{F}$ to $14^{\circ} \mathrm{F}$ to the peak fuel temperatures from Phase 2.

Table 5-3 presents the thermal performance results for the same sceanario as Table 5-2 for nominal and maximum decay heat, including the affects of chemical reactions for various reaction rate relationships. Specifically, as illustrated in Figure 3-5, the Tyfield [oxygen free $\left(-\mathrm{O}_{2}\right)$ ] and Ritchie [oxygenated $\left(\mathrm{H}_{2}\right)$, and oxygen free $\left(-\mathrm{O}_{2}\right)$ ] rate relationships were simulated. Table 5-3 also indicates the corresponding figures for time history plots of the peak fuel temperature (Node 1206).

By comparison with Table 5-2, Table 5-3 indicates a very small increase in Phase 1 peak fuel temperature for the oxygen free reaction rate relationships. (The Tyfield $-\mathrm{O}_{2}$ and Ritchie- $\mathrm{O}_{2}$ result in nearly identical peak fuel temperatures.) No increase in Phase 1 peak fuel temperature was noted for the nominal decay heat case with the Ritchie-oxygenated rate relationship. This confirms the trend first noted in Figure 3-5, the presence of oxygen poisons the uranium reactions. The time history plots for the Phase 1 peak fuel temperatures (Node 1206) for the various reaction rate relationships are presented in Figures 5-13, 5-16, and 5-19.

Figure 5-13 indicates that for Phase 1 conditions approximately 8 days $(691,200$ seconds) are required to reach an equilibrium temperature of 88.5 ${ }^{\circ} \mathrm{F}\left(304.6^{\circ} \mathrm{K}\right)$. The endpoint of Figure $5-13$ provides the initial temperature for Figure 5-14. Figure 5-14 indicates that a "runaway" temperature excursion occurs for Phase 2 conditions given the Tyfield oxygen free $\left(-0_{2}\right)$ reaction rate relationship. The rate of temperature increase begins to rise significantly after approximately 10 days $(864,000$ seconds) into the simulation. Figure 5-15 indicates that a similar temperature excursion occurs for the Ritchie oxygen free $\left(-\mathrm{O}_{2}\right)$ reaction rate relationship. A comparison between Figures 5-14 and 5-15 indicates that the Ritchie- $0_{2}$ rate relationship requires a longer time ( 13 days, $1,123,200$ seconds) to evolve into a "runaway" temperature excursion. This is expected, as shown in Figure 3-5, given that the Ritchie- $0_{2}$ reaction rate is slightly less than the Tyfield $-0_{2}$ reaction rate. By inspection, the Phase 3 cases for nominal decay heat and oxygen-free conditions are expected to result in similar "runaway" temperature exursions.

Figures 5-16 through 5-18 present time history plots of the peak fuel temperature for each phase given nominal decay heat and the Ritchie oxygenated $\left(+0_{2}\right)$ chemical reaction rate relationship. Figures 5-19 through 5-21 present simular results for each phase given maximum decay heat and the Ritchie oxygenated $\left(+\mathrm{O}_{2}\right)$ reaction rate relationship. The results indicate that the presence of oxygen reduces the chemical reation rates and, hence, the peak fuel temperature. It is evident that the $K$ Basin water must be oxygenated to prevent increased chemical reaction rates. If oxygenated water cannot be assured, it is recommended that the actual time sequences associated with each of the three process phases described in Section 5.1 .2 be 1 imited to prevent a

15 days.

"Analysis terminated if equilibrium temperature achieved in less than 
temperature excursion or an auxillary cooling mechanism be developed to provide ambient conditions low enough to maintain peak fuel temperature less than $170^{\circ} \mathrm{F}\left(350^{\circ} \mathrm{K}\right)$.

Table 5-2. Peak Fuel Temperatures for Initial Fuel Loading, Removal from Basin, and Transportation to Vacuum Drying Station (Decay Heat Only).

\begin{tabular}{|c|c|c|c|c|}
\hline & & \multicolumn{3}{|c|}{ Peak Fuel Temperature, ${ }^{0} F\left({ }^{0} K\right)$} \\
\hline Model Description & $\begin{array}{l}\text { Process } \\
\text { Phase }\end{array}$ & $\begin{array}{c}\text { Minimum } \\
\text { Decay Heat } \\
\text { (142W) }\end{array}$ & $\begin{array}{c}\text { Nominal } \\
\text { Decay Heat } \\
\text { (426W) }\end{array}$ & $\begin{array}{l}\text { Maximum } \\
\text { Decay Heat } \\
\text { (929W) }\end{array}$ \\
\hline Water in MCO/Air Gap/Basin Water O $50^{\circ}{ }^{* *}$ & 1 & $\begin{array}{r}62.4 \\
(290.1) \\
\end{array}$ & $\begin{array}{r}86.7 \\
(303.6) \\
\end{array}$ & $\begin{array}{r}127.4 \\
(326.2) \\
\end{array}$ \\
\hline Water in MCO/Air Gap/Basin Air a $100^{{ }^{\circ}}{ }^{* * *}$ & 2 & $\begin{array}{l}115.0 \\
(319.3)\end{array}$ & $\begin{array}{r}143.1 \\
(334.9) \\
\end{array}$ & $\begin{array}{r}189.1 \\
(360.5) \\
\end{array}$ \\
\hline Water in MCO/Air Gep/Air a $100^{\circ} \mathrm{F}+$ OSOLAR & 3 & $\begin{array}{c}129.0 \\
(327.1)\end{array}$ & $\begin{array}{r}155.5 \\
(341.8) \\
\end{array}$ & $\begin{array}{c}199.9 \\
(366.5)\end{array}$ \\
\hline
\end{tabular}

t. Mark IV fuel within MCO within shipping cask, dry gap

* Submerted in basins

*** Removal from basin (under cover, no solar heating)

***** Transportation to vacum drying station (with solar heating)

Table 5-3. Peak Fuel Temperatures for Initial Fuel Loading, Removal from Basin, and Transportation to Vacuum Drying (Decay + Chemical Heat).

\begin{tabular}{|c|c|c|c|c|c|}
\hline \multirow[b]{3}{*}{ Model Description } & \multicolumn{5}{|c|}{ Peak Fuel Temperatures, ${ }^{\circ} f\left({ }^{\circ} \mathrm{K}\right)$} \\
\hline & \multirow[b]{2}{*}{ Process Phase } & \multirow{2}{*}{$\begin{array}{c}\text { Tyfield-02 } \\
\begin{array}{c}\text { Nom. Decay } \\
\text { Heat } \\
(426 \mathrm{~W})\end{array} \\
\end{array}$} & \multirow{2}{*}{$\begin{array}{c}\text { Ritchie-0, } \\
\text { Nom. Decsy } \\
\text { Heat } \\
(426 \mathrm{~W}) \\
\end{array}$} & \multicolumn{2}{|c|}{ Ritchie $+\mathrm{O}_{2}$} \\
\hline & & & & $\begin{array}{c}\text { Nom. Decay } \\
\text { Heat } \\
(426 \mathrm{~W}) \\
\end{array}$ & $\begin{array}{c}\text { Max. Decay } \\
\text { Heat } \\
\text { (929w) } \\
\end{array}$ \\
\hline $\begin{array}{l}\text { Water in MCO/Air } \\
\text { Gap/Bas in Water a } \\
50 \text { F }\end{array}$ & 1 & $\begin{array}{c}88.5(304.6) \\
\text { Figure } 5.13\end{array}$ & $88.3(304.5)$ & $\begin{array}{c}86.7(303.6) \\
\text { Figure } 5-16\end{array}$ & $\begin{array}{c}127.8(326.4) \\
\text { Figure } 5-19\end{array}$ \\
\hline $\begin{array}{l}\text { Water in MCO/Air } \\
\text { Gap/Basin Air a } \\
100 \mathrm{~F}\end{array}$ & 2 & $\begin{array}{c}>260.2(>400)^{*} \\
\text { Figure } 5.14\end{array}$ & $\begin{array}{c}>260.2(>400) * \\
\text { Figure } 5-15\end{array}$ & $\begin{array}{c}144.1(335.5) \\
\text { Figure } 5.17\end{array}$ & $\begin{array}{c}197.4(365.1) \\
\text { Figure } 5-20\end{array}$ \\
\hline $\begin{array}{l}\text { Water in MCO/Ajr } \\
\text { Gap/Air a } 100 \mathrm{~F} \\
+ \text { Q SOLAR }\end{array}$ & 3 & $>260.2(>400)^{*}$ & $>260.2(>400)^{*}$ & $\begin{array}{c}157.5(342.9) \\
\text { Figure } 5-18\end{array}$ & $\begin{array}{c}215.1(374.9)^{* *} \\
\text { Figure } 5-21\end{array}$ \\
\hline
\end{tabular}

* Time must be limited to prevent temperature excursion

** St ightly above B.P. of water $\left(212{ }^{\circ}, 373.2{ }^{\circ}\right)$. Maximum decay heat load a 12/31/97 is estimated to be 835 watts. Temperatures of greater than $212{ }^{\circ}$ are not expected for the revised maximum decay heat load.

\subsubsection{TH2-4: Thermal Performance During Dewatering and Vacuum Drying}

Table 5-4 and Figures 5-22 through 5-33 present the results of the analyses that were performed investigating the thermal performance of a MCO containing Mark IV fuel assemblies within a shipping cask during dewatering and vacuum drying. These analyses should be considered scoping in nature, since they do not reflect the final design of the vacuum system and are assumed to bound the thermal conditions expected to exist during vacuum drying. The effects of the system pumpdown, gas/vapor mixtures, and oxygen 
WHC-SD-WM-ER-525

Rev. 0

depletion will be investigated in the detailed 3-D thermal-hydraulic models currently being developed.

The analyses were performed assuming nominal and maximum decay heat loads of 426 and 929 watts per MCO, respecitvely, for helium and air fill gases.

The analyses were performed based on the following scenario assumptions:

1. The water-filled MCO containing 270 Mark IV fuel assemblies are assumed to be at a uniform initial temperature of $50^{\circ} \mathrm{F}\left(283.2^{\circ} \mathrm{K}\right)$.

2. The shipping cask was assumed to be at $50^{\circ} \mathrm{F}\left(283.2^{\circ} \mathrm{K}\right)$.

3. Most of the water was assumed to be instantenously removed and replaced with either helium or air as the backfill gas. The effects of mixtures ( $f i l l$ gas and water vapor) were not modeled. The thermal analyses utilized pure fill gases and are assumed to bound the expected conditions with water vapor. The helium was assumed to contain enough oxygen that oxygenated conditions exist. The effects of gas mixtures, including hydrogen production, will be addressed in the detailed 3-D thermal-hydraulic models currently being developed.

4. A $122^{\circ} \mathrm{F}$ water flow was established through the 0.25 in. gap between the MCO and shipping cask. The flow rate was assumed to be sufficiently large enough to provide a uniform system boundary condition of $122^{\circ} \mathrm{F}$. If air filled, the temperature drop across an 0.25 in. gap was calculated.

5. $2.5 \mathrm{~kg}$ of residual water was assumed to remain after dewatering.

6. The McGillivary with oxygen reaction rate relationship was assumed for the chemical reactions. The water vapor pressure was assumed to be $2 \mathrm{kPa}$. (This corresponds approximately 3 times the water vapor pressure expected for Hanford average conditions of $54^{\circ} \mathrm{F}$ and 42\% RH.) Preliminary vacuum system performance modeling indicate that pressures in the $2 \mathrm{kPa}$ range will be obtained approximately 30 to 50 seconds after commencing vacuum drying. Thirty to 50 seconds represents an insignificant time for thermal heatup, but does provide a conservative estimate of the maximum water vapor pressure to use with the McGillivary reaction rate relationship. This will be confirmed with more detailed 3-D flow and vacuum system response models.

7. The heat of reaction for uranium with oxygen or uranium and water vapor plus oxygen was assumed to be $3.4 \mathrm{E}+7 \mathrm{~J} / \mathrm{KgO}_{2}$.

8. No solar heating. The MCO and shipping cask are assumed to be located within a covered vaccum drying station.

9. Conductive and radiative heat transfer was assumed to occur internal to the MCO. No convective heat transfer mechanisms were modeled internal to the MCO and shipping cask.

10. Convective and radiative heat transfer losses were assumed from the outer surface of the shipping cask. 
WHC-SD-WM-ER-525

Rev. 0

11. The ambient air temperature was assumed to be $100^{\circ} \mathrm{F}$.

The results as presented in Table 5-4 indicated that establishing a water heating/cooling mechanism using the $0.25 \mathrm{in}$. MCO-cask gap is an extremely effective means to raise the internal temperature enough to supply the energy necessary to evaporate the residual water without freezing. Comparison of Figures 5-22 with 5-23, 5-25 with 5-26, 5-28 with 5-29, and 5-31 with 5-32 indicate that the water gap significantly reduces the time necessary to achieve equilibrium peak fuel temperatures. For nominal decay heat peak temperatures are achieved after approximately 2 days $(17,2800 \mathrm{~s})$ for the water-filled gap versus approximately 6 days $(518,400 \mathrm{~s})$ for the air-filled gap. For maximum decay heat, the corresponding values are approximately 1.5 days $(129,600 \mathrm{~s})$ versus approximately 5 days $(432,000 \mathrm{~s})$.

For nominal decay heat, increasing the emissivities associated with stainless steel from 0.25 to 0.75 completely offsets the higher temperatures associated with an air-filled versus water-filled gap, but does not reduce the longer heatup time associated with the air-filled gap. For maximum decay heat, increasing the emissivity of stainless steel 304 from 0.25 to 0.75 offsets approximately half of the temperature increase and does not significantly reduce the heatup time associated with an air-filled gap.

As shown in Figures 5-26 and 5-27, the time to reach peak equilibrium fuel temperatures is not significantly reduced even if air with its lower thermal conductivity was used. Even increasing the emissivity of stainless stee 1304 from 0.25 to 0.75 with an air-filled MCO does not significantly decrease the time to reach peak fuel temperatures. This is understandable when one considers that a water-filled gap at a constant temperature of $122^{\circ} \mathrm{F}$ is actually supplying energy to the system in addition to the decay heat. The proposed $50{ }^{\circ} \mathrm{C}\left(122^{\circ} \mathrm{F}\right) \mathrm{MCO}-$ shipping cask gap heating system is an extremely effective means to achieve equilibrium peak fuel temperatures in a timely manner.

However, the peak fuel temperatures for all the air cases are much higher than the helium/water gap or helium/air gap cases. The higher temperatures lead to increased chemical reaction rates and greater rate of energy production from chemical reactions. Figure 5-29 shows a nominal decay heat analysis with a breakpoint around 9 days $(777,600 \mathrm{~s})$. This breakpoint is associated with a decrease in chemical energy after $2.5 \mathrm{Kg}$ of residual water has been consumed via the uranium water vapor reaction. If less residual water as assumed, the breakpoint would occur earlier and later if more residual water was assumed. The results of the same case but with increased emissivities are shown in Figure 5-30. The increased emissivities decrease peak temperatures enough that equilibrium fuel temperatures can be achieved even with chemical reactions.

For the maximum decay heat cases, as shown in Figure 5-32 and 5-33, taking the second derivative of the peak fuel temperature versus time indicates that a temperature excursion occurred. For Figure 5-32 the second derivative went positive at approximately $297^{\circ} \mathrm{F}\left(420^{\circ} \mathrm{K}\right)$ and 2.3 days $(200000 \mathrm{~s})$. For Figure 5-33 the second derivative went positive at the same temperature, but at 5.4 days $(466560 \mathrm{~s})$. The excursions were terminated after the chemical energy equivalent to $2.5 \mathrm{~kg}$ of water was produced. For the nominal emissivity case presented by Figure 5-32, the peak fuel temperature 
WHC-SD-WM-ER-525

Rev. 0

eventually decrease to a equilibrium temperatures of $307.2^{\circ} \mathrm{F}\left(426.1^{\circ} \mathrm{K}\right)$. This temperature is identical to the baseline peak fuel temperature presented in Table 5-1 for a MCO and shipping cask containing Mark IV fuel assemblies for a maximum decay heat of $929 \mathrm{~W}$ and an ambient air temperature of $100^{\circ} \mathrm{F}$.

The increased emissivity case presented in Figure 5-33 can be compared to Figure 5-32. The increased emissivity for stainless steel significantiy reduces the rate of increase for the peak fuel temperatures. However, increased emissivities alone do not prevent a temperature excursion (i.e., "runaway") from occurring for these conditions.

The results as summarized in Table 5-4 indicated that a water gap heating/cooling system is required to reduce the transient heatup time and helium fill gas is required to prevent a temperature excursion (i.e., runaway chemical reaction) for the maximum expected decay heat load. Additional means to control MCO temperatures must be provided if air is used as the purge gas. Since the reactions are limited by assumed amounts of residual water, the peak fuel temperatures for the maximum decay heat load reach a maximum value then decrease and eventually reach equilibrium conditions.

Table 5-4. Peak Fuel Temperatures for Dewatering and Vacuum Drying.

\begin{tabular}{|c|c|c|c|c|c|}
\hline & \multirow[b]{2}{*}{ Model Conditions } & & \multirow[b]{2}{*}{$\begin{array}{c}\text { Emissivity } \\
(\mathrm{SS304})\end{array}$} & \multicolumn{2}{|c|}{ Peak Fuel Temperatures ${ }^{*},{ }^{0}{ }^{0}\left({ }^{0}\right)$} \\
\hline & & & & $\begin{array}{c}\text { Nom. Decay } \\
\text { Heat } \\
\text { (426W) } \\
\end{array}$ & $\begin{array}{l}\text { Max. Decay Heat } \\
\text { (929w) }\end{array}$ \\
\hline $\mathrm{MCO}$ & Gap & Ambient & & & \\
\hline $\mathrm{He}$ & Water a $122{ }^{\circ} \mathrm{F}$ & Air a $100^{\circ} \mathrm{F}$ & 0.25 & $\begin{array}{c}152.5(340.1) \\
\text { Figure } 5-22 \\
\end{array}$ & $\begin{array}{c}186.8(359.2) \\
\text { Figure } 5-28\end{array}$ \\
\hline He & Air & Air a $100^{\circ} \mathrm{F}$ & 0.25 & $\begin{array}{c}163.2(346.1) \\
\text { Figure 5-23 }\end{array}$ & $\begin{array}{c}235.0(386.0) \\
\text { Figure } 5-29 \\
\end{array}$ \\
\hline $\mathrm{He}$ & Air & Air a $100^{\circ} \mathrm{F}$ & 0.75 & $\begin{array}{c}152.1(339.9) \\
\text { Figure } 5-24 \\
\end{array}$ & $\begin{array}{c}207.5(370.7) \\
\text { Figure } 5-30\end{array}$ \\
\hline Air & Water a $122{ }^{\circ} \mathrm{F}$ & Air $\bigcirc 100^{\circ} \mathrm{F}$ & 0.25 & $\begin{array}{c}205.8(369.7) \\
\text { figure } 5.25 \\
\end{array}$ & $\begin{array}{c}330.7(439.1)^{* *} \\
\text { Figure } 5-31\end{array}$ \\
\hline Air & Air & Air $\bigcirc 100^{\circ} \mathrm{F}$ & 0.25 & $\begin{array}{c}219.2(377.2) \\
\text { Figure } 5.26\end{array}$ & $\begin{array}{c}355.9(453.1)^{* * *} \\
\text { Figure } 5.32\end{array}$ \\
\hline Air & Air & Air a $100^{\circ} \mathrm{F}$ & 0.75 & $\begin{array}{l}191.7(361.9) \\
\text { Figure } 5-27)\end{array}$ & $\begin{array}{c}303.4(423.9)^{* *} \\
\text { Figure } 5.33\end{array}$ \\
\hline
\end{tabular}

- Chemical reaction rate relationship, based on McGillivary $+\mathrm{O}_{2}$ at a water vapor pressure of $2 \mathrm{kPa}$ and * $\quad 2.5 \mathrm{~kg}$ of residual water.

Temperature exursion; temperature increase terminated due to consumption of limited reactions (i.e., $2.5 \mathrm{~kg}$ water).

\subsubsection{TH2-5: Thermal Performance in a Transportation Shipping Cask}

Table 5-5 and Figures 5-34 and 5-35 present the results of a series of analyses that were performed investigating the thermal performance of a MCO and shipping cask containing Mark IV fuel assemblies during transportation from the vacuum drying station to the CSB. 
WHC-SD-WM-ER-525

Rev. 0

The analyses were performed assuming nominal decay heat for two fill gases; helium and moist air.

The analyses were performed based on the following assumptions:

1. A fully loaded MCO containing Mark IV fuel assemblies within a shipping cask

2. Helium and moist air fill gas

3. Nominal decay heat, plus chemical reactiions

4. Variable ambient conditions from $80{ }^{\circ} \mathrm{F}$ to $160{ }^{\circ} \mathrm{F}$

5. Solar heating (10CFR71)

6. 0.0 and $2.5 \mathrm{Kg}$ of residual water

The results presented in Table 5-5 and Figures 5-34 and 5-35 indicate that temperature excursions (i.e., "runaway" chemical reactions) will occur for a MCO containing residual water within a transportation shipping cask, but are eventually terminated due to 1 imited reactants.

The analyses were performed for an oxygen-free environment with helium as the backfill gas and an oxygenated environment with moist air as the fill gas. Cases 1 through 5 simulated the thermal performance of an MCO just released from the vacuum drying station with $2.5 \mathrm{~kg}$ of frozen residual water, helium fill gas, and an oxygen-free environment. Cases 7 through 11 simulated the same conditions, but the helium backfill was lost due to faulty seals and was replaced by moist ${ }^{*}$ air at standard atmospheric pressure (14.7 psia, 101.325 $\mathrm{KPa}$ ) with a water vapor pressure of $2 \mathrm{kPa}$. Cases 6 and 12 simulated the thermal performance of an MCO with no residual water, hence, no chemical reactions, just decay heat only for helium and air as the fill gases. (Readers are also referred to Table 5-1, which presents peak fuel temperatures for the baseline models, which were derived assuming decay heat only.)

The results from Cases 1 through 6, as shown in Table 5-5 and Figure 5-34 indicate that the Ritchie reaction rate relationship for an oxygen-free environment does not result in the highest temperatures, but does result in the greatest rate of temperature increase. The lower peak fuel temperatures are due to the presence of helium, which as shown in Sections 5.1.1, 5.1.2, and 5.1 .3 will mitigate the peak temperatures.

The results from the moist air cases 7 through 12, as shown in Table 5-5 and Figure 5-35, using the McGillivary reaction rate relationship give the maximum peak fuel temperatures, but not the highest rate of temperature increase. The reduced rate of temperature increase is due to the presence of oxygen, which reduces the chemical reaction rates, and, hence, the rate of chemical heat generation.

*Water vapor pressure assumed to be $2 \mathrm{kPa}$. This is approximately three times the water vapor pressure expected for Hanford average conditions of $54{ }^{\circ} \mathrm{F}$ at $42 \% \mathrm{RH}$. 
Rev. 0

Figure 5-34 for all ambient conditions and Figure 5-35 for ambient conditions of $160^{\circ} \mathrm{F}$ and $140^{\circ} \mathrm{F}$ clearly show the temperature signatures associated with "runaway" chemical reactions. The temperature excursions are terminated after the chemical energy equivalent to $2.5 \mathrm{Kg}$ of water was produced. The temperature profiles begin to decrease and eventually reach equilibrium peak temperatures associated with decay heat only. Figures 5-34 and 5-35 also present for comparison purposes the peak fuel temperatures obtained for no residual water (decay heat only) for an ambient temperature of $80^{\circ} \mathrm{F}$.

Table 5-5. Peak Fuel Temperature for Transportation Shipping Cask.

\begin{tabular}{|c|c|c|c|c|c|}
\hline & & \multicolumn{4}{|c|}{ Peak Fuel Temperatures $\left.{ }^{*},{ }^{0}{ }^{\circ}{ }^{\circ}\right)$} \\
\hline \multicolumn{2}{|r|}{ Model Description } & \multicolumn{2}{|c|}{ Helium fill Gas } & \multicolumn{2}{|c|}{ Moist Air Fill Gas } \\
\hline Gap & Ambient Conditions & Case & Ritchie- $\mathrm{O}_{2}$ & Case & McGillivary ${ }^{* *}+\mathrm{O}_{2}$ \\
\hline Air & Air a $160^{\circ} F+a_{\text {SOLAR }}$ & 1 & $267.6(404.1)$ & 7 & $309.2(427.2)$ \\
\hline Air & Air a $140^{\circ} F+a_{\text {SOLAR }}$ & 2 & $244.8(391.4)$ & 8 & $284.2(413.3)$ \\
\hline Air & Air a $120^{\circ} F+0_{\text {SOLAR }}$ & 3 & $230.5(383.5)$ & 9 & $257.9(398.7)$ \\
\hline Air & Air a $100^{\circ} \mathrm{F}+0_{\text {SOLAR }}$ & 4 & $210.7(372.5)$ & 10 & $233.4(385.1)$ \\
\hline Air & Air a $80^{\circ} \mathrm{F}+0_{\text {SOLAR }}$ & 5 & $193.1(362.7)$ & 11 & $212.7(373.6)$ \\
\hline Air & Air a $80^{\circ} \mathrm{F}+a_{\text {SOLAAR }}$ & 6 & $156.9(342.6)^{\star \star *}$ & 12 & $204.6(369.1)^{\hbar * \hbar}$ \\
\hline
\end{tabular}

\footnotetext{
* $\epsilon_{\text {ss304 }}=0.25, \epsilon_{Z I R C}=0.40 \epsilon_{\text {CASKID }}=0.25 \epsilon_{\text {CASKOO }}=0.55$

** $2 \mathrm{kPa}$ water vapor pressure, $2.5 \mathrm{Kg}$ resictual water

*** No chemical reactions, decay heat only.
}

\subsubsection{TH2-7: Thermal Performance in a Canister Storage Building Storage Tube}

Tables 5-6 and 5-7 and Figures 5-36 through 5-38 present the results of a series of analyses that were performed investigating the thermal performance of. a MCO containing Mark IV fuel assemblies within a CSB storage tube. Section 5.1 provides additional information that will allow the MCO and CSB design efforts to be decoupled.

The results indicate that the reduced heat transfer conditions and high ambient temperature associated with the CSB result in the most agressive fue 1 temperatures. The above analyses were performed for three different fill gases; helium (He) nitrogen $\left(\mathrm{N}_{2}\right)$, and argon ( $\left.\mathrm{Ar}\right)$, and different amounts of residual water $(0.0,1.5,2.5$ and $3.5 \mathrm{Kg})$.

The analyses were performed based on the following assumptions:

1. A fully loaded MCO containing Mark IV fuel assemblies

2. Nominal decay heat of $426 \mathrm{~W}$ per $M C O$

3. Fill gases, helium, nitrogen, and argon 
Rev. 0

4. Variable amounts of residual water $(0.0,1.5,2.5$, and $3.5 \mathrm{Kg})$

5. No radiative heat losses from outer surface of storage tube

6. Convective heat losses from outer surface of storage tube based on a CSB ambient air temperature of $140^{\circ} \mathrm{F}$

7. No solar heating

8. Chemical reactions based on the Ritchie oxygen free rate relationship.

The results presented in Table 5-6 were obtained for nominal and maximum decay heats. No chemical reactions were modeled. The analyses used early low and high estimates of the emissivities to determine a range of temperatures. These early estimates of the emissivities are close, but are slightly less than the final values used to produce Table 5-1 and, thus, bound the results presented in Table 5-1. The results presented in Table 5-6 are unique, given than an energy balance was performed to determine the relative amount of energy transferred by conductive and radiative means. The results indicate that when helium is used as a backfill gas, the MCO/storage tube system is conduction dominated and peak fuel temperatures are the lowest. The effect of doubling the emissivities is minimal when helium is used. A maximum reduction

Table 5-6. Peak Fuel Temperature and Energy Balance for MCO Within A CSB Storage Tube Versus Fil1 Gas and Decay Heat (No Chemical Reactions)

\begin{tabular}{|c|c|c|c|c|c|c|}
\hline \multirow[b]{2}{*}{ Case } & \multirow[b]{2}{*}{ Model Description } & \multirow[b]{2}{*}{$\begin{array}{c}\text { Energy } \\
\text { Balance }\end{array}$} & \multicolumn{3}{|c|}{ Peak Fuel Temperatures, ${ }^{\circ} \mathrm{F}\left({ }^{\circ} \mathrm{K}\right)$} & \multirow{2}{*}{$\frac{\Delta T,{ }_{F}{ }^{\circ}\left({ }_{K}\right)}{\text { Argon-Helium }}$} \\
\hline & & & Helium & Nitrogen & Argon & \\
\hline 1 & 426H, $1^{\star} \mathrm{XE}$ & $\begin{array}{l}\text { COND. } \\
\text { RAD. }\end{array}$ & $\begin{array}{c}219.0(377.1) \\
0.73 \\
0.27 \\
\end{array}$ & $\begin{array}{c}285.3(413.9) \\
0.32 \\
0.68 \\
\end{array}$ & $\begin{array}{c}298.4(421.2) \\
0.24 \\
0.76 \\
\end{array}$ & $79.2(44.0)$ \\
\hline 2 & $426 H, 2^{* *} x \in$ & $\begin{array}{l}\text { COND. } \\
\text { RAD. }\end{array}$ & $\begin{array}{c}207.9(370.9) \\
0.54 \\
0.46\end{array}$ & $\begin{array}{c}238.6(388.0) \\
0.18 \\
0.82 \\
\end{array}$ & $\begin{array}{c}243.3(390.6) \\
0.13 \\
0.87\end{array}$ & $35.5(19.7)$ \\
\hline 3 & 929\%, $1 \times \in$ & $\begin{array}{l}\text { COND. } \\
\text { RAD. }\end{array}$ & $\begin{array}{c}292.1(417.7) \\
0.70 \\
0.30 \\
\end{array}$ & $\begin{array}{c}395.2(4 \pi .0) \\
0.29 \\
0.71 \\
\end{array}$ & $\begin{array}{c}415.0(486.0) \\
0.21 \\
0.79\end{array}$ & $122.9(68.3)$ \\
\hline 4 & $929 w, 2 X \epsilon$ & $\begin{array}{l}\text { COND. } \\
\text { RAD. }\end{array}$ & $\begin{array}{c}268.7(404.7) \\
0.52 \\
0.48 \\
\end{array}$ & $\begin{array}{c}317.8(432.0) \\
0.16 \\
0.84 \\
\end{array}$ & $\begin{array}{c}324.7(435.8) \\
0.11 \\
0.89\end{array}$ & $56.0(31.1)$ \\
\hline
\end{tabular}

* $\epsilon_{\mathrm{ss} 304}=0.25, \epsilon_{\mathrm{ZIRC}}=0.30, \epsilon_{\mathrm{sTID}}=0.30$

$\epsilon_{\mathrm{ss} 304}=0.50, \epsilon_{\text {ZIRC }}=0.60, \epsilon_{\mathrm{sTID}}=0.60$

in peak fuel temperature of $23.4^{\circ} \mathrm{F}\left(13^{\circ} \mathrm{K}\right)$ was noted when helium is present. The exact opposite is true when nitrogen or argon are used as the back fill gas. Peak fuel temperatures are their highest when argon is used. Nitrogen is a close second and since the systems are now radiation dominant, the effect of doubling the emissivities is dramatic. Peak fuel temperatues can be reduced by approximately $90^{\circ} \mathrm{F}\left(50^{\circ} \mathrm{K}\right)$ when argon is present, approximately $77^{\circ} \mathrm{F}\left(43^{\circ} \mathrm{K}\right)$ when nitrogen is present, but only $23^{\circ} \mathrm{F}\left(13^{\circ} \mathrm{K}\right)$ with helium. 
WHC-SD-WM-ER-525

Rev. 0

The results presented in Table 5-7 and Figures 5-36 through 5-38, are for nominal decay plus the effect of chemical reactions for various amounts of residual water and three different fill gases. Some additional emissivity sensitivity analyses were also performed for decay heat only.

The scenario assumed for these analyses was as follows:

1. The dewatering and vacuum drying process does not remove all the residual water. Residual amounts of water ranging from 0.0 to $3.5 \mathrm{Kg}$ were assumed.

2. The residual water is frozen due to the vacuum drying process.

3. Transportation process from the vacuum drying station to the CSB is accomplished before the frozen water can melt.

4. Fuel movement during the transportation and handling at the CSB process removes some of the oxide layers that were formed during the vacuum drying process.

5. The residual water melts, evaporates and begins to interact with the exposed uranium metal.

The results represented in Table 5-7 were performed for slightly different emissivities than Table 5-6. In particular, the emissivities of the Zircaloy 4 cladding and storage tube were increased to values representative of the latest material data.

The Table 5-7 results confirm the beneficial effects of reducing peak fuel temperatures through the use of helium as the backfill gas and enhancing emissivites. The peak fuel temperatures range from a maximum value of $407.8^{\circ} \mathrm{F}\left(482.0^{\circ} \mathrm{K}\right)$ to a minimum value of $217.9^{\circ} \mathrm{F}\left(376.5^{\circ} \mathrm{K}\right)$ depending on the fill gas and residual water. If there was no residual water, the maximum peak fuel temperature decreased to $279.0^{\circ} \mathrm{F}\left(410.4^{\circ} \mathrm{K}\right)$ and the minimum peak fuel temperature decreases to $205.5^{\circ} \mathrm{F}\left(369.6^{\circ} \mathrm{K}\right)$. Again, note that the minimum peak fuel temperature is achieved through a combination of both helium and enhanced emissivities. The peak fuel temperature derived using nitrogen and argon as the backfill gas are higher and very close to each other. Cost issues alone would recommend that nitrogen be used for the backfill gas.

The results presented in Figures 5-36, 5-37, and 5-38 clearly show the effects of various amounts of residual water for helium, nitrogen, and argon fill gas, respectively. The greater the amount of residual water, the higher the peak fuel temperature. The subject figures clearly show breakpoints associated with the consumption of the residual water. Once the chemical energy equivalent to the amount of residual water has been produced, the chemical reaction is terminated and the thermal response of the system proceeds based on stored energy and decay heat. The results presented in Figures 5-36 through 5-38 al so clearly indicate that minimum peak fuel temperatures are obtained when both helium and enhanced emissivities are used. If argon is to be used as the fill gas, then enhancing the emissivities is strongly recommended. It is strongly recommended that the stainless surface of the MCO be chemically heated or that the same surface be passiviated to increase emissivity to the range of 0.7 to 0.8 . The emissivity of the CSB 
Rev. 0

storage tube surfaces and the inner surface of the transportation shipping cask should be held to eimilar high values.

Additional calculations were performed for decay heat only (i.e., zero residual water) with and without enhanced emissivities. These analyses provided a consistency check for those analyses that involved both decay heat and chemical reactions and are consistent with the values previously reported in Table 5-1.

Table 5-7. Peak Fuel Temperatures for Interim Storage in the Canister Storage Building Versus Fill Gas and Residual Hater (Nominal Decay + Chemical Reactions).

\begin{tabular}{|c|c|c|c|}
\hline & \multicolumn{3}{|c|}{$\begin{array}{l}\text { Peak Fuel Temperatures, }{ }^{\circ} \mathrm{F}\left({ }^{\circ} \mathrm{K}\right) \\
\text { (Ritchie- } 0_{2} \text {, Reation Rate Relationship) }\end{array}$} \\
\hline $\begin{array}{l}\text { Residual Water } \\
(\mathrm{Kg})\end{array}$ & Helium* & Nitrogen" & Argon* \\
\hline 3.5 & $288.3(415.6)$ & $390.0(472.1)$ & $407.8(482.0)$ \\
\hline 2.5 & $255.9(397.6)$ & $290.1(416.6)$ & $290.7(416.9)$ \\
\hline 1.5 & $217.9(376.5)$ & $268.5(404.6)$ & $279.0(410.4)$ \\
\hline No water $+1 X \epsilon_{\text {ses }}^{* *}$ & $213.3(373.9)$ & $268.5(404.6)$ & $279.0(410.4)$ \\
\hline No water $+3 X \epsilon^{\text {ses }}$ & $205.5(369.6)$ & $241.7(389.7)$ & $248.4(393.4)$ \\
\hline
\end{tabular}

Fill gas assumed internal to both MCO and storage tube-MCO gap $1 X \epsilon ; \epsilon_{\text {ss304 }}=0.25, \epsilon_{\text {ZIRC }}=0.40, \epsilon_{\text {stI0 }}=0.55$ $3 X \epsilon ; \epsilon_{\text {ss304 }}=0.75, \epsilon_{\text {ZIRC }}=0.40, \epsilon_{\text {sTID }}=0.55$

\subsection{HUB ANALYTICAL SOLUTIONS}

The results of key analytical solutions that have been performed using the HUB engineering spreadsheet models are presented in this section.

\subsubsection{TH2-2: MCO Natural Convection Assessment}

An assessment of the effectiveness of natural convection internal to the MCO in reducing peak fuel temperatures was performed. The MCO was assumed to be positioned within a shipping cask in an ambient environment of $100^{\circ} \mathrm{F}$. The following emissivities were used for the analysis; $\epsilon_{\text {fuel }}=0.4, \epsilon_{\text {mco }}=0.2$, $\epsilon_{\text {IDcask }}=0.2$, and $\epsilon_{\text {opcask }}=0.55$. A comparison of the radial temperature profiles with and without convection is shown in Figure 5-39. Both of the analyses assumed thermal radiation and conduction. Internal convection within the MCO produces a reduction in the peak temperature of $22^{\circ} \mathrm{K}$ for these conditions. No chemical reactions were assumed to occur for this case. Section 4.2.2.l discusses the derivation of the internal MCO convective heat transfer coefficient. 
WHC-SD-WM-ER-525

Rev. 0

\subsubsection{TH2-3: MCO Thermal Performance During Reracking/Dewatering}

An assessment of the MCO thermal performance during reracking and dewatering prior to vacuum drying was performed. Reracking was assumed to refer to the dense pack option with 48 or 54 fuel assemblies per tier within a MCO. During the reracking process, the MCO and shipping cask are assumed to be submerged within the K-Basin. The fuel is unloaded from existing Fuel Encapsulation Canisters and loaded into the basket. The baskets are then placed within the MCO with five to six tiers depending on the fuel type.

Water is expected to remain in the MCO until the MCO is drained just prior to vacuum drying. Water is not expected in the gap between the MCO and Shipping Cask. An inflatible seal will be used to prevent basin water from filling the gap and contaminating the exterior surface of the MCO. During reracking, the basin water will be at the $K$ basin water temperature of $10^{\circ} \mathrm{C}$. During dewatering, a water cooling system will be connected to the cask to maintain the water in the gap at $10^{\circ} \mathrm{C}\left(50^{\circ} \mathrm{F}\right)$. During vacuum drying, the water temperature will be raised to $50^{\circ} \mathrm{C}\left(122^{\circ} \mathrm{F}\right)$. The following calculations evaluate several bounding scenarios for fuel stored in MCOs during vacuum drying to provide additional energy to evaporate any residual bulk water.

5.2.2.1 Water Temperature Required to Reach Ignition Temperature. The steady state temperature profile in the fuel for a water jacket temperature that is sufficiently high for the fuel to reach the ignition temperature, assuming the fuel has a reacting surface area equal to the geometric area of completely declad fuel and that the MCO is filled with air containing steam at a partial pressure of $11.9 \mathrm{psi}(82 \mathrm{kPa})$, is shown in Figure 5-40. The water temperature corresponding to ignition for these conditions is $85^{\circ} \mathrm{C}\left(186^{\circ} \mathrm{F}\right)$.

The assumptions for this calculation are as follows:

- The geometry can be modeled with an equivalent 1D annular ring model.

- The MCO is filled with atmospheric air at standard pressure. The modes of heat transfer are thermal radiation, conduction, and convection. Convection is assumed to occur on the outside of the fuel elements, across the annulus between the inner and outer fuel elements, and across the center flow channel.

- The gap between the MCO and the cask is filled with water at a constant temperature.

- The emissivities are 0.4 for the fuel, and 0.2 for the MCO wall.

- The decay heat load is $1228 \mathrm{~W} / \mathrm{m}^{3}$ of fuel or 426 Watts per MCO.

- The reaction rate is given by the steam portion of the McGillivary rate equation and the steam pressure is assumed to be $82 \mathrm{kpa}$ and the heat of reaction is assumed to be $3.4 E+7$ Joules $/ \mathrm{kg}$.

- There is a sufficient supply of steam to maintain the reaction. 
Rev. 0

The conclusions that can be drawn from this analysis are as follows. The heat of reaction for this condition is 3.6 times higher than the heat of reaction with Hanford average air at these conditions. Even with these higher reaction rates, the cooling water around the MCO would have to reach a temperature of $85^{\circ} \mathrm{C}\left(186^{\circ} \mathrm{F}\right)$ for the fuel to reach the ignition point. Since these water temperatures are much higher than the planned operating temperature $\left(10^{\circ} \mathrm{C}\right)$, the fuel should be safe at temperatures expected during reracking and dewatering as long as the fuel reaction surface area is not significantly higher than the geometric area of completely declad fuel.

5.2.2.2 Fuel Temperatures with Maximum Specified Water Temperature. This case is essentially the same as the case in the previous section except that the cooling water temperature is specified to be $50{ }^{\circ} \mathrm{C}$.

The assumptions for this case are as follows:

- The geometry can be modeled with an equivalent 10 annular ring model.

- The MCO is filled with atmospheric air at standard pressure. The modes of heat transfer are thermal radiation, conduction, and convection. Convection is assumed to occur on the outside of the fuel elements, across the annulus between the inner and outer fuel elements, and across the center flow channel.

- The inerting gas is nitrogen.

- The gap between the MCO and the cask is filled with water at a constant temperature of $50{ }^{\circ} \mathrm{C}$.

- The emissivities are 0.4 for the fuel and 0.2 for the MCO wall.

- The decay heat load is $1228 \mathrm{~W} / \mathrm{m}^{3}$ of fuel or 426 Watts per MCO.

- The reaction rate is given by the steam portion of the McGillivary rate equation and the steam pressure is assumed to be $82 \mathrm{kPa}$. The heat of reaction is assumed to be $3.4 \mathrm{E}+7 \mathrm{~J} / \mathrm{kg}$.

- There is a sufficient supply of steam to maintain the reaction.

The results of this calculation are shown in Figure 5-41. The peak fuel temperature is well below the fuel ignition temperature for the assumed reaction areas and rates. Comparing this figure with Figures $5-40$, it is clear that storage of the fuel in this condition is less severe than storing the fuel in an MCO filled with ambient air inside of a cask with air filling the gap between the cask and the MCO when the cask is exposed to $100^{\circ} \mathrm{F}$ ambient conditions.

The maximum fuel temperature inside the MCO is well below the ignition temperature for the fuel under the conditions specified for this case. This is true even though the steam pressure is assumed to be $82 \mathrm{Kpa}$ which is much higher than the MCO pressure is expected to be under vacuum drying conditions (5-10 Torr or 0.67 to $1.33 \mathrm{Kpa}$ ). 
WHC-SD-WM-ER-525

Rev. 0

\subsubsection{TH2-5: MCO Thermal Performance in Shipping Cask}

The following results are for a MCO stored in a shipping cask with no cooling water in the MCO/Cask Gap. The following assumptions have been made for this calculation.

1. The geometry can be modeled with an equivalent ID annular ring mode1.

2. The MCO is filled with atmospheric air at standard pressure. The modes of heat transfer are thermal radiation, conduction and convection.

3. The gap between the MCO and the cask is filled with air at atmospheric pressure.

4. The emissivities are 0.4 for the fuel, 0.2 for the $M C O$ wall and inside wall of the cask and 0.55 for the outer surface of the cask.

5. The cask radiates and convects to a constant temperature environment of $100^{\circ} \mathrm{F}$.

6. The decay heat load is $1228 \mathrm{~W} / \mathrm{m} 3$ of fuel or 426 Watts per MCO.

7. The reaction rate is given by the McGillivary rate equation and the steam pressure is assumed to be $2 \mathrm{kPa}$.

8. There is a sufficient supply of steam and oxygen to maintain the reaction.

The radial temperature profile for this case with and without chemical reactions are shown in Figure 5-42. The peak fuel temperature is well below the ignition temperature for these conditions.

If the MCO is filled with air having the average relative humidity for Hanford, and the surface area available for chemical reaction is no larger than the geometrical surface area of completely declad fuel, and if the reaction rate is no higher than that given by the McGillivary correlation, then the maximum fuel temperature will be well below the ignition temperature. The fact that the $M C O$ is filled with air assumes that an accident condition has occurred that has allowed air to enter the MCO since the MCO would normally be filled with an inert gas. The assumptions also assume that the breach is large enough that the supply of air is not limiting the reaction rate. It is also assumed that there is not sufficient water in the MCO to raise the moisture content of the air above the normal relative humidity for Hanford air. Storage of the fuel in the cask is a less severe condition than storing the fuel in the CSB storage tubes once the fuel has been dried.

\subsubsection{TH2-5a: Thermal Performance of Rubble Basket}

The conditions from the analysis presented in Section 5.2.3 were used to provide the thermal boundary conditions for a fuel basket filled with fuel fragments. The analysis performed for the fuel rubble is idealized. The purpose of this analysis was to obtain an order of magnitude estimate of the 
Rev. 0

effect of the rubble geometry on heat transfer. In this analysis, it is assumed that the fuel rubble basket occupys the center of a Mark-IV fuel basket and that the decay heat generation rate and surface to volume ratio is the same as that for declad fuel elements. The rubble basket is divided into 10 annular rings. The analytical solution for the temperature of each annular ring is discussed in Section 4.2.3.1. The model must be divided into annular rings because the heat generation rate is not uniform but is a function of temperature because of the heat of reaction due to fuel oxidation. The model for the fuel basket is shown in Figure 4-18. In the model, it is assumed that the surface temperature is held constant and that the decay heat per unit volume is constant. The heat released due to chemical reaction is temperature dependent so it is different for each region of fuel in the basket, however, it is assumed that the temperature of each region is uniform so that the chemical reaction heat release is constant within that region.

The numerical solution for the problem described above for the stated heat generation rates, thermal conductivity and surface temperature are shown in Figure 5-43. The temperature profile through the rubble fuel is nearly flat for these conditions. This indicates that, for the temperatures that the fuel is expected to be at while stored in the cask, the thermal conductivity of the rubble bed is sufficiently high to remove all of the heat generated within the rubble bed due to decay heat or oxidation reactions without creating a significant temperature gradient in the rubble bed.

The effective thermal conductivity of the rubble bed is high enough to prevent significant temperature gradients in the fuel, assuming that the decay heat is equal to that of the average fuel and that the surface area to volume ratio of the fuel is no greater than that of 0.25 inch spherical fuel packed to a maximum packing volume fraction of 0.62 . Additional calculations will be performed using the two-dimensional finite element model discussed in

Section 4.1.5.

\subsubsection{TH2-7: MCO Thermal Performance in CSB Storage Tube}

The following calculation is for the MCO stored inside of the CSB storage tube. The following assumptions have been made for this calculation.

1. The geometry can be modeled with an equivalent ID annular ring model.

2. The $M C O$ is stored inside of a storage tube in the CSB.

3. The air pressure in the MCO is atmospheric, so the modes of heat transfer-are thermal radiation, conduction and convection.

4. The gap between the MCO and the tube is filled with air at atmospheric pressure so heat is transferred across the gap by both thermal radiation and conductive heat transfer.

5. The emissivities are 0.4 for the fuel, 0.3 for the $M C O$ and the tube. 
WHC-SD-WM-ER-525

Rev. 0

6. The tube convects to a constant temperature environment. It sees other tubes at the same temperature so there is no net radiant heat loss from the tube surface.

7. The decay heat load is $1228 \mathrm{~W} / \mathrm{m} 3$ of fuel or 426 Watts per MCO.

8. The reaction rate is given by the McGillivary rate equation, and the steam pressure is assumed to be $2 \mathrm{kPa}$.

9. There is a sufficient supply of steam and oxygen to maintain the reaction.

The results of this calculation are shown in Figure 5-44. For this condition, the fuel temperature is near the ignition point for completely declad fuel and an ambient temperature of $96^{\circ} \mathrm{F}$. Since the ambient temperature of the CSB is expected to be higher than this, we will have to rely on additional benefits to maintain the fuel below ignition. The fuel temperatures are higher for this case than for the case with the fuel stored in the cask near the same ambient air temperature even though higher emissivities have been assumed for the $M C O$ and Tube. The exterior surface area of the tube is smaller than the outside surface area of the cask and the tube is surrounded by other tubes that are at nearly the same temperature. Therefore, there is less surface area for natural convection to remove heat and there is no radiant heat loss from the surface because the surface "sees" surrounding surfaces at the same temperature.

If there are sufficient air and water vapor present in the MCO to sustain the reaction, the fuel will be above the ignition temperature of the fuel based on the McGillivary rate equation and the assumption that the fuel reaction surface area is equal to the geometric surface area of declad fuel. Additional steps will have to be taken to lower the temperature of the fuel within the MCO. These may include:

1. Inerting the MCO with a higher conductivity, non-reacting gas such as helium.

2. Increasing the emissivity of the $M C O$ and tube surfaces by oxidizing them at high temperature or coating them with a high emissivity paint.

3. Assuring that the fuel has less reaction surface area than the geometric surface area of completely declad fuel.

4. Enhancing convective heat transfer within the MCO.

5. Reducing the gap between the MCO and the tube.

6. Decreasing the number of fuel assemblies in each basket (i.e., reduce the decay heat load).

\subsubsection{Parameter Sensitivities}

The main parameters that effect the ignition temperature of the fuel are listed below. Where possible, parametric calculations have been performed to 
WHC-SD-WM-ER-525

Rev. 0

evaluate the relative order of magnitude effect each of these parameters could have on the fuel temperature. Each calculation will not be presented here but the relative sensitivity of each parameter is given in terms of the ignition temperature variation caused by the indicated variation in the parameter.

- Decay Power. $39 \%$ reduction in power results in a $\Delta T$ of $22^{\circ} \mathrm{K}$

- Emissivities. Range of 0.34 to 0.7 results in a $\Delta \mathrm{T}$ of $55^{\circ} \mathrm{K}$

- Geometry and Environment. Cask versus Storage Tube Geometry results in a $\Delta T$ of $40^{\circ} \mathrm{K}$. Factors that affect this parameter are:

- Convective heat transfer in CSB

- Outside Diameter of storage tube or shipping cask

- Reacting Surface Area. Ignition occurs at $3.3 \times$ geometric surface area of completely declad fuel when the average decay heat (426W) MCO is stored in a cask with air in the cask and MCO and the ambient temperature is $100^{\circ} \mathrm{F}$. Factors that affect this parameter are:

- Damage due to corrosion

- Cleaning methods

- Handling and stacking of fuel

- Fuel rubble.

- Convective Cooling results in a $\Delta T$ of $20^{\circ} \mathrm{K}$

- Dewatering results in a $\Delta T$ of $57^{\circ} \mathrm{K}$. Factors that affect this parameter are:

- Amount of water remaining

- Heat up time before vacuum is applied

- Local Ignition Effects

- Integrity of the purge system

- Cold vacuum drying

- Integrity of Cask Cooling/Heating System. $\Delta T 57^{\circ} \mathrm{K}$

- Maximum basket power. $\Delta \mathrm{T}^{2} 20^{\circ} \mathrm{K}$

- Local Ignition Effects

- Integrity of the vacuum system

- Lack of convective cooling. $\Delta T 20^{\circ} \mathrm{K}$

- Amount of water remaining

- Vacuum achieved and what rate

- Storage Tube Performance

- Effectiveness of Basin Convective Cooling

- Emissivities. $\Delta \mathrm{T} 30^{\circ} \mathrm{K}$

- Maximum basket power. $\Delta \mathrm{T} 36^{\circ} \mathrm{K}$

- Local Ignition Effects

- Effectiveness of vacuum drying and hot conditioning in removing water from fuel

- Rate Law

- Steam pressure and avajiability

- Oxygen availability

- Local ignition conditions

- Hydride concentrations in uranium 
WHC-SD-WM-ER-525

Rev. 0

- Fuel irradiation

- Fuel temperature

The results of the simulations that provided the estimate of changes in ignition temperature are presented in Tables 5-8 and 5-9.

Both Tables 5-8 and 5-9 are based on maintaining a peak fuel temperature of 415.2 "K. This peak fuel temperature is associated with a "runaway" condition, hence, the ambient temperature represents the minimum ignition temperature. Tables 5-8 and 5-9 reflect the limiting conditions associated with the CSB storage tubes.

By inspection, Table 5-8 indicates that a change from a high decay heat load of $2000 \mathrm{~W} / \mathrm{m}^{3}$ of fuel to a lower decay heat load of $1228 \mathrm{~W} / \mathrm{m}^{3}$ of fuel results in a $21.6^{\circ} \mathrm{K}$ increase in the ignition temperature. Changing the emissivities to lower, more conservative values decreases the ignition temperature by almost $55^{\circ} \mathrm{K}$. The ignition temperature reached a minimum value of $15.3^{\circ} \mathrm{F}\left(263.9^{\circ} \mathrm{K}\right)$ for a high decay heat load of $2000 \mathrm{~W} / \mathrm{m}^{3}$, low emissivity values and no radiative heat losses from the $O D$ of the storage tube.

Table 5-8. Ignition Temperature (To) Sensitivity for Various Cases.

\begin{tabular}{|c|c|c|c|}
\hline Conditions & $\mathrm{T}_{\infty}$ & $\begin{array}{l}\text { Tmco } \\
\left({ }^{\circ} \mathrm{K}\right)\end{array}$ & $\begin{array}{c}\text { Tpeak } \\
\left({ }^{\circ} \mathrm{K}\right)\end{array}$ \\
\hline Storage Tube, $P=2000 \mathrm{w} / \mathrm{m}^{3}$, high 6 & $\begin{array}{r}320.6 \\
\left(117.4{ }^{\circ} \mathrm{F}\right) \\
\end{array}$ & 381.6 & 415.2 \\
\hline Storage Tube, $P=1228 \mathrm{~W} / \mathrm{m}^{3}$, high $\epsilon$ & $\begin{array}{r}342.2 \\
\left(156.3^{\circ} \mathrm{F}\right) \\
\end{array}$ & 390.3 & 415.2 \\
\hline Storage Tube, $P=1228 \mathrm{w} / \mathrm{m}^{3}$, low $\epsilon$ & $\begin{array}{r}287.5 \\
\left(57.0^{\circ} \mathrm{F}\right) \\
\end{array}$ & 357.8 & 415.2 \\
\hline $\begin{array}{l}\text { Storage Jube, } P=2000 \mathrm{~W} / \mathrm{m}^{3} \text {, high } \epsilon \\
\text { with radiant heat loss }\end{array}$ & $\begin{array}{r}336.5 \\
\left(146.3^{\circ} \mathrm{F}\right) \\
\end{array}$ & 381.6 & 415.2 \\
\hline Shipping Cask, $P=1228 \mathrm{w} / \mathrm{m}^{3}$, low $\epsilon$ & $\begin{array}{r}310.9 \\
\left(100.0^{\circ} \mathrm{F}\right) \\
\end{array}$ & 338.0 & 366.0 \\
\hline Shipping Cask, Dewatering, low $6, P=1228 \mathrm{w} / \mathrm{m}^{3}$ & -- & $\left(185.5^{\circ} \mathrm{F}\right)$ & 415.2 \\
\hline $\begin{array}{l}\text { Storage Tube, } P=2000 \mathrm{~W} / \mathrm{m}^{3}, \text { low } 6 \\
\text { No radiant heat loss }\end{array}$ & $\begin{array}{r}263.9 \\
\left(15.3^{\circ} \mathrm{F}\right)\end{array}$ & 359.3 & 415.2 \\
\hline
\end{tabular}

NOTE: High $\epsilon$ is 0.7 for the fuel, MCO, tube and cask.

Low $\epsilon$ is 0.4 for the fuel, 0.2 for the MCO and tube and inside of cask, and 0.55 for the outside of cask.

Table 5-9 presents the results of a series of ignition temperature analyses for various changes to the storage tube geometry and its associated heat transfer assumptions.

The baseline storage ignition temperature was assumed to be $344.6{ }^{\circ} \mathrm{K}$ $\left(160.5^{\circ} \mathrm{F}\right)$. By correcting the geometry for the storage tube to account for a 1.5 inch gap, rather than a 1.0 inch gap, the ignition temperature decreases to $341.0^{8} \mathrm{~K}\left(154.1^{\circ} \mathrm{F}\right)$. By providing temperature dependent air properties, the ignition decreases slightly to $338.5^{\circ} \mathrm{K}\left(149.6^{\circ} \mathrm{K}\right)$. The ignition 
temperature decreases approximately $20^{\circ} \mathrm{K}$ when no radiative heat transfer from the $O D$ of the storage tube is allowed. Correcting for the actual A/V of $220 \mathrm{~m}^{-1}$, raises the ignition temperature by $2^{\circ} \mathrm{K}$. Using the lower emissivities and all of the above corrections results in an ignition temperature of $15.3^{\circ} \mathrm{F}$ $\left(263.9^{\circ} \mathrm{F}\right)$, which is consistent with Table 5-8.

Table 5-9. Ignition Temperature (To) Versus

Storage Tube Geometry Variations.

\begin{tabular}{||l|c|c|c|c||}
\hline \multicolumn{1}{|c|}{ Case } & $\begin{array}{c}\text { To } \\
\left({ }^{\circ} \mathrm{K}\right)\end{array}$ & $\begin{array}{c}\text { Tube } \\
\text { Temp } \\
\left({ }^{\circ} \mathrm{K}\right)\end{array}$ & $\begin{array}{c}\text { MCO } \\
\text { Temp } \\
\left({ }^{\circ} \mathrm{K}\right)\end{array}$ & $\begin{array}{c}\text { Max } \\
\text { Fuel } \\
\text { Temp } \\
\left({ }^{\circ} \mathrm{K}\right)\end{array}$ \\
\hline \hline$Q=2000 \mathrm{~W} / \mathrm{m}^{3}$ cases: & & & & \\
\hline Baseline storge tube ignition temp & 344.6 & 358.1 & 381.0 & 415.2 \\
\hline Correct geometry - for storage tube & 341.0 & 355.3 & 380.0 & 415.2 \\
\hline Temp dep air prop & 338.5 & 356.3 & 380.9 & 415.2 \\
\hline No radiation from storage tube & 318.6 & 356.3 & 380.9 & 415.2 \\
\hline Corrected fuel A/V $=220 \mathrm{~m}^{-1}$ & 320.6 & 357.8 & 381.7 & 415.2 \\
\hline Low bound on $\epsilon$ & 263.9 & 298.2 & 359.3 & 415.2 \\
\hline
\end{tabular}

Clearly, the CSB storage tube environment results in higher peak fuel temperatures or the minimum ignition temperatures. Given unlimited reactants and nominal conditions, the CSB storage tube environment will undergo a "runaway" temperature excursion. The presence of limited amounts of residual reactants, such as frozen water from the warm vacuum drying process, will result in rapid chemical reactions with limited temperature excursions. The probability of fuel igniting is minimized by maintaining the fuel at the lowest possible temperatures. Therefore, actual parameters used in the design of the fuel storage facility should be chosen to minimize the fuel temperature. It is recommended that helium be used as the back fill gas for the MCO and storage tube configuration. If leakage and cost considerations prevent the use of helium, then atl of the MCO and storage surfaces should be conditioned to increase emissivities into the range of 0.7 to 0.8 .

\subsection{SEMI-INFINITE PLATE MODEL - CHEMICAL REACTION SENSITIVITIES}

The pyrophoricity sensitivity studies of unirradiated uranium are continuing. The following results should be considered preliminary. It is anticipated that an addendum to this report will be issed documenting the final results of the pyrophoricity sensitivity studies.

Transient calculations were performed in each case and allowed to proceed until a steady-state condition was reached or until the resulting temperatures were obviously unstable. Steady-state calculations could not be performed because it was not known "a priori" whether the boundary conditions would result in a stable condition or an unstable, runaway condition. 
WHC-SD-WM-ER-525

Rev. 0

The results of the oxygen-free calculations show that the uranium plate reaches a stable condition when the boundary condition is $214^{\circ} \mathrm{F}$ but goes unstable when the boundary condition is $232^{\circ} \mathrm{F}$. When the hydrogen solubility coefficient is increased by a factor of 10 , the oxygen-free case reaches a stable condition when the boundary condition is $61^{\circ} \mathrm{F}$ but goes unstable when the boundary condition is $79^{\circ} \mathrm{F}$.

The results for an oxygenated atmosphere show that the uranium plate reaches a stable condition when the boundary condition is $179^{\circ} \mathrm{F}$ but goes unstable when the boundary condition is $187^{\circ} \mathrm{F}$. When the hydrogen solubility coefficient is increased by a factor of 10, the oxygenated case reaches a stable condition when the boundary condition is $80^{\circ} \mathrm{F}$ but goes unstable when the boundary condition is $134^{\circ} \mathrm{F}$.

\subsection{STORAGE TUBE MCO GAP CIRCULATION MODEL}

At steady state the fluid flow within the gap is calculated to be laminar with a maximum velocity on the order of $0.04 \mathrm{~m} / \mathrm{s}$. Because of the large aspect ratio of the gas gap (length to width) the flow field is calculated to be made up of regions of relatively uniform flow in the vertical direction which break up into smaller intervening regions of recirculation. The uniform flow regions support velocity profiles which are either up or down along the surface of the MCO with the opposite flow direction along the surface of the storage tube.

The temperature gradient across the air gap is calculated to be on the order of $30^{\circ} \mathrm{K}$ with variations induced by the convective flow patterns. In regions where the flow field is relatively uniform and parallel with the MCO surface the temperature gradient across the gap is very uniform. In regions, where recirculation flow results in irregular velocity fields or velocity fields that are broken up into smaller eddies, the temperature gradients become more non-uniform. Those regions of the MCO surface that are adjacent to flow field recirculation exhibit considerable temperature fluctuation while regions adjacent to more uniform flow exhibit a more uniform temperature profile.

The mixing of a contaminant (hydrogen) species was evaluated by assuming that a small quantity of hydrogen gas leaks past the lid of the lower MCO into the gas space. The duration of the leak was assumed to be 5 seconds. Concentration of the hydrogen gas was then tracked as it diffused and advected through the gas space over the next hour. These results indicate that significant hydrogen concentrations will not reach the top of the gas space until more than a half hour after initiation of the leak and will require more than an hour to reach the bottom. The difference in arrival times is due to larger advective flows in the upper portion of the gas space. The time required to completely mix hydrogen with the trapped air is estimated to require on the order of two and a half to three hours. 
WHC-SD-WM-ER-525

Rev. 0

Figure 5-1. Center and Peak Fuel Temperature Node Numbers and Locations for $30^{\circ}$ Sector Model of MCO and Shipping Cask With

Mark Ia Fuel Assemblies.

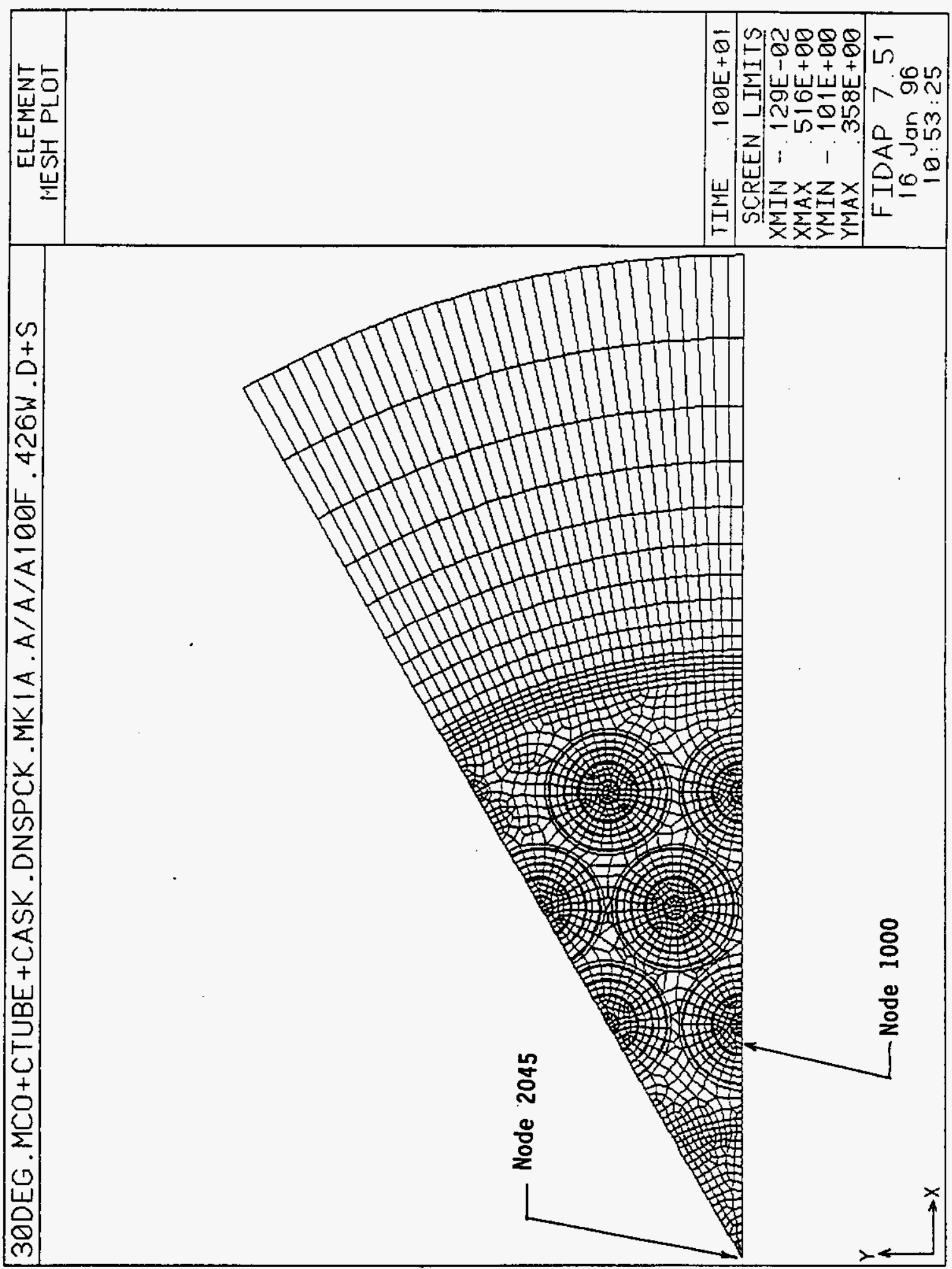


WHC-SD-WM-ER-525

Rev. 0

Figure 5-2. Peak Fuel Temperature Versus Time for a MCO and Shipping Cask With Mark Ia Fuel (Decay Heat Only).

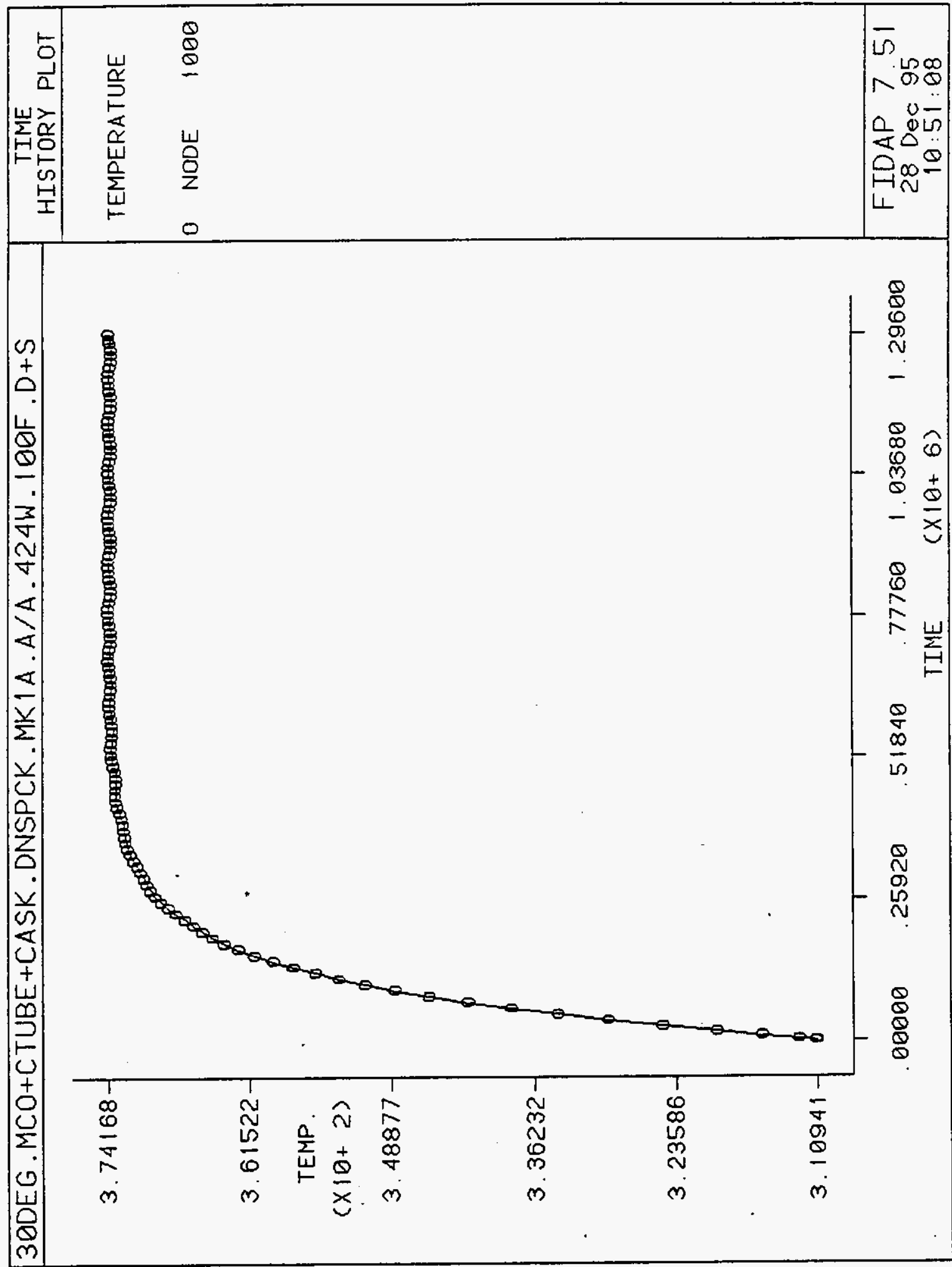


WHC-SD-WM-ER-525

Rev. 0

Figure 5-3. Radial Temperature Contour Plot for a MCO and Shipping Cask With Mark Ia Fuel After 15 Days (Decay Heat Only).

\begin{tabular}{|c|c|c|c|c|c|}
\hline 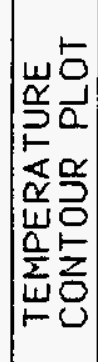 & 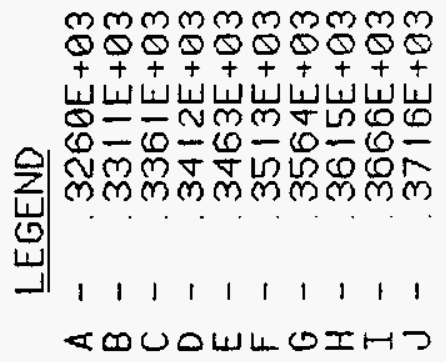 & 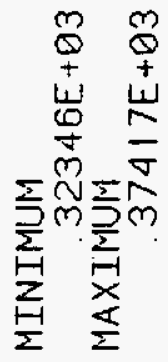 & 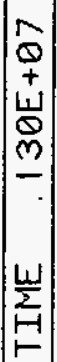 & 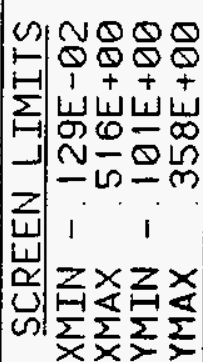 & 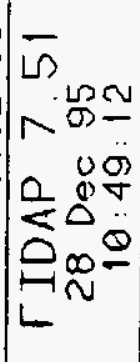 \\
\hline
\end{tabular}

en

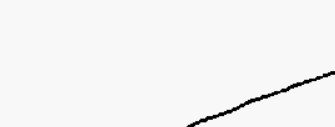

岕

-

$\frac{3}{5}$

v

4

$<$

$\leq$

$\frac{x}{\Sigma}$

U

을

$\frac{1}{0}$

$\frac{1}{\cos }$

ड

4.

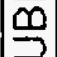

5

+

$\frac{1}{\Sigma}$

(1)

0 

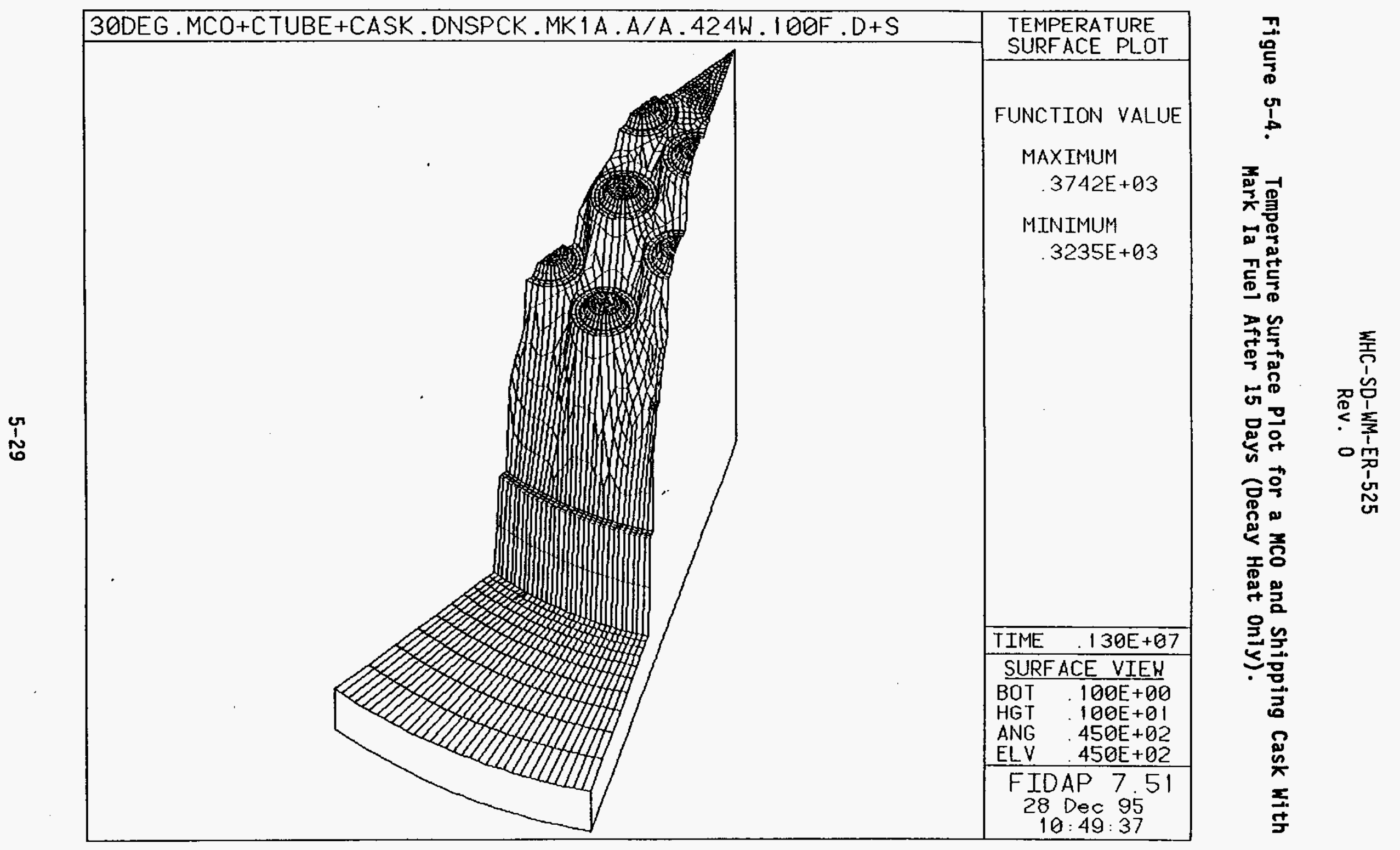


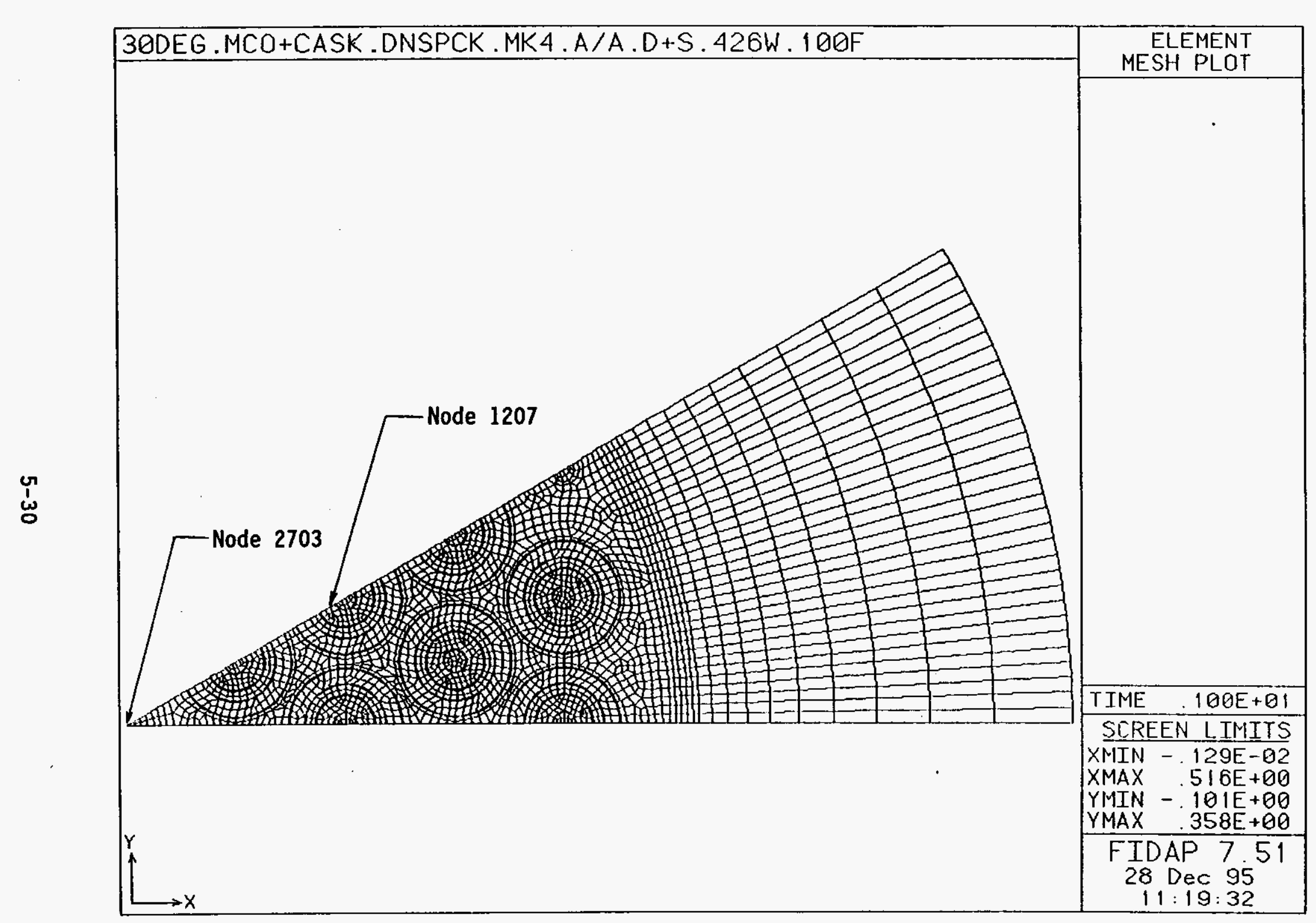

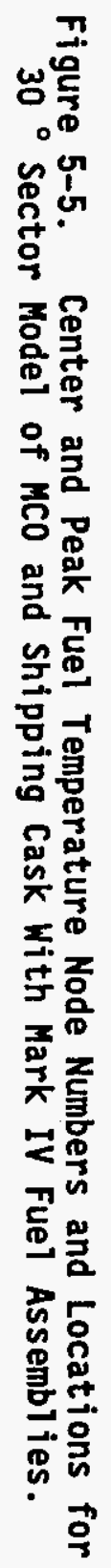


WHC-SD-WM-ER-525

Rev. 0

Figure 5-6. Peak Fuel Temperature Versus Time for a MCO and Shipping Cask With Mark IV Fuel (Decay Heat Only).

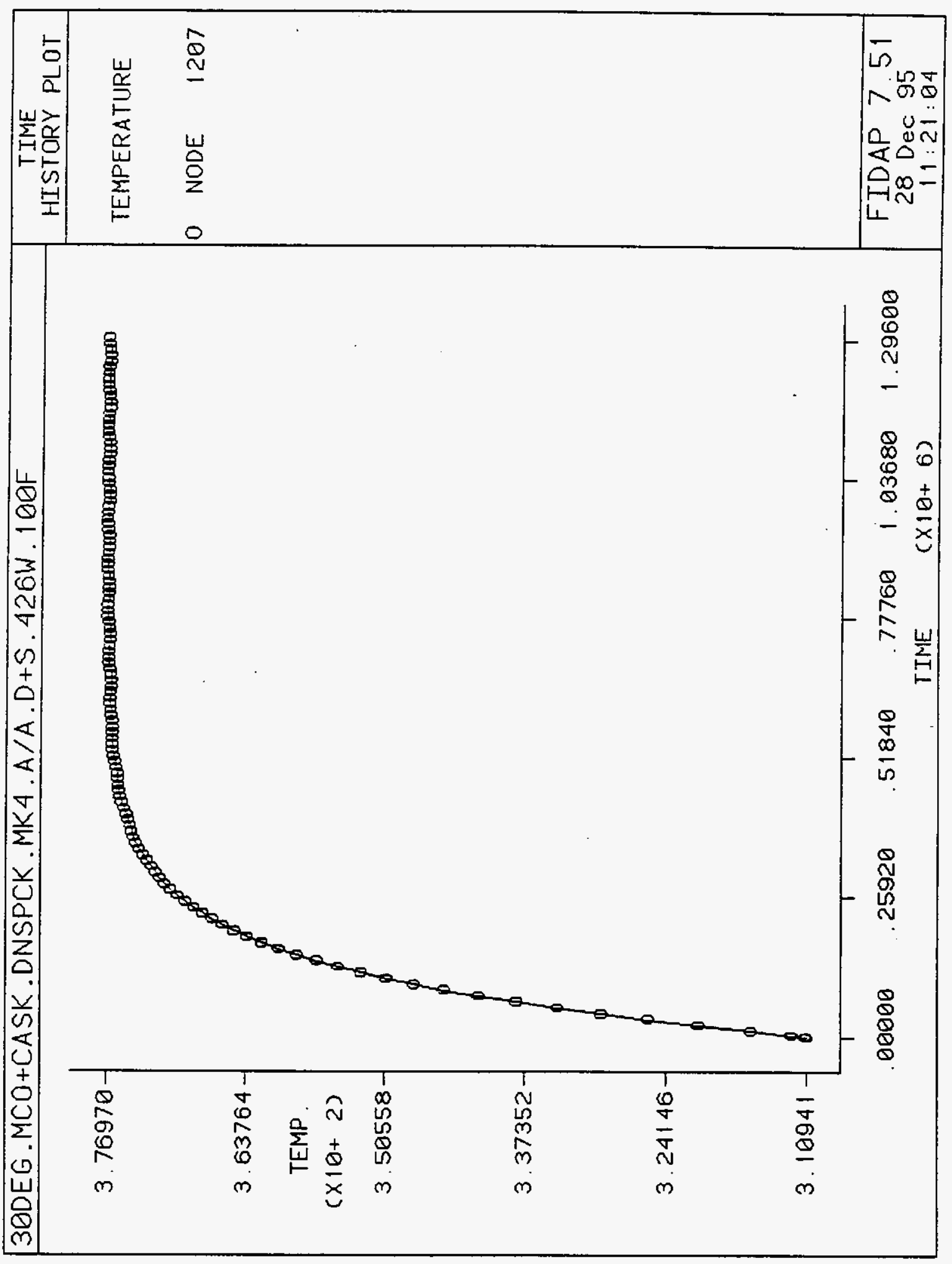


Figure 5-7. Radial Temperature Contour Plot for a MCO and Shipping Cask With Mark IV Fuel After 15 Days (Decay Heat Only).

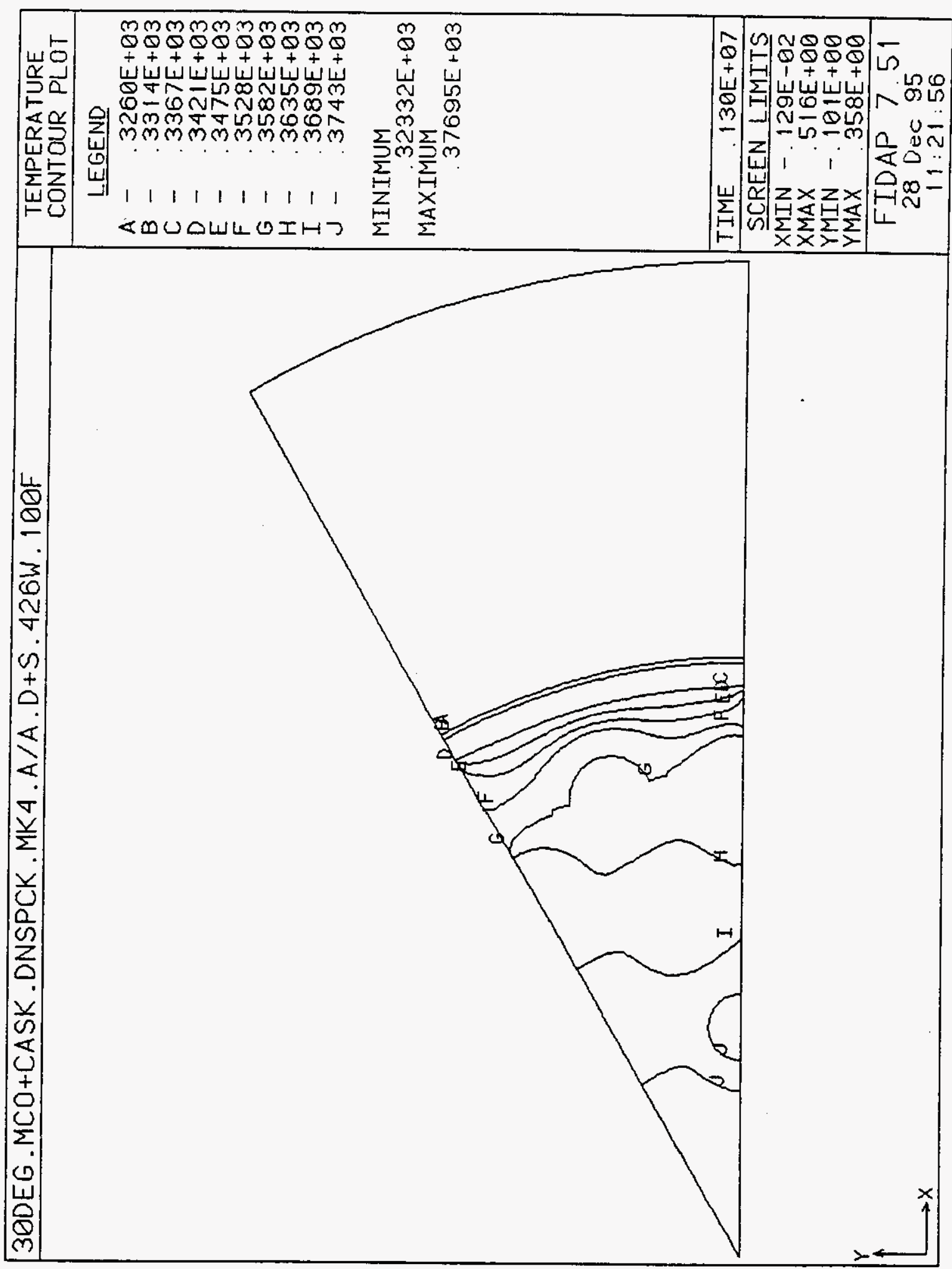




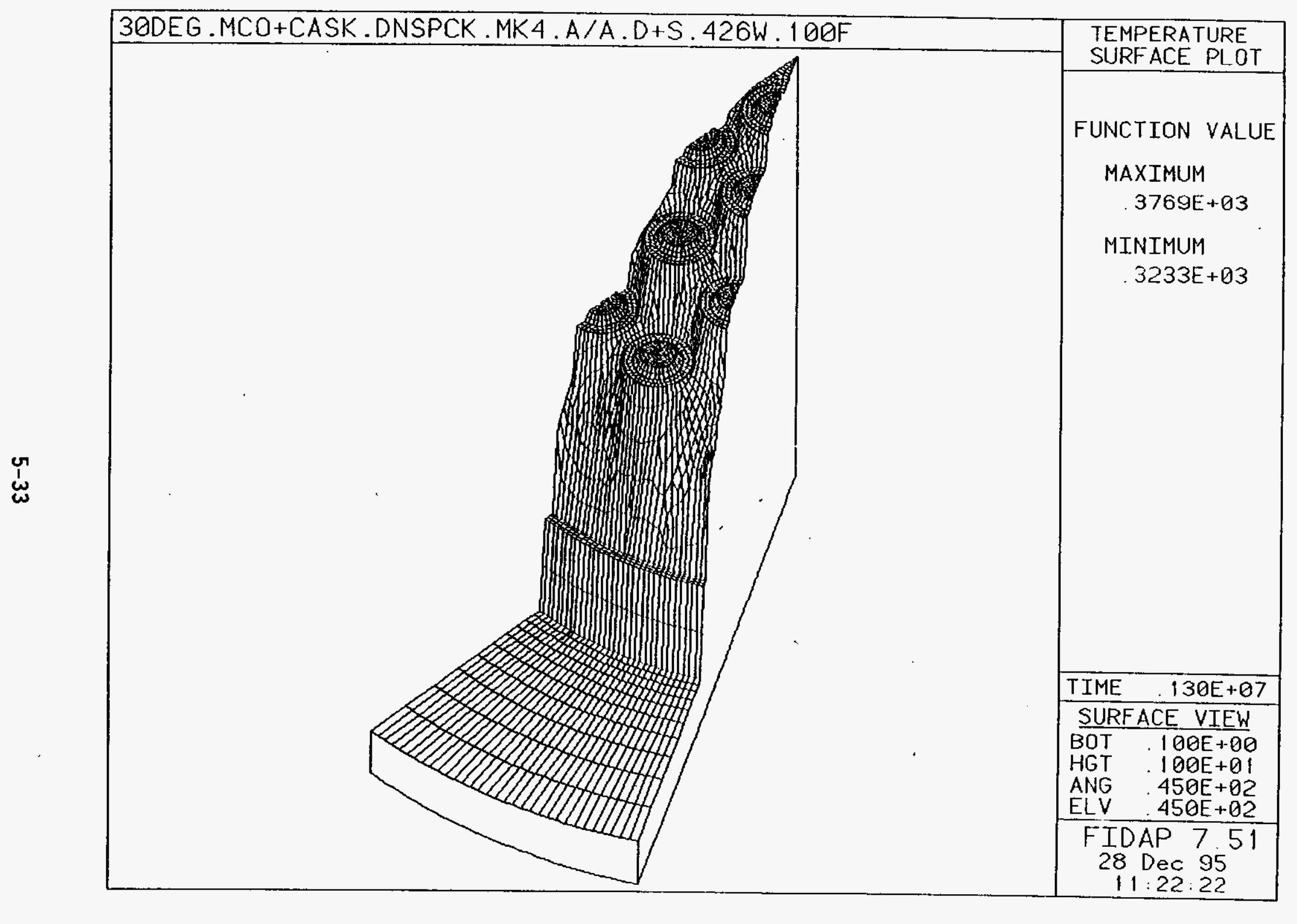


WHC-SD-WM-ER-525

Rev. 0

Figure 5-9. Center and Peak Fuel Temperature Node Numbers and Locations for $30^{\circ}$ Sector Model of MCO and Storage Tube With Mark IV Fuel Assemblies.

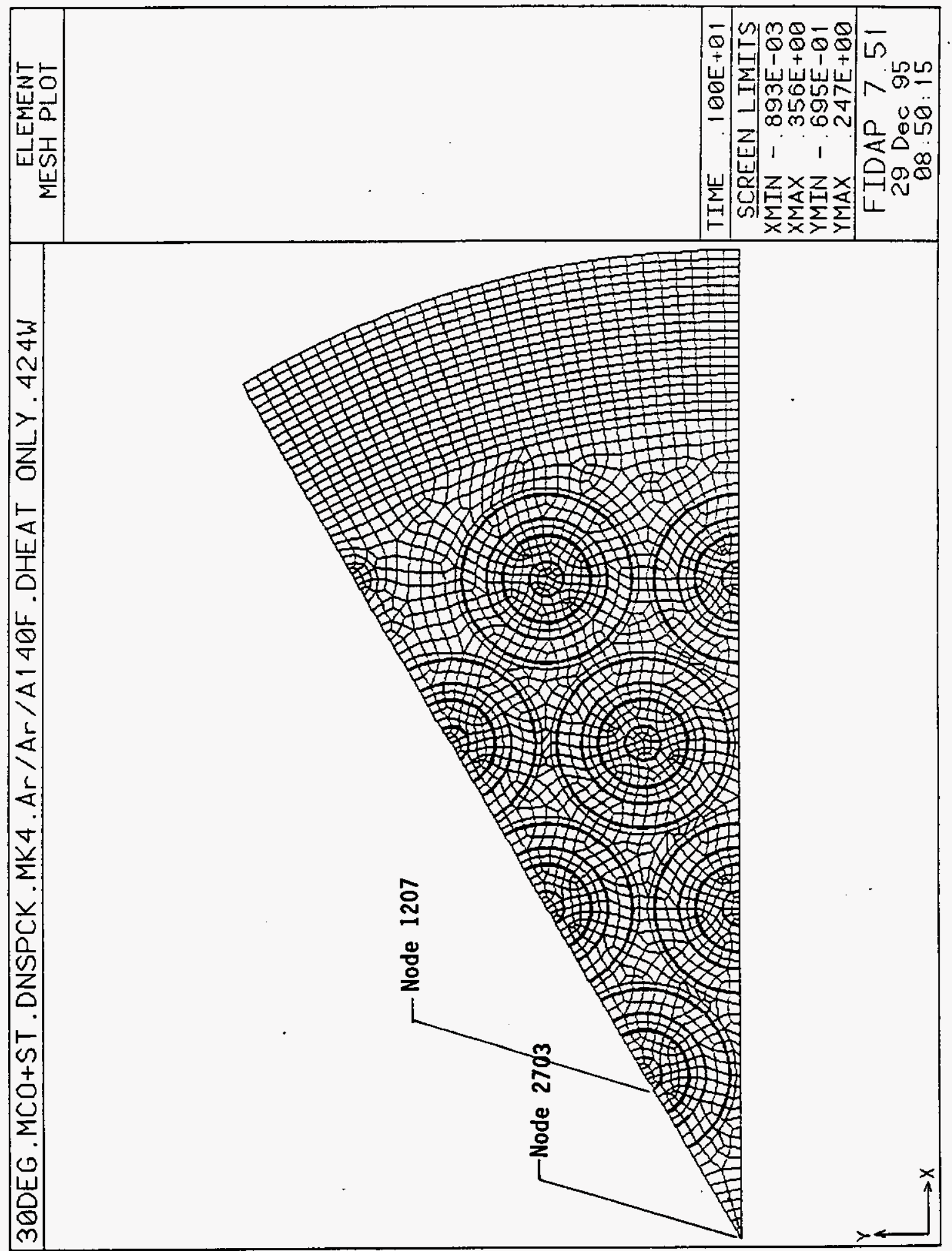


WHC-SD-WM-ER-525

Rev. 0

Figure 5-10. Peak Fuel Temperature Versus Time for a MCO and Storage Tube With Mark IV Fuel (Decay Heat Oniy).

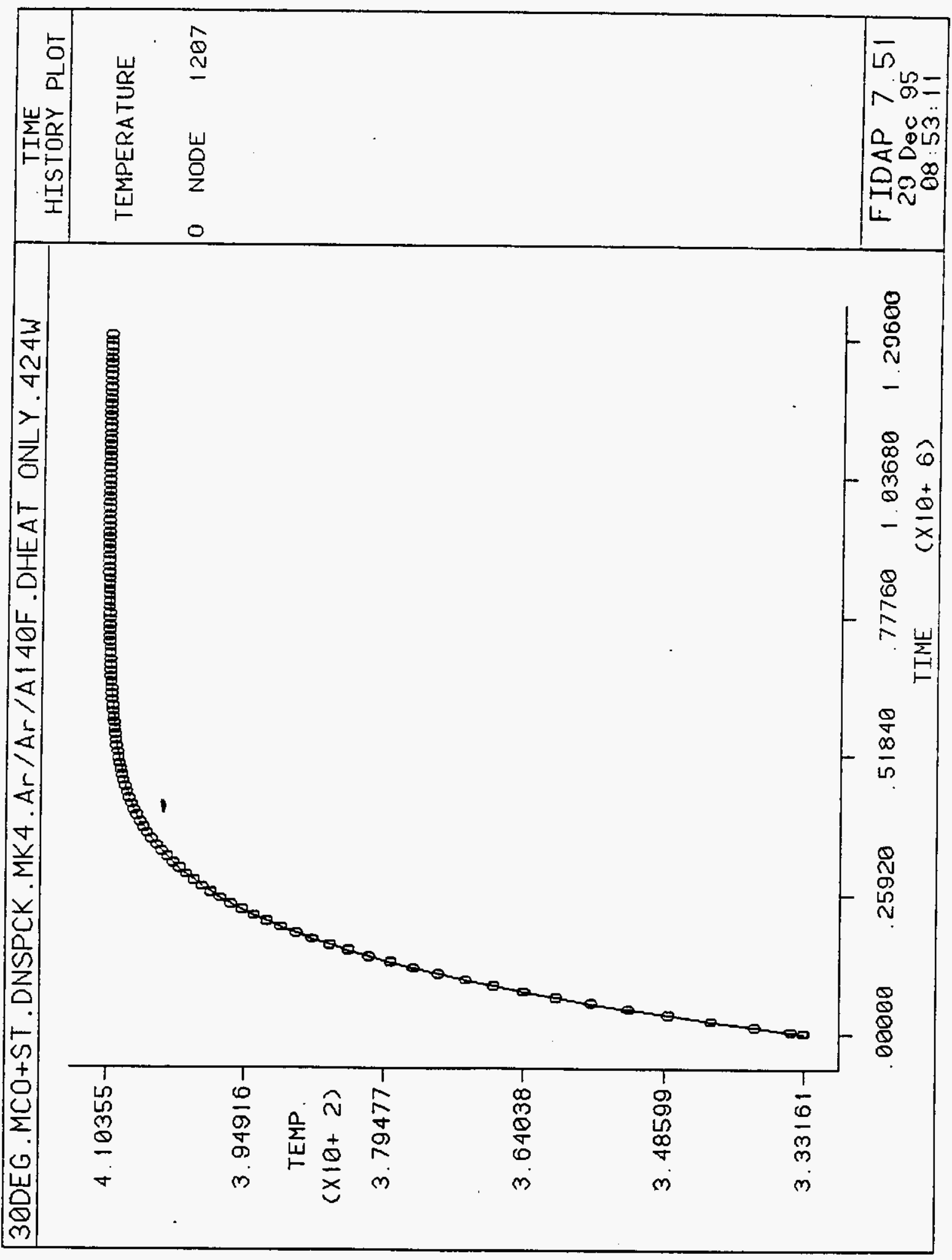




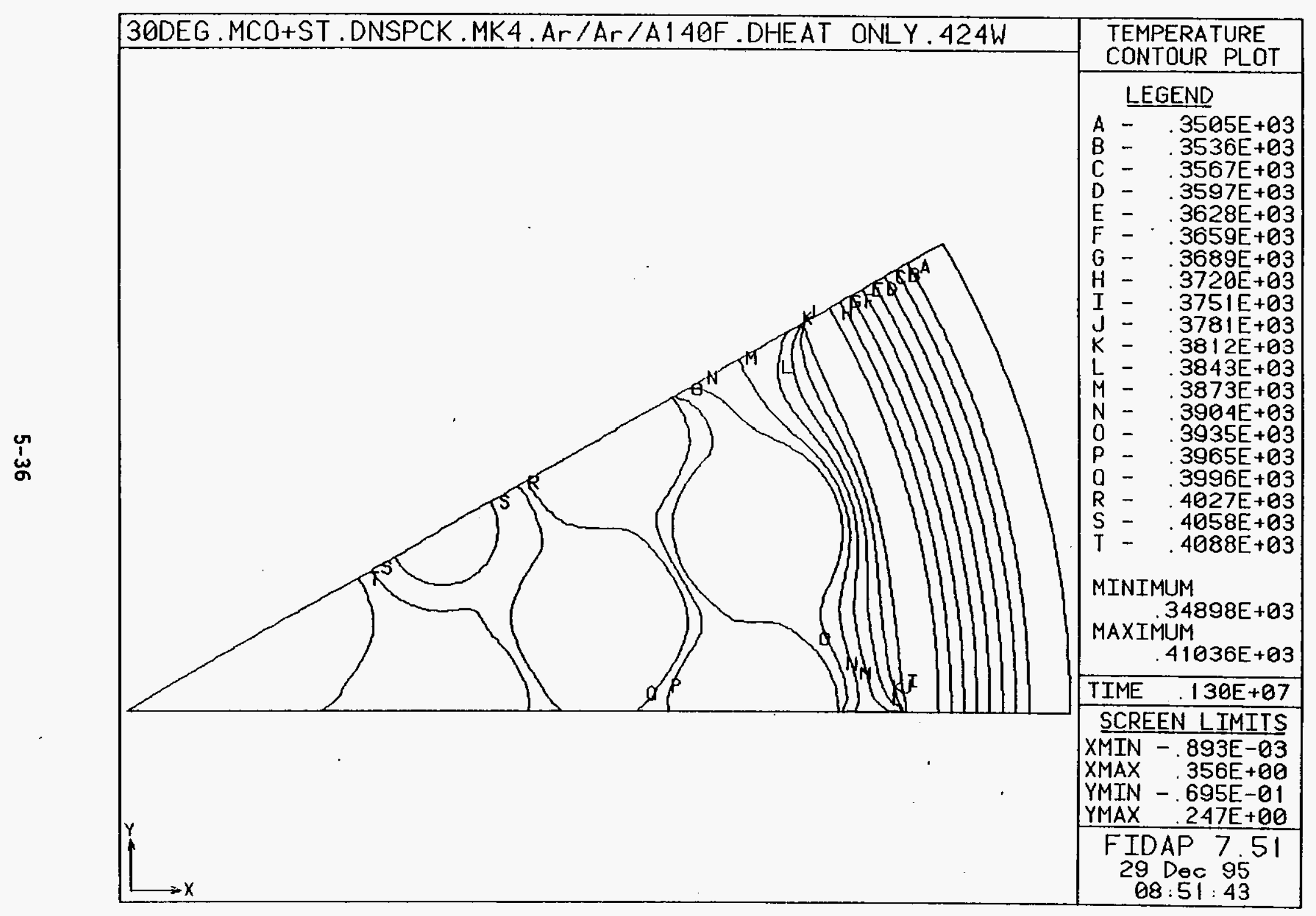



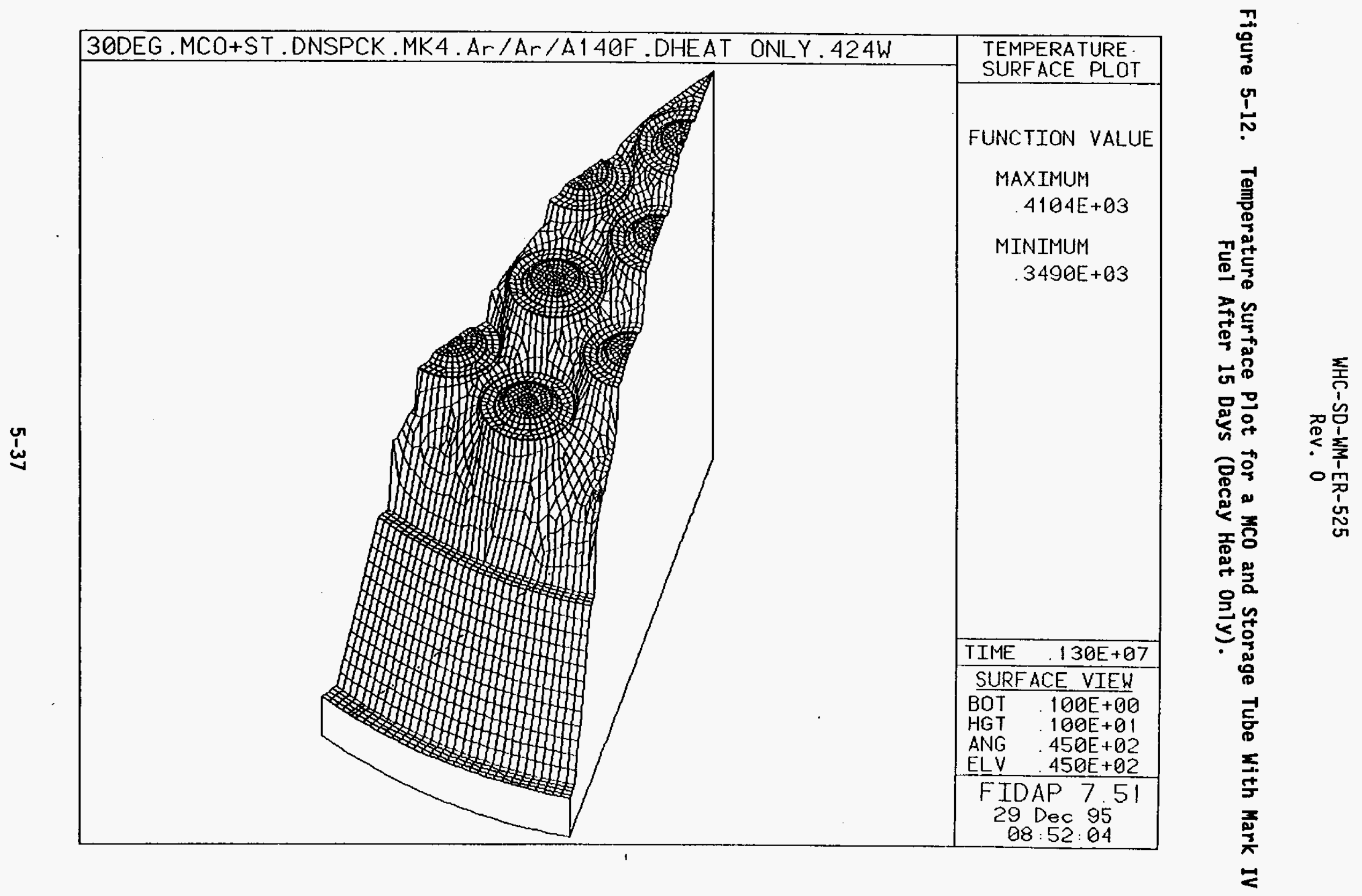
WHC-SD-WM-ER-525

Rev. 0

Figure 5-13. Peak Fuel Temperature Versus Time for Initial Fuel Loading for $K$ Basin Ambient Water Temperature of $10{ }^{\circ} \mathrm{C}\left(50^{\circ} \mathrm{F}\right.$ ) (Nominal Decay Heat + Chemical Heat (Tyfield 0xygen Free)).

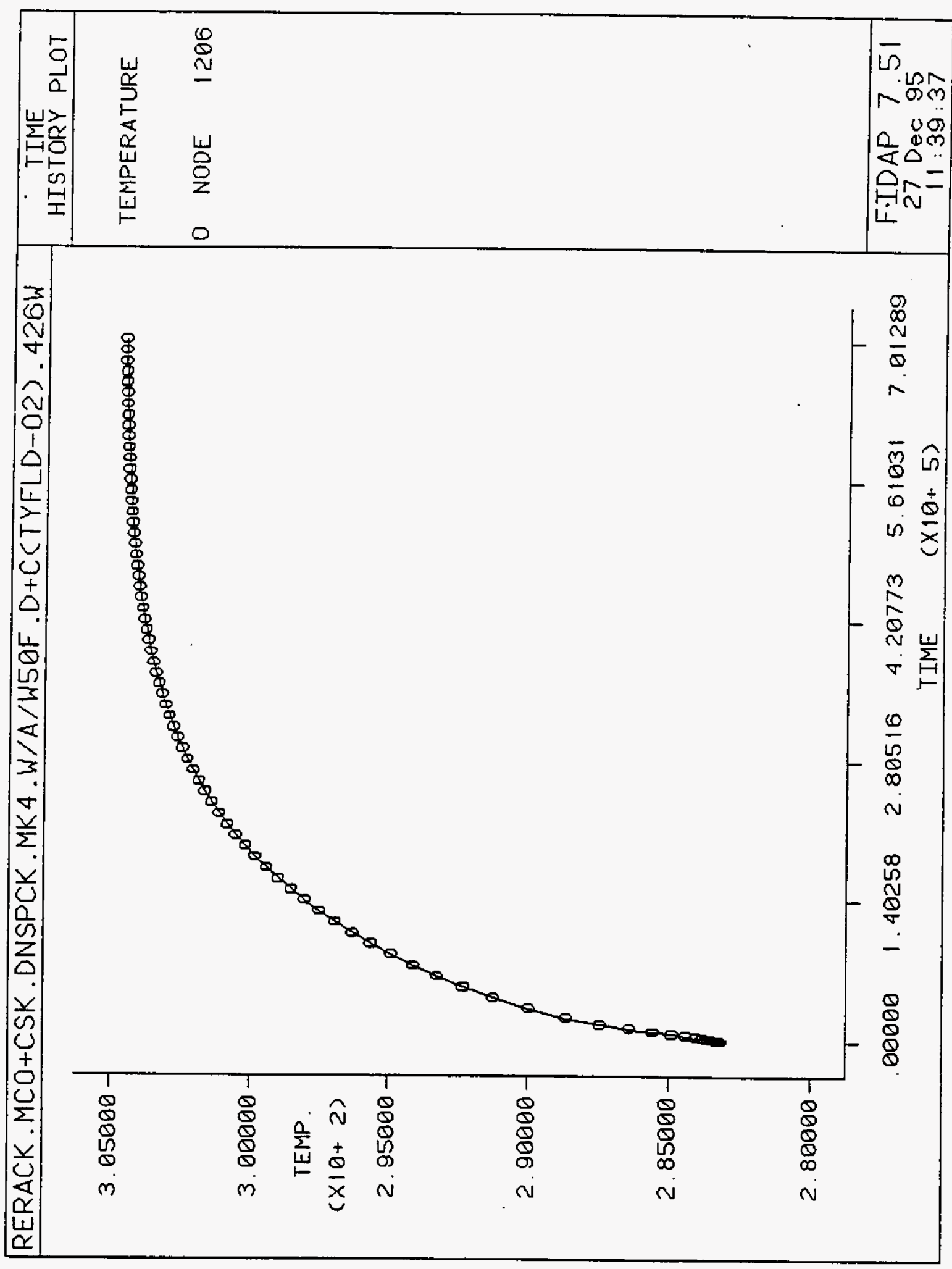


WHC-SD-WM-ER-525

Rev. 0

Figure 5-14. Peak Fuel Temperature Versus Time for Fully Loaded MCO With Water for an Ambient Air Temperature of $37.8{ }^{\circ} \mathrm{C}\left(100{ }^{\circ} \mathrm{F}\right)$

(Nominal Decay Heat + Chemical Heat (Tyfield Oxygen Free)).

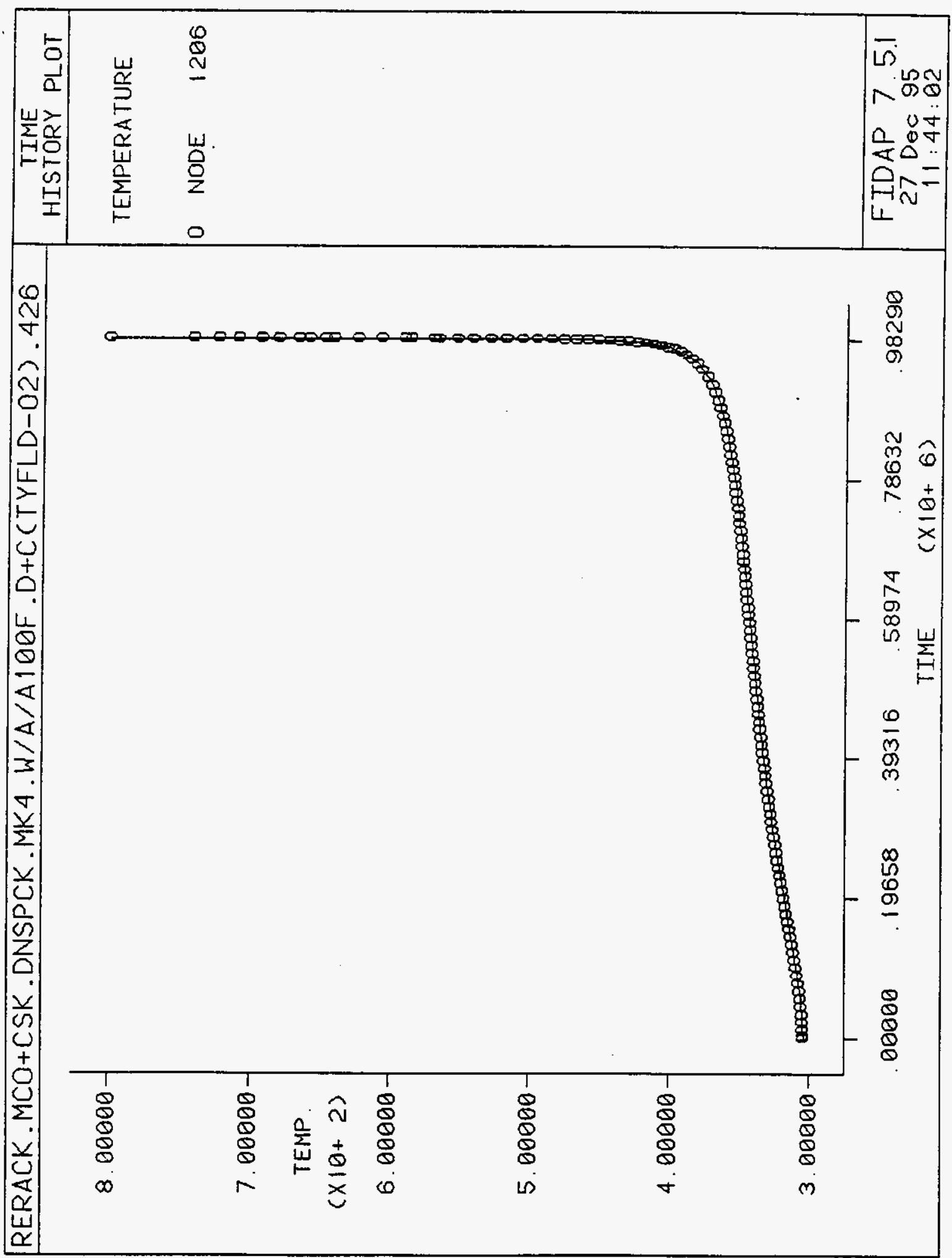


WHC-SD-WM-ER-525

Rev. 0

Figure 5-15. Peak Fuel Temperature Versus Time for Fully Loaded MCO With Water for an Ambient Air Temperature of $37.8{ }^{\circ} \mathrm{C}\left(100^{\circ} \mathrm{F}\right)$ (Nominal Decay Heat + Chemical Heat (Ritchie Oxygen Free)).

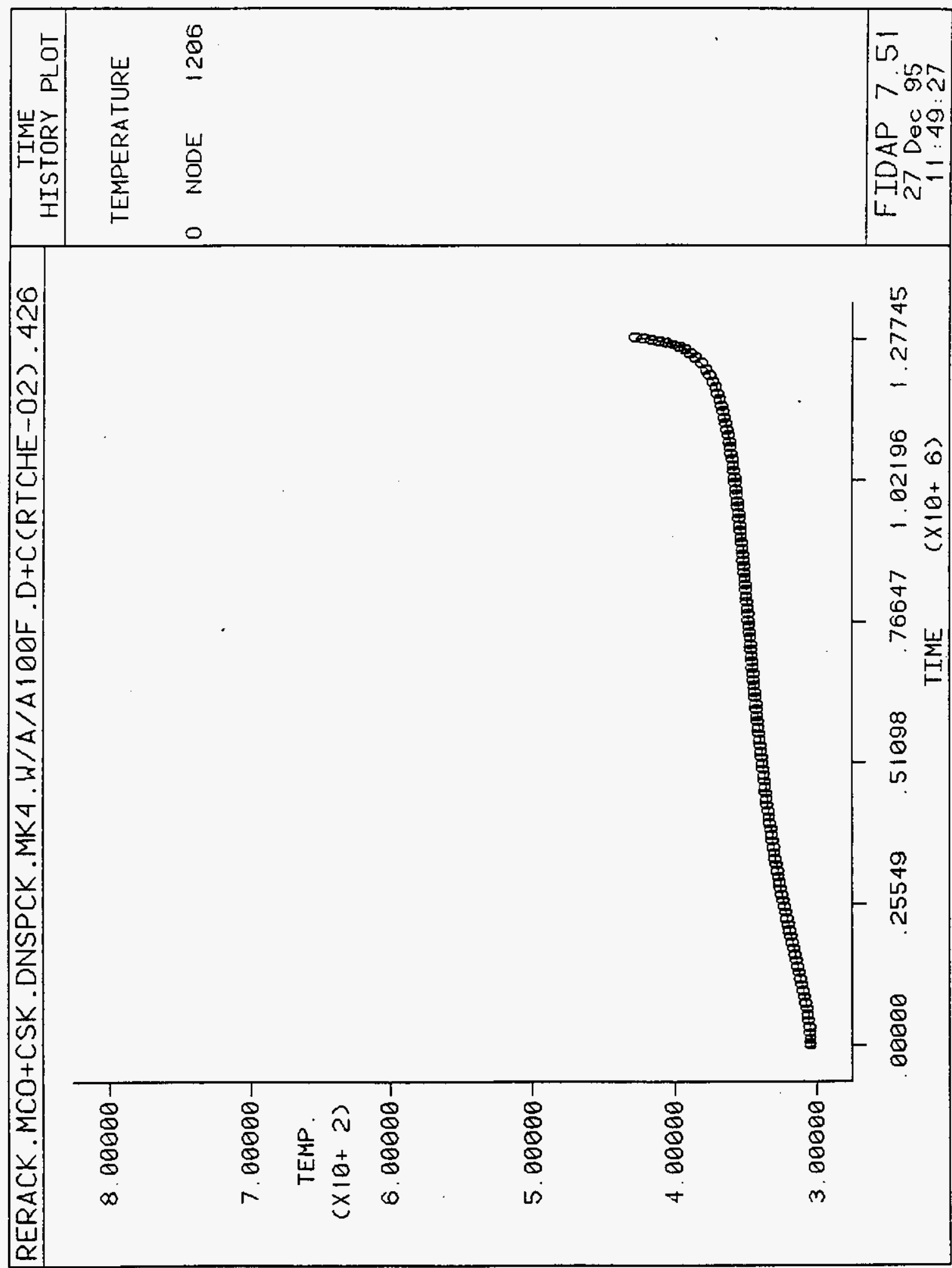


Rev. 0

Figure 5-16. Peak Fuel Temperature Versus Time for Initial Fuel Loading for $\mathrm{K}$ Basin Ambient Water Temperature of $100^{\circ} \mathrm{C}\left(50^{\circ} \mathrm{F}\right.$ ) (Nominal Decay Heat + Chemical Heat (Ritchie with Oxygen)).

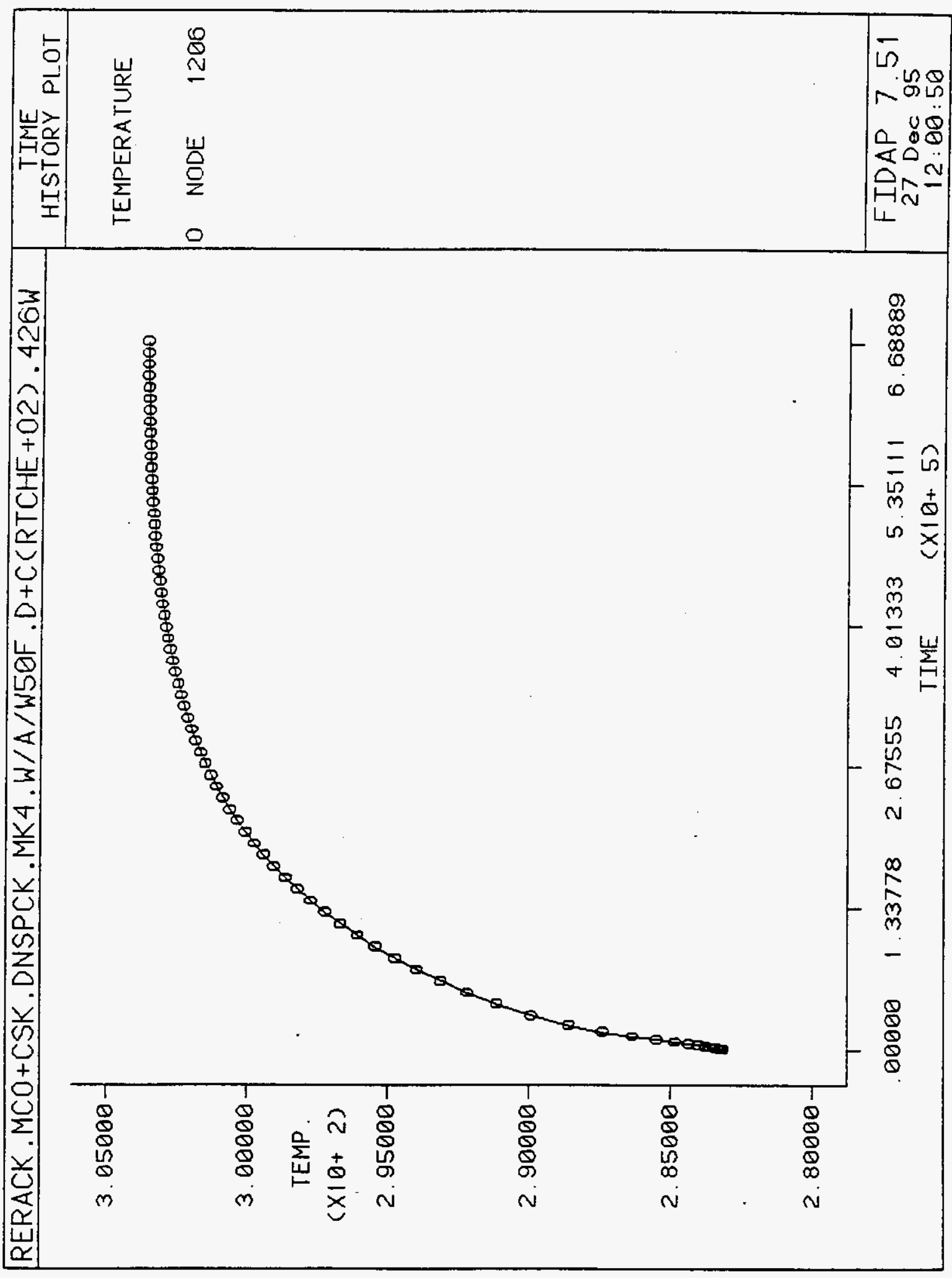


Rev. 0

Figure 5-17. Peak Fuel Temperature Versus Time for Fully Loaded MCO With Water for an Ambient Air Temperature of $37.8^{\circ} \mathrm{C}$ ( $100{ }^{\circ} \mathrm{F}$ ) (Nominal Decay Heat + Chemical Heat (Ritchie with Oxygen)).

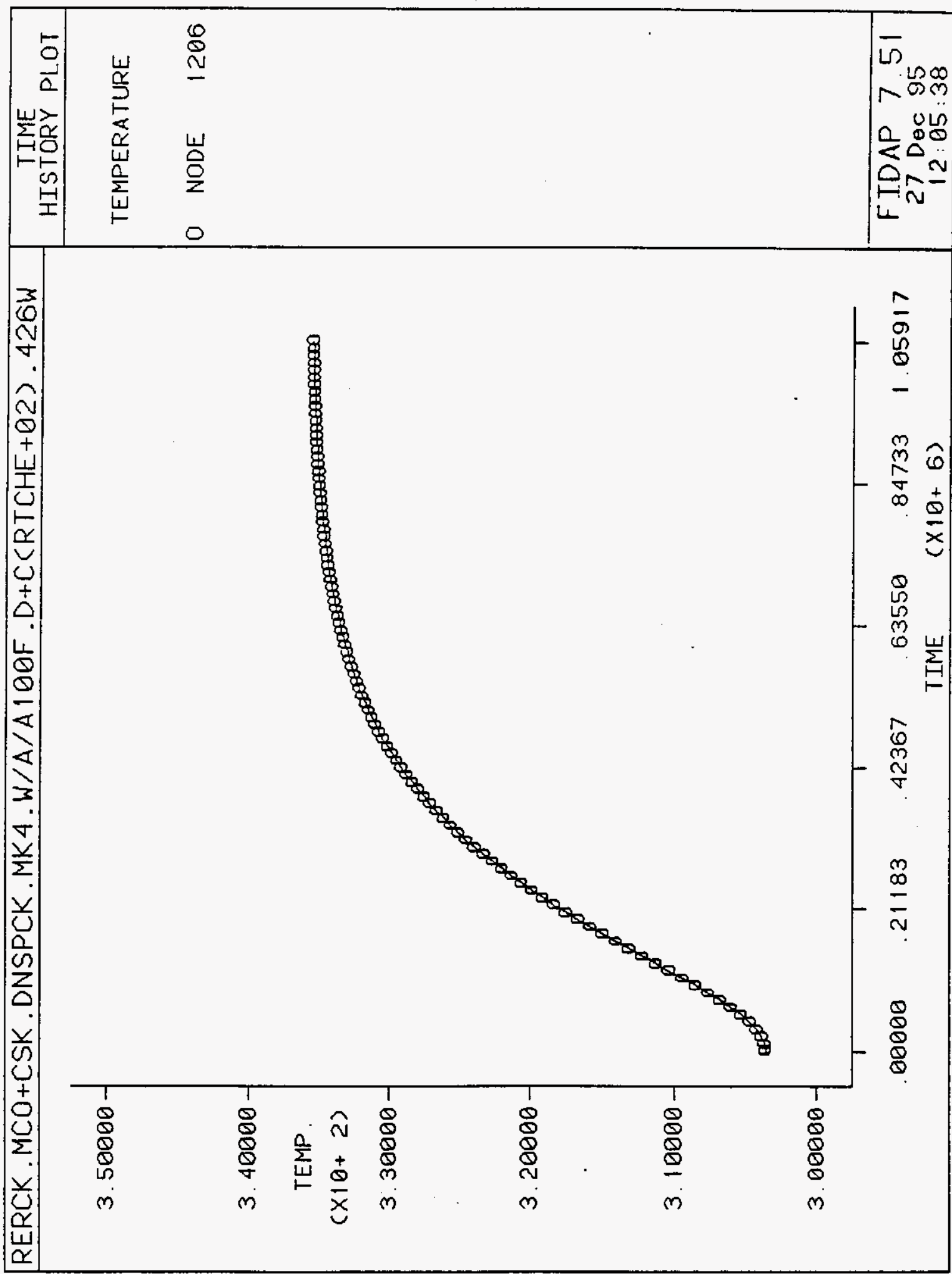


WHC-SD-WM-ER-525

Rev. 0

Figure 5-18. Peak Fuel Temperature Versus Time for Fully Loaded MCO With Water for an Ambient Air Temperatures of $37.8^{\circ} \mathrm{C}$ (100 ${ }^{\circ} \mathrm{F}$ ) (Normal Decay Heat + Solar Heat + Chemical Heat (Ritchie with Oxygen)).

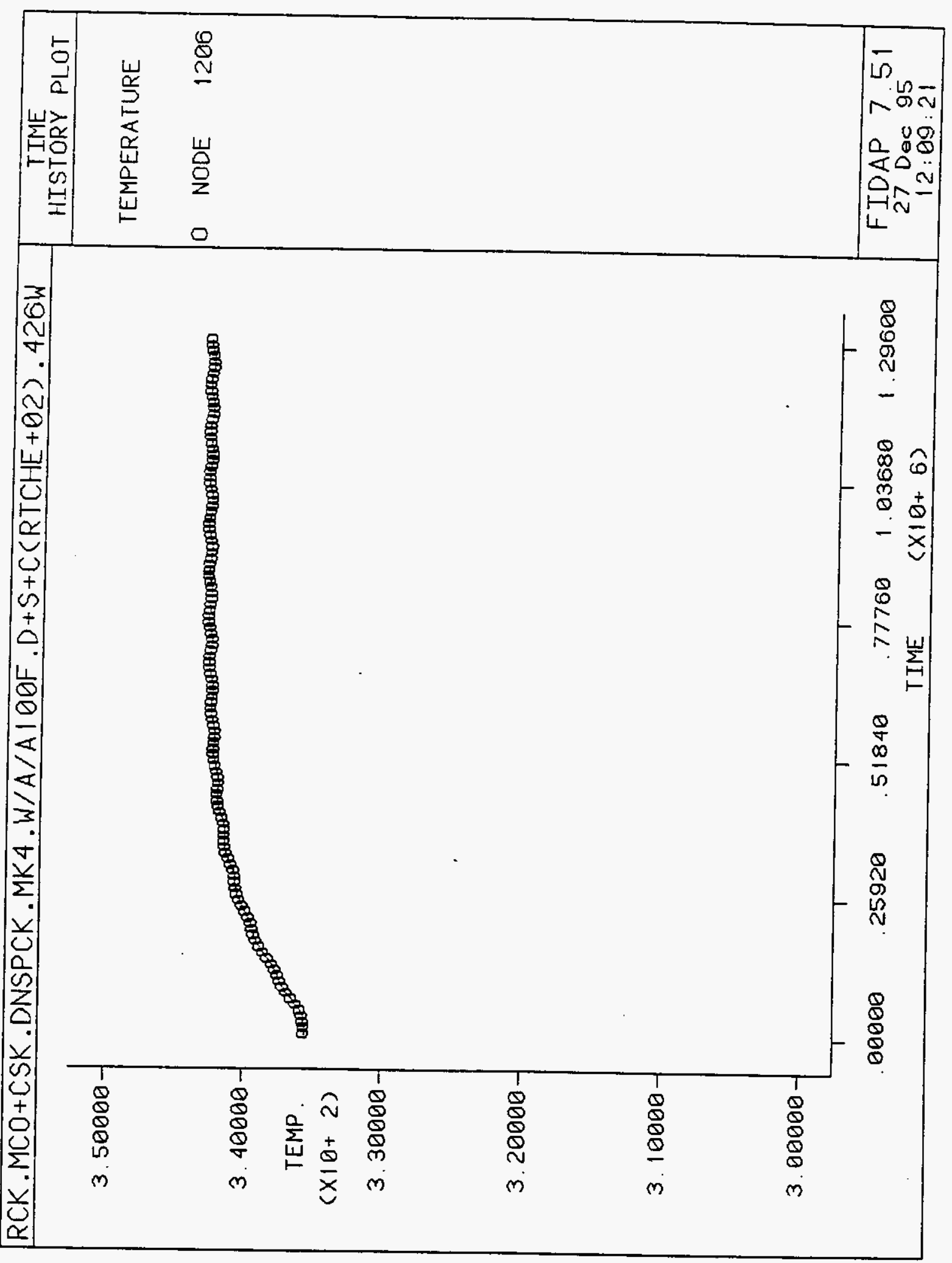


WHC-SD-WM-ER-525

Rev. 0

Figure 5-19. Peak Fuel Temperature Versus Time for Initial Fuel Loading for $\mathrm{K}$ Basin Ambient Water Temperature of $100{ }^{\circ} \mathrm{C}\left(50^{\circ} \mathrm{F}\right)$ (Maximum Decay Heat + Chemical Heat (Ritchie with Oxygen)).

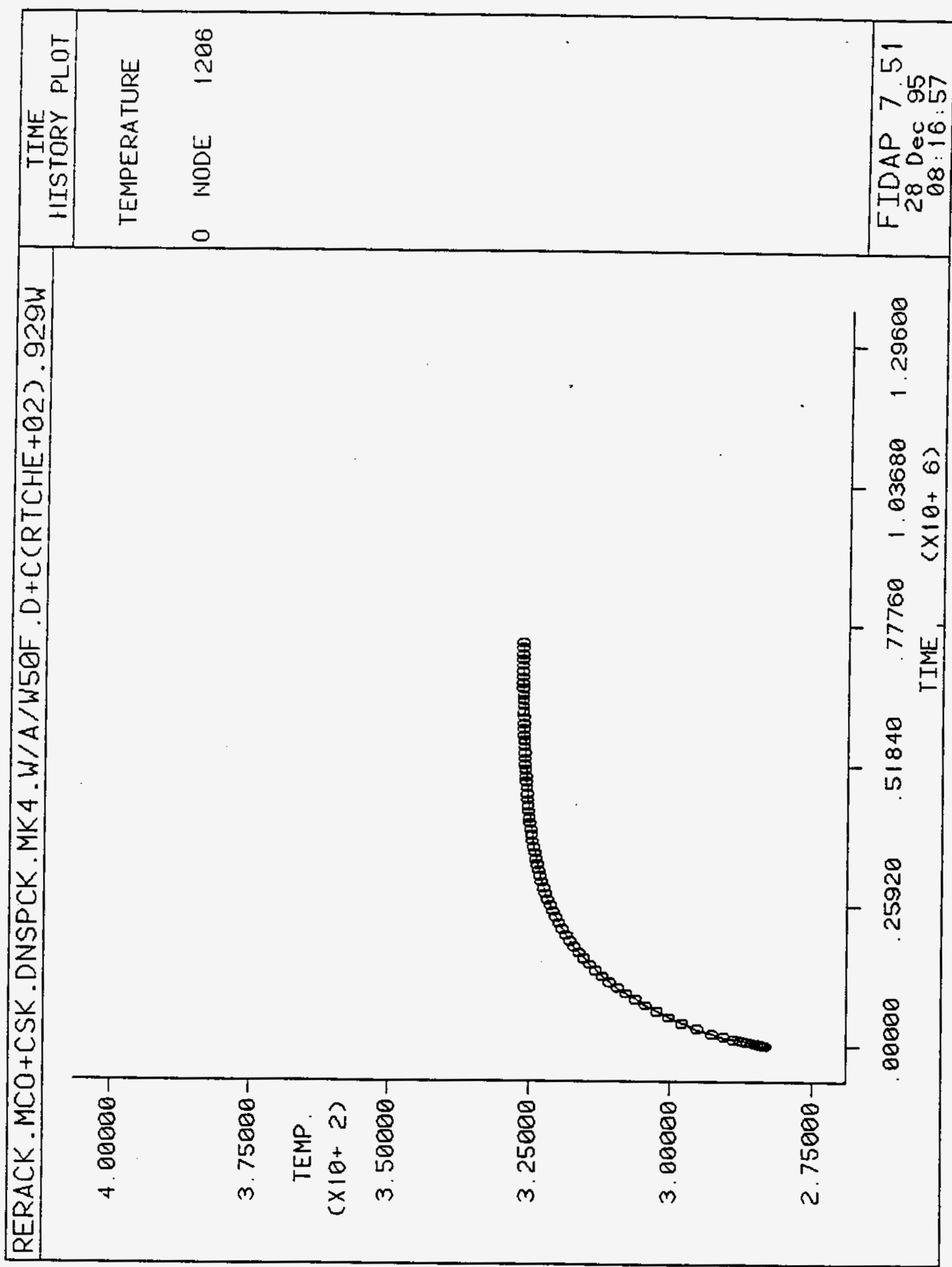




\section{WHC-SD-WM-ER-525 \\ Rev. 0}

Figure 5-20. Peak Fuel Temperature Versus Time for Fully Loaded MCO With Water for an Ambient Air Temperature of $37.8{ }^{\circ} \mathrm{C}$ ( $100^{\circ} \mathrm{F}$ ) (Naximum Decay Heat + Chemical Heat (Ritchie with Oxygen)).

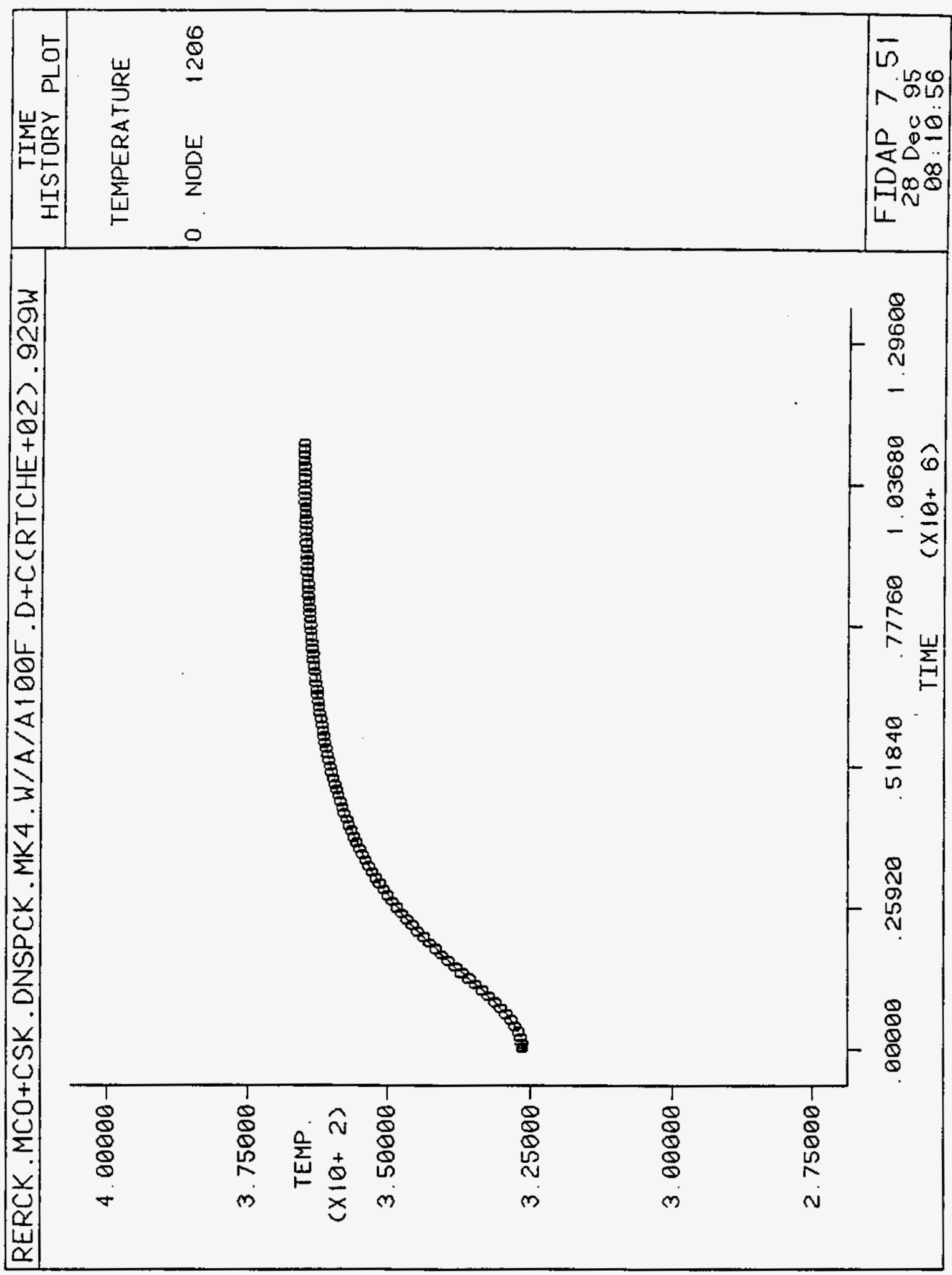


WHC-SD-WM-ER-525

Rev. 0

Figure 5-21. Peak Fuel Temperature Versus Time for Fully Loaded MCO With Water for an Ambient Air Temperature of $37.8^{\circ} \mathrm{C}\left(100^{\circ} \mathrm{F}\right.$ ) (Maximum Decay Heat + Solar Heat + Chemical Heat (Ritchie with Oxygen)).

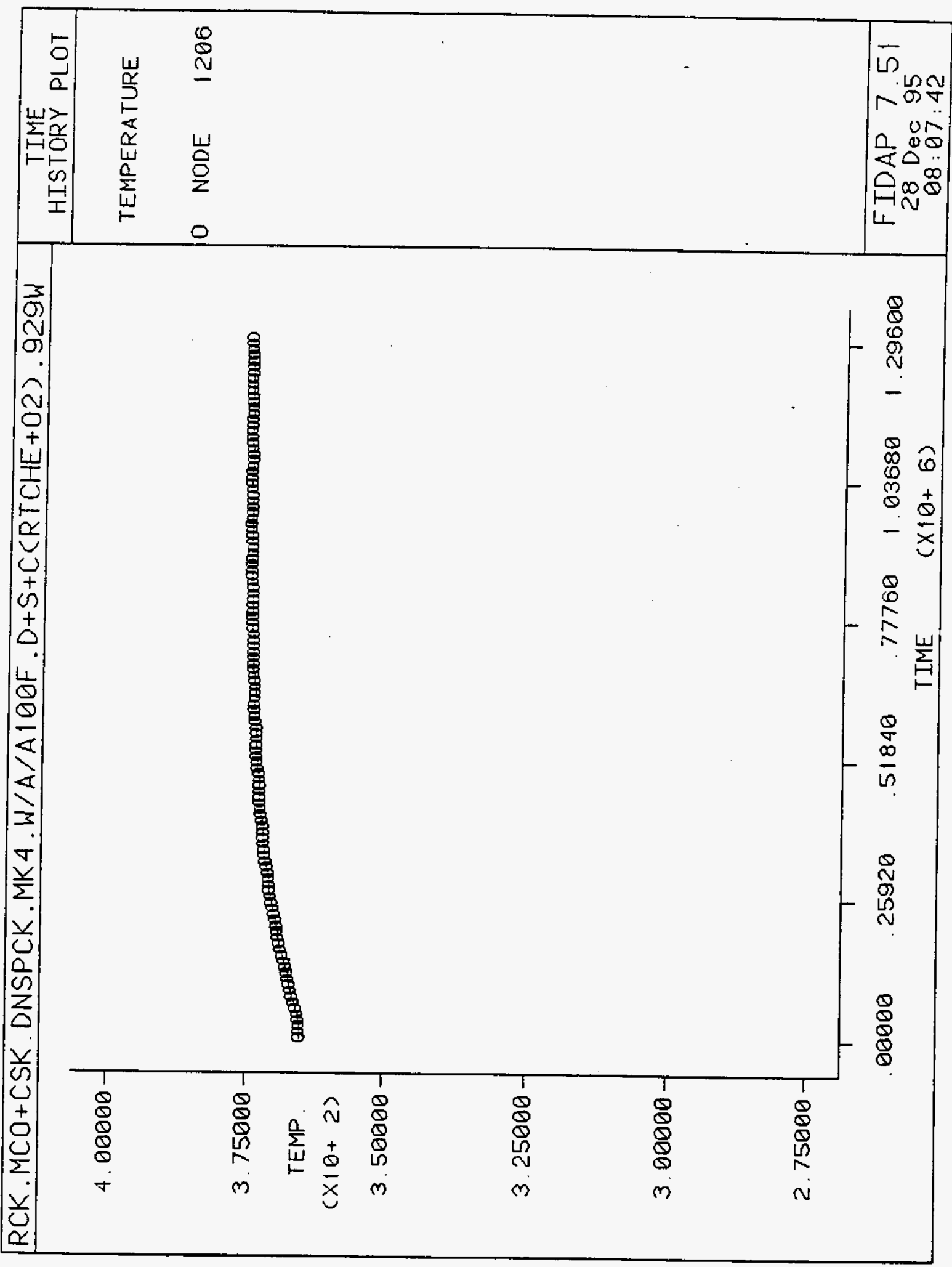


Rev. 0

Figure 5-22. Peak Fuel Temperature Versus Time for MCO During Dewatering and Vacuum Drying with Helium Fill Gas and Water Gap Heating at $50^{\circ} \mathrm{C}\left(122{ }^{\circ} \mathrm{F}\right)$ (Nominal Decay Heat + Chemical Heat (McGill ivary with Oxygen, $2 \mathrm{kPa}$ Water Vapor Pressure)).

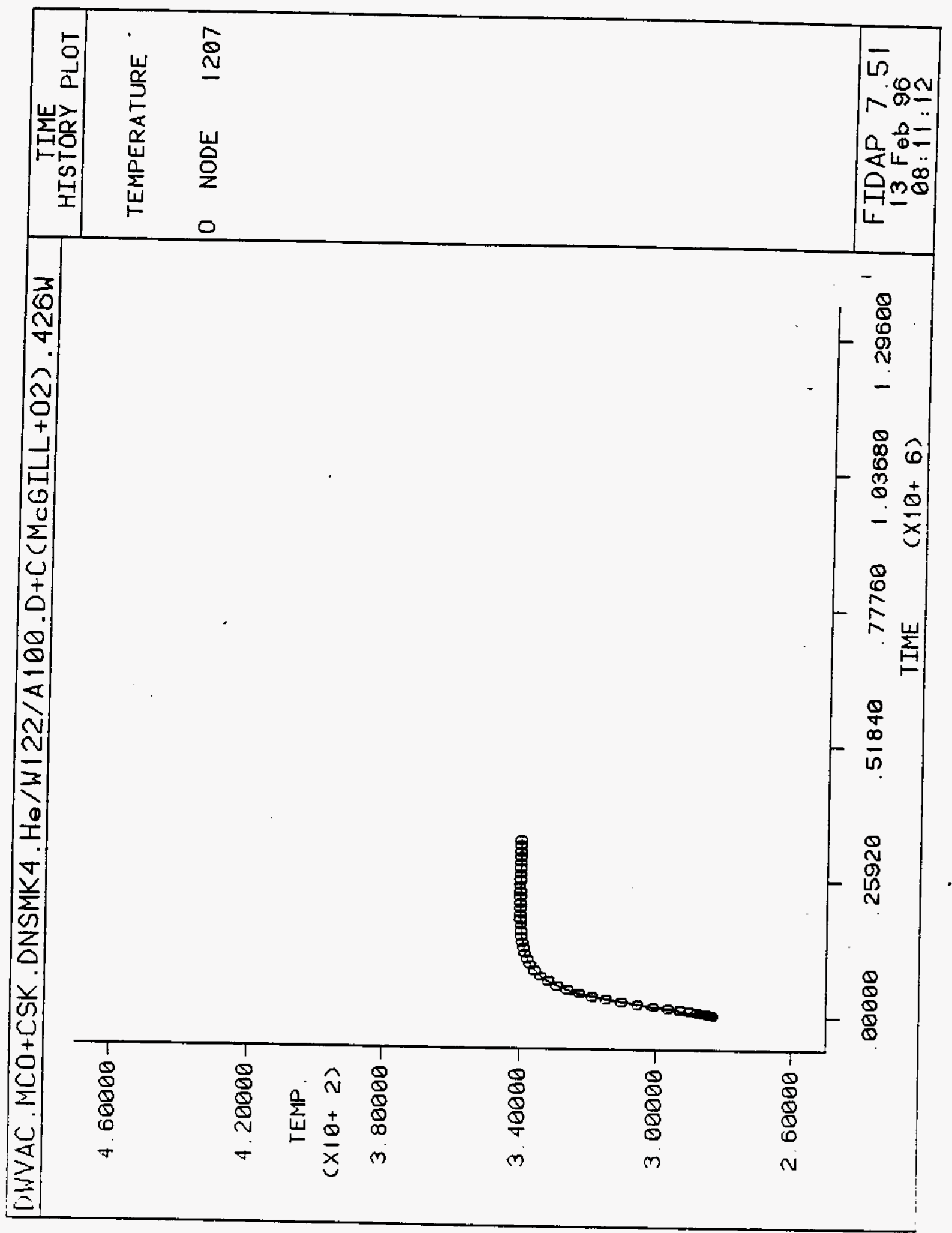


WHC-SD-WM-ER-525

Rev. 0

Figure 5-23. Peak Fuel Temperature Versus Time for MCO During Dewatering and Vacuum Drying with Helium Fill Gas, Air Gap, and Ambient Temperature of $37.8{ }^{\circ} \mathrm{C}\left(100^{\circ} \mathrm{F}\right)$ (Nominal Decay Heat + Chemical Heat (McGillivary with oxygen, 2kPa Water Vapor Pressure)).

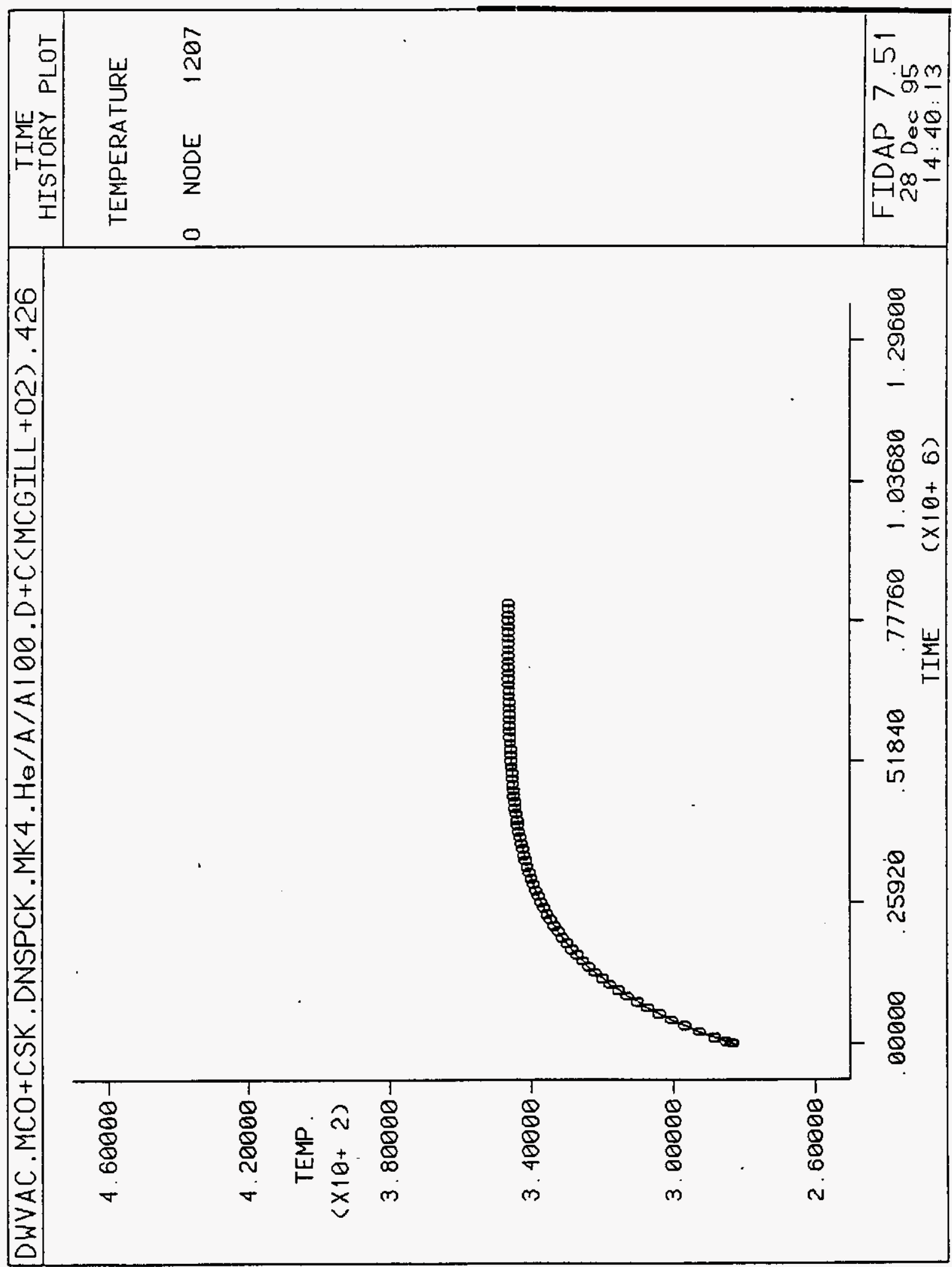


WHC-SD-WM-ER-525

Rev. 0

Figure 5-24. Peak Fuel Temperature Versus Time for MCO $\left(\epsilon_{\mathrm{ss} 304}=0.75\right)$ During Dewatering and Vacuum Drying with Helium Fill Gas, Air Gap, and Ambient Temperature of $37.8{ }^{\circ} \mathrm{C}\left(100{ }^{\circ} \mathrm{F}\right)$ (Nominal Decay Heat + Chemical Heat (McGillivary with 0xygen, 2kPa Water Vapor Pressure)).

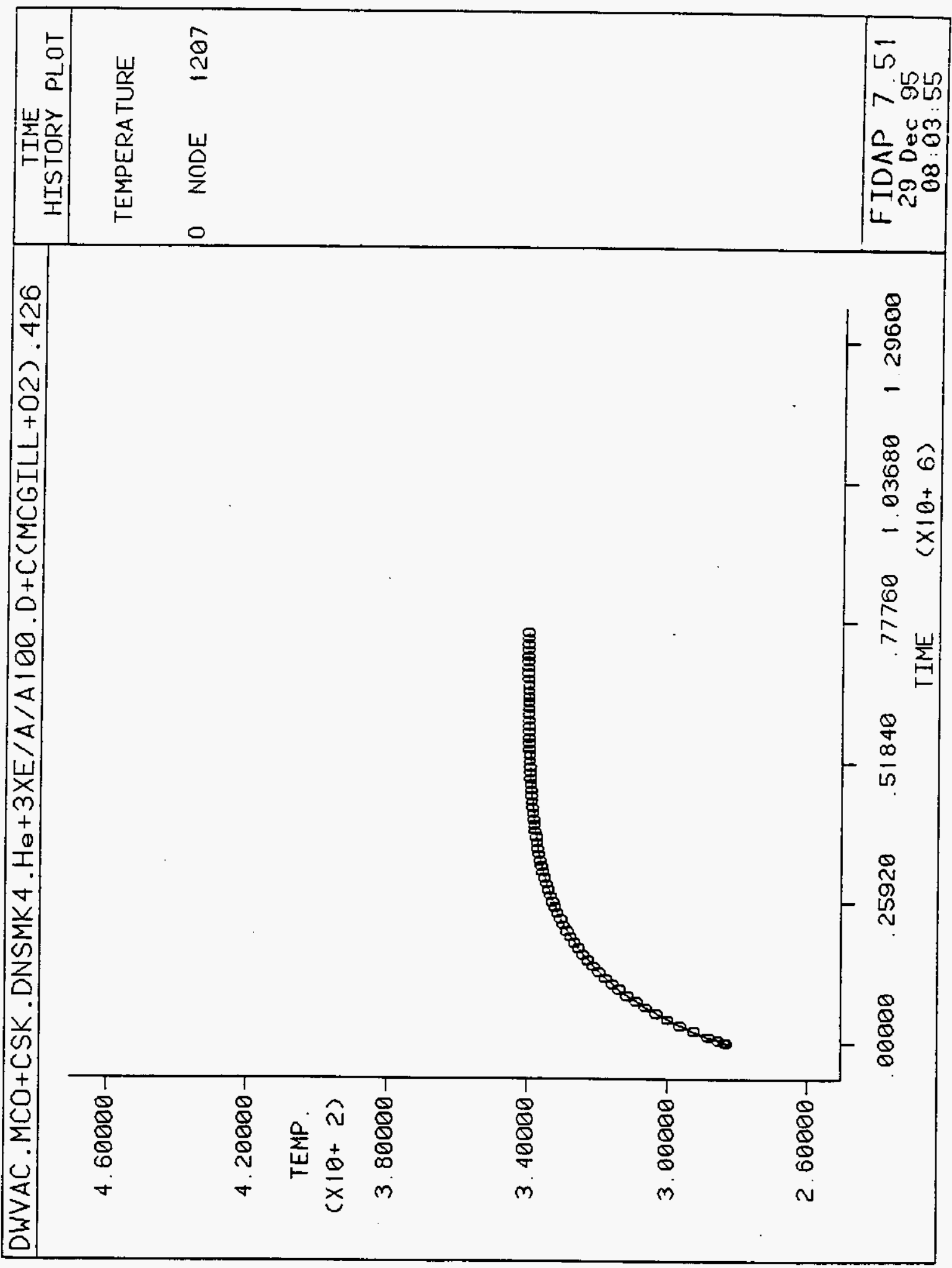


Rev. 0

Figure 5-25. Peak Fuel Temperature Versus Time for MCO During Dewatering and Vacuum Drying With Air Fill Gas and Water Gap Heating at $50{ }^{\circ} \mathrm{C}\left(122{ }^{\circ} \mathrm{F}\right.$ )

(Nominal Decay Heat + Chemical Heat (McGillivary With

Oxygen, 2kPa Water Pressure)).

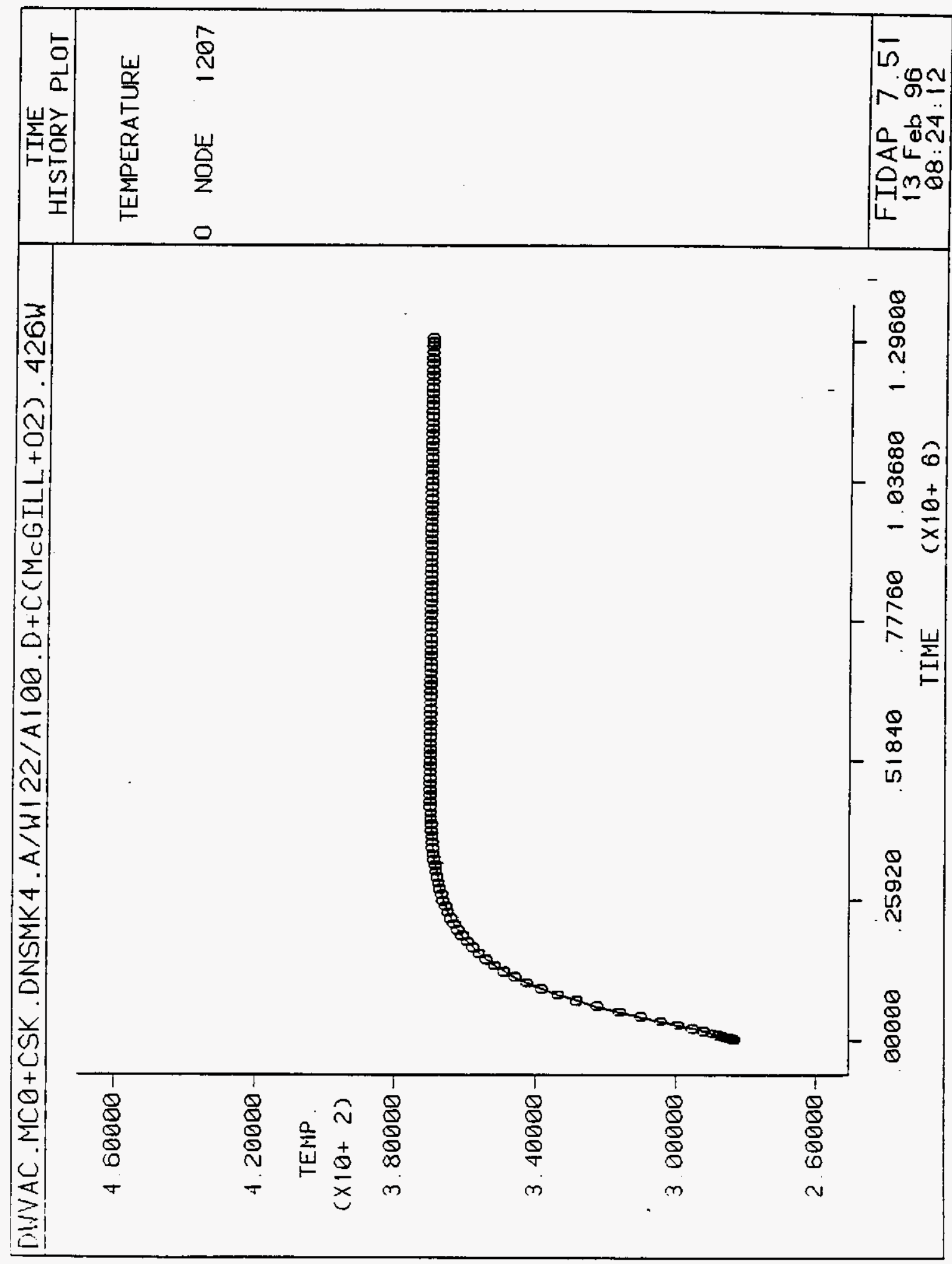


Rev. 0

Figure 5-26. Peak Fuel Temperature Versus Time for MCO During Dewatering and Vacuum Drying with Air Fill Gas, Air Gap, and Ambient Air Temperature of $37.8^{\circ} \mathrm{C}\left(100^{\circ} \mathrm{F}\right)$ (Nominal Decay Heat + Chemical Heat

(McGillivary with Oxygen, 2kPa Water Pressure)).

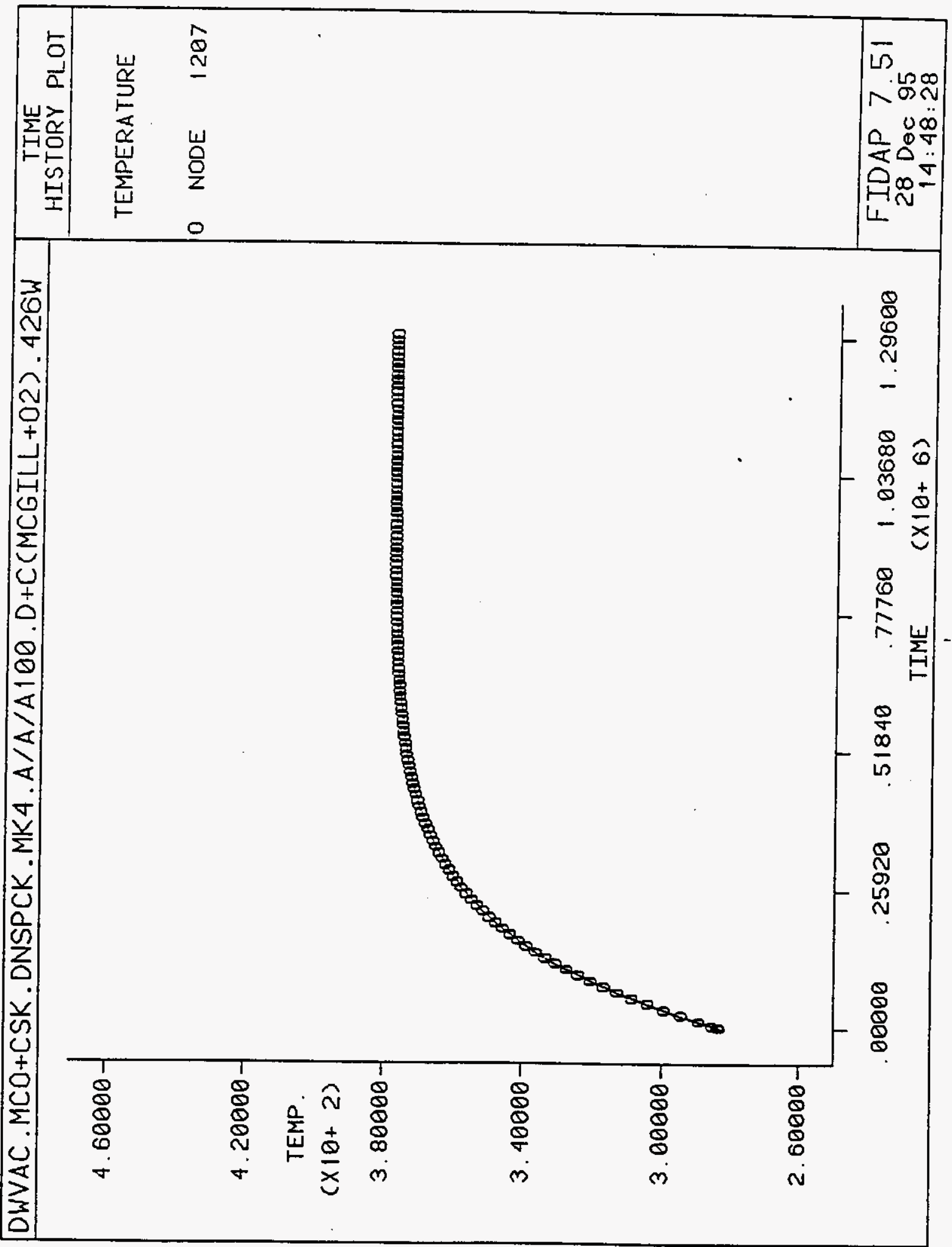


Rev. 0

Figure 5-27. Peak Fuel Temperature Versus Time for MCO $\left(\epsilon_{\mathrm{ss} 304}=0.75\right)$ During Dewatering and Vacuum Drying with Air Fill Gas, Air Gap, and Ambient Air Temperature of $37.8^{\circ} \mathrm{C}\left(100^{\circ} \mathrm{F}\right)$ (Nominal Decay Heat + Chemical Heat (McGillivary with Oxygen, 2kPa Water Pressure)).

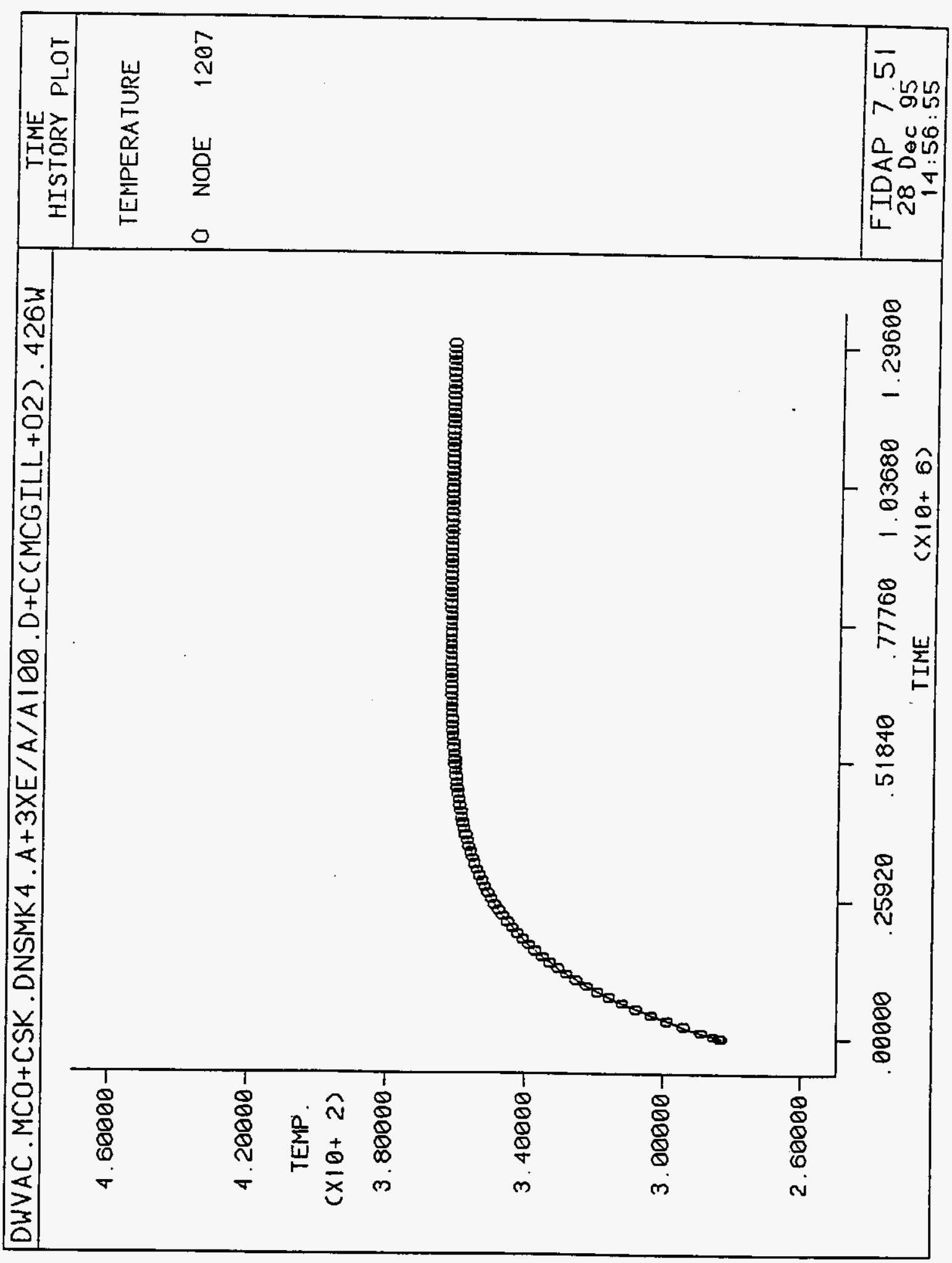




\section{WHC-SD-WM-ER-525}

Rev. 0

Figure 5-28. Peak Fuel Temperature Versus Time for MCO During Dewatering and Vacuum Drying with Helium Fill Gas, and Water Gap Heating at $50^{\circ} \mathrm{C}$

$\left(122{ }^{\circ} \mathrm{F}\right.$ ) (Maximum Decay Heat + Chemical Heat (McGillivary with Oxygen, 2kPa Water Pressure)).

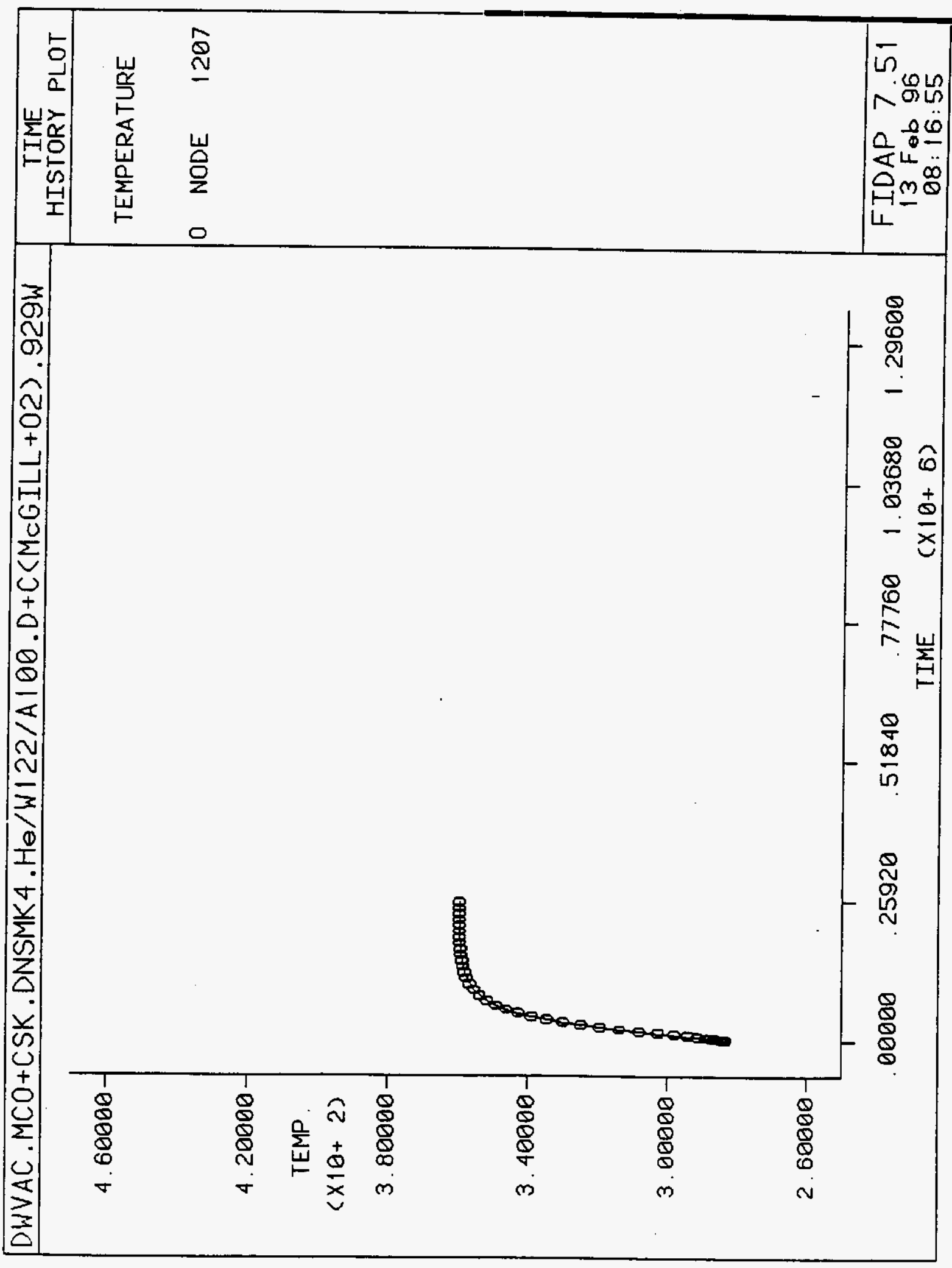


Figure 5-29. Peak Fuel Temperature Versus Time for MCO During Dewatering and Vacuum Drying with Helium Fill Gas, Air Gap, and Ambient Air Temperature of $37.8^{\circ} \mathrm{C}\left(100^{\circ} \mathrm{F}\right.$ ) (Maximum Decay Heat + Chemical Heat (McGillivary with 0xygen, 2kPa Water Pressure)).

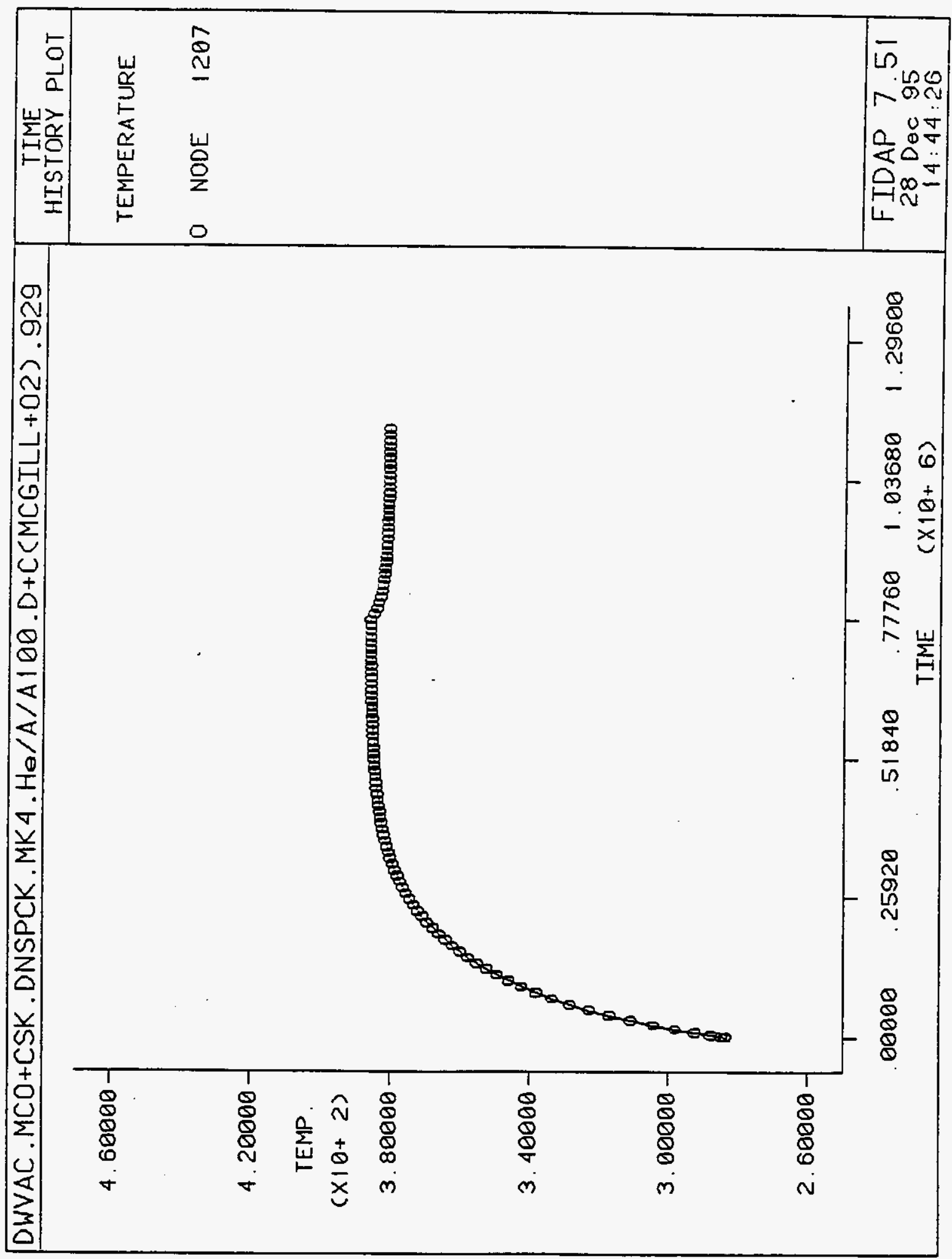


Rev. 0

Figure 5-30. Peak Fuel Temperature Versus Time for $M \mathrm{MCO}\left(\epsilon_{\mathrm{s} s 304}=0.75\right)$ Dewatering and Vacuum Drying with Helium Fill Gas, Air Gap, and Ambient Air Temperature of $37.8^{\circ} \mathrm{C}\left(100{ }^{\circ} \mathrm{F}\right)$ (Maximum Decay Heat + Chemical Heat (McGillivary with 0xygen, 2kPa Water Pressure)).

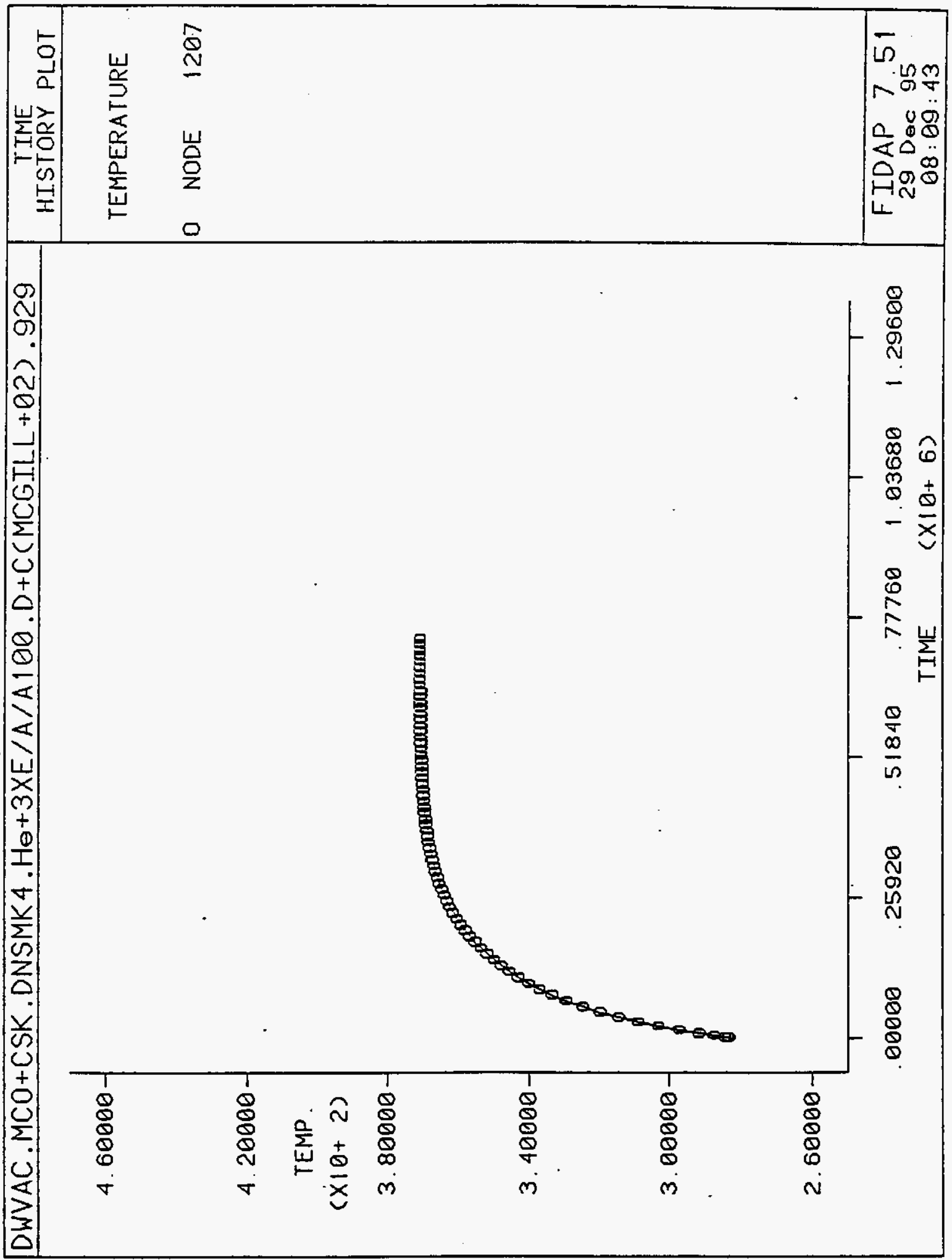


WHC-SD-WM-ER-525

Rev. 0

Figure 5-31. Peak Fuel Temperatures Versus Time for MCO During Dewatering and Vacuum Drying With Air. Fill Gas and Water Gap Heating at $50{ }^{\circ} \mathrm{C}\left(122{ }^{\circ} \mathrm{F}\right)$ (Maximum Decay Heat + Chemical Heat (McGillivary With 0xygen, 2kPa Water Pressure)).

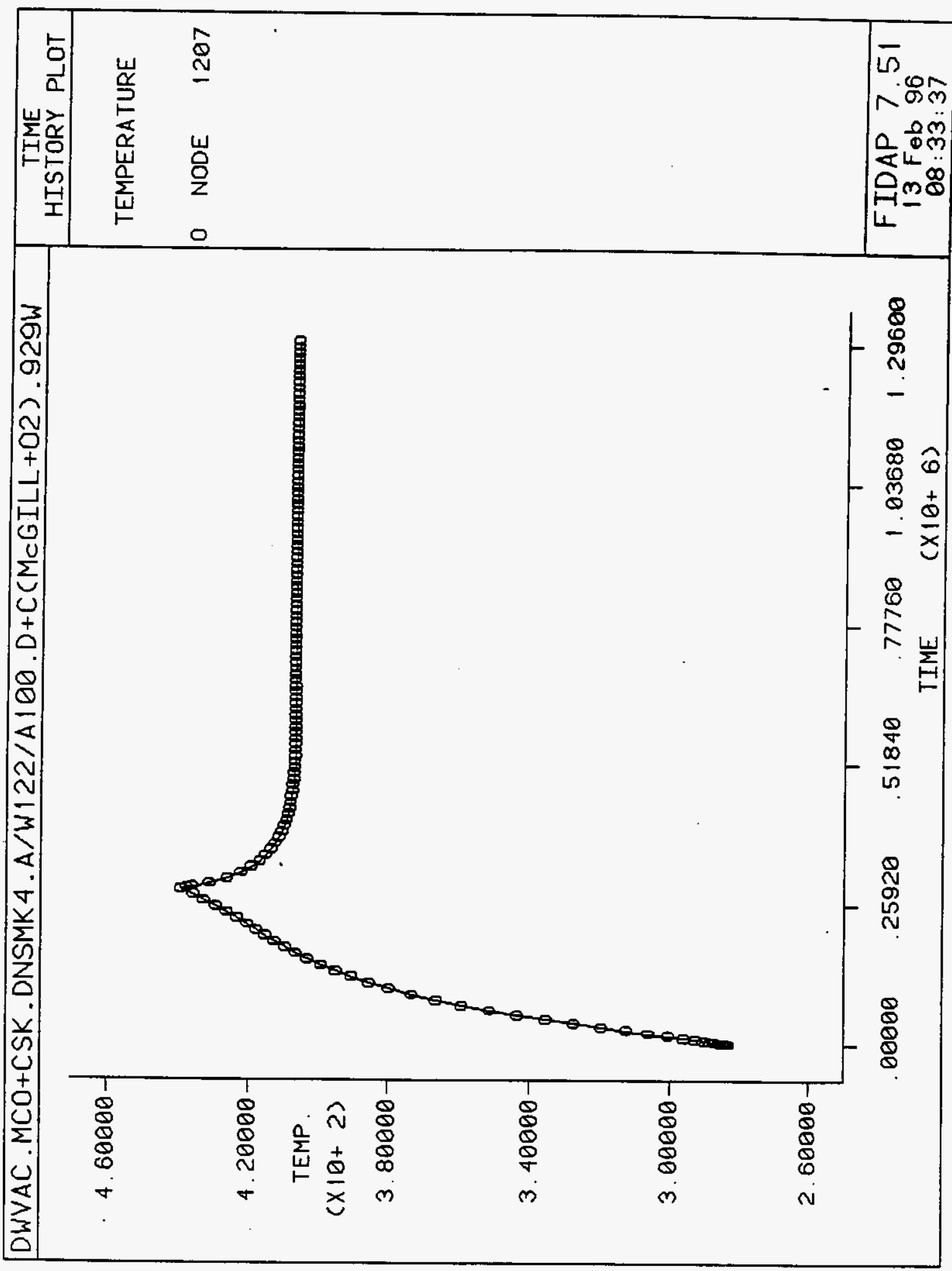


Rev. 0

Figure 5-32. Peak Fuel Temperature Versus Time for MCO During Dewatering and Vacuum Drying with Air Fill Gas, Air Gap, and Ambient Air Temperature of $37.8^{\circ} \mathrm{C}\left(100^{\circ} \mathrm{F}\right)$ (Maximum Decay Heat + Chemical Heat (McGillivary with 0xygen, 2kPa Water Pressure)).

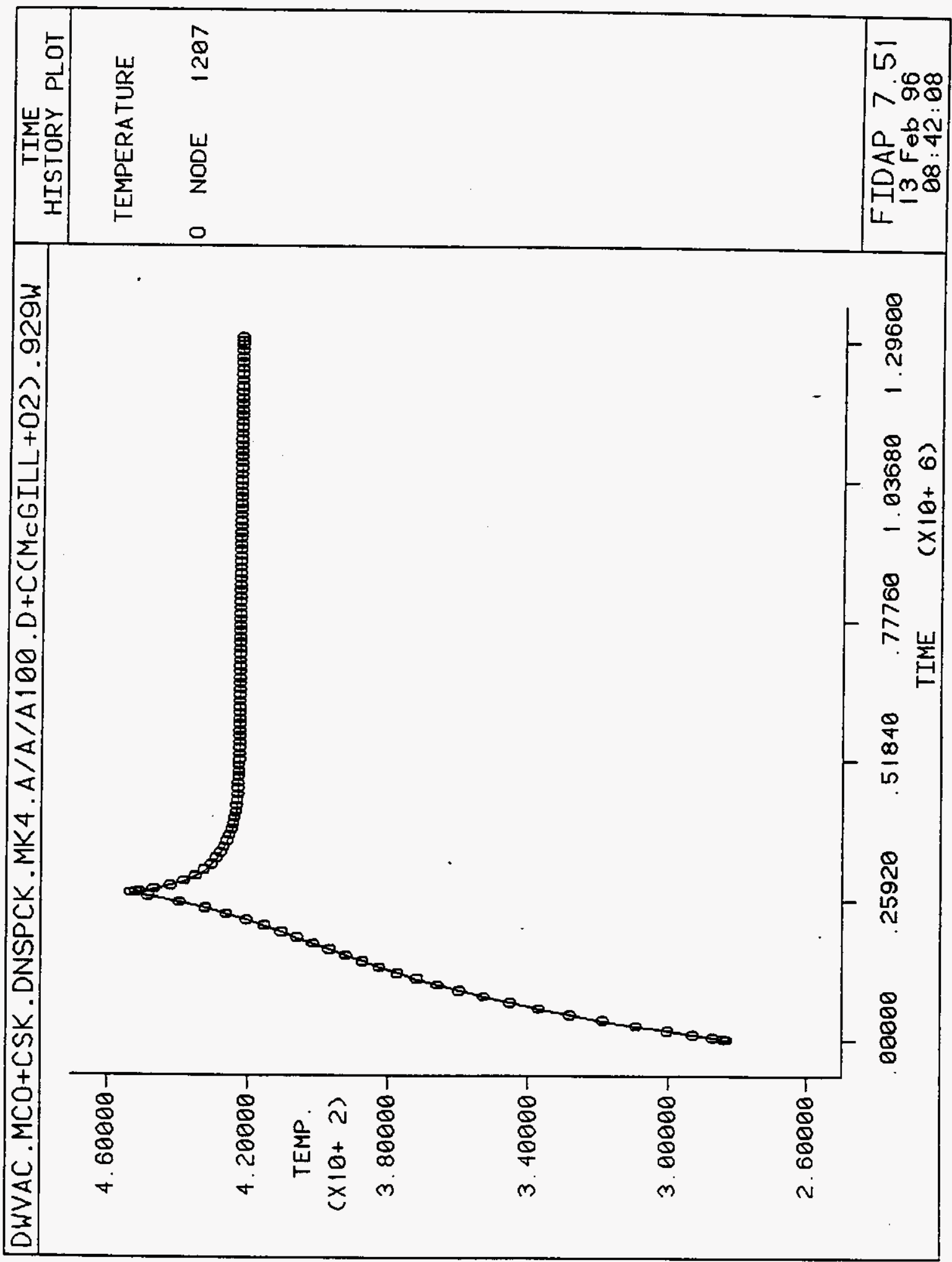


Rev. 0

Figure 5-33. Peak Fuel Temperature Versus Time for MCO $\left(\epsilon_{\mathrm{ss} 304}=0.75\right)$ During Dewatering and Vacuum Drying with Air Fill Gas, Air Gap, and Ambient Air Temperature of $37.8^{\circ} \mathrm{C}\left(100^{\circ} \mathrm{F}\right.$ ) (Maximum Decay Heat + Chemical Heat (McGillivary with Oxygen, 2kPa Water Pressure)).

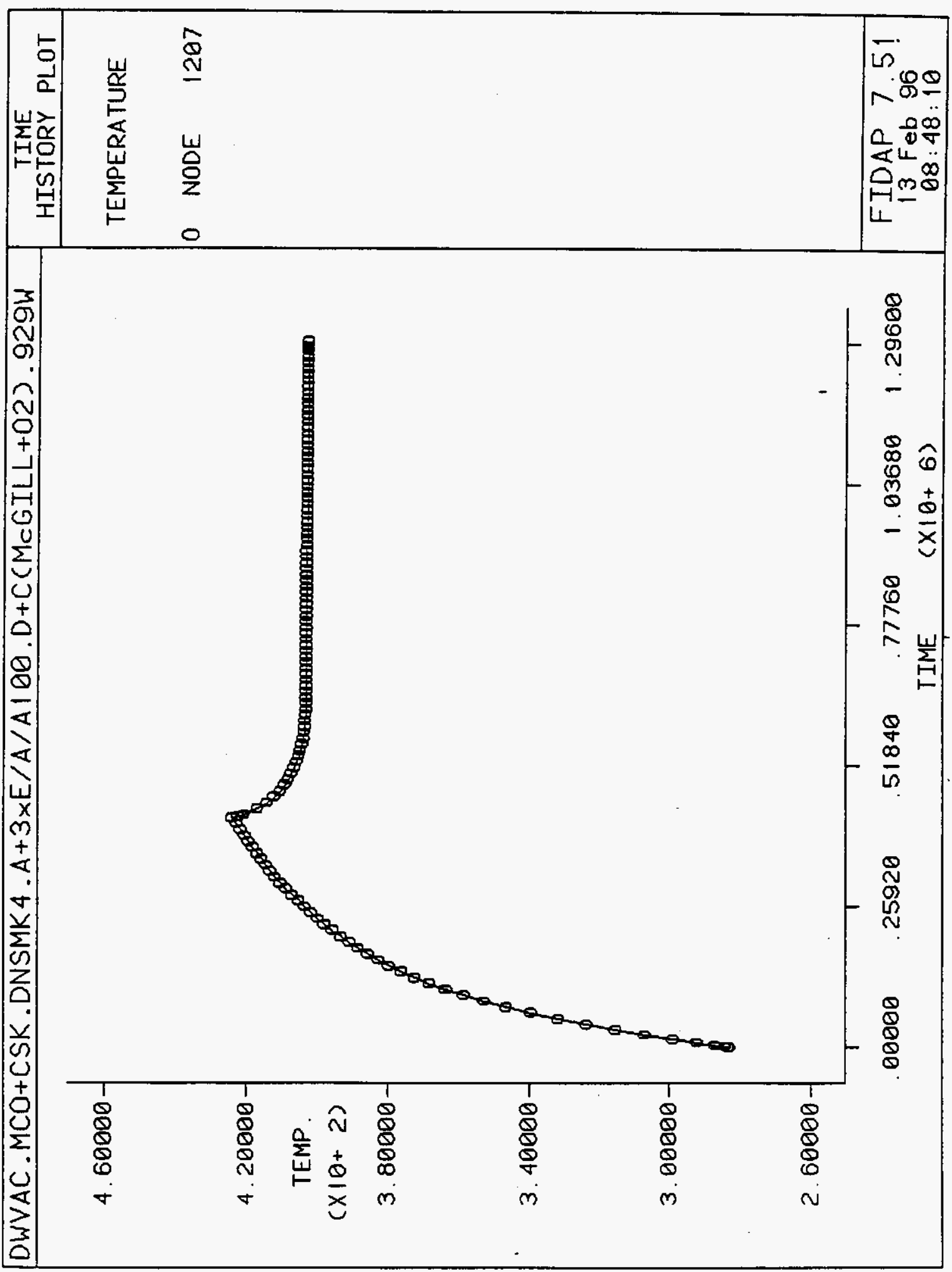


Figure 5-34. Peak Fuel Temperature Versus Time for a MCO and Shipping Cask With Mark IV Fuel with Helium Fill Gas for Various Ambient Temperature (Nominal Decay Heat, Solar Heating, $2.5 \mathrm{Kg}$ Residual Water, Ritchie Oxygen Free).

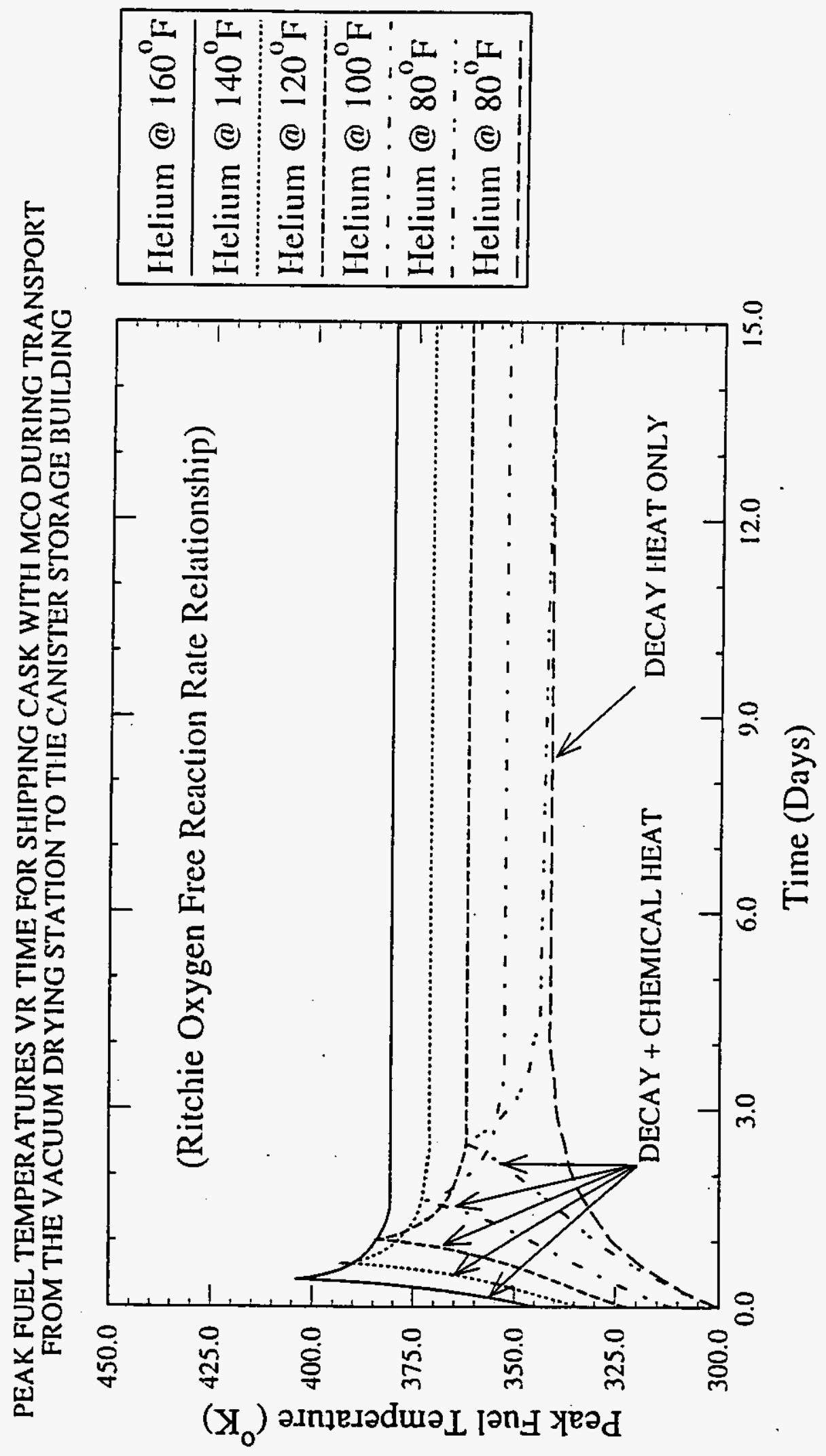


Rev. 0

Figure 5-35. Peak Fuel Temperature Versus Time for a MCO and Shipping Cask With Mark IV Fuel Within a Shipping Cask with Moist Air for Varying

Ambient Temperatures (Nominal Decay Heat, Solar Heating, $2.5 \mathrm{Kg}$ Residual Water, McGillivary with 0xygen, 2kPa Water Vapor Pressure).

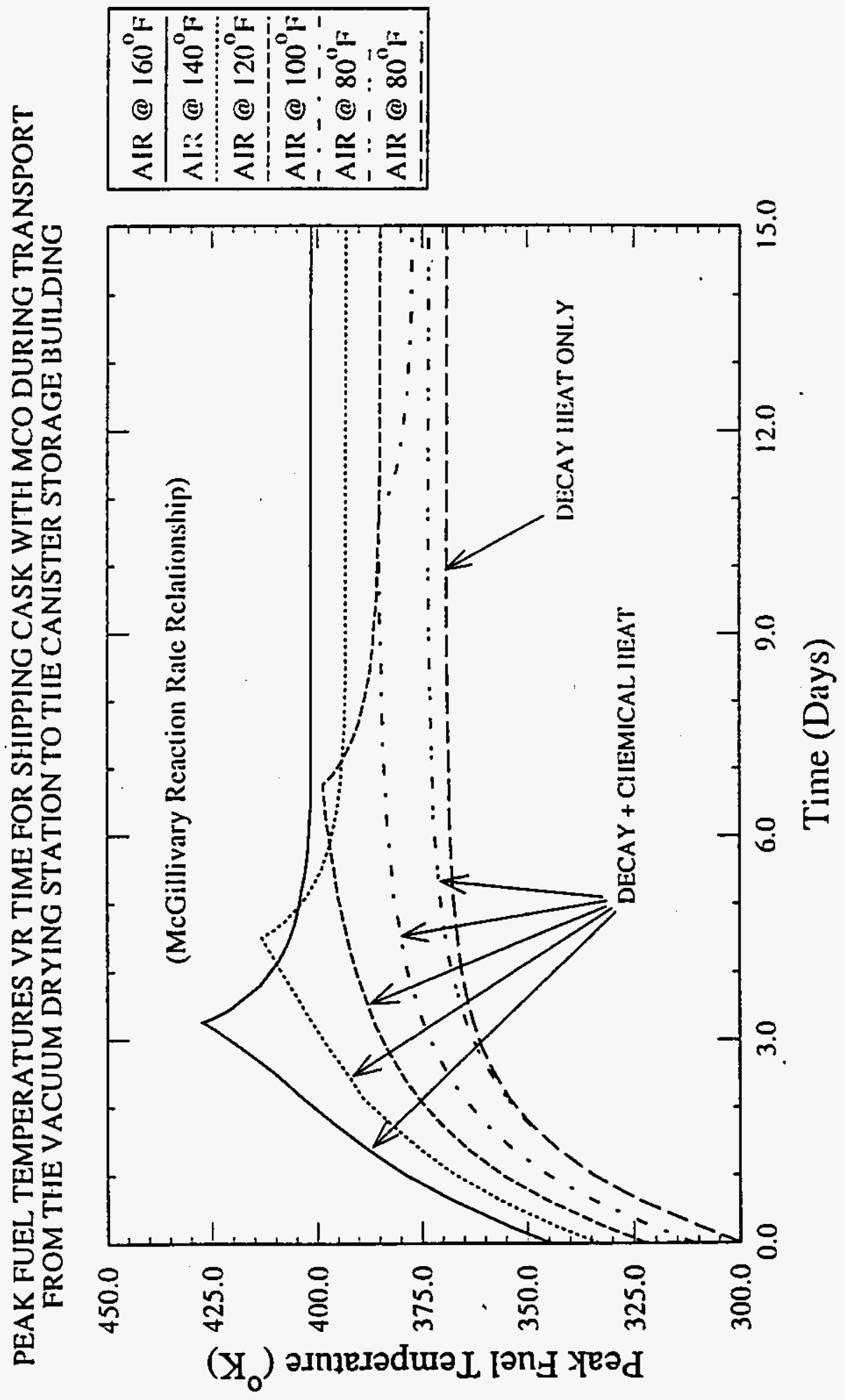


Rev. 0

Figure 5-36. Peak Fuel Temperature Versus Time for MCO and Storage Tube With Mark IV Fue1, Helium Fill Gas, Various Amouonts of Residual

$$
\text { Water, and } 140^{\circ} \mathrm{F} \text { Ambient Vault Air Temperature }
$$

(Nominal Decay Heat + Chemical Heat (Ritchie Oxygen Free))

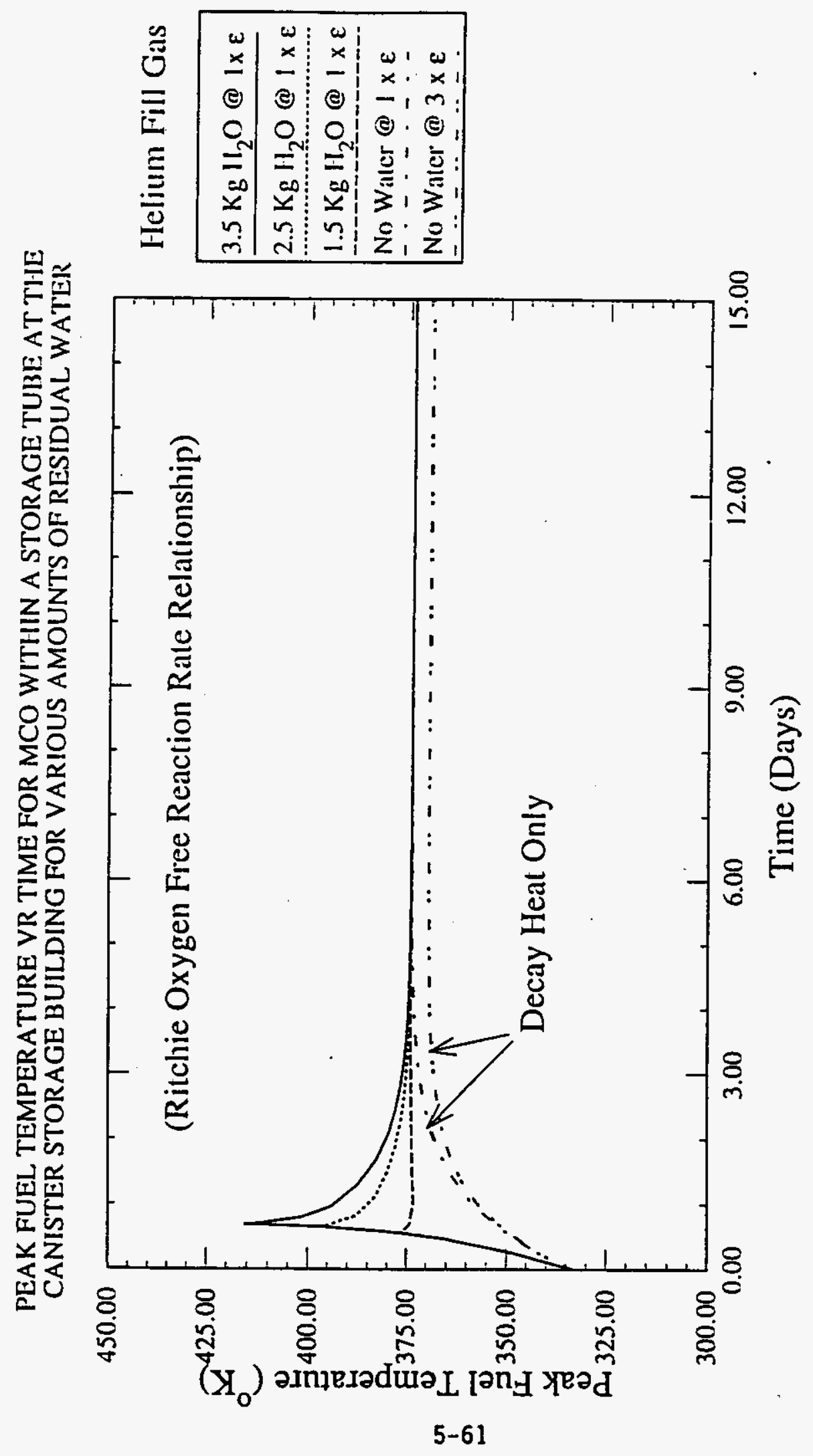


Figure 5-37. Peak Fuel Temperature Versus Time for $M C O$ and Storage Tube With Mark IV Fuel, Nitrogen Fill Gas, Various Amounts of Residual Water, and $140^{\circ} \mathrm{F}$ Ambient Vault Air Temperature (Nominal Decay Heat + Chemical Heat (Ritchie Oxygen Free)).
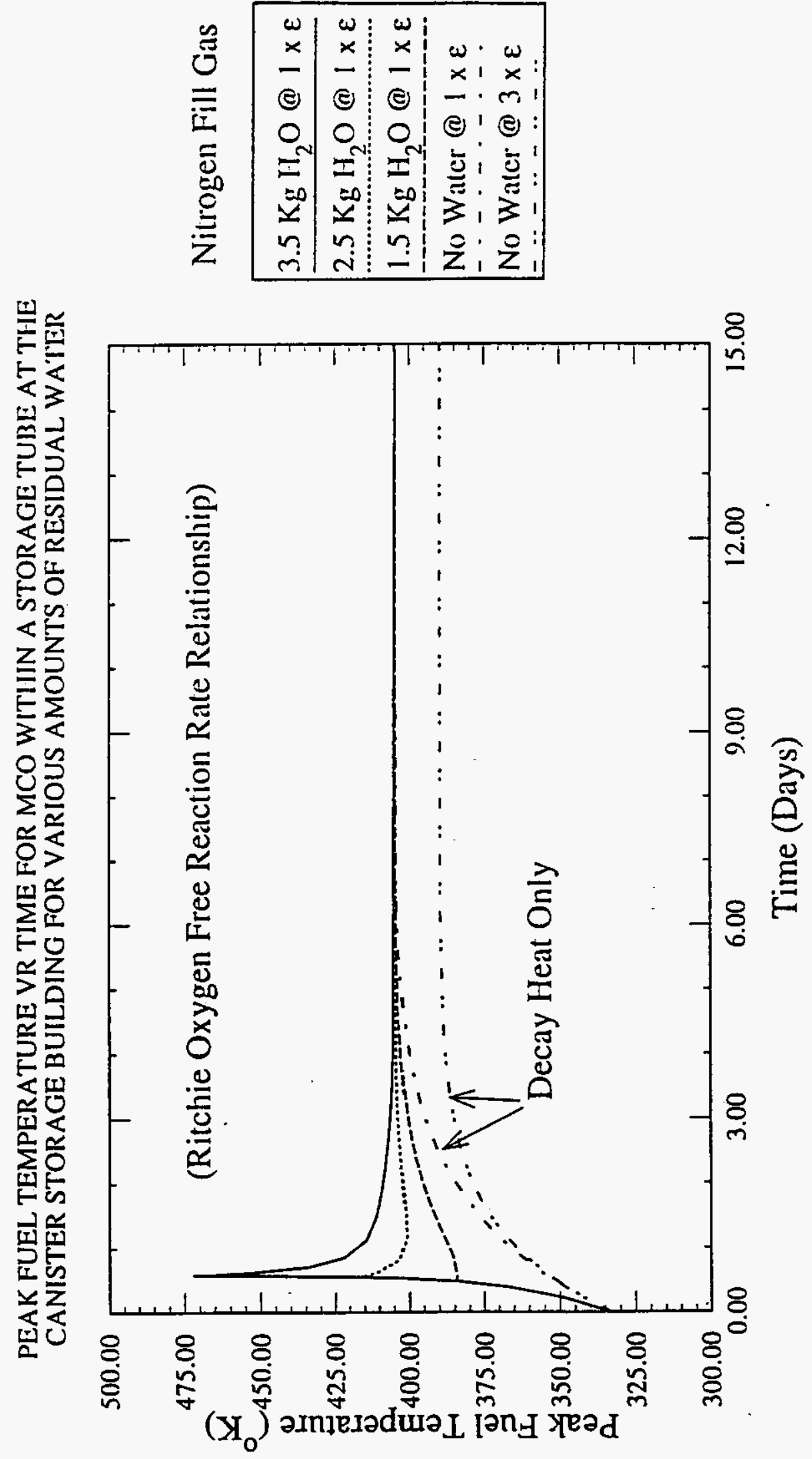
PEAK FUEL TEMPERATURE VR TIME FOR MCO WITHIN A STORAGE TUBE AT THE CANISTER STORAGE BUILDING FOR VARIOUS AMOUNTS OF RESIDUAL WATER
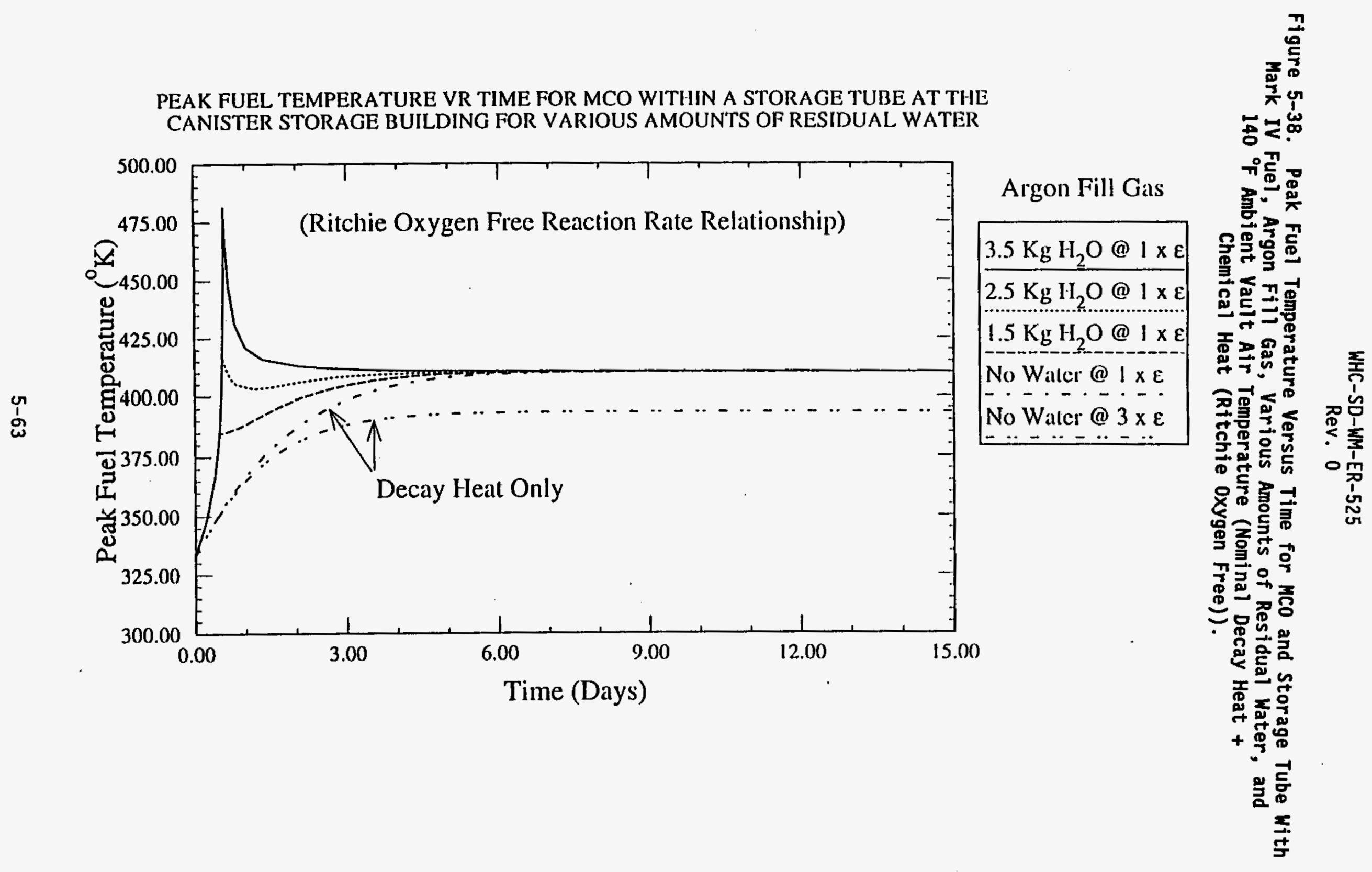
Figure 5-39. A Comparison Between the Analytical HUB and FIDAP Models With and Without Convection.

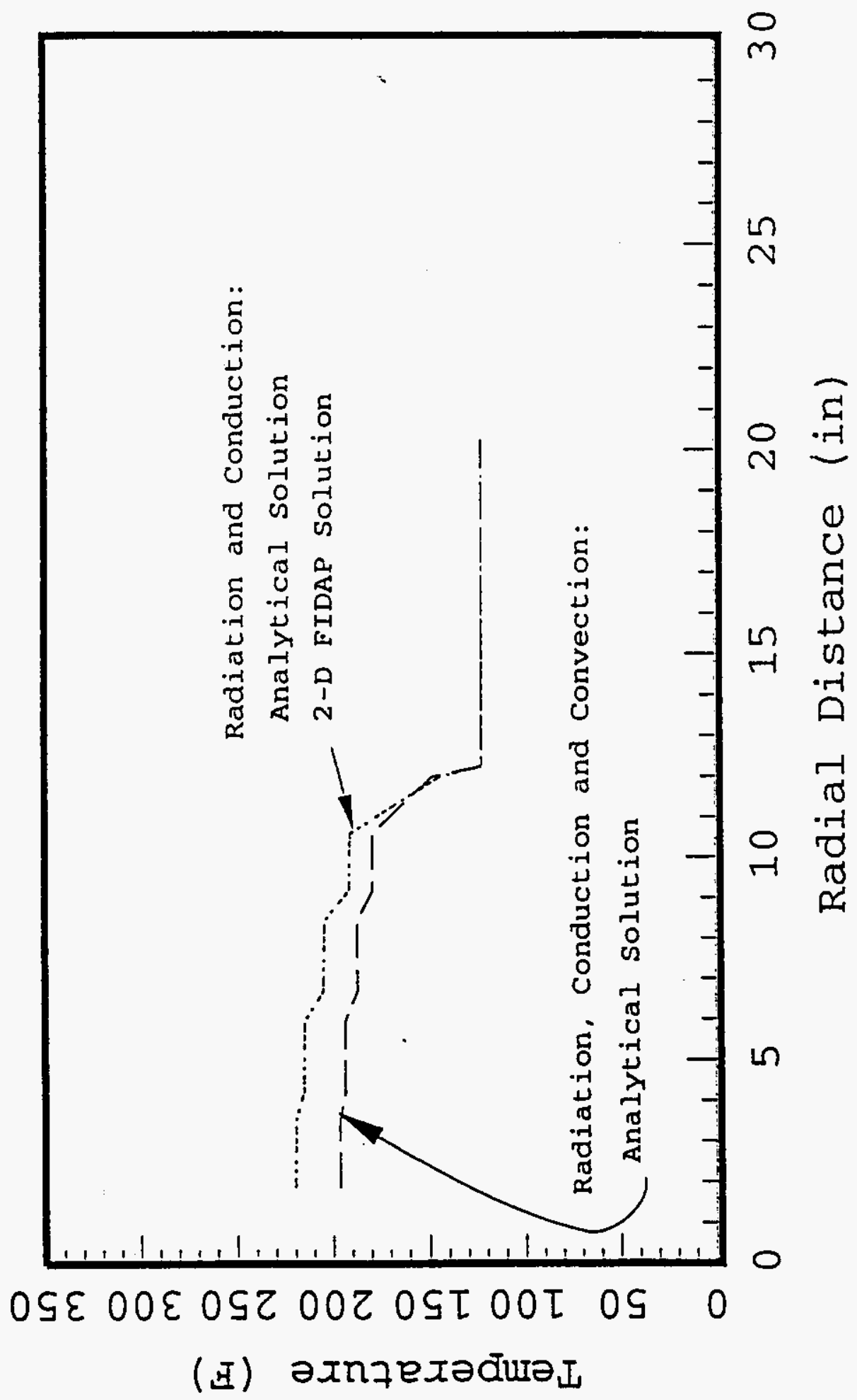


WHC-SD-WM-ER-525

Rev. 0

Figure 5-40. Radial Temperature Profile Near the Ignition Temperature (10 ${ }^{\circ} \mathrm{C}$ Water MCO-Shipping Cask Gap).

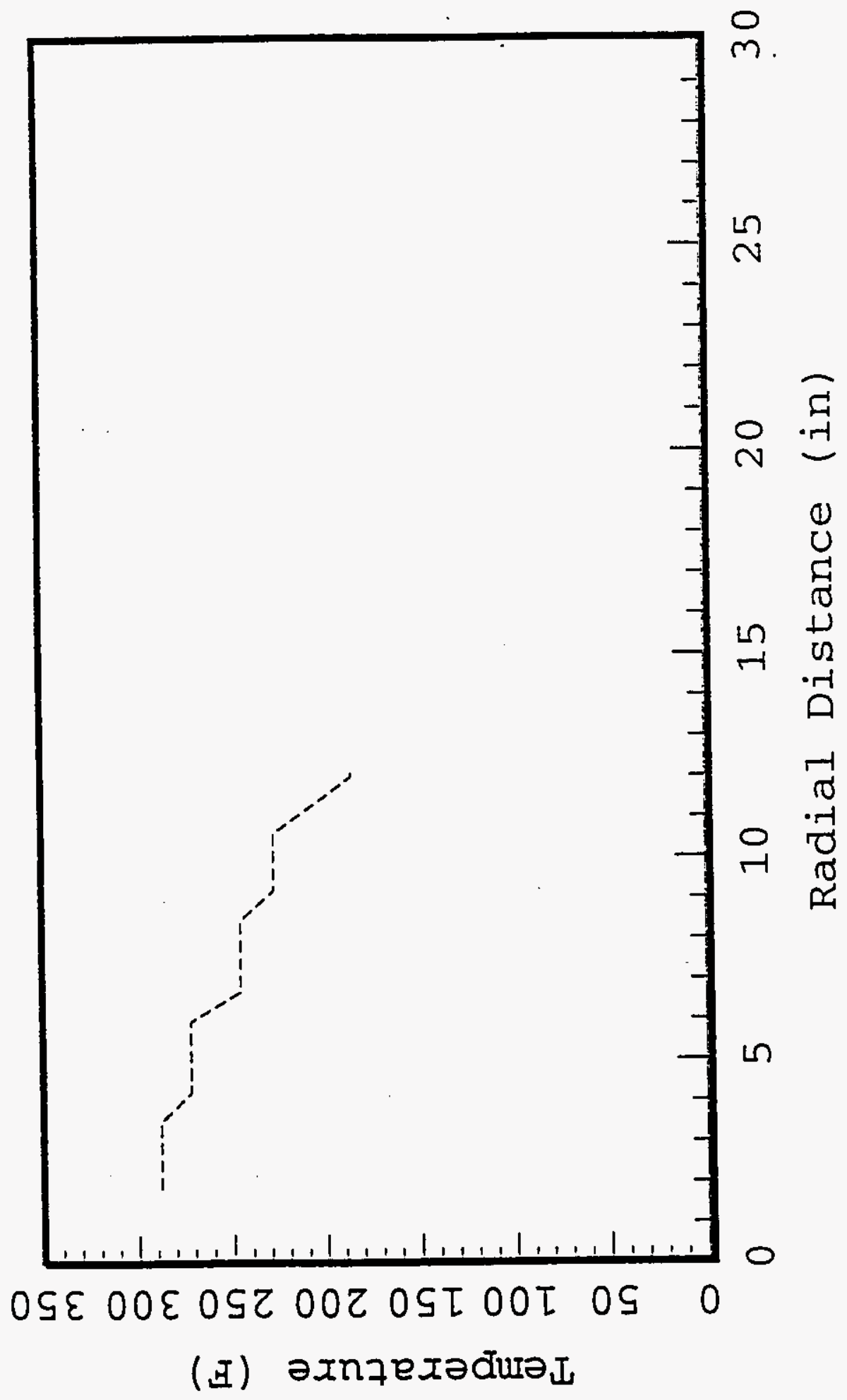


WHC-SD-WM-ER-525
ReV. 0

Figure 5-41. Radial Temperature Profile for MCO Within a Shipping Cask ( $50{ }^{\circ} \mathrm{C}$ Water MCO-Shipping Cask Gap).

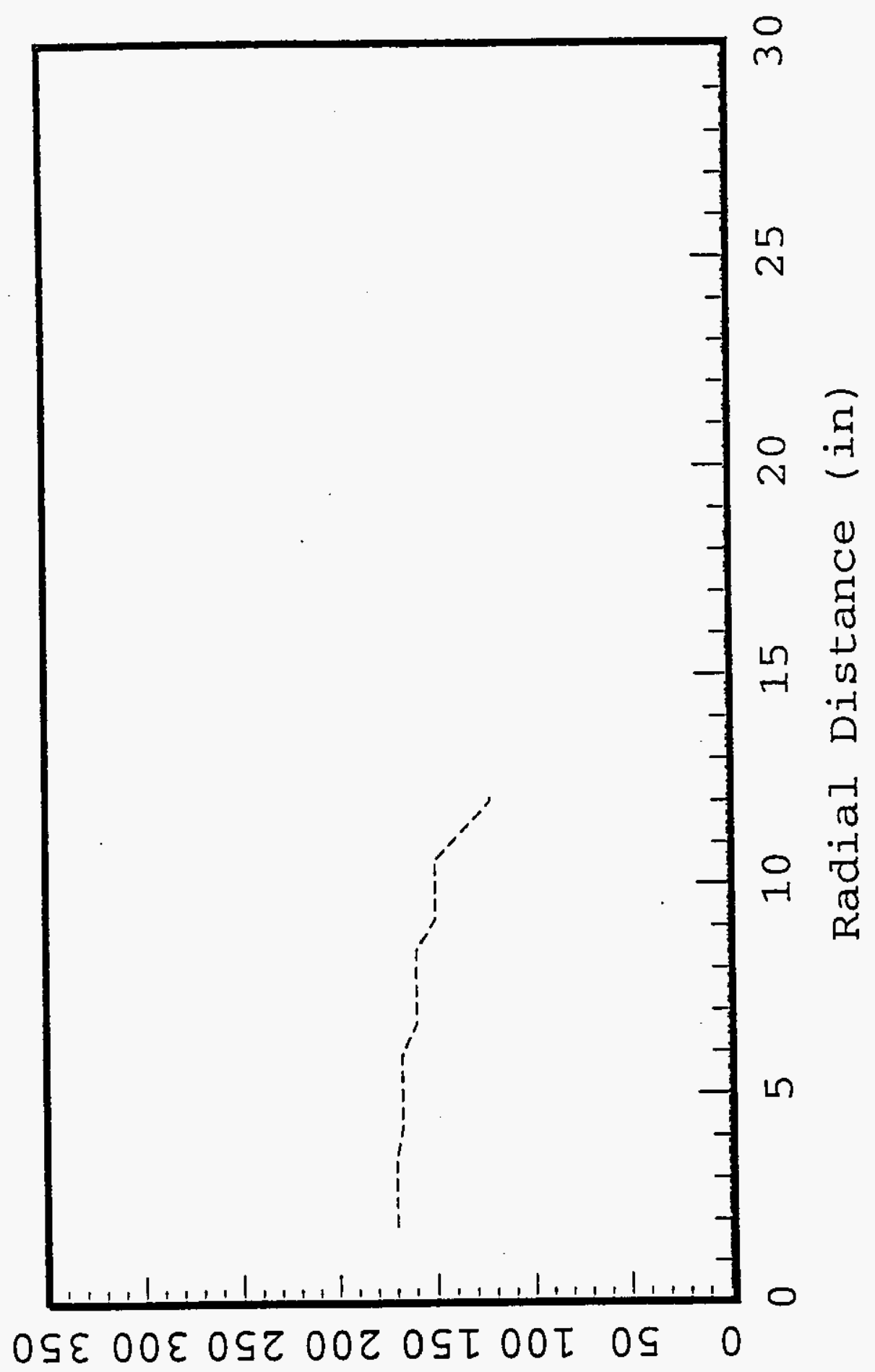

(a) әxnาexәđur๖ 
WHC-SD-WM-ER-525

Rev. 0

Figure 5-42. Radial Temperature Profile Due to Conduction, Radiation and Convection for MCO Within a Shipping Cask.

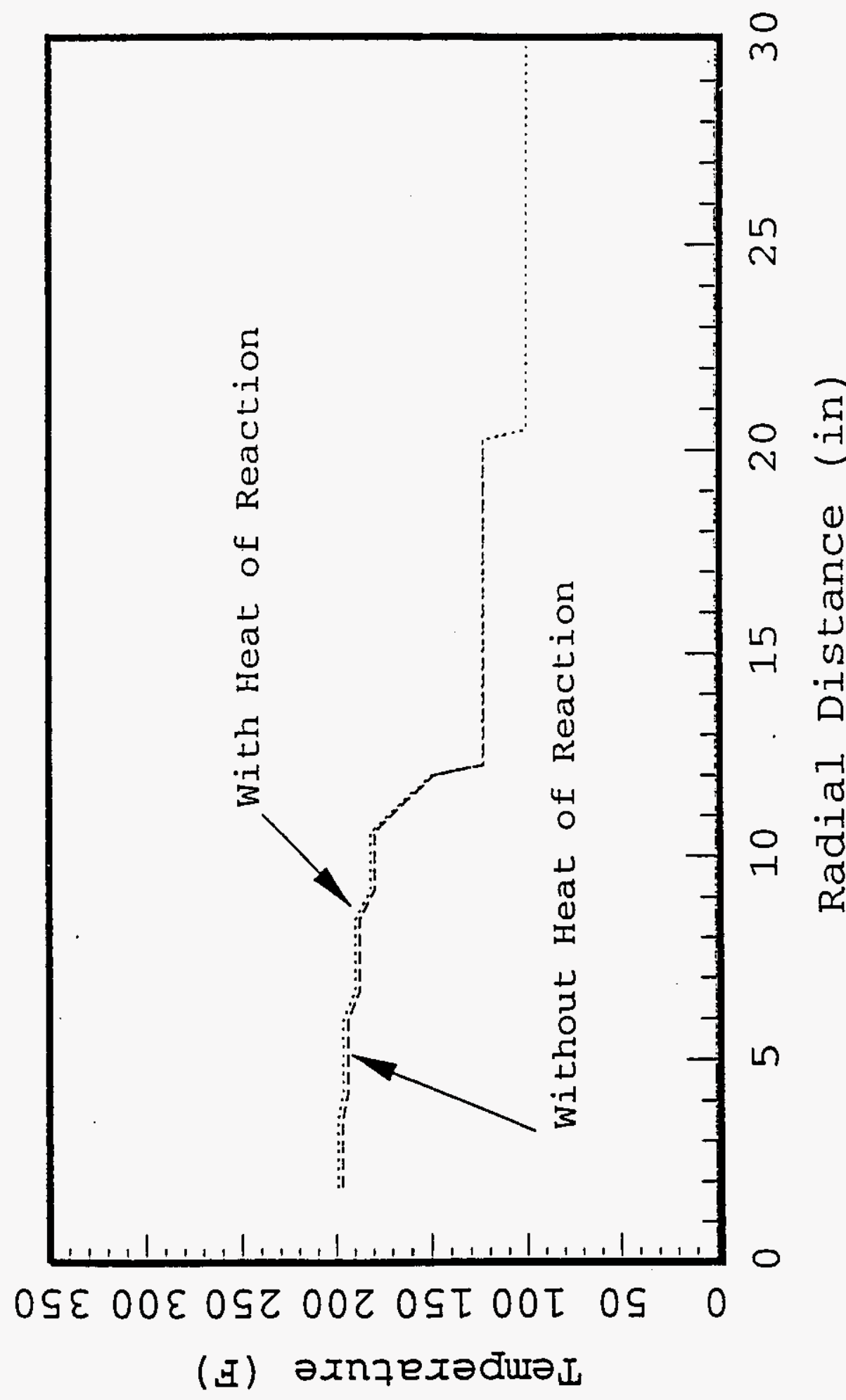


WHC-SD-WM-ER-525

Rev. 0

Figure 5-43. Radial Temperature Profile for Rubble.

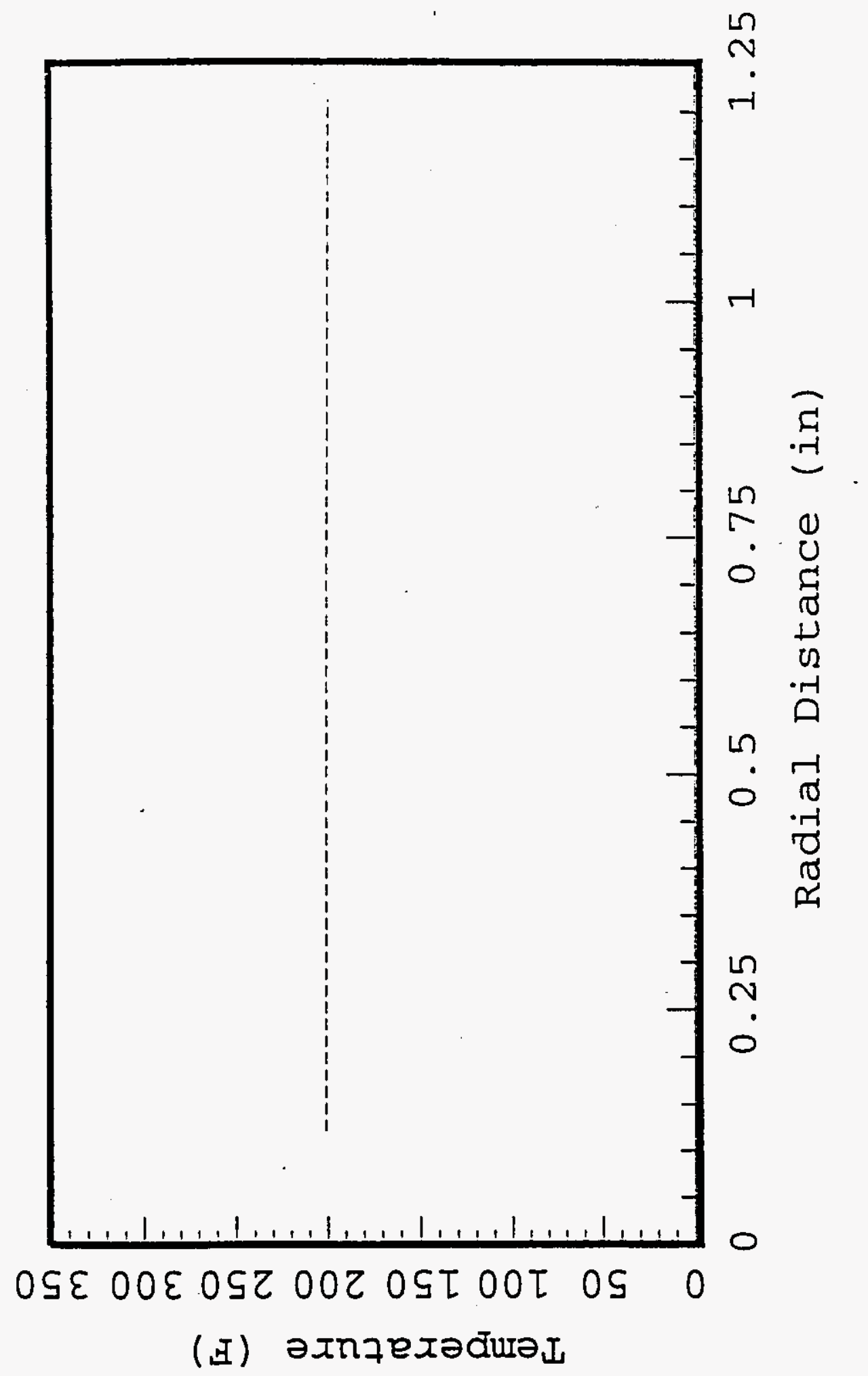


WHC-SD-WM-ER-525

Rev. 0

Figure 5-44. Radial Temperature Profile in MCO Stored in CSB Storage Tube.

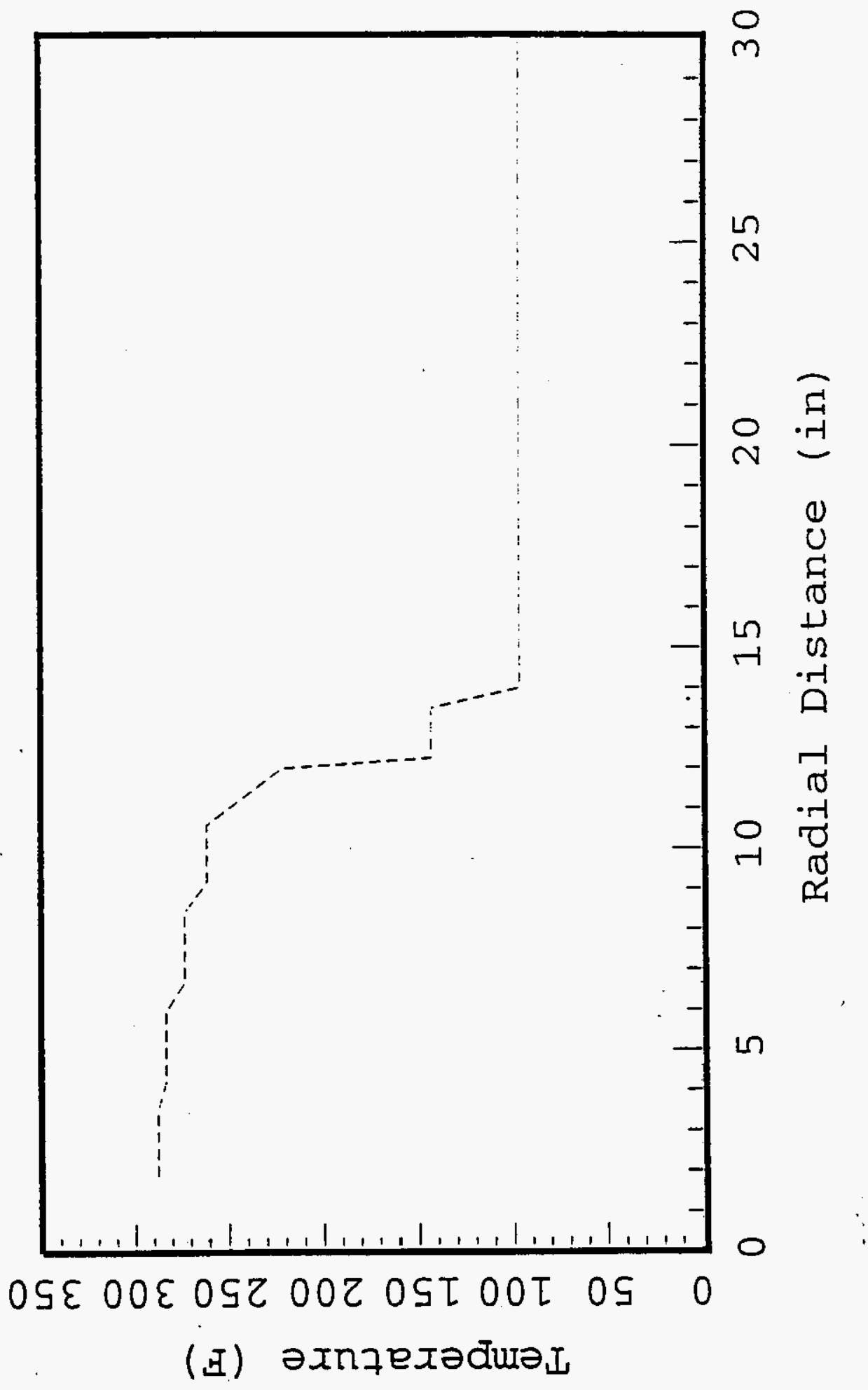


WHC-SD-WM-ER-525

Rev. 0

\subsection{CONCLUSIONS AND RECOMNENDATIONS}

A series of scoping analyses have been completed investigating the thermal hydraulic performance and feasibility of the Spent Nuclear Fuel Project (SNFP) Integrated Process Strategy (IPS). The subject analyses utilized the FIDAP and HUB computer programs.

The subject efforts focused on investigating, quantifying, and establishing the governing heat production and removal mechanisms for each of the individual IPS operations and configurations, obtaining preliminary results for comparison with and verification of other analyses, and providing technology based recommendations for consideration and incorporation into the design bases for the SNFP. The goal was to develop a series of thermalhydraulic models that could respond to all process and safety related issues that may arise pertaining to the SNFP. A series of sensitivity analyses were al so performed to help identify those parameters that have the greatest impact on energy transfer and, hence, temperature control. It is anticipated that the subject thermal-hydraulic models will form the basis for a series of advanced and more detailed models that will more accurately reflect the thermal performance of the IPS and alleviate the necessity for some of the more conservative assumptions and over simplifications, as well form the basis for the final process and safety analyses.

By necessity the level of thermal analysis documented within this report was scoping in nature. This was driven by the general complexity of the IPS, the preliminary realization of the extent of fuel corrosion, the large number of possible geometrical configurations, the rapidly evolving Multi-Canister Overpak (MCO) and transportation shipping cask designs, the incredible demand for thermal hydraulic information, and the limited time to preform the analyses.

The six MCO, transportation shipping cask, and CSB storage tube thermal models that were developed are considered "generic" in nature, in the sense that extensive flexibility was build into the treatment of the individual fuel assemblies. Figures 3-1 through 3-4 present planar views of the subject MCOs with Mark Ia or Mark IV fuel assemblies, while Figures 4-8 through 4-11 present the resulting finite-element mesh. The thermal models considered the spent nuclear fuel types, physical condition of the fuel, potential chemical reactions, the various packing configurations for loading, and the ambient environmental conditions including solar heating associated with the transportation of the fuel to the CSB for interim storage. The user has complete control to specify the type of chemical reaction, reactive surface area, reactant mass limits, and nuclear decay heat generation values for groups of elements, single elements, or down to the nodal level.

Four Arrhenius Rate Law based relationships involving reactions between unirradiated uranium, liquid water, and water vapor with or without oxygen were also modeled via user written subroutines. These reactions are referred to by the name of the author that published the results; i.e, Tyfield (1988), McGillivary (1994), Ritchie (1981), and Condon (1983). The McGillivary and Ritchie reactions can be subdivided further on the basis of having an oxygenated or oxygen free environment. The fourth reaction relationship (Condon), which is based on thermodynamic principles, is still being 
WHC-SD-WM-ER-525

Rev. 0

investigated, but is mentioned for completeness. The Tyfield, Ritchie and McGillivary reaction rate relationships are illustrated in Figures 3-5 through 3-7. It must be emphasized that these reaction rate relationships were developed using unirradiated uranium metal samples. Reaction rate correlations remain to be confirmed or developed for irradiated uranium metal. It is expected that reaction rate relationship(s) for irradiated uranium fuel will be developed from data scheduled to be obtained by Pacific Northwest National Laboratory (PNNL) personnel from chemical kinetic reaction studies of irradiated K-West fuel samples. The irradiation reaction rate relationship(s) will be added to the above thermal models when they are made available.

Table 5-1 presents a comparison of the equilibrium peak fuel temperatures after a simulated 15 day transient heatup for the baseline models given representative environmental conditions, fill gases, and decay heats. The results from Table 5-1 indicate that the Mark IV fuel assemblies with 54 assemblies per tier will have slightly higher temperatures than the corresponding results for Mark la fuel assemblies. This is expected considering the reduced fuel loading required for Mark Ia fuel. Table 5-1 also indicates that the CSB storage tube will have the higher peak fuel temperatures, due to the reduced heat transfer from the MCO, and that the use of helium as a fill gas will minimize the peak fuel temperatures and can offset the peak fuel temperatures associated with a maximum decay heat load of $929 \mathrm{~W}$ per MCO and the use of argon as the fill gas.

The results as presented in Tables 5-2 and 5-3 indicate that the presence of oxygen reduces the chemical reaction rates and, hence, the peak fuel temperature. It is evident that the $K$ Basin water must be oxygenated to prevent increased chemical reaction rates. If oxygenated water cannot be assured, it is recommended that the time sequences associated with each of the three process phases described in Section 5.1.2 be limited or an auxiliarycooling mechanism be developed to provide ambient conditions low enough to maintain the peak fuel temperature less than $170^{\circ} \mathrm{F}\left(350^{\circ} \mathrm{K}\right)$. These measures are necessary to prevent a "runaway" temperature excursion within an environment that contains essentially an unlimited supply of reactants.

The results as presented in Table 5-4 indicate that establishing a water heating/cooling mechanism using the 0.25 in. MCO-cask gap is an extremely effective means to raise internal temperature enough to supply the energy necessary to evaporate the residual water without freezing. Comparison of Figures 5-22 with 5-23 and 5-28 with 5-29 indicated that the water gap significantly reduces the time necessary to achieve equilibrium peak fuel temperatures. For nominal decay heat peak temperatures are achieved after approximately 2 days $(17,2800 \mathrm{~s})$ for the water-filled gap versus approximately 6 days $(518,400 \mathrm{~s})$ for the air-filled gap. For maximum decay heat, the corresponding values are approximately 1.5 days $(129,600 \mathrm{~s})$ versus approximately 5 days $(432,000 \mathrm{~s})$.

For nominal decay heat, increasing the emissivities associated with stainless steel from 0.25 to 0.75 completely offsets the temperature increase associated with an air-filled versus water-filled gap, but does not reduce the longer heatup time associated with the air-filled gap. For maximum decay heat, increasing the emissivity of stainless steel 304 from 0.25 to 0.75 offsets approximately half of the temperature increase and does not significantly reduce the heatup time associated with an air-filled gap. 
For most conditions within a MCO, shipping cask, or storage tube, the reaction rate will be 1 imited by the availability of reactants such as water vapor and oxygen. The chemical reaction can proceed no faster than the rate at which water vapor is generated by evaporation (or oxygen can be supplied) and transported to the reaction surface. The present analyses are considered conservative in this sense by assuming that no energy is required to evaporate water and no time delay occurs in transporting the chemical species to the reacting surface. The thermal models do have the capability to limit the reactions based on an assumed mass of residual reactants or the total amount of chemical energy produced, but do not account for mass transfer delays. Other mass transport effects that may need to be accounted for are the rate limiting effects of hydrogen production and blanketing, an inert gas purge, and the buildup of a diffusion limiting oxide or scale layer.

Table 5-5 and Figures 5-34 and 5-35 present the thermal performance of a MCO within a shipping cask for various ambient temperatures given $2.5 \mathrm{Kg}$ of residual water with and without oxygen. The resulting peak fuel or $\mathrm{cladding}$ temperature profiles were plotted and numerically differentiated. The goal was to determine when the second derivative of temperature with respect to time went positive. This was judged to be a prime indication of the ignition temperature necessary to start a "runaway" chemical reaction. The results of the second derivative analysis indicate that Figure 5-34 (0xygen free) for al1 ambient conditions and Figure 5-35 (0xygenated) for ambient conditions of $160{ }^{\circ} \mathrm{F}$ and $140^{\circ} \mathrm{F}$ the temperature signatures are representative of a "runaway" chemical reaction. These excursions are terminated after the chemical energy equivalent to $2.5 \mathrm{Kg}$ of water was produced. The peak fuel temperatures begin to decrease and eventually reach an equilibrium peak fuel temperatures associated with decay heat only.

The results presented in Table 5-6 are for decay heat only. Low estimates of the emissivities were also used to derive the sensitivities of the peak fuel temperatures. An energy balance was also performed to determine the relative amount of energy transferred by conductive and radiative means. The results indicate that when helium is used as a backfill gas, the $\mathrm{MCO} /$ storage tube system is conduction dominated and peak fuel temperatures are the lowest. The effect of doubling the emissivities is minimal when helium is used. The exact opposite is true when nitrogen or argon are used. Peak fuel temperatures are their highest when argon is used. Nitrogen is a close second and the systems are now radiation dominant. The effect of doubling the emissivities is dramatic. Peak fuel temperatures can be reduced by $90^{\circ} \mathrm{F}$ $\left(50^{\circ} \mathrm{K}\right)$.

The results presented in Table 5-7 and Figures 5-36, 5-37, and 5-38 clearly show the effect of various amounts of residual water and various fill gases. The greater the amount of residual water, the higher the transient peak fuel temperature. The CSB performance specification (Swenson 1995) indicates that 4 pounds (approximately $1.82 \mathrm{Kg}$ ) of residual water are expected to remain after warn vacuum drying. The temperature traces corresponding to $2.5 \mathrm{Kg}$ of water can be to used to establish the expected thermal performance of the CSB storage tube. The subject figures all show a breakpoint associated with the consumption of the residual water. Once the chemical energy equivalent to the amount of residual water has been produced, the chemical reaction is terminated and the thermal response of the system proceeds based on stored energy and decay heat. 
Additional three-dimensional thermal-hydraulic models, representative of the axial configuration of a MCO within shipping cask and storage tube containing up to six levels of fuel, are currently in development and will be used to quantify internal natural convection patterns, mass transfer, potential hot spots, and the extent and duration of surface chemical reactions under various normal operating and off-normal scenarios. It is expected that these models will have the capability to model an evaporative source of water vapor, the transport of the reacting species throughout the system by diffusion or internal convection flows, and the removal of mass from the system by the vacuum pump.

In summary, the results of preliminary thermal analyses do not preclude any of the current path options given nominal material properties, representative environmental conditions, and the anticipated process timeline sequences. However, uncertainties in the material properties, definition of the multiple and competing chemical reactions, concerns about residual reactants within the MCO after vacuum drying, and the reactive surface area associated with corroded fuel presently make definitive statements difficult.

The subject thermal analyses have shown that natural convection within the MCO will provide a significant mechanism for axial and radial heat redistribution and mass transport just prior to vacuum drying and during transportation to the CSB. To maximize the thermal performance of the MCO and, hence, temperature control, it is recommended that the MCO be designed to enhance natural circulation by providing enough uniformly spaced parallel low resistance flow paths around and through each tier of individual fuel assemblies, upper and lower plenums, and tier-to-tier alignment (i.e, to enhance the "chimney effect" for mass transport). Tier-to-tier alignment should be balanced with the need to promote mixing and prevent flow channeling during the hot conditioning process.

A series of sensitivity analyses have also shown that radiative heat transfer is a significant mechanism for heat transfer, especially under vacuum conditions when natural convection is not possible. Consideration must be given to special coatings or passivation treatments to enhance the emissivity and, hence, radiative heat transfer. It is strongly recommended that the emissivities of the fuel baskets and the MCO inner and outer surfaces be maximized to achieve surface emissivities in the range of 0.7 to 0.8 , regardless of the fill gas. The emissivity of the canister storage building (CSB) storage tube surfaces and the inner surface of the transportation shipping cask should also be held to similar high values. In addition, the emissivity of the zircaloy cladding surfaces must be confirmed to be equal or greater than 0.4

The use of helium as a back fill or inerting cover gas in the MCO is very effective in reducing the temperature of the fuel and is strongly recommended, but leakage issues and cost considerations may 1 imit the effectiveness of this option. However, because of the potential off-normal event concerning the loss-of-helium fill gas and higher fuel temperatures if nitrogen or argon are used as the back fill gas, the recommendation for enhanced fuel basket and MCO emissivities remains. 
Rev. 0

The above recommendations for enhanced emissivities and helium as the fill gas become non-issues, if the proposed MCO temperature profile, corresponding to a peak fuel temperature of $400^{\circ} \mathrm{F}$ and a maximum $M C O$ surface temperature of $270^{\circ} \mathrm{F}$, provides an acceptable pre-condition (i.e., basis) for the required safety analyses.

Current analyses have also shown that the proposed $50^{\circ} \mathrm{C}\left(122^{\circ} \mathrm{F}\right) \mathrm{MCO}-$ shipping cask gap cooling/heating water system is an important means to supply enough energy to evaporate any residual water and achieve higher fuel temperatures in a timely manner, but low enough to prevent rapid uranium metal reaction rates.

During vacuum drying, the supply of oxidants will be limited to the amount of residual water remaining in the cask and the amount of air that could flow through the cask through broken inlet and outlet vacuum lines. Current estimates show that for nominal conditions the amount of air flow or the amount of residual water expected to remain in the MCO after draining and vacuum drying. will not be sufficient to sustain a runaway oxidation reaction, even if temperatures are high enough to reach such a condition.

Ignition and runaway oxidation reactions in the CSB storage tubes are unlikely because most of the moisture will have been removed by vacuum drying. Residual water or air inleakage through failed ports will not be sufficient to sustain a runaway oxidation reaction and, normally, the fuel is expected to be stored in an inert atmosphere. However, the highest fuel temperatures will occur within the CSB storage tubes due to reduced heat transfer. Any residual reactants, such as frozen water, will react quite rapidly given the high temperature conditions within the CSB.

Since maximum fuel temperatures are likely for high decay heat MCOs, gas generation, especially hydrogen, and the ability to vent these gases are likely to be an issue. Large concentrations of hydrogen in the MCO and/or storage tube could be hazardous if an air ingress incident occurs. High pressures caused by gas generation could also become an issue if they are sufficiently high and the MCOs and/or storage tubes are sealed. 
WHC-SD-WM-ER-525

Rev. 0

\subsection{REFERENCES}

Bird, R. B., W. E. Stewart, and E. N. Lightfoot, 1960, Transport Phenomena, John Wiley and Sons, Inc, New York, New York.

Condon, J. B., S. B. Cristy, and J. R. Kirkpatrick, 1983, Final Progress Report - Uranium Reactions With Water Vapor, Y/DU-274, Union Carbide Corporation, Oak Ridge National Laboratory, Oak Ridge, Tennessee.

El-Waki1, M. M., 1971, Nuclear Heat Transport, International Textbook Company, Scranton, Pennsylvania.

Heard, F. J., 1994, FIDAP Version 7.06 - Validation/Verification, WHC-SD-WM-ER-302, Rev. 1, Westinghouse Hanford Company, Richland, Washington.

Holman, J. P., 1990. Heat Transfer, Seventh Edition, McGraw-Hi11, New York, New York.

Lawrence, L. A., 1995, Data Quality Objectives for the Reaction Kinetic Studies of $K$ West Fuel Samples, WHC-SD-SNF-DQ0-007, Rev. 0, Westinghouse Hanford Company, Richland, Washington.

McAdams, W. H., 1954, Heat Transmission, 3rd Ed., McGraw-Hi11 Book Company, New York, New York.

McGillivary, G. D. Geeson, and R. Greenwood, 1994, Studies of the Kinetics and Mechanisms of the Oxidation of Uranium by Dry and Moist Air, Journal of Nuclear Materia1s, 208, pp 81-97.

Nuclear Systems Material Handbook, TID-26666, Oak Ridge National Laboratory, Oak Ridge, Tennessee.

Puigh, R. J., et a1., 1995, Technology Status in Support of Refined Technical Baseline for the Spent Nuclear Fuel Project, WHC-SD-SNF-TI-014, Rev. 1, Westinghouse Hanford Company, Richiand, Washington.

Ritchie, A. G., 1981, "A Review of the Rates of Reactions for Uranium in Oxygen and Water Vapor at Temperatures up to $300^{\circ} \mathrm{C}, "$ Journal of Nuclear Materials, 102, pp 170-182.

Short, S. M., and M. M. Beary, 1995, SNF Project Technical Databook, WHC-SD-SNF-TI-015, Rev. 0, Westinghouse Hanford Company, Richl and, Washington.

Swenson, C. E., 1995, Performance Specification for the Spent Nuclear Fuel Canister Storage Building, WHC-S-0425, Rev. 0, Westinghouse Hanford Company, Richland, Washington.

Tyfield, S. P., 1988, Corrosion of Reactor Grade Uranium in Aqueous Solutions Relevant to Storage and Transport, Nuclear Energy, No. 2. 
WHC-SD-WM-ER-525

Rev. 0

APPENDIX A

SURFACE HEAT FLUX - USER SUBROUTINE (USRBCF) 
WHC-SD-WM-ER-525

Rev. 0

\section{APPENDIX A}

\section{SURFACE HEAT FLUX - USER SUBROUTINE (USRBCF)}

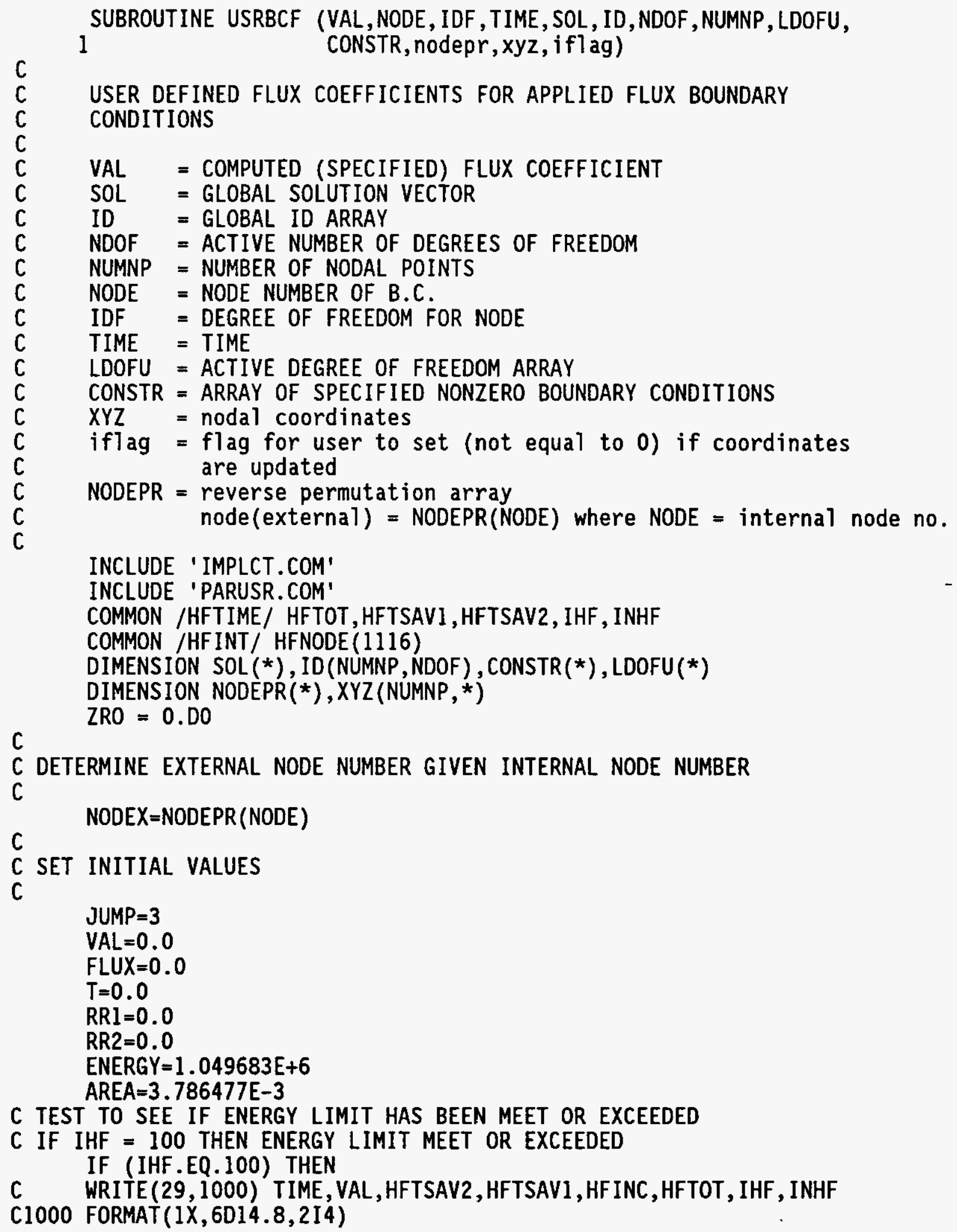




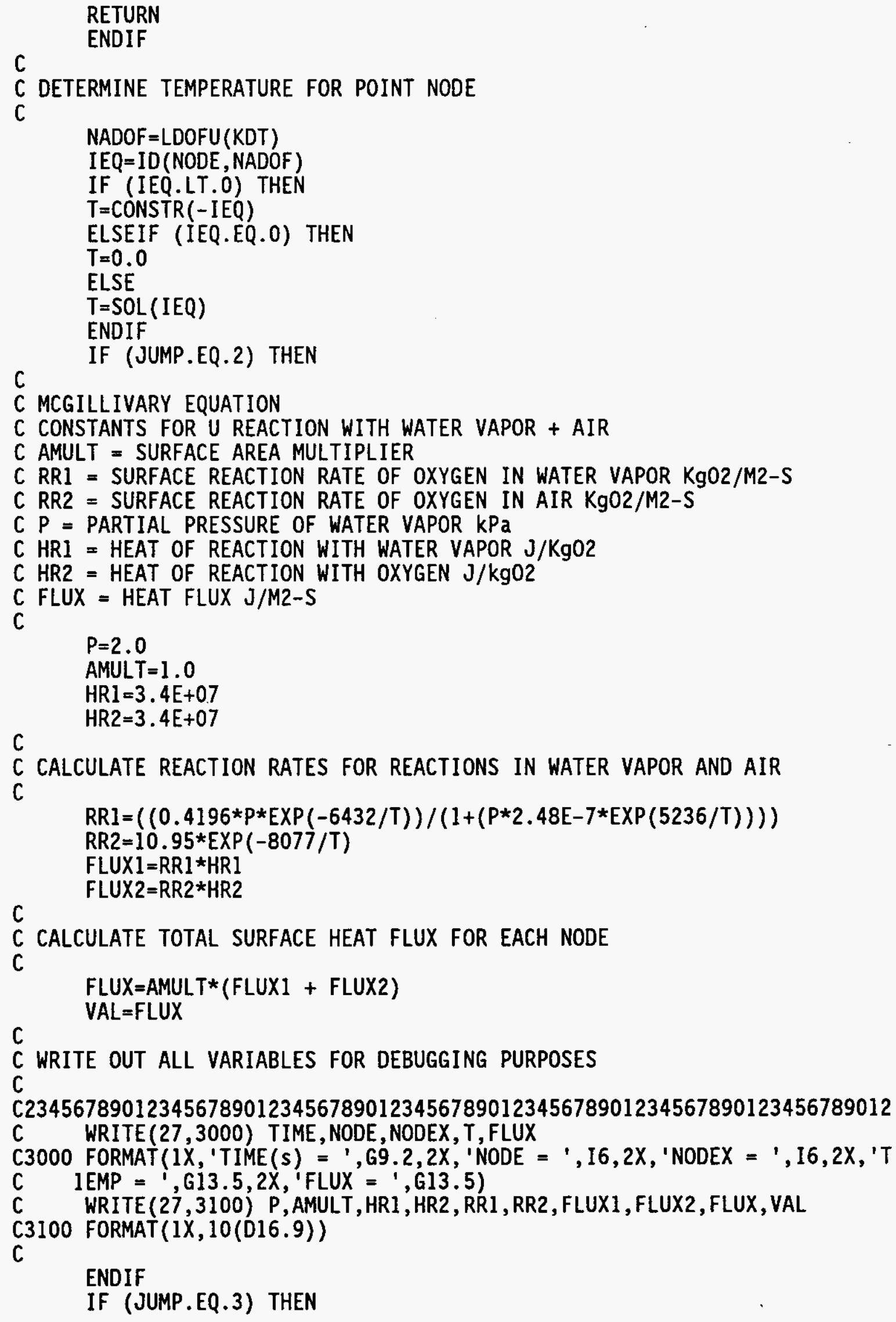




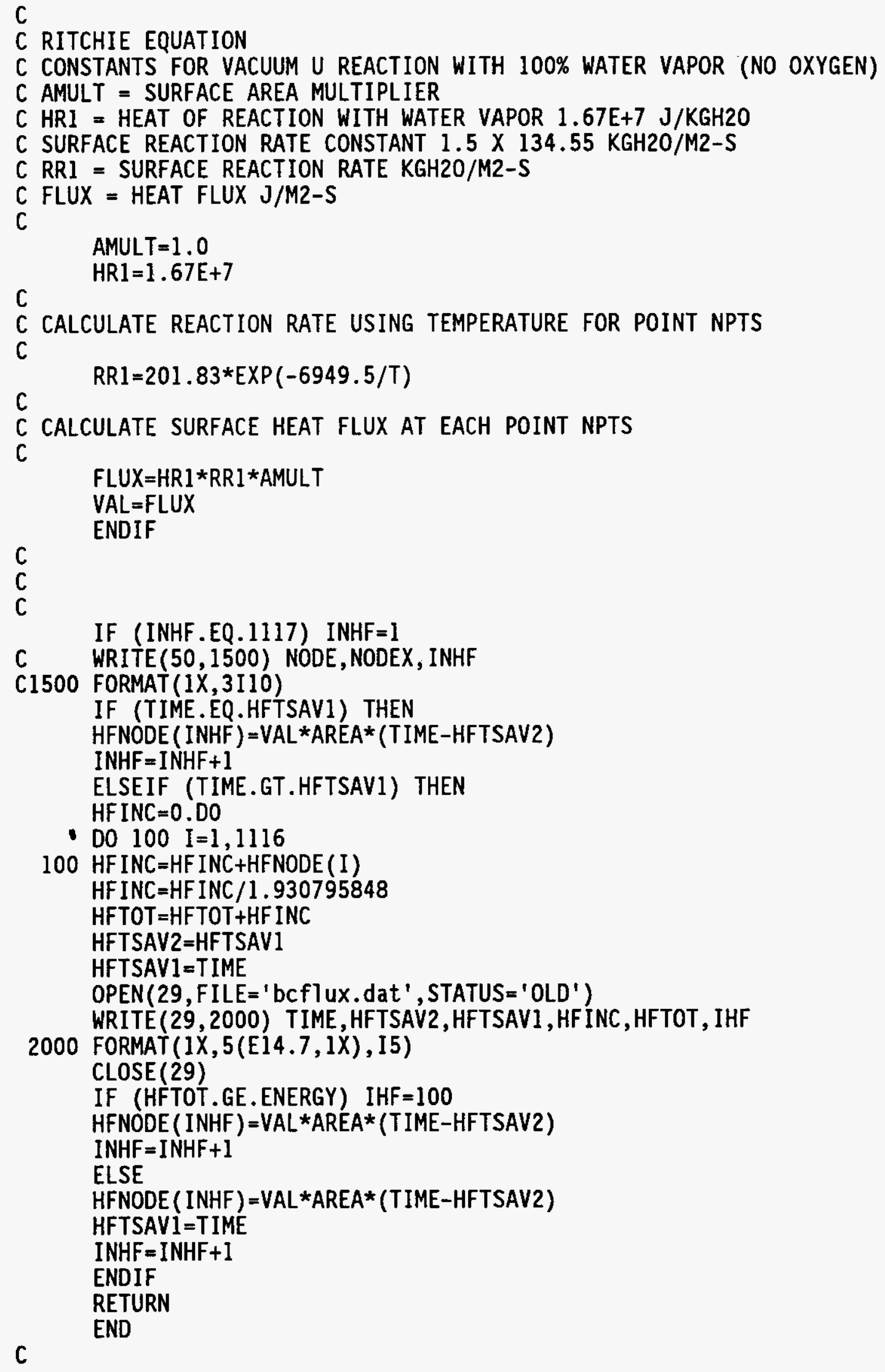


WHC-SD-WM-ER-525

Rev. 0

\section{APPENDIX B}

VOLUMETRIC HEAT SOURCE - USER SUBROUTIN (USRSRC)

B-1 


\section{APPENDIX B}

\section{VOLUMETRIC HEAT SOURCE - USER SUBROUTIN (USRSRC)}

SUBROUTINE USRSRC (NELT, NE, NG, SORCE, VARI, DVARI, NDFCD, LDOFU, SHP, 1

DSDX, XYZL, PROP, TIME, NPTS, ndp, MNDP, IERR, IOPT)

$$
\begin{aligned}
& C \\
& C \\
& C \\
& C \\
& C \\
& C \\
& C \\
& C \\
& C \\
& C \\
& C \\
& C \\
& C \\
& C \\
& C
\end{aligned}
$$

C

C

C

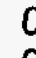

$$
\text { con }
$$

$$
\text { c }
$$

c

C

C$$
\text { C }
$$

C

C

C

C

C

C

C

C PROP (2) $=$ NORMALIZED REACTION SURFACE AREA MULTIPLIER

C PROP (3) = SURFACE TO VOLUME CORRECTION FACTOR TYPE

C PROP(4) $=$ PARTIAL PRESSURE OF WATER VAPOR IN KPa

C

C $\operatorname{PROP}(5)=1$ = REACTANT LIMITED; 2 = NOT REACTANT LIMITED

C PROP(6) = CROSS SECTIONAL AREA OF AVG ELEMENT FOR EACH ENTITY

C

C PROP $(7)=$ MAX ENERGY IN JOULES FOR LIMITED REACTANT CALC

C PROP $(8)=1$ OXYGEN ATMOSPHERE; $=2$ OXYGEN FREE ATMOSPHERE

$C \operatorname{PROP}(9)=$ RELATIVE HUMIDITY; ZERO $=0.0$ AND $100 \%=1.0$

C

C

INCLUDE 'IMPLCT.COM'

INCLUDE 'PARUSR.COM'

COMMON /COUNTER/ENGTOT, TIMSAV1, TIMSAV2, ICOUNT 
WHC-SD-WM-ER-525

Rev. 0

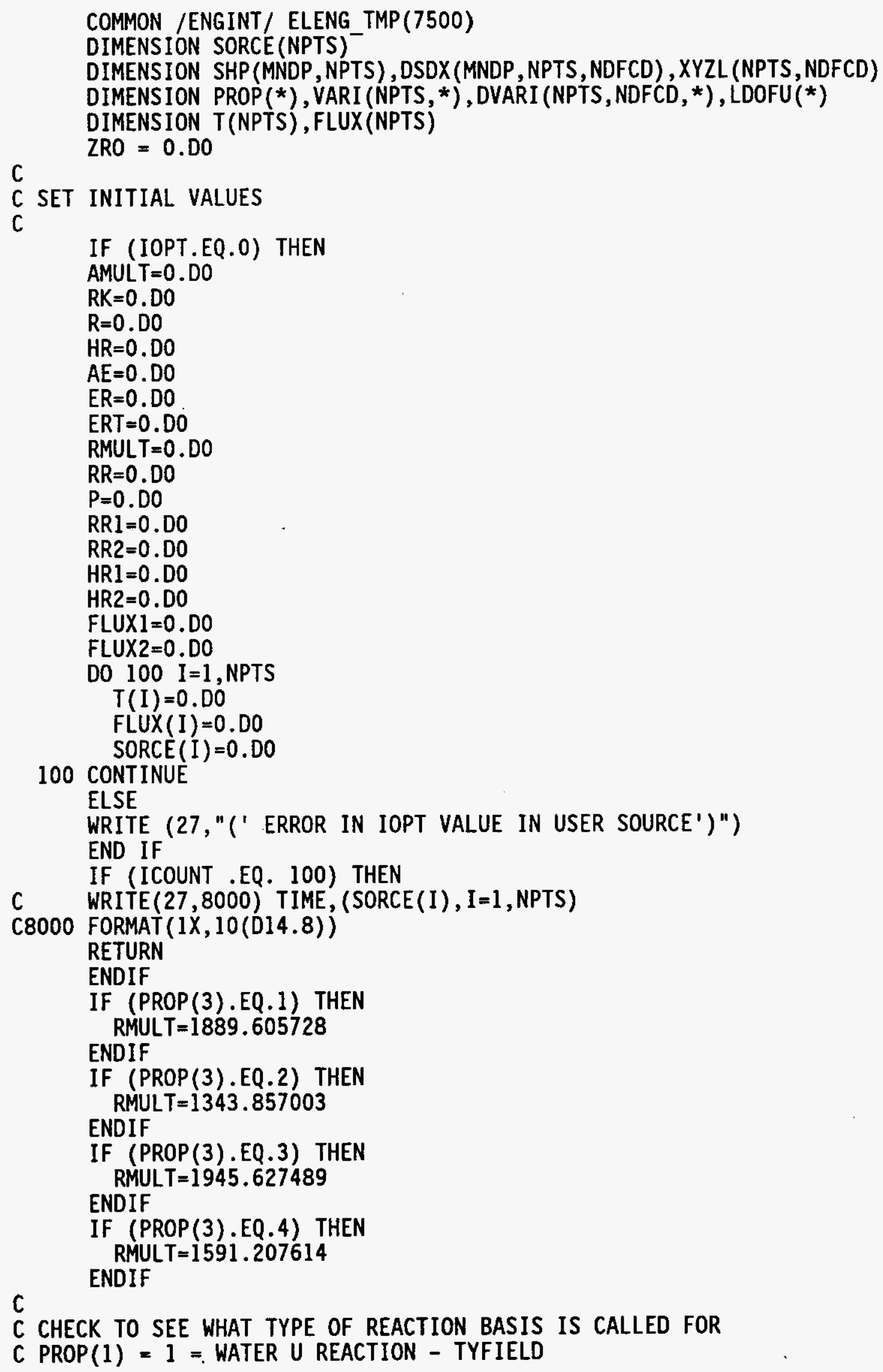


WHC-SD-WM-ER-525

Rev. 0

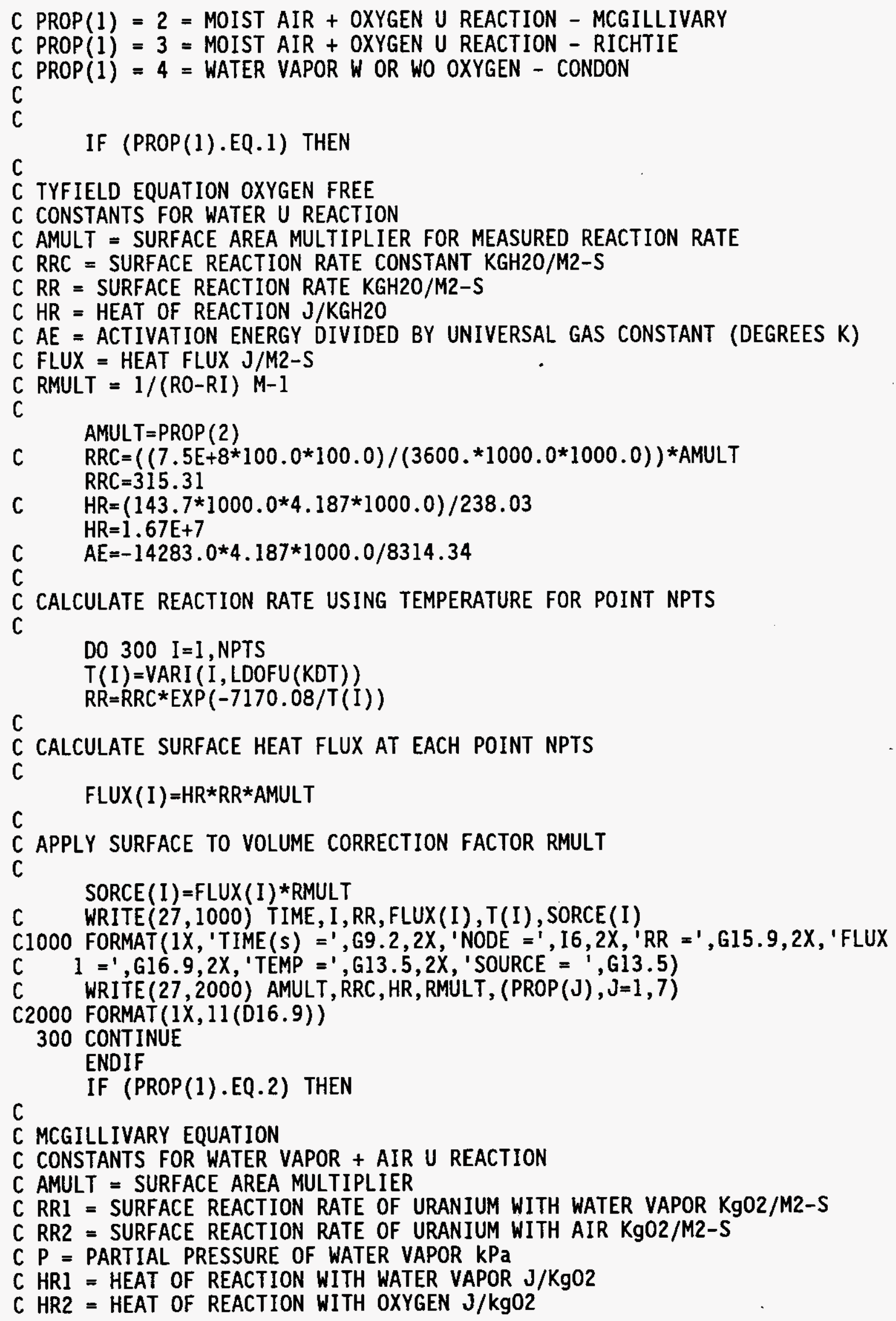


WHC-SD-WM-ER-525

Rev. 0

C FLUX = HEAT FLUX J/M2-S

C RMULT $=1 /($ RO-RI) $M-1$

C

$P=P R O P(4)$

AMULT $=P R O P(2)$

C $\operatorname{PROP}(8)=1$ INDICATES OXYGENATED ATMOSPHERE

C PROP $(8)=2$ INDICATES OXYGEN 'FREE ATMOSPHERE

IF (PROP(8).EQ.1) THEN

$\operatorname{RRC2}=10.95$

$\mathrm{HRl}=3.4 \mathrm{E}+7$

$H R 2=3.4 E+7$

ELSE

$\mathrm{RRC2}=0 . \mathrm{DO}$

$H R 1=1.88 E+7$

$H R 2=0.00$

$C$

ENDIF

C CALCULATE REACTION RATE USING TEMPERATURE FOR POINT NPTS

$\mathrm{C}$

DO $400 \mathrm{I}=1$, NPTS

$T(I)=V A R I(I, L D O F U(K D T))$

$R R 1=((0.4196 * P * \operatorname{EXP}(-6432 / T(I))) /(1+(P * 2.48 E-7 * \operatorname{EXP}(5237 / T(I)))))$

$R R 2=R R C 2 \star E X P(-8077 / T(I))$

FLUXI $=R R 1 * H R I$

C FLUX2 $=R R 2 * H R 2$

C CALCULATE SURFACE HEAT FLUX AT EACH POINT NPTS

$\mathrm{C}$

FLUX (I) $=$ AMULT* $(F L U X 1+F L U X 2)$

C

C APPLY SURFACE TO VOLUME CORRECTION FACTOR RMULT

C

$\operatorname{SORCE}(I)=F L U X(I) \star R M U L T$

C

C WRITE OUT ALL VARIABLES FOR DEBUGGING PURPOSES

C C23456789012345678901234567890123456789012345678901234567890123456789012 C WRITE $(27,3000)$ TIME, I, RRI, FLUX(I), T(I), SORCE(I)

C3000 FORMAT(1X, 'TIME(s) =', G9.2,2X, 'NODE =', I6,2X, 'RR1 =' , G15.9, 2X, 'FLUX C $1=', G 16.9,2 X,{ }^{\prime}$ TEMP $=1, G 13.5,2 X$, 'SOURCE $=$ ', G13.5)

C WRITE $(27,4000)$ P, AMULT, HR1, HR2, RMULT, RR1, RR2, FLUX1, FLUX2, (PROP(J), C $1 \mathrm{~J}=1,7$ )

C4000 FORMAT(1X,16(D16.9))

400 CONTINUE

ENDIF

C

IF (PROP(1).EQ.3) THEN

C RITCHIE EQUATION

C CONSTANTS FOR U REACTION WITH WATER VAPOR; W AND WO OXYGEN

C AMULT = SURFACE AREA MULTIPLIER

C HR1 = HEAT OF REACTION WITH WATER VAPOR AND NO $021.67 \mathrm{E}+7 \mathrm{~J} / \mathrm{KGH} 20$

$C$ HRI $=$ HEAT OF REACTION WITH WATER VAPOR AND $023.4 E+7 \mathrm{~J} / \mathrm{KGH} 20$

C RRC = REACTION RATE CONSTANT KGH2O/M2-S

C $A E=$ ACTIVATION ENERGY DEGREES $K$ 
C RRI = SURFACE REACTION RATE KGH20/M2-S

C FLUX $=$ HEAT FLUX J/M2-S

C RMULT $=1 /($ RO-RI $)$ M-1

C SORCE $=$ VOLUMETRIC HEAT SOURCE $\mathrm{J} / \mathrm{M3}-\mathrm{S}$

C

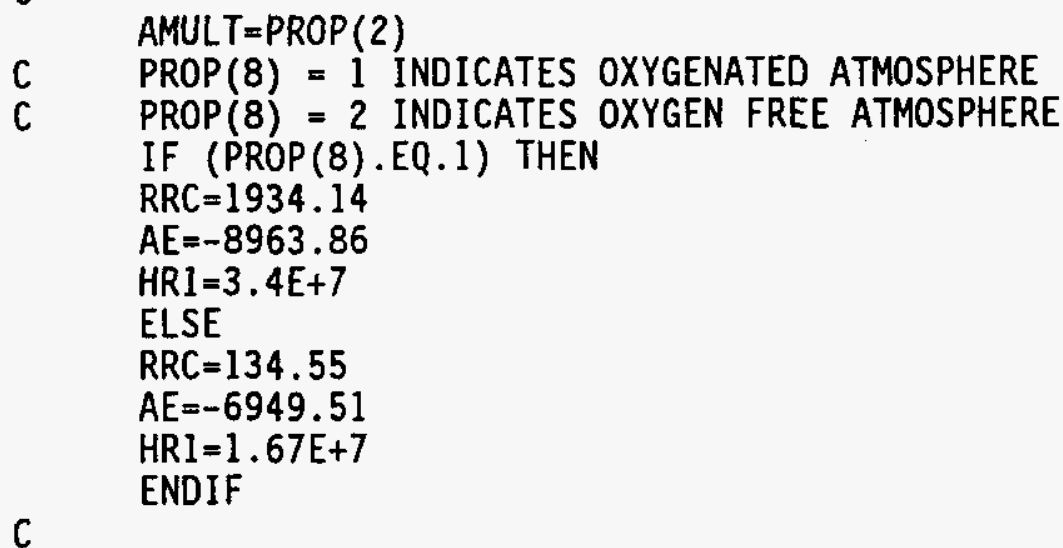

C CALCULATE REACTION RATE USING TEMPERATURE FOR POINT NPTS

$\mathrm{C}$

DO $500 \quad I=1$, NPTS

$T(I)=V A R I(I$, LDOFU (KDT))

C

$R R I=R R C * E X P(A E / T(I))$

C CALCULATE SURFACE HEAT FLUX AT EACH POINT NPTS

C

FLUX $(I)=H R I * R R I * A M U L T$

$C$

C APPLY SURFACE TO VOLUME CORRECTION FACTOR RMULT

C

C WRITE (27,5000) TIME, I,RR1, FLUX(I),T(I), SORCE(I)

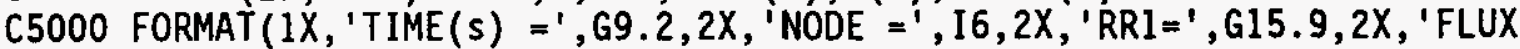

C $\quad 1={ }^{\prime}, G 16.9,2 X,{ }^{\prime}$ TEMP $=', G 13.5,2 X,{ }^{\prime}$ SOURCE $=', G 13.5$ )

C WRITE $(27,6000)$ AMULT, HRI, RK, AE, R, ER, ERT, RMULT, (PROP(J) , J=1,7)

C6000 FORMAT (IX, 15(016.9))

500 CONTINUE

ENDIF

C

C

C

IF (PROP(1).EQ.4) THEN

AMULT $=P R O P(2)$

$A=3.0$

US $=0.9775$

DO $550 \quad I=1$, NPTS

$T(I)=V A R I(I, L D O F U(K D T))$

C PROP (8) = 1 INDICATES OXYGENATED ATMOSPHERE

C PROP $(8)=2$ INDICATES OXYGEN FREE ATMOSPHERE

C $\quad$ PH $=$ HYDROGEN PRESSURE IN PASCALS

IF (PROP(8) .EQ. 1) THEN

$A L N P H=69.32-14640 . / T(I)-5.65 * \operatorname{DLOG}(T(I))$

$\mathrm{PH}=\operatorname{EXP}(\mathrm{ALNPH})$

$\mathrm{DH}=259.3 \star 4187 . / 0.23803$ 


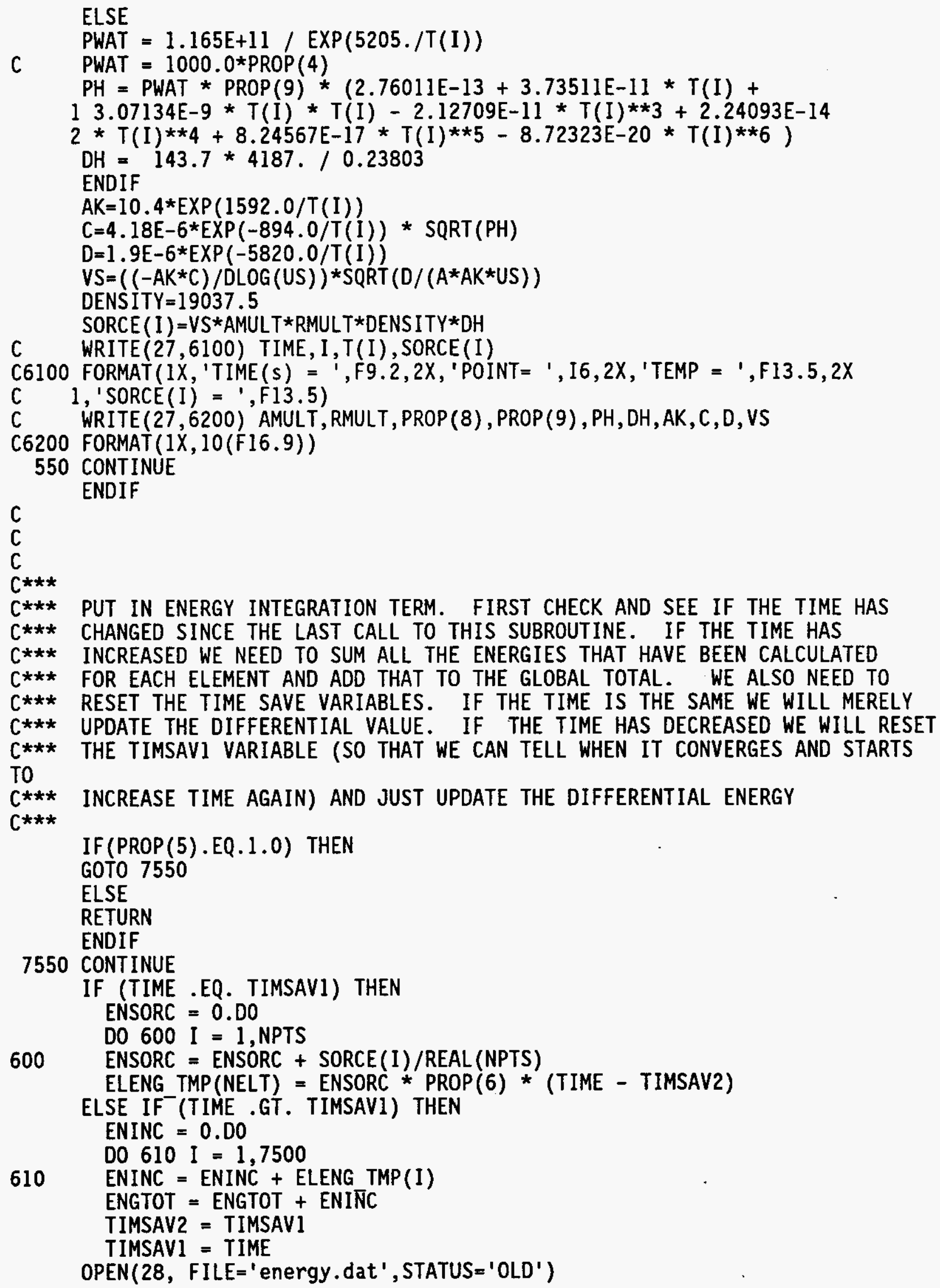


WHC-SD-WM-ER-525

Rev. 0

WRITE $(28,7000)$ TIME, TIMSAV2, TIMSAV1, ENINC, ENGTOT, ICOUNT

CLOSE (28)

7000 FORMAT $(1 X, 5(014.8,1 X), 14)$

$C * \star *$

$C * \star *$

IF IT IS DESIRED TO LIMIT THE ENERGY BUT CONTINUE THE CALCULATION

$C * * *$

SET ICOUNT TO 100 AND THEN IF ICOUNT IS 100 ZERO OUT THE DECAY HEAT

$C * * *$ SOURCE AT THE NEXT CALL TO USRSRC

$C * * *$

$\mathrm{C} * \star * \quad U+2 \mathrm{H} 2 \mathrm{O}=\mathrm{UO2}+2 \mathrm{H} 2+143.7 \mathrm{kcal} / \mathrm{gm}-\mathrm{mole} U$ or $2.5277146 \mathrm{E}+6 \mathrm{~J} / \mathrm{KGU}$

$C * * * \quad$ ENERGY $=1.6699193 \mathrm{E}+07 \mathrm{~J} / \mathrm{KG}-\mathrm{H} 20$ OR $1.8802835 \mathrm{E}+07 \mathrm{~J} / \mathrm{KG}-02$

$C * * *$ CALCULATE WATER PER UNIT LENGTH THEN DIVIDE BY FACTOR FOR SYMMETRY

C***

IF (ENGTOT .GE. PROP(7)) ICOUNT $=100$

$C * * *$

NOW GO AHEAD AND CALCULATE A NEW DIFFERENTIAL ENERGY FOR THIS ELEMENT

ENSORC $=0$. DO

D0 $620 \mathrm{I}=1$,NPTS

620 ENSORC = ENSORC + SORCE(I)/REAL (NPTS)

ELSE

ELENG_TMP $($ NELT $)=$ ENSORC * PROP $(6) *($ TIME - TIMSAV2 $)$

ENSORC $=0 . D 0$

DO $630 \mathrm{I}=1$,NPTS

630

ENSORC = ENSORC + SORCE(I)/REAL(NPTS)

ELENG TMP $($ NELT) $=$ ENSORC * PROP (6) $\bullet($ TIME - TIMSAV2 $)$

TIMSAVI = TIME

END IF

RETURN

C

END 
WHC-SD-WM-ER-525

Rev. 0

APPENDIX C

LISTING OF COMPUTER PROGRAM (SOLAR.F) TO CALCULATE SOLAR INSOLATION

C-1 
Rev. 0

\section{APPENDIX C}

\section{LISTING OF COMPUTER PROGRAM (SOLAR.F) TO CALCULATE SOLAR INSOLATION}

program solar

dimension whc1992(24), cfr7l (24), cfrcos (24), ashrae (24), heat (24)

data whcl $1992 / 0.0,0.0,0.0,0.0,9.2,36.1,81.5,134.9,184.0,223.8,2$

$151.8,265.8,265.1,250.0,223.1,184.0,137.2,87.0,41.7,10.7,4 * 0.0$ /

data $\operatorname{cfr} 71 / 4 * 0.0,11.4,44.7,100.7,166.8,227.5,276.7,311.3,328.6$

$1,327.7,309.0,275.8,227.5,169.6,107.6,51.5,13.2,4 * 0.0 /$

data cfrcos / $4 * 0.0,50.1,98.8,143.8,184.0,218.3,244.8,262.9,272$.

$11,272.1,262.9,244.8,218.3,184.0,143.8,98.8,50.1,4 * 0.0 /$

data ashrae / $6 * 0.0,67.3,156.0,235.5,300.4,346.0,370.0,370.0,346$

$1.0,300.4,235.5,156.0,67.3,6 * 0.0 /$

do $100 i=1,24$

heat $(i)=0.0$

100 continue

write $(*, 10)$ "ENTER CHOICE FOR TYPE OF SOLAR INSOLATION(I1)"

10 format $(A)$

read $(*, 11)$ insol

11 format $(i 1)$

write $(*, 10)$ "ENTER GEOMETRY FACTOR(F12.5)"

read $(*, 12)$ geof

12 format (F12.5)

write $(*, 10)$ "ENTER SOLAR ADSORPTION FOR SURFACE(F12.5)"

read $(*, 12)$ adsorp

write $(*, 10)$ "ENTER NUMBER OF DAYS FOR SOLAR CYCLE(I3)"

read $(*, 13)$ ndays

13 format (i3)

write $(28,10)$ "INITIALIZING OUTPUT FOR SOLAR INSOLATION DATA"

write $(28,14)$ insol, geof, adsorp, ndays

14 format (1x,10x,il, 2F12.5,9x,i3)

if (insol.eq.1) then

do $200 i=1,24$

heat $(i)=(($ whcl $1992(i) * 1055.0 * 10.76391) / 3600.0) *$ geof*adsorp

200 cont inue

endif

if ( insol.eq.2) then

do $300 i=1,24$

heat $(i)=((c f r 71(i) * 1055.0 * 10.76391) / 3600.0) *$ geof*adsorp

300 cont inue

endif

if (insol.eq.3) then

do $400 i=1,24$

400 continue

heat $(i)=((\operatorname{cfrcos}(i) \star 1055.0 * 10.76391) / 3600.0) *$ geof*adsorp

endif

if (insol.eq.4) then

do $500 i=1,24$

heat $(i)=(($ ashrae $(i) * 1055.0 * 10.76391) / 3600.0) *$ geof*adsorp

500 continue

endif

second $=0.0$

heat $1=0.0$ 
write $(28,1000)$ second, heat 1

1000 format $(1 X, F 12.1, F 12.5)$

adder $=86400.0$

do $600 \mathrm{j}=1$, ndays

do $700 \mathrm{k}=1,24$

second $=$ adder $\star(j-1)+k \star 3600.0$

700 continue

600 continue

second $=$ second +3600.0

write $(28,1000)$ second, heat 1

end 
WHC-SD-WM-ER-525

Rev. 0

APPENDIX D

ASSUMPTIONS FOR $30^{\circ}$ SECTOR MARK IV MODEL AND REPRESENTATIVE FIDAP INPUT

D-1 


\section{WHC-SD-WM-ER-525}

Rev. 0

\section{ASSUMPTIONS}

1. $30^{\circ}$ Sector Model (MCO within a shipping cask)

2. Mark IV Fuet Assemblies

3. Dense Pack (54 fuel assemblies/MCO at 5 tiers) - 270 Fuel Assemblies/MCO

4. 15-day transient heatup

5. Nominal Decay (426W/MCO) Heat

6. No Chemical Reactions

7. Solar Heating (10CFR71)

8. Ambient Temperature $=100^{\circ} \mathrm{F}\left(310.9^{\circ} \mathrm{K}\right)$

9. Convective and Radiative heat transfer from outer surface of shipping cask

10. Air fill gas

11. Gap - Conduction and radiation

- No convection

12. Internal to $\mathrm{MCO} \quad-\quad$ Conduction and radiation

- No convection

13. Nominal material properties

14. SI Units $\left(\mathrm{Kg}, \mathrm{m}, \mathrm{s},{ }^{\circ} \mathrm{K}\right)$ 
Rev. 0

\section{APPENDIX D}

\section{REPRESENTATIVE FIDAP INPUT}

TITLE

30DEG, MCO+CASK, DNSPCK, MK4 , A/A, D+S, 426W, 100F

1

/ input file = cask 1 . input

I

1

/ $\$$ tole $=0.001$

Stole $=0.0042$

FI-GEN(TOLE = \$tole)

/UTILITY(MESH, LIVE)

1

/ Insert global WINDOW command here for first part of construction I

WINDOW (CHANGE $=1$, MATRIX )

1.000000

.000000 .000000

.000000

1.000000

.000000

.000000

.000000

.000000

.000000

.000000

$-1.92606$

.000000

1.000000

.000000

.000000

24.52182

45.000000

45.000000

$-9.23830$

45.000000

1.000000

10.59761

45.000000

$-23.73077$

23.73077

MACRO ( name $=$ "full")

I

/ argument 6 increments entity names for given fuel assembly numbers

I

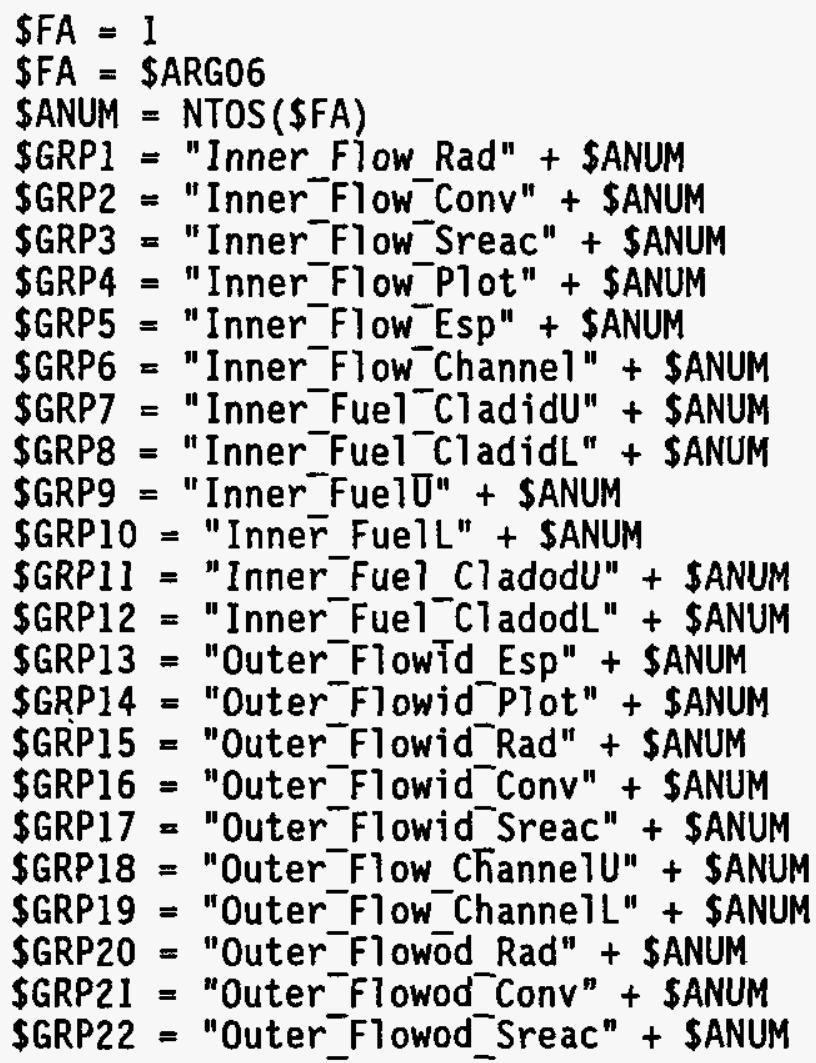




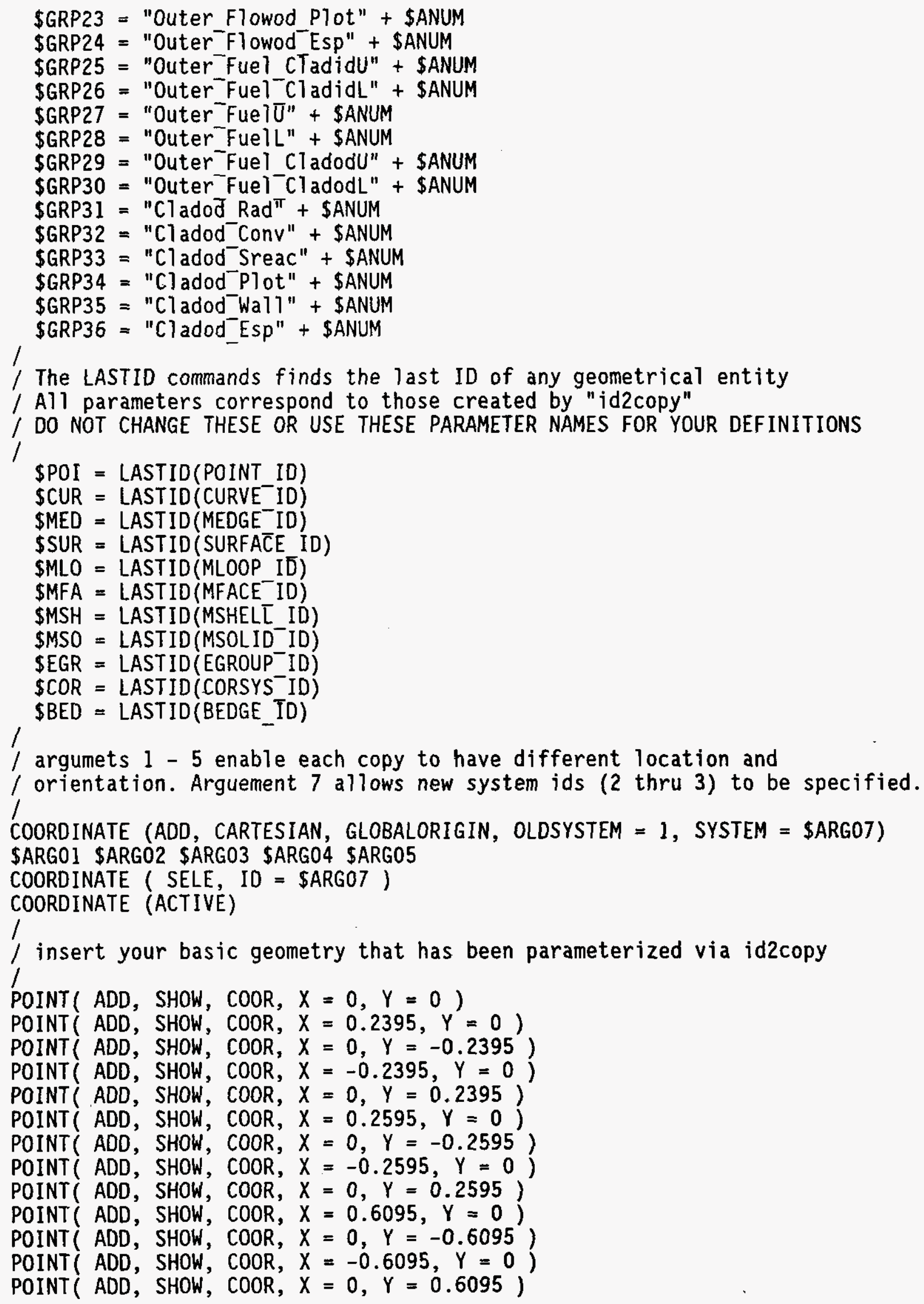




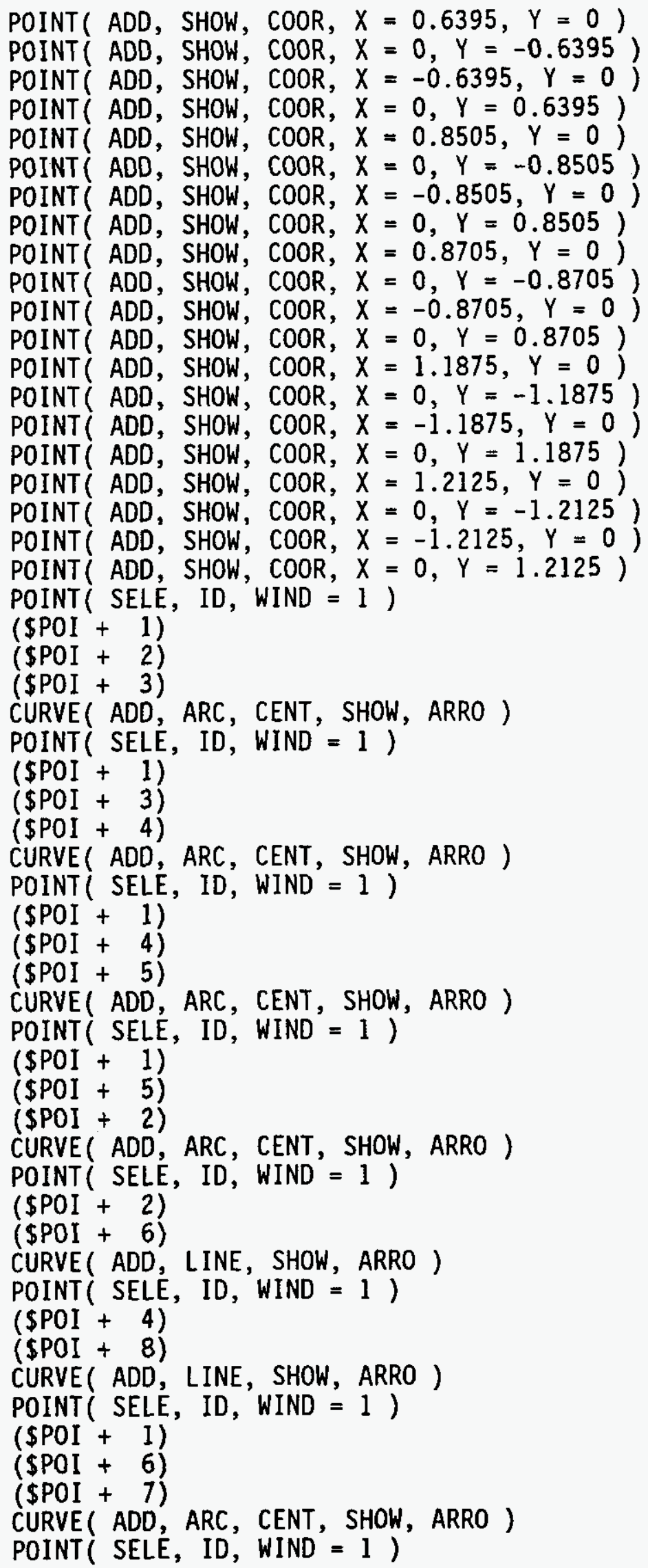




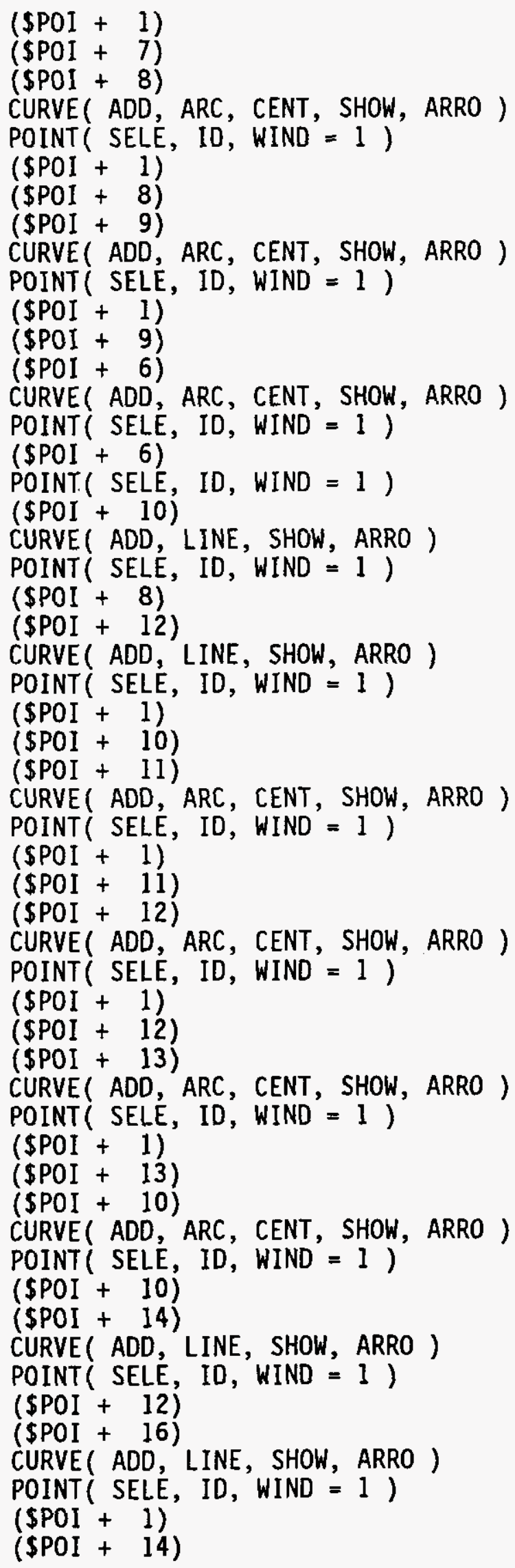


POINT( SELE, ID, WIND = 1 )

(\$POI + 15)

CURVE ( ADD, ARC, CENT, SHOW )

POINT( SELE, ID, WIND = 1 )

$($ SPOI +1$)$

$($ SPOI + 15)

POINT( SELE, ID, WIND = 1 )

$(\$ P O I+16)$

CURVE ( ADD, ARC, CENT, SHOW )

POINT( SELE, ID, WIND = 1 )

$(\$ P O I+1)$

(SPOI + 16)

POINT( SELE, ID, WIND = 1 )

(\$POI + 17)

CURVE ( ADD, ARC, CENT, SHOW )

POINT( SELE, ID, WIND = 1 )

$(\$ P O I+1)$

$($ SPOI +17$)$

(\$POI + 14)

CURVE( ADD, ARC, CENT, SHOW)

POINT( SELE, ID, WIND = 1 )

$($ \$POI + 14)

(\$POI + 18)

CURVE( ADD, LINE, SHOW, ARRO )

POINT( SELE, ID, WIND = 1 )

$(\$ P O I+16)$

$(\$ P O I+20)$

CURVE( ADD, LINE, SHOW, ARRO )

POINT( SELE, ID, WIND = 1 )

$($ SPOI +1$)$

$(\$ P O I+18)$

$(\$ P O I+19)$

CURVE ( ADD, ARC, CENT, SHOW, ARRO)

POINT( SELE, ID, WIND = 1 )

$(\$ P O I+1)$

$(\$ P O I+19)$

$(\$ P O I+20)$

CURVE( ADD, ARC, CENT, SHOW, ARRO )

POINT( SELE, ID, WIND = 1 )

$(\$ P O I+1)$

$(\$ P O I+20)$

$(\$ P O I+21)$

CURVE ( ADD, ARC, CENT, SHOW, ARRO)

POINT( SELE, ID, WIND = 1 )

$(\$ P O I+1)$

$(\$ P O I+21)$

$($ \$POI +18$)$

CURVE( ADD, ARC, CENT, SHOW, ARRO )

POINT( SELE, ID, WIND = 1 )

$($ POI +18$)$

$(\$ P O I+22)$

CURVE( ADD, LINE, SHOW, ARRO)

POINT( SELE, ID, WIND = 1 )

$(\$ P O I+20)$ 


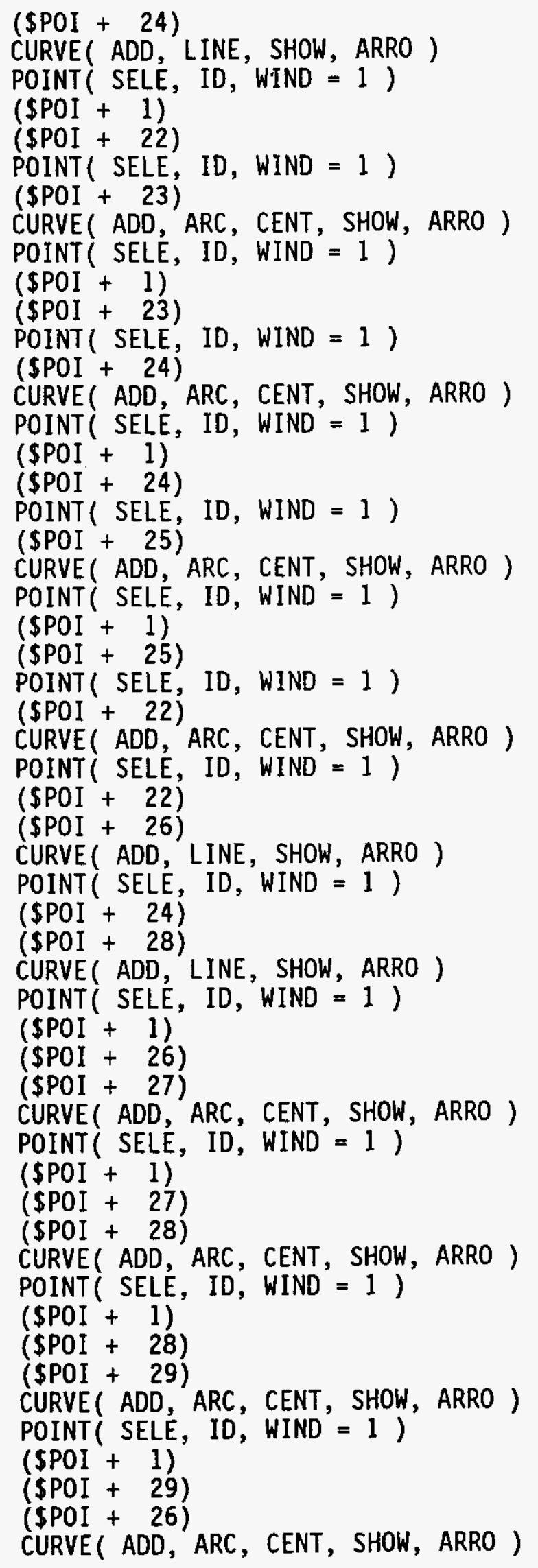




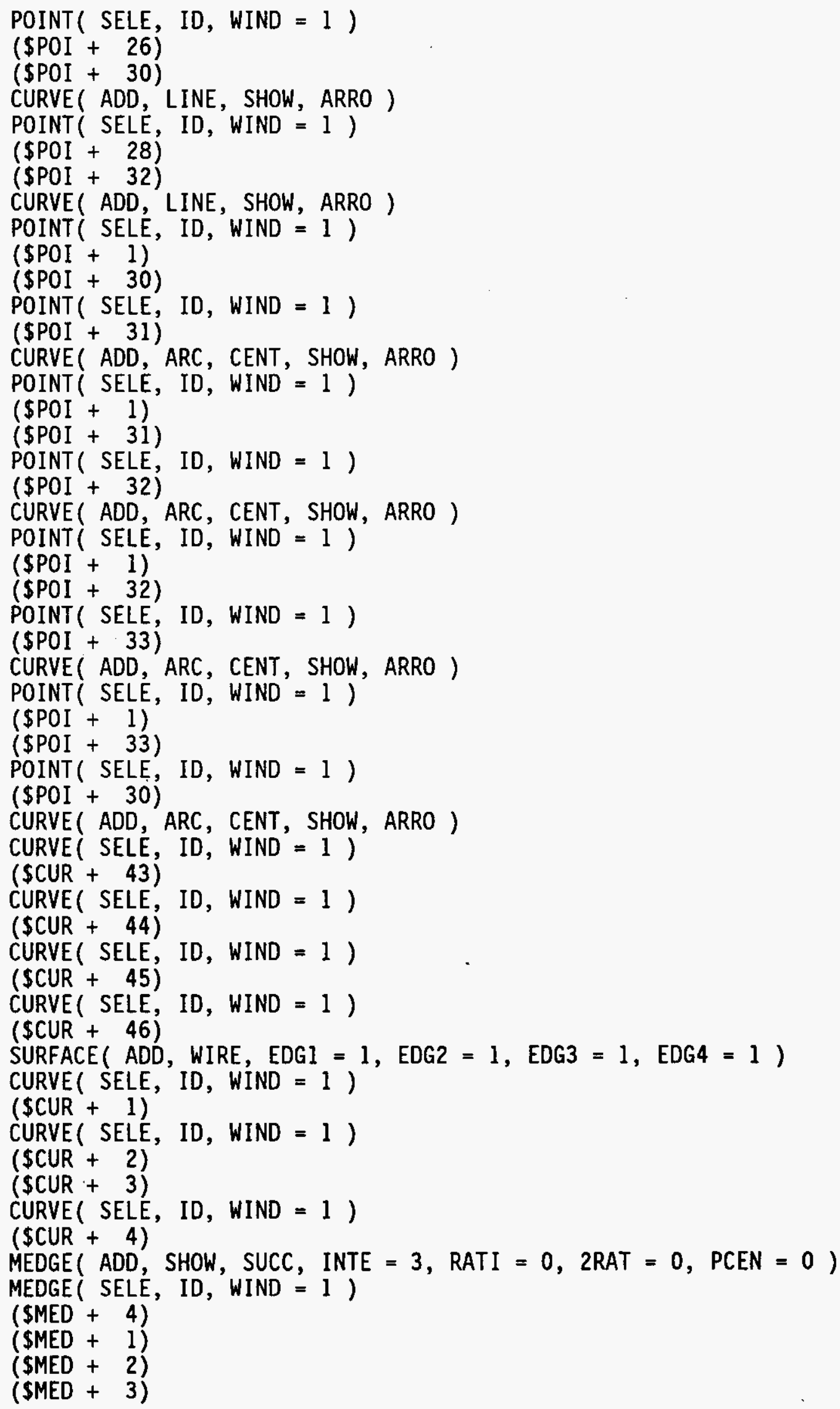


ELEMENT( SETD, EDGE, NODE = 2)

MEDGE ( MESH, MAP, ENTI = \$GRP1)

MEDGE ( SELE, ID, WIND $=1$ )

$($ SMED + 4)

(SMED + 1)

(SMED + 2)

$($ SMED + 3)

MEDGE ( MESH, MAP, ENTI = \$GRP2)

MEDGE ( SELE, ID, WIND = 1)

$(\$ M E D+4)$

$($ \$MED + 1)

$($ SMED +2$)$

$($ SMED + 3)

MEDGE (MESH, MAP, ENTI $=\$$ SRP3 $)$

MEDGE ( SELE, ID, WIND = 1 )

$($ SMED + 4)

(SMED + 1)

$($ SMED +2$)$

(\$MED + 3)

MEDGE ( MESH, MAP, ENTI $=$ \$GRP4)

MEDGE( SELE, ID, WIND = 1 )

$($ SMED + 4)

$($ SMED +1$)$

$($ SMED + 2)

$($ SMED + 3)

MEDGE ( MESH, MAP, ENTI $=$ \$GRP5 $)$

CURVE( SELE, ID, WIND = 1 )

$(\$ C U R+4)$

$(\$ C U R+1)$

$(\$ C U R+2)$

$($ SCUR + 3)

MLOOP ( ADD, PAVE, SHOW )

CURVE( SELE, ID, WIND $=1$ )

(\$CUR + 4)

$(\$ C U R+1)$

$(\$ C U R+2)$

( $S C U R+3)$

MFACE ( WIRE, SHOW, EDG1 $=1, E D G 2=1, E D G 3=1, E D G 4=1$ )

MFACE ( SELE, ID, WIND = 1 )

(\$MFA + 1)

ELEMENT( SETD, QUAD, NODE = 4 )

MFACE ( MESH, PAVE, ENTI = \$GRP6)

CURVE( SELE, ID, WIND = 1 )

( $\$$ CUR + 5)

MEDGE ( ADD, SHOW, SUCC, INTE $=2$, RATI $=0,2 R A T=0$, PCEN $=0$ )

CURVE( SELE, ID, WIND = 1 )

( $\$ C U R+6)$

MEDGE ( ADD, SHOW, SUCC, INTE $=2$, RATI $=0,2$ RAT $=0$, PCEN $=0$ )

CURVE( SELE, ID, WIND = 1 )

$(\$ C U R+9)$

( $\$ C U R+10)$

CURVE( SELE, ID, WIND = 1 )

(\$CUR + 7)

CURVE( SELE, ID, WIND = 1 ) 
$(\$ C U R+8)$

MEDGE ( ADD, SHOW, SUCC, INTE $=3$, RATI $=0,2 R A T=0$, PCEN $=0$ )

CURVE ( SELE, ID, WIND = 1 )

$(\$ C U R+6)$

CURVE ( SELE, ID, WIND = 1)

(\$CUR + 9)

$(\$ C U R+10)$

(\$CUR + 5)

CURVE ( SELE, ID, WIND = 1 )

(\$CUR + 4)

$(\$ C U R+3)$

MLOOP ( ADD, MAP, VISI, SHOW, EDG1 = 1, EDG2 $=2, E D G 3=1, E D G 4=2$ )

SURFACE ( SELE, ID, WIND = 1)

(\$SUR + 1)

UTILITY ( HIGH $=9$ )

MLOOP( SELE, ID, WIND = I)

$(\$ M L O+2)$

UTILITY ( HIGH $=3$ )

MFACE ( ADD)

MFACE ( SELE, ID, WIND = 1 )

(\$MFA + 2)

MFACE ( MESH, MAP, ENTI = \$GRP7)

CURVE ( SELE, ID, WIND $=1$ )

( $\$ C U R+5)$

CURVE( SELE, ID, WIND = 1 )

$($ \$CUR +7$)$

(\$CUR + 8)

$(\$ C U R+6)$

CURVE( SELE, ID, WIND = 1 )

(\$CUR + 2)

$(\$ C U R+1)$

MLOOP( $A D D, M A P, V I S I, N O S H, E D G 1=1, E D G 2=2, E D G 3=1, E D G 4=2$ )

SURFACE ( SELE, ID, WIND = 1 )

(\$SUR + 1)

UTILITY ( HIGH $=9$ )

MLOOP( SELE, ID, WIND = 1 )

(\$MLO + 3)

UTILITY ( HIGH $=3$ )

$\operatorname{MFACE}(A D D)$

MFACE( SELE, ID, WIND = 1 )

$($ SMFA + 3)

MFACE ( MESH, MAP, ENTI = \$GRP8)

CURVE( SELE, ID, WIND = 1 )

(\$CUR + 11)

MEDGE ( ADD, SHOW, SUCC, INTE $=3$, RATI $=0,2 R A T=0$, PCEN $=0$ )

CURVE( SELE, ID, WIND = 1 )

( $\$$ CUR + 12)

MEDGE ( ADD, SHOW, SUCC, INTE $=3$, RATI $=0,2 R A T=0$, PCEN $=0$ )

CURVE ( SELE, ID, WIND = 1 )

$(\$ C U R+15)$

$(\$ C U R+16)$

$($ SCUR +13$)$

(\$CUR + 14)

MEDGE ( ADD, SHOW, SUCC, INTE $=8$, RATI $=0,2$ RAT $=0$, PCEN $=0$ ) 
CURVE( SELE, ID, WIND = 1 )

$(\$ C U R+12)$

$(\$ C U R+15)$

$(\$ C U R+16)$

$(\$ C U R+11)$

$(\$ C U R+10)$

$(\$ C U R+9)$

MLOOP ( $A D D, P A V E, V I S I, N O S H, E D G 1=1, E D G 2=2, E D G 3=1, E D G 4=2$ )

SURFACE ( SELE, ID, WIND $=1$ )

(\$SUR + 1)

UTILITY( HIGH $=9$ )

MLOOP ( SELE, ID, WIND = 1)

$(\$ M L O+4)$

UTILITY ( HIGH $=3$ )

MFACE ( ADD)

MFACE( SELE, ID, WIND = 1 )

(SMFA + 4)

MFACE ( MESH, PAVE, ENTI = \$GRP9)

CURVE( SELE, ID, WIND = 1 )

$(\$ C U R+11)$

(\$CUR + 13)

$($ SCUR + 14)

(\$CUR + 12)

$(\$ C U R+8)$

$(\$ C U R+7)$

MLOOP( ADD, PAVE, VISI, NOSH, EDG1 = 1, EDG2 = 2, EDG3 = 1, EDG4 = 2)

SURFACE ( SELE, ID, WIND $=1$ )

(\$SUR +1$)$

UTILITY( HIGH $=9$ )

MLOOP( SELE, ID, WIND = 1 )

$(\$ M L O+5)$

UTILITY ( HIGH $=3$ )

$\operatorname{MFACE}(A D D)$

MFACE ( SELE, ID, WIND = 1 )

$(\$ M F A+5)$

MFACE ( MESH, PAVE, ENTI $=\$$ GRP10)

CURVE( SELE, ID, WIND = 1 )

(\$CUR + 17)

CURVE( SELE, ID, WIND = 1 )

( $\$$ CUR + 29)

CURVE( SELE, ID, WIND = 1 )

$($ SCUR + 41)

MEDGE ( ADD, SHOW, SUCC, INTE $=2$, RATI $=0,2$ RAT $=0$, PCEN $=0$ )

CURVE( SELE, ID, WIND = 1 )

(\$CUR + 18)

CURVE( SELE, ID, WIND = 1 )

( $\$$ CUR + 30)

CURVE( SELE, ID, WIND = 1 )

( $\$ C U R+42)$

MEDGE ( ADD, SHOW, SUCC, INTE $=2$, RATI $=0,2 R A T=0$, PCEN $=0$ )

CURVE( SELE, ID, WIND $=1$ )

$(\$ C U R+23)$

MEDGE ( ADD, SHOW, SUCC, INTE $=2$, RATI $=0,2$ RAT $=0$, PCEN $=0$ )

CURVE( SELE, ID, WIND = 1 ) 
$(\$ C U R+24)$

MEDGE ( ADD, SHOW, SUCC, INTE $=2$, RATI $=0,2 R A T=0$, PCEN $=0$ )

CURVE ( SELE, ID, WIND = 1 )

(\$CUR + 21)

$(\$ C U R+22)$

(\$CUR + 19)

CURVE( SELE, ID, WIND = 1 )

( $\$ C U R+20)$

MEDGE ( ADD, SHOW, SUCC, INTE $=8$, RATI $=0,2$ RAT $=0$, PCEN $=0$ )

CURVE ( SELE, ID, WIND = 1 )

(\$CUR + 35)

MEDGE ( ADD, SHOW, SUCC, INTE $=2$, RATI $=0,2$ RAT $=0$, PCEN $=0$ )

CURVE ( SELE, ID, WIND $=1$ )

(\$CUR + 36)

MEDGE ( ADD, SHOW, SUCC, INTE $=2$, RATI $=0,2 R A T=0$, PCEN $=0$ )

CURVE ( SELE, ID, WIND = 1 )

$($ SCUR +27$)$

$($ SCUR +28$)$

( $\$$ CUR +25$)$

$(\$ C U R+26)$

MEDGE ( ADD, SHOW, SUCC, INTE $=8$, RATI $=0,2 R A T=0$, PCEN $=0$ )

CURVE( SELE, ID, WIND = 1 )

(\$CUR + 33)

( $\$ C U R+34)$

CURVE( SELE, ID, WIND = 1 )

$(\$ C U R+31)$

CURVE( SELE, ID, WIND = 1 )

(\$CUR + 32)

MEDGE ( ADD, SHOW, SUCC, INTE $=8$, RATI $=0,2 R A T=0$, PCEN $=0$ )

CURVE ( SELE, ID, WIND = 1 )

(\$CUR + 39)

$(\$ C U R+40)$

(\$CUR + 37)

(\$CUR + 38)

MEDGE ( ADD, SHOW, SUCC, INTE $=12$, RATI $=0,2$ RAT $=0$, PCEN $=0$ )

CURVE ( SELE, ID, WIND = 1 )

$(\$ C U R+45)$

(\$CUR + 46)

( $\$ C U R+43)$

CURVE( SELE, ID, WIND = 1 )

(\$CUR + 44)

MEDGE ( ADD, SHOW, SUCC, INTE $=12$, RATI $=0,2$ RAT $=0$, PCEN $=0$ )

CURVE ( SELE, ID, WIND = 1 )

(\$CUR + 18)

$(\$ C U R+21)$

CURVE( SELE, ID, WIND = 1 )

(\$CUR + 22)

$($ SCUR +17$)$

(\$CUR + 16)

CURVE( SELE, ID, WIND = 1 )

(\$CUR + 15)

MLOOP ( $A D D, M A P, V I S I, S H O W, E D G 1=1, E D G 2=2, E D G 3=1, E D G 4=2$ )

SURFACE ( SELE, ID, WIND $=1$ )

$(\$ S U R+1)$ 


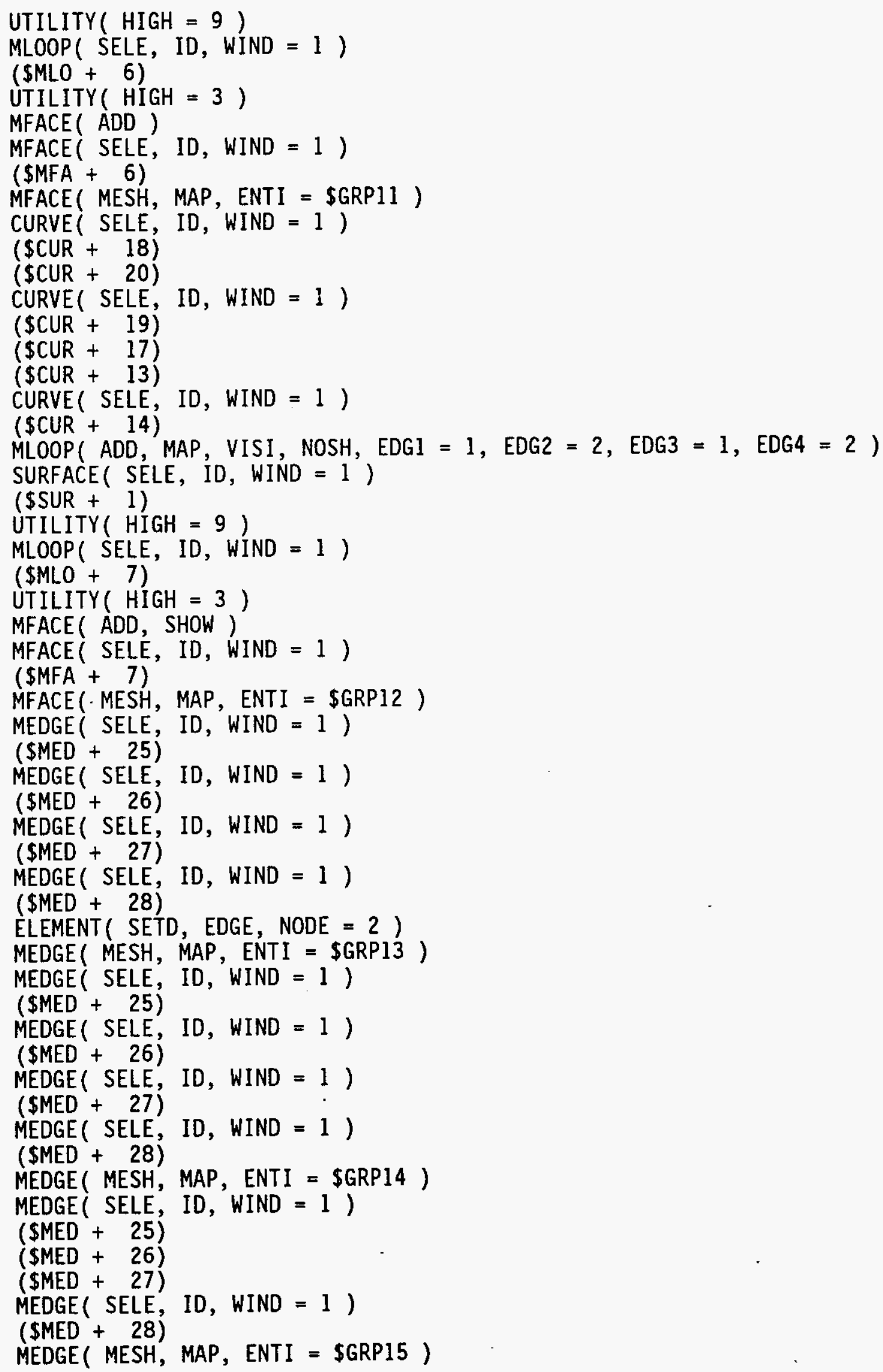




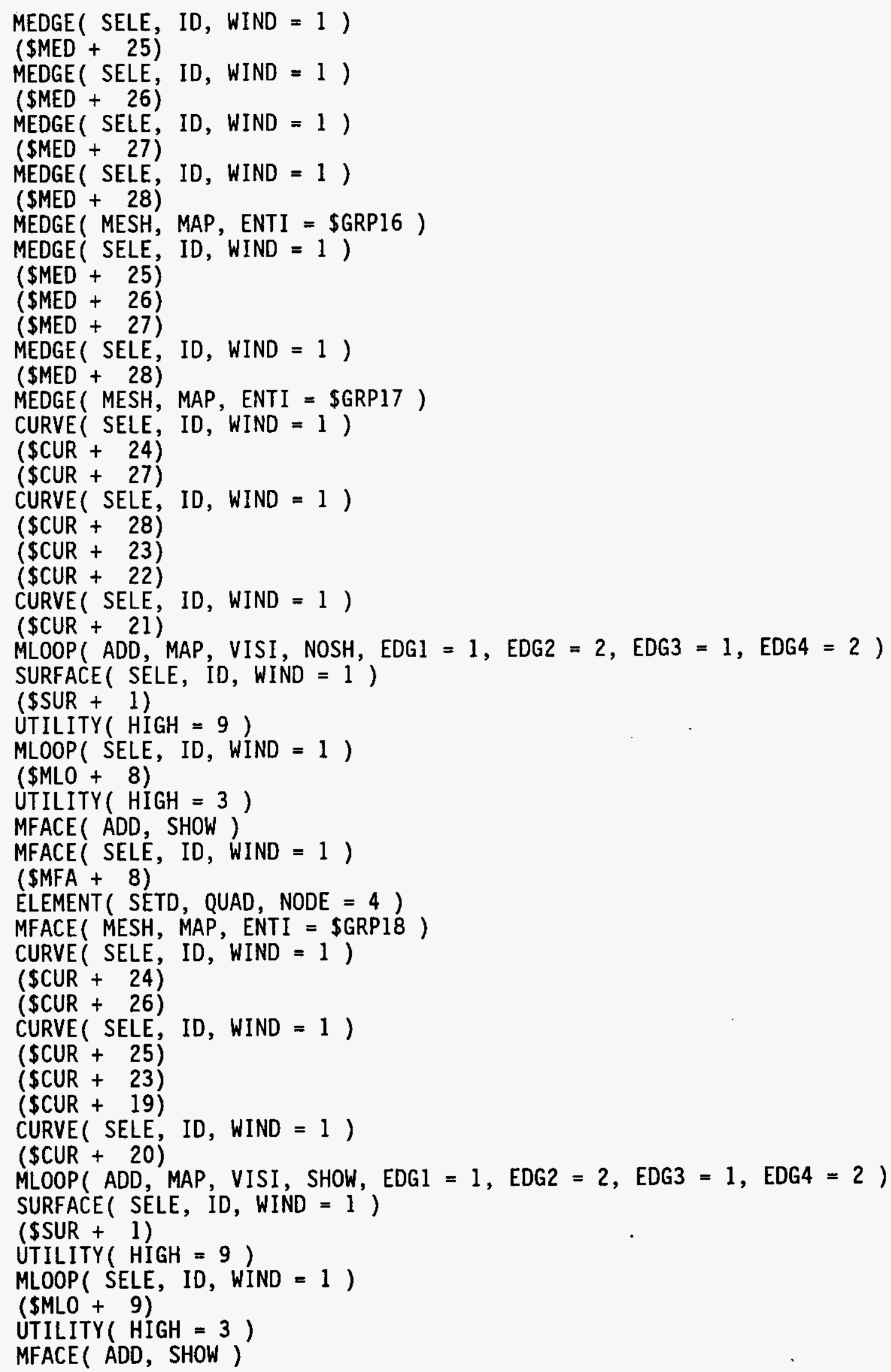




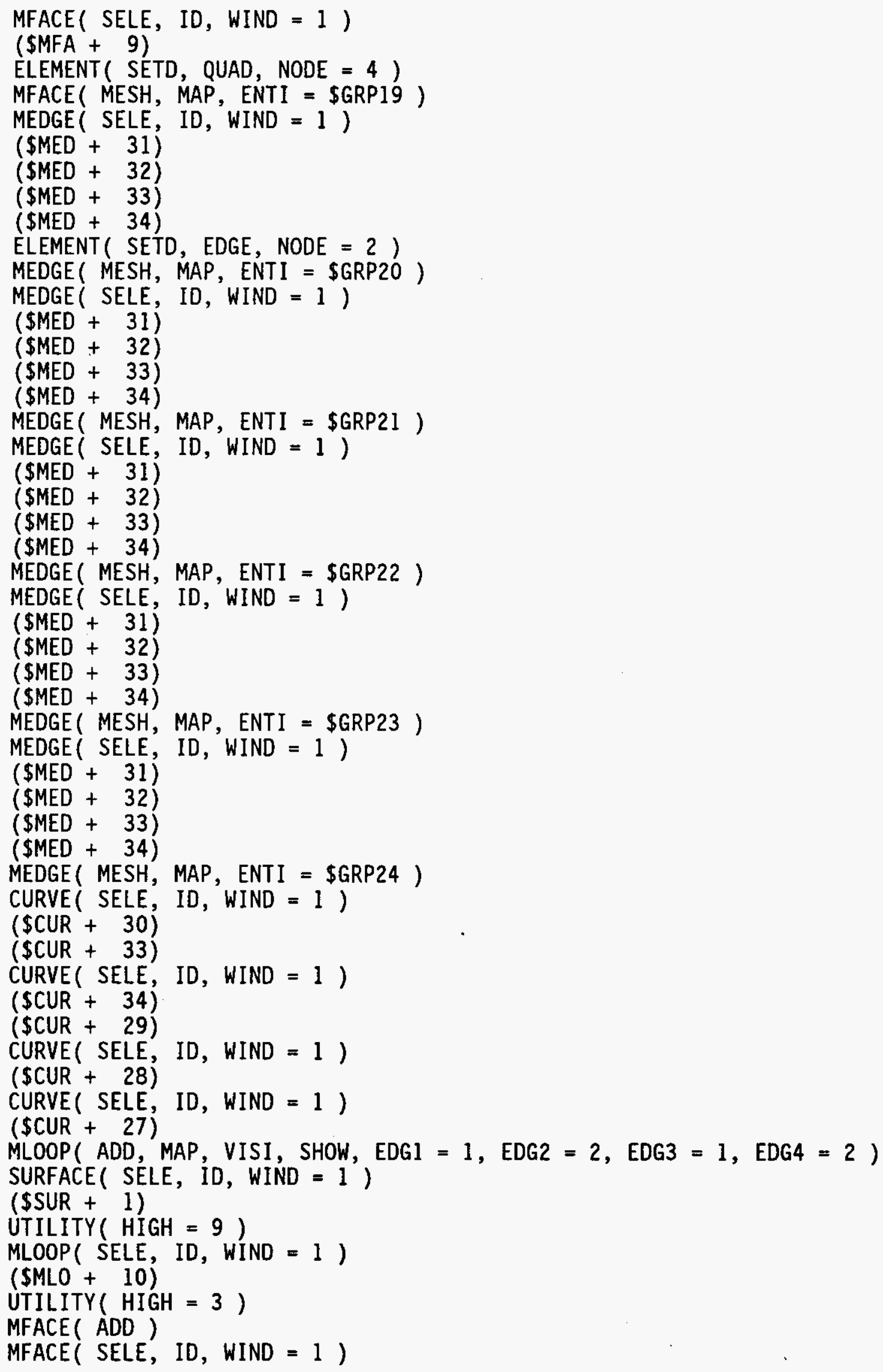


(\$MFA +10$)$

ELEMENT( SETD, QUAD, NODE $=4$ )

MFACE ( MESH, MAP, ENTI $=\$$ GRP25)

CURVE( SELE, ID, WIND $=1$ )

$($ SCUR +30$)$

(\$CUR + 32)

CURVE ( SELE, ID, WIND = 1 )

(\$CUR + 31)

CURVE ( SELE, ID, WIND $=1$ )

(\$CUR + 29)

(\$CUR + 25)

CURVE ( SELE, ID, WIND = 1)

$(\$ C U R+26)$

MLOOP ( $A D D, M A P, V I S I, N O S H, E D G 1=1, E D G 2=2, E D G 3=1, E D G 4=2$ )

SURFACE ( SELE, ID, WIND $=1$ )

(\$SUR + 1)

UTILITY ( HIGH $=9$ )

MLOOP ( SELE, ID, WIND = 1)

$(\$ M L O+11)$

UTILITY ( HIGH = 3 )

MFACE ( ADD)

MFACE ( SELE, ID, WIND = 1 )

(\$MFA + 11)

MFACE ( MESH, MAP, ENTI $=$ \$GRP26)

CURVE( SELE, ID, WIND = 1)

(\$CUR + 36)

(\$CUR + 39)

$(\$ C U R+40)$

(\$CUR + 35)

(\$CUR + 34)

CURVE ( SELE, ID, WIND = 1 )

(\$CUR + 33)

MLOOP ( ADD, PAVE, VISI, NOSH, EDGI = 1, EDG2 = 2, EDG3 = 1, EDG4 = 2)

SURFACE ( SELE, ID, WIND = 1 )

(\$SUR + 1)

UTILITY ( $\cdot$ HIGH $=9$ )

MLOOP ( SELE, ID, WIND = 1 )

$($ SMLO + 12)

UTILITY ( HIGH $=3$ )

MFACE ( ADD)

MFACE ( SELE, ID, WIND = 1 )

(\$MFA + 12)

MFACE ( MESH, PAVE, ENTI = \$GRP27)

CURVE( SELE, ID, WIND = I)

$(\$ C U R+36)$

(\$CUR + 38)

(\$CUR + 37)

(\$CUR + 35)

(\$CUR + 31)

(SCUR + 32)

MLOOP( $A D D, P A V E, V I S I, N O S H, E D G I=1, E D G 2=2, E D G 3=1, E D G 4=2$ )

SURFACE ( SELE, ID, WIND = 1 )

(SSUR + 1)

UTILITY( HIGH $=9$ ) 


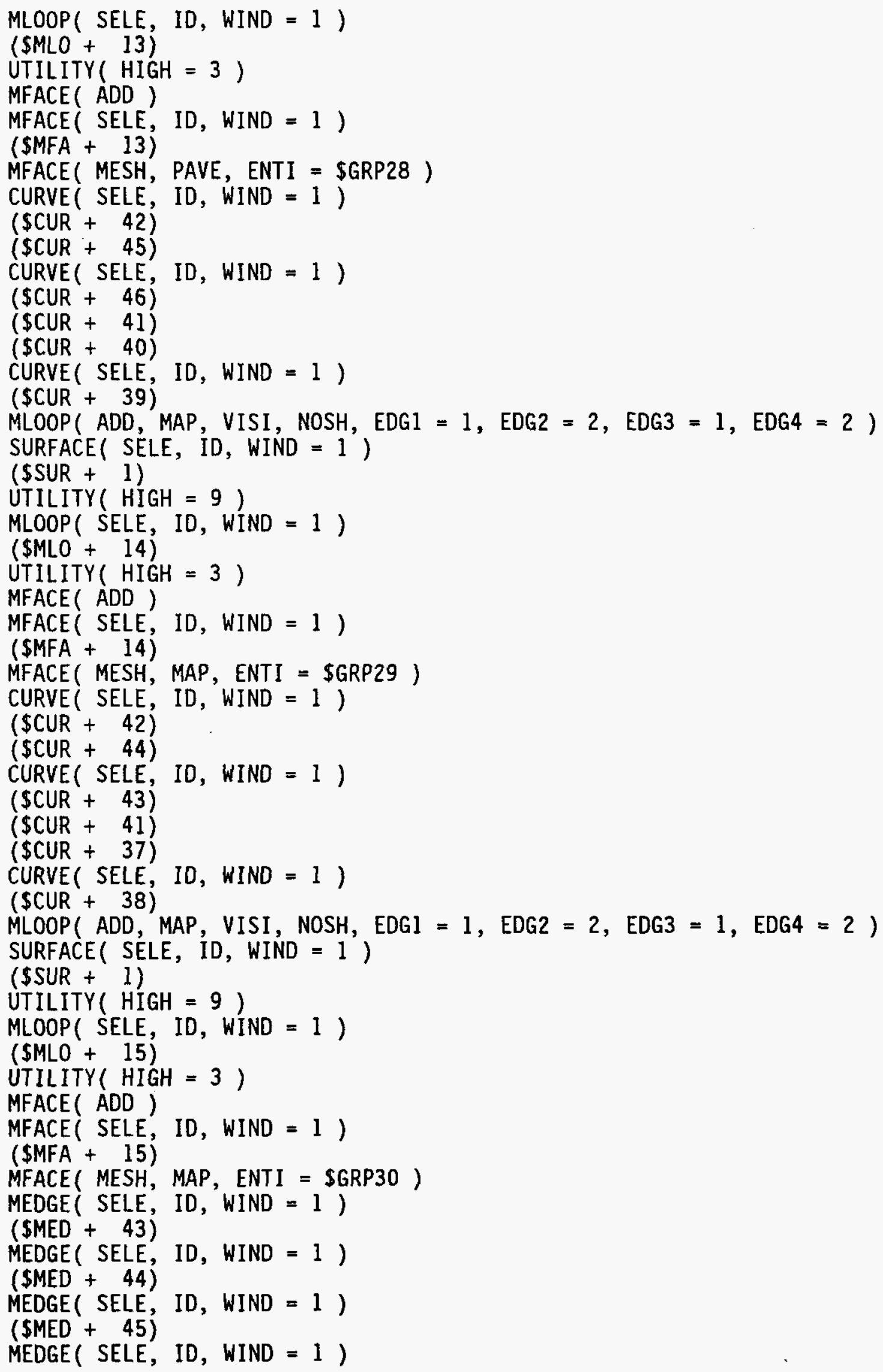




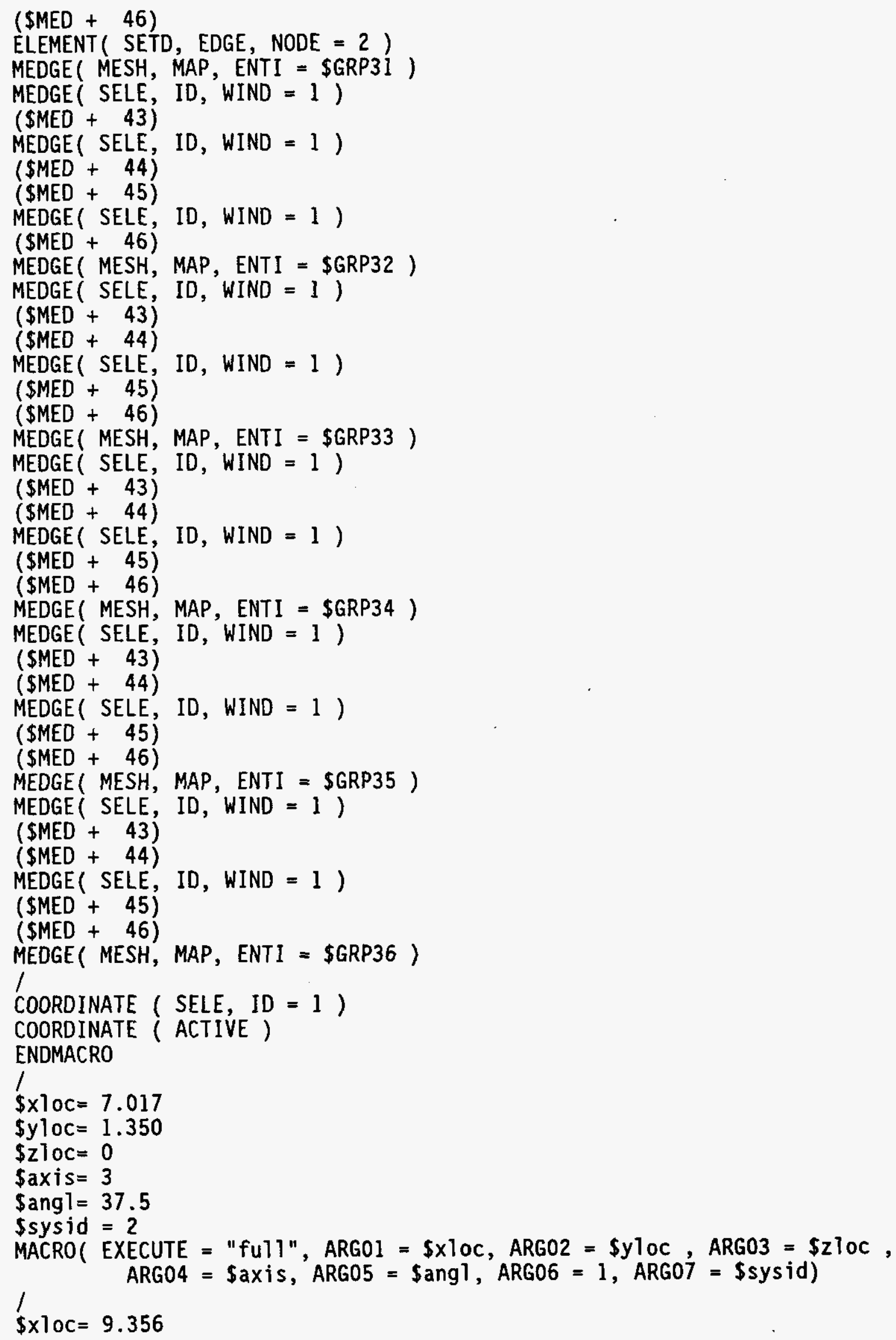




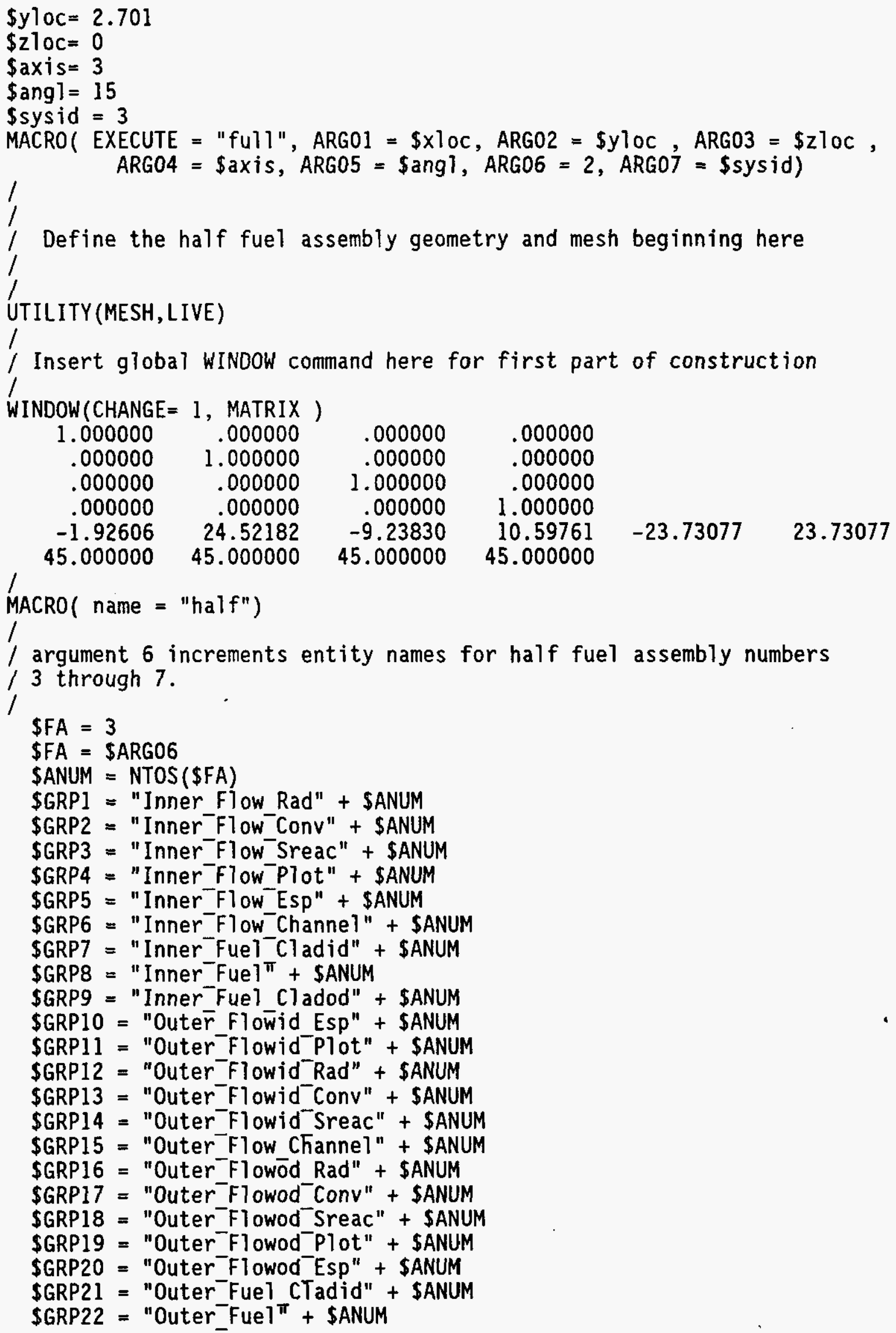




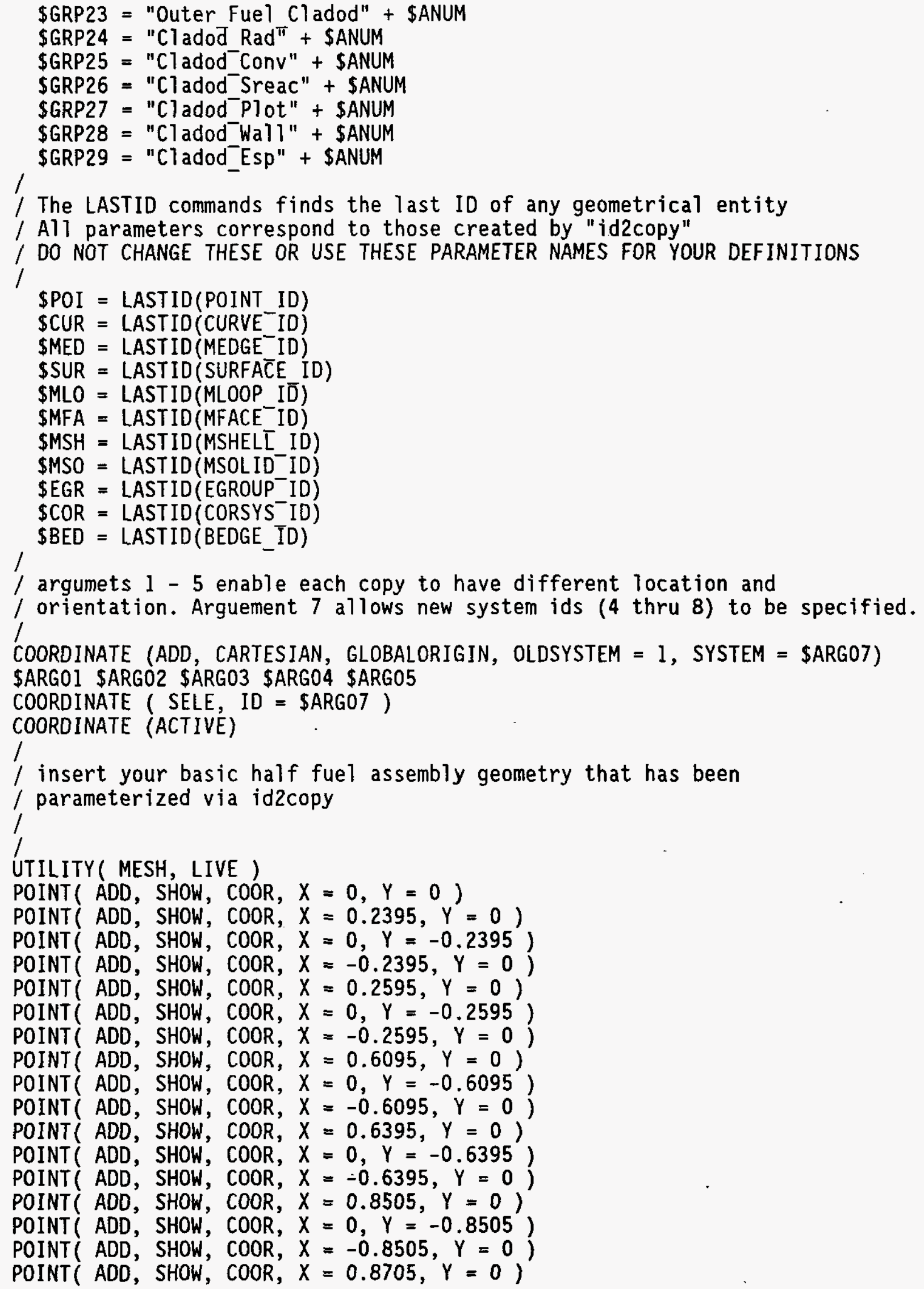




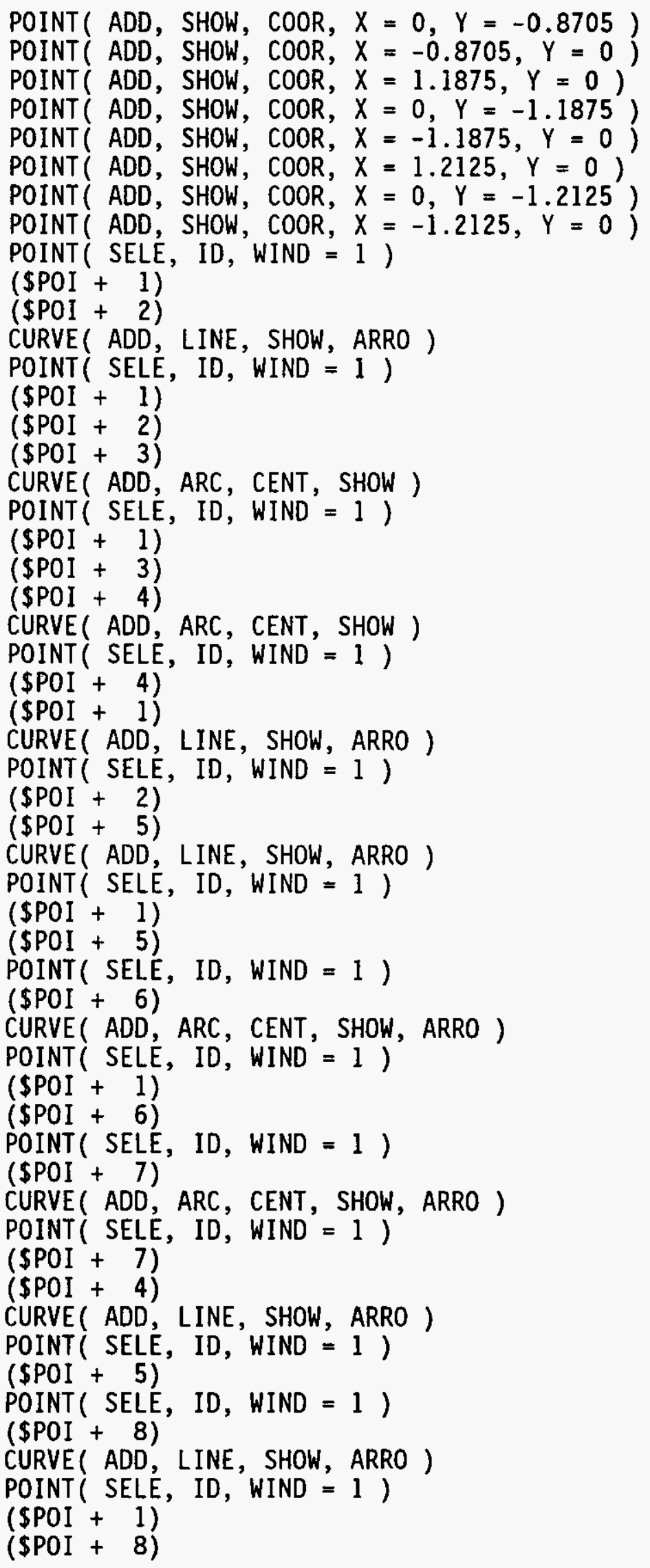


$(\$ P O I+9)$

CURVE ( ADD, ARC, CENT, SHOW, ARRO)

POINT( SELE, ID, WIND = 1 )

$(\$ P O I+1)$

$(\$ P O I+9)$

$(\$ P O I+10)$

CURVE( ADD, ARC, CENT, SHOW, ARRO )

POINT( SELE, ID, WIND = 1 )

$(\$ P O I+10)$

$(\$ P O I+7)$

CURVE( ADD, LINE, SHOW, ARRO )

POINT( SELE, ID, WIND = 1 )

$(\$ P O I+8)$

$(\$ P O I+11)$

CURVE( ADD, LINE, SHOW, ARRO )

POINT( SELE, ID, WIND = 1 )

$(\$ P O I+1)$

$(\$ P O I+11)$

POINT( SELE, ID, WIND = 1 )

(\$POI + 12)

CURVE( ADD, ARC, CENT, SHOW, ARRO )

POINT( SELE, ID, WIND = 1 )

$(\$ P O I+1)$

$(\$ P O I+12)$

POINT( SELE, ID, WIND = 1)

(\$POI + 13)

CURVE ( ADD, ARC, CENT, SHOW, ARRO )

POINT( SELE, ID, WIND $=1$ )

$(\$ P O I+13)$

$(\$ P O I+10)$

CURVE( ADD, LINE, SHOW, ARRO )

POINT( SELE, ID, WIND $=1$ )

$(\$ P O I+11)$

POINT( SELE, ID, WIND = 1 )

$(\$ P O I+14)$

CURVE( ADD, LINE, SHOW, ARRO )

POINT( SELE, ID, WIND = 1 )

$($ SPOI +1$)$

$(\$ P O I+14)$

(\$POI + 15)

CURVE ( ADD, ARC, CENT, SHOW, ARRO )

POINT( SELE, ID, WIND = 1 )

$(\$ P O I+1)$

$(\$ P O I+15)$

(\$POI + 16)

CURVE ( ADD, ARC, CENT, SHOW, ARRO)

POINT( SELE, ID, WIND = 1 )

$(\$ P 0 I+16)$

(\$POI + 13)

CURVE ( ADD, LINE, SHOW, ARRO )

POINT ( SELE, ID, WIND = 1 )

$(\$ P O I+14)$

$(\$ P O I+17)$

CURVE( ADD, LINE, SHOW, ARRO ) 


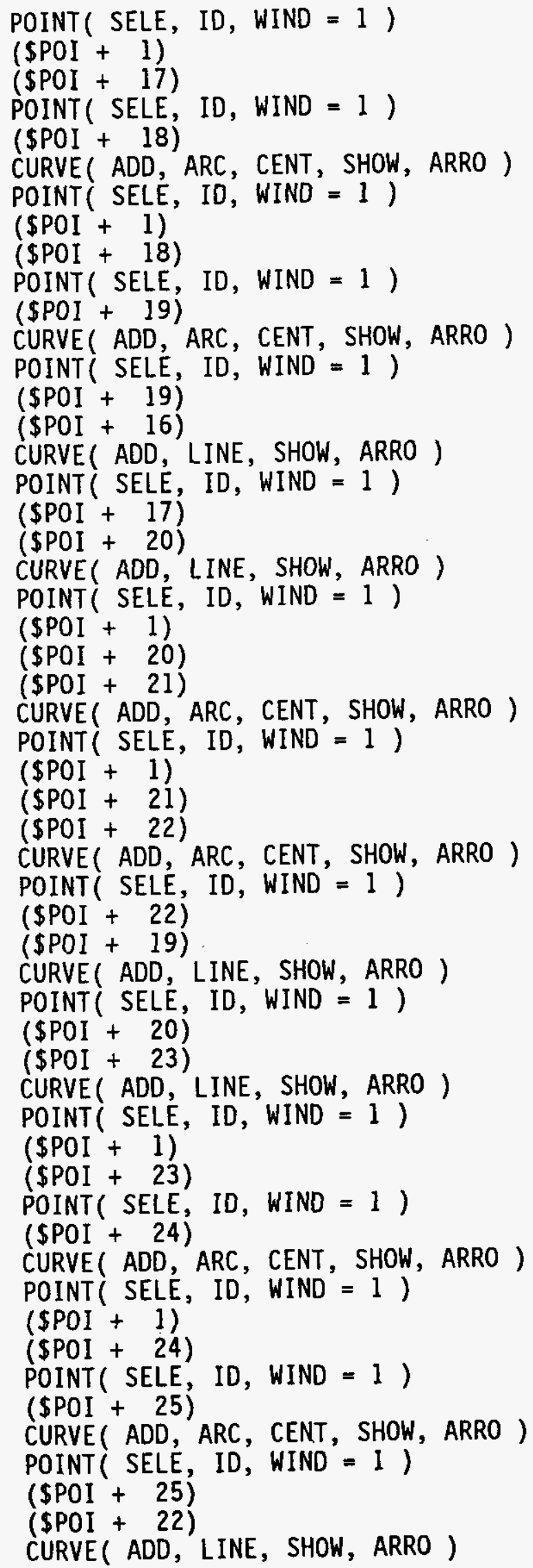




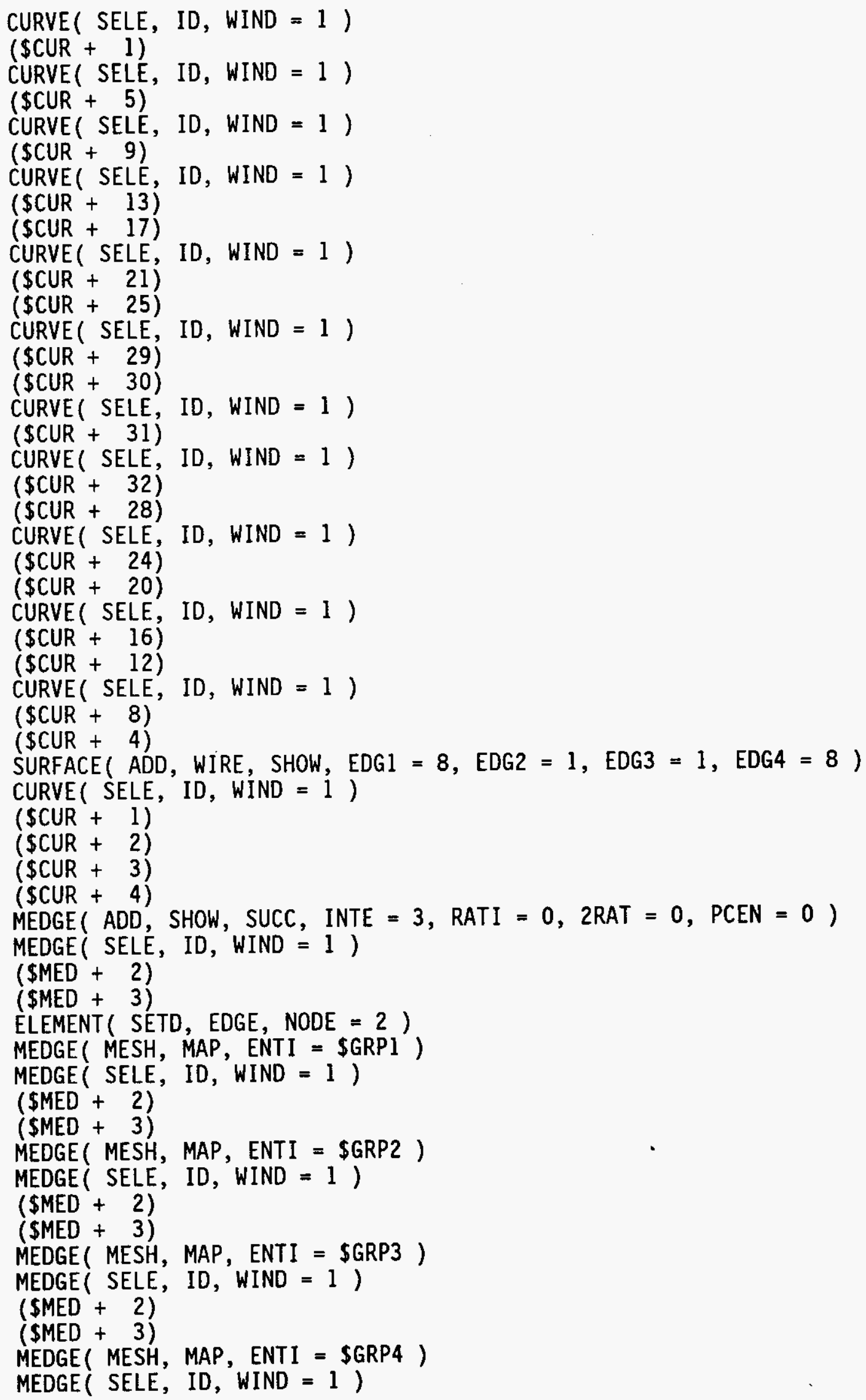




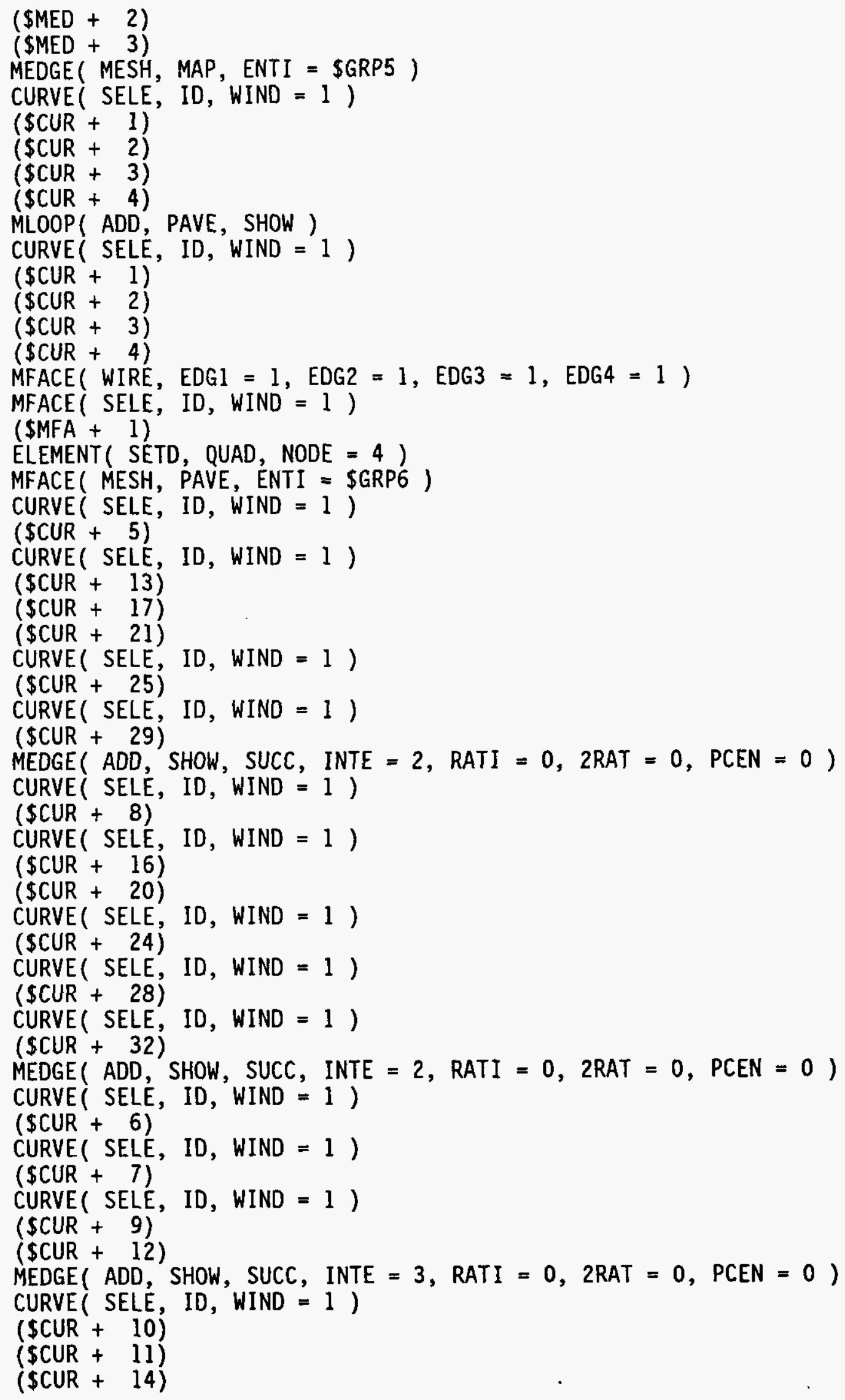


WHC-SD-WM-ER-525

Rev. 0

$(\$ C U R+15)$

MEDGE ( ADD, SHOW, SUCC, INTE $=8$, RATI $=0,2 R A T=0$, PCEN $=0$ )

CURVE( SELE, ID, WIND $=1$ )

(\$CUR + 18)

$(\$ C U R+19)$

$(\$ C U R+22)$

(\$CUR + 23)

MEDGE ( ADD, SHOW, SUCC, INTE $=8$, RATI $=0,2$ RAT $=0$, PCEN $=0$ )

CURVE( SELE, ID, WIND = 1 )

$(\$ C U R+26)$

$(\$ C U R+27)$

$(\$ C U R+30)$

(\$CUR + 31)

MEDGE ( ADD, SHOW, SUCC, INTE $=12$, RATI $=0,2$ RAT $=0$, PCEN $=0$ )

CURVE ( SELE, ID, WIND = 1 )

$(\$ C U R+5)$

$(\$ C U R+6)$

CURVE( SELE, ID, WIND = 1 )

(\$CUR +7$)$

$(\$ C U R+8)$

$(\$ C U R+3)$

CURVE( SELE, ID, WIND = 1 )

(\$CUR + 2)

MLOOP ( ADD, MAP, VISI, SHOW, EDG1 $=1, E D G 2=2, E D G 3=1, E D G 4=2$ )

SURFACE( SELE, ID, WIND = 1)

(\$SUR + 1)

UTILITY( HIGH $=9$ )

$\operatorname{MLOOP}($ SELE, ID, WIND = 1 )

$($ SMLO + 2)

UTILITY ( HIGH $=3$ )

MFACE ( ADD )

MFACE ( SELE, ID, WIND = 1 )

(\$MFA + 2)

MFACE ( MESH, MAP, ENTI $=$ \$GRP7)

CURVE ( SELE, ID, WIND = 1 )

(\$CUR + 9)

$(\$ C U R+10)$

(\$CUR + 11)

(\$CUR + 12)

( $\$ C U R+7)$

CURVE( SELE, ID, WIND = 1 )

(\$CUR + 6)

MLOOP ( ADD, PAVE, SHOW )

SURFACE ( SELE, ID, WIND = 1 )

(\$SUR + 1)

UTILITY ( HIGH $=9$ )

MLOOP( SELE, ID, WIND = 1 )

$(\$ M L O+3)$

UTILITY( HIGH $=3$ )

MFACE ( ADD, SHOW)

MFACE( SELE, ID, WIND = 1 )

(SMFA + 3)

MFACE ( MESH, PAVE, ENTI = \$GRP8)

CURVE( SELE, ID, WIND = 1 ) 


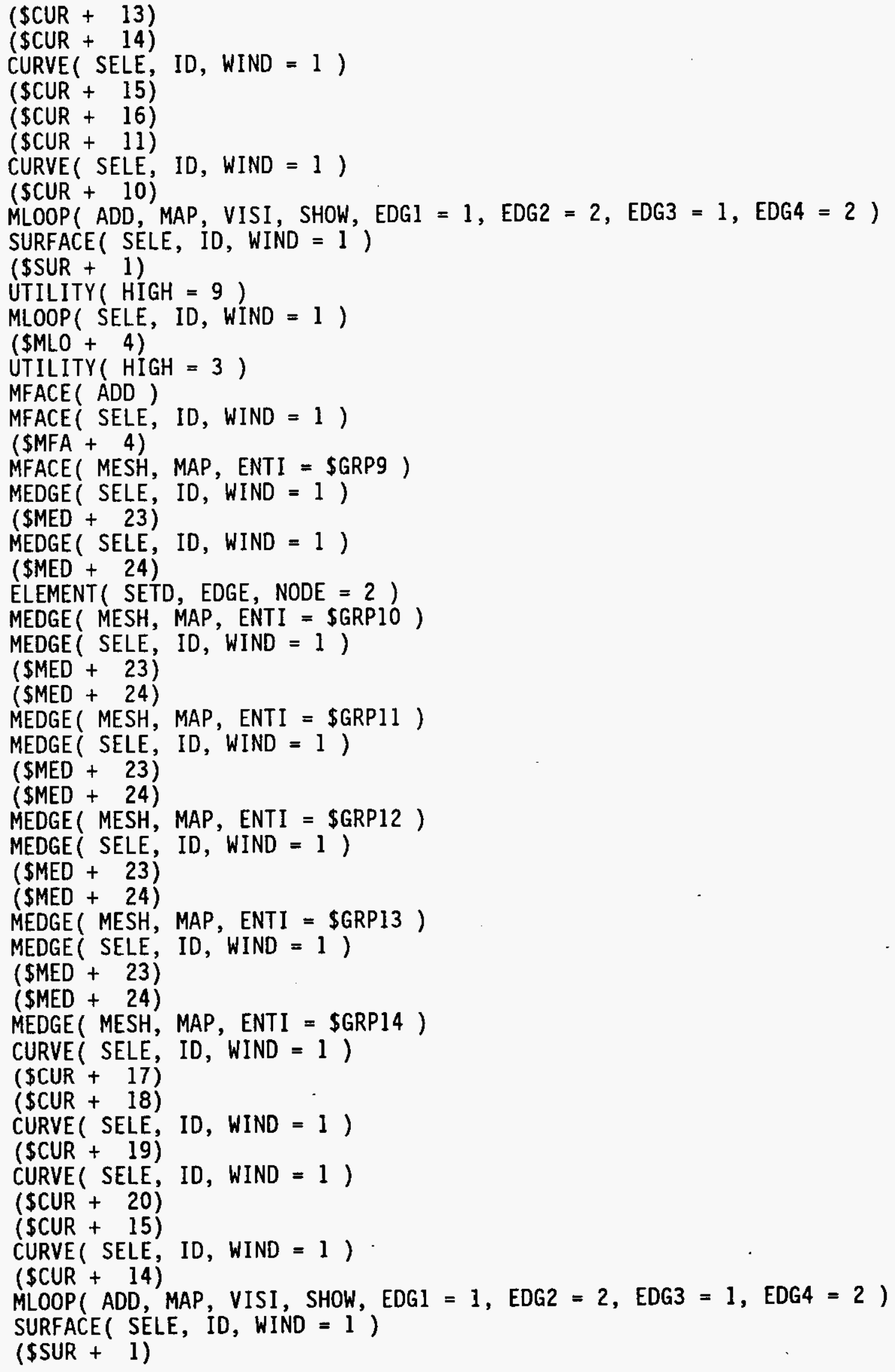




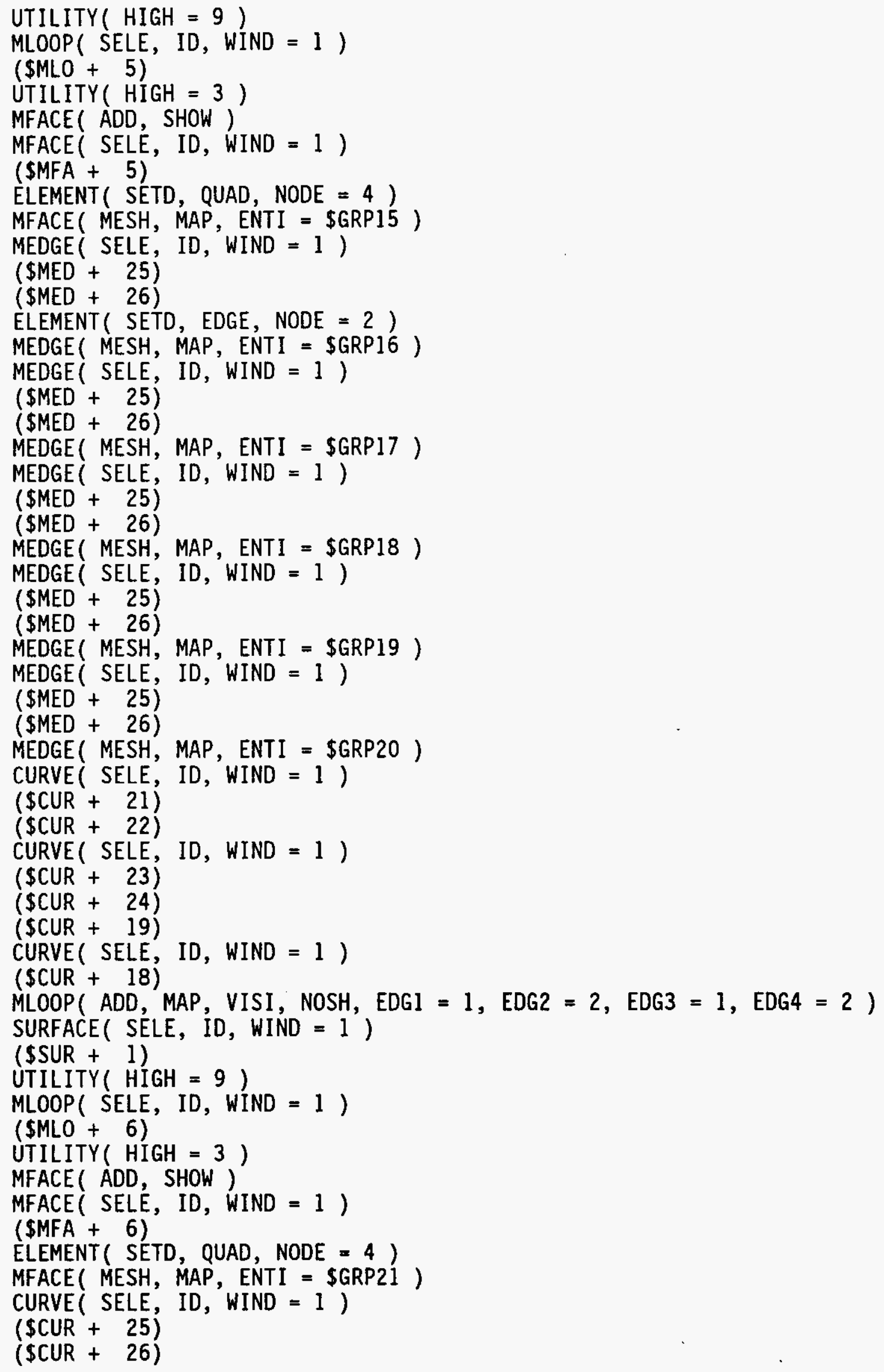




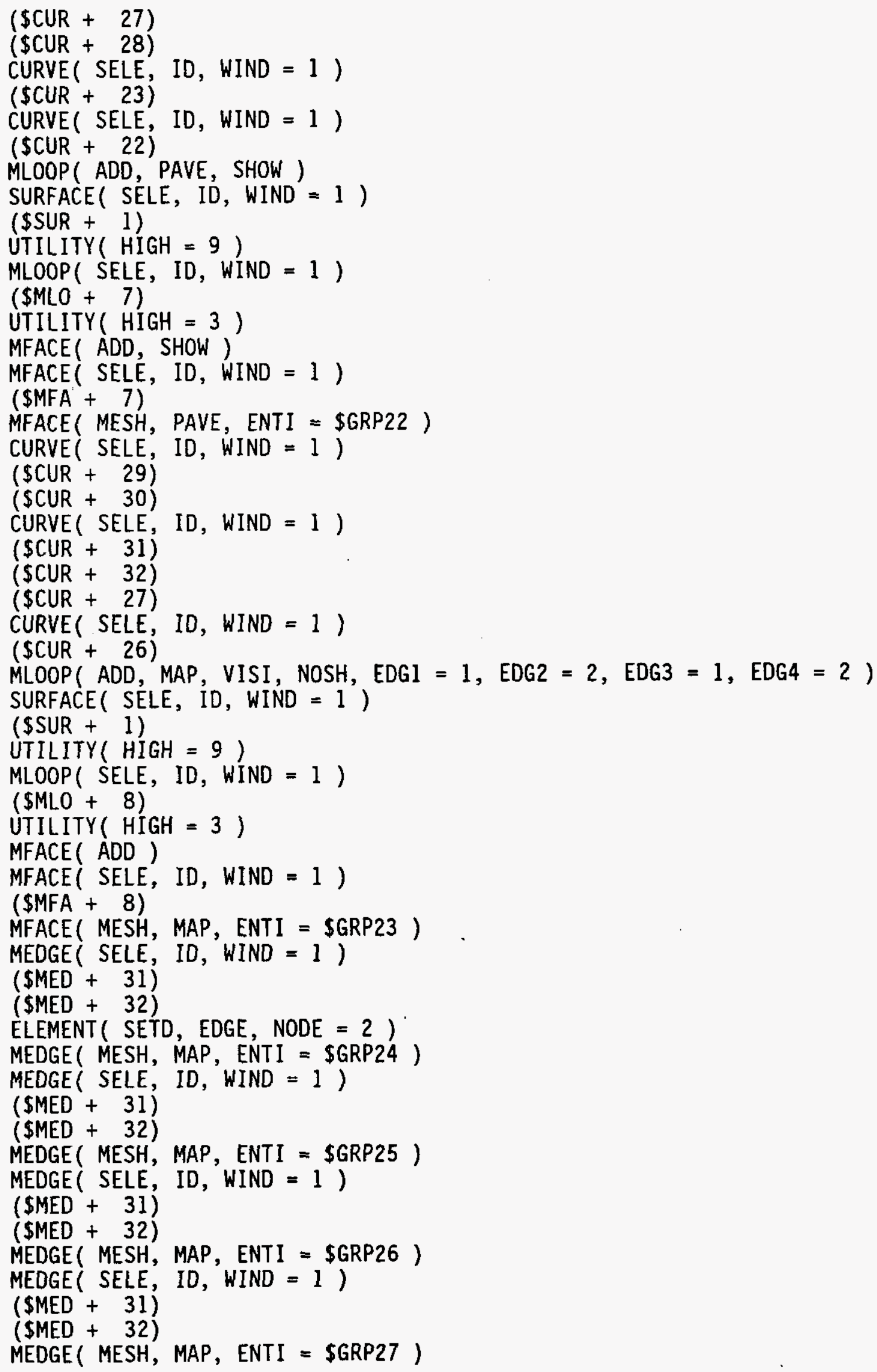




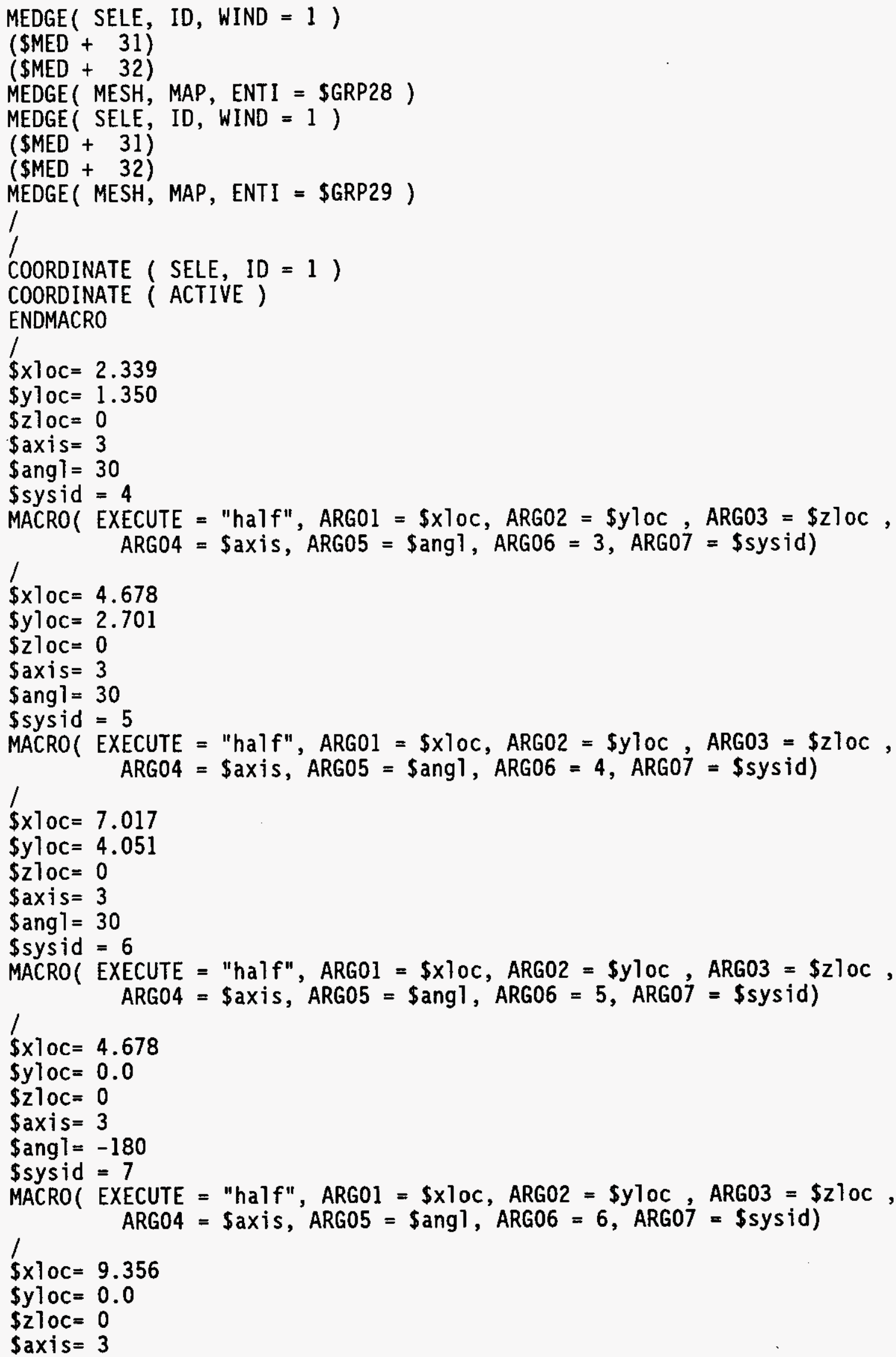




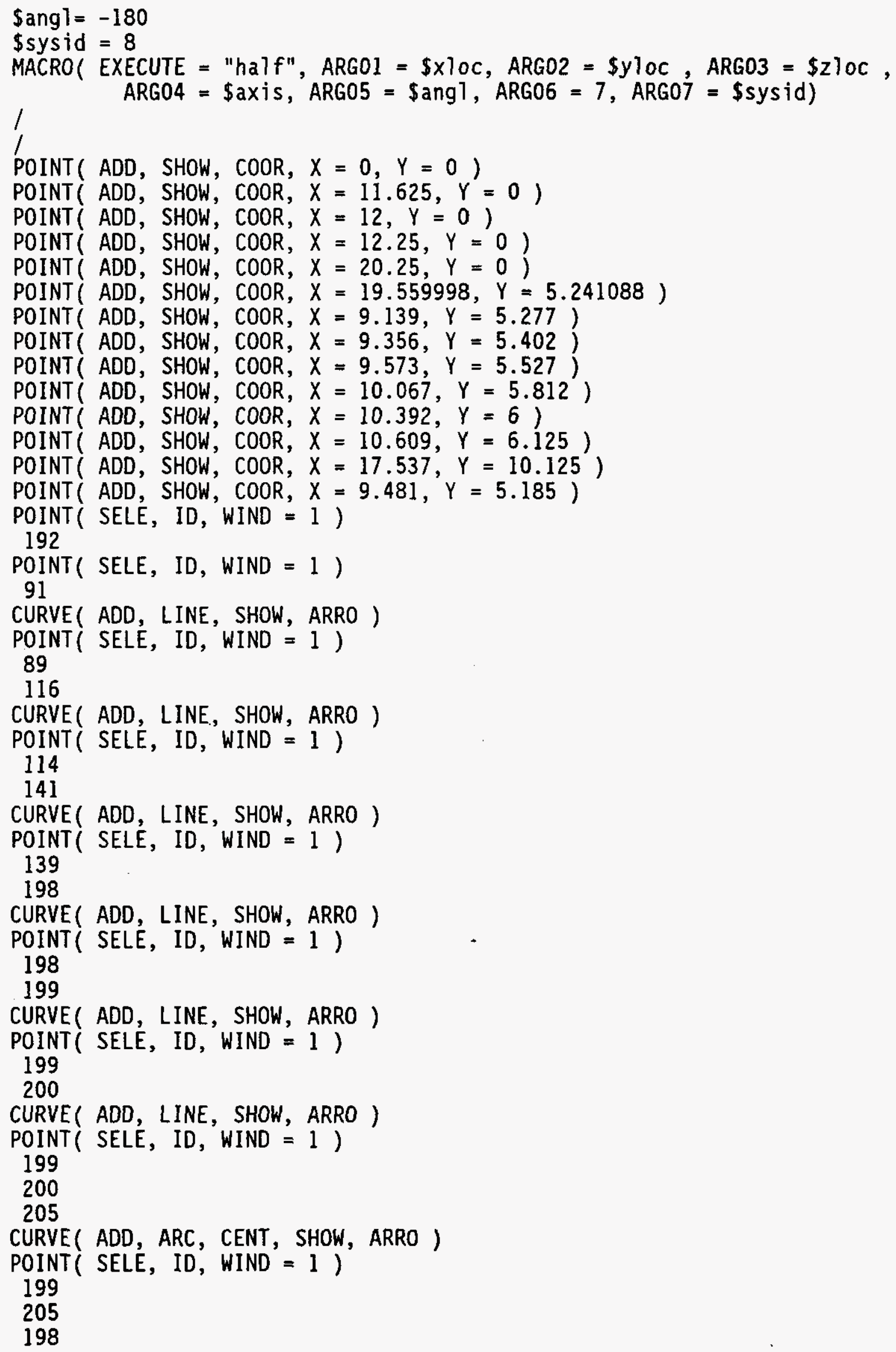


CURVE ( ADD, ARC, CENT, SHOW, ARRO )

POINT( SELE, ID, WIND $=1$ )

200

201

CURVE( ADD, LINE, SHOW )

POINT( SELE, ID, WIND = 1 )

201

202

CURVE( ADD, LINE, SHOW )

POINT( SELE, ID, WIND $=1$ )

202

203

CURVE( ADD, LINE, SHOW )

POINT( SELE, ID, WIND = 1 )

203

POINT( SELE, ID, WIND = 1 )

204

CURVE( ADD, LINE, SHOW )

POINT( SELE, ID, WIND = 1 )

192

POINT( SELE, ID, WIND = 1 )

164

CURVE( ADD, LINE, SHOW )

POINT( SELE, ID, WIND = 1 )

166

POINT( SELE, ID, WIND = 1 )

189

CURVE( ADD, LINE, SHOW )

POINT( SELE, ID, WIND = 1 )

191

POINT( SELE, ID, WIND = 1 )

193

CURVE( ADD, LINE; SHOW )

POINT( SELE, ID, WIND = 1 )

193

194

CURVE( ADD, LINE, SHOW )

POINT( SELE, ID, WIND = 1 )

194

195

CURVE( ADD, LINE, SHOW )

POINT( SELE, ID, WIND = 1 )

195

POINT( SELE, ID, WIND = 1 )

196

CURVE( ADD, LINE, SHOW )

POINT( SELE, ID, WIND = 1 )

192

POINT( SELE, ID, WIND = 1 )

201

POINT( SELE, ID, WIND = 1 )

193

CURVE( ADD, ARC, CENT, SHOW, ARRO )

POINT( SELE, ID, WIND $=1$ ) 


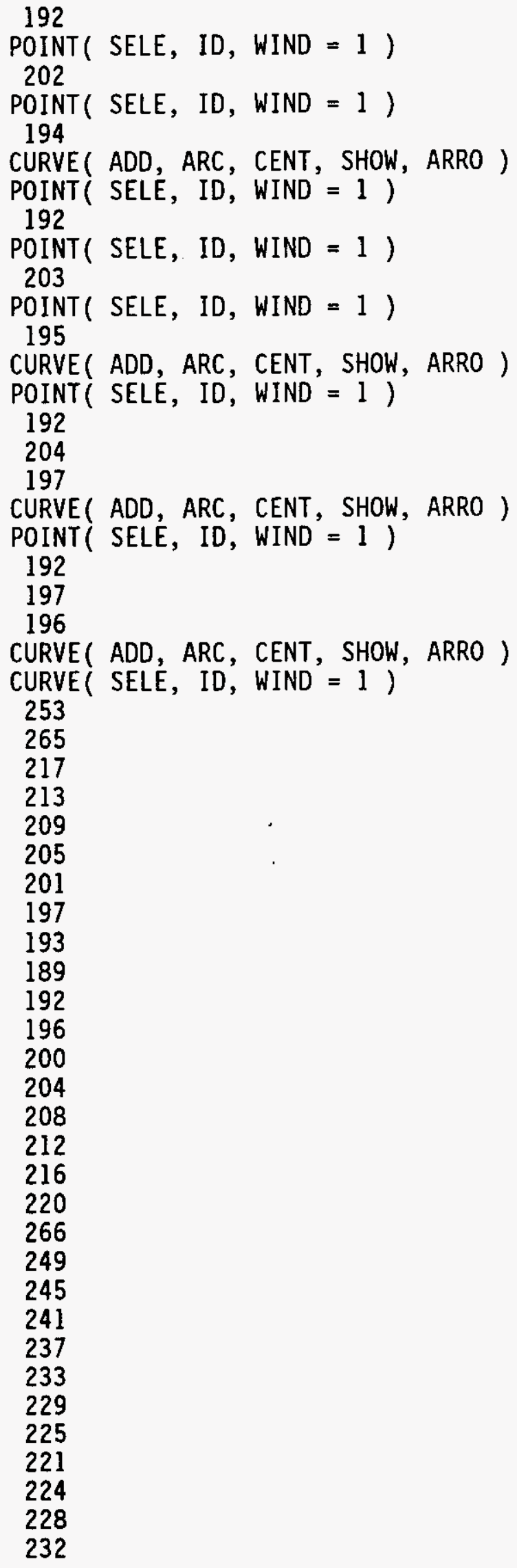


WHC-SD-WM-ER-525

Rev. 0

236

240

244

248

252

267

268

269

270

274

275

264

263

262

261

258

257

256

185

181

177

173

169

165

161

157

160

164

168

172

176

180

184

188

255

153

149

145

141

137

133

129

125

128

132

136

140

144

148

152

156

254

121

117

D-35 
SURFACE ( ADD, WIRE, SHOW, EDGI $=2, E D G 2=37, E D G 3=2, E D G 4=57$ ) CURVE( SELE, ID, WIND = 1 ) 265

MEDGE ( ADD, SHOW, SUCC, INTE $=24$, RATI $=0,2 R A T=0$, PCEN $=0$ ) CURVE( SELE, ID, WIND = 1 ) 266 MEDGE ( ADD, SHOW, SUCC, INTE $=12$, RATI $=0,2 R A T=0, P C E N=0$ ) CURVE( SELE, ID, WIND = 1 ) 267 MEDGE ( ADD, SHOW, SUCC, INTE $=7$, RATI $=0,2$ RAT $=0$, PCEN $=0$ ) CURVE( SELE, ID, WIND = I) 253

MEDGE ( ADD, SHOW, SUCC, INTE $=10$, RATI $=0,2 R A T=0$, PCEN $=0$ ) CURVE( SELE, ID, WIND $=1$ ) 254 MEDGE ( ADD, SHOW, SUCC, INTE $=3$, RATI $=0,2$ RAT $=0$, PCEN $=0$ ) CURVE( SELE, ID, WIND = 1 ) 255

MEDGE ( ADD, SHOW, SUCC, INTE $=3$, RATI $=0,2 R A T=0$, PCEN $=0$ ) CURVE ( SELE, ID, WIND $=1$ ) 256

MEDGE ( ADD, SHOW, SUCC, INTE $=10$, RATI $=0,2$ RAT $=0$, PCEN $=0$ ) CURVE( SELE, ID, WIND = 1 ) 257 258 259 260

MEDGE ( ADD, SHOW, SUCC, INTE $=3$, RATI $=0,2 R A T=0$, PCEN $=0$ ) CURVE ( SELE, ID, WIND = 1) 261

MEDGE ( ADD, SHOW, SUCC, INTE $=5$, RATI $=0,2 R A T=0$, PCEN $=0$ ) CURVE ( SELE, ID, WIND = 1) 262 MEDGE ( ADD, SHOW, SUCC, INTE $=3$, RATI $=0,2 R A T=0$, PCEN $=0$ ) CURVE ( SELE, ID, WIND = 1 )

MEDGE ( ADD, SHOW, SUCC, INTE $=2$, RATI $=0,2 R A T=0$, PCEN $=0$ ) CURVE( SELE, ID, WIND = 1) 
273

MEDGE ( ADD, SHOW, SUCC, INTE $=32$, RATI $=0,2 R A T=0$, PCEN $=0$ )

CURVE ( SELE, ID, WIND = 1 )

275

274

MEDGE( ADD, SHOW, SUCC, INTE $=16$, RATI $=0,2$ RAT $=0$, PCEN $=0$ )

CURVE( SELE, ID, WIND = 1 )

268

MEDGE ( ADD, SHOW, SUCC, INTE $=3$, RATI $=0,2 R A T=0, P C E N=0$ )

CURVE( SELE, ID, WIND = 1 )

269

MEDGE ( ADD, SHOW, SUCC, INTE $=2$, RATI $=0,2 R A T=0$, PCEN $=0$ )

CURVE( SELE, ID, WIND = 1 )

270

264

MEDGE ( ADD, SHOW, LSTF, INTE $=10$, RATI $=6,2$ RAT $=0$, PCEN $=0$ )

MEDGE ( SELE, ID, WIND = 1 )

267

MEDGE( MESH, MAP, ENTI = "MCO_ID_Rad" )

MEDGE ( SELE, ID, WIND $=1$ )

267

MEDGE ( MESH, MAP, ENTI = "MCO_ID_Conv" )

MEDGE ( SELE, ID, WIND = 1 )

267

MEDGE ( MESH, MAP, ENTI = "MCO_ID_Wa11")

MEDGE ( SELE, ID, WIND = I )

267

MEDGE ( MESH, MAP, ENTI = "MCO_ID_Plot" )

MEDGE ( SELE, ID, WIND $=1$ )

253

254

255

MEDGE ( MESH, MAP, ENTI = "MCO X Radl")

MEDGE（ SELE, ID, WIND = 1 )

195

MEDGE( MESH, MAP, ENTI = "MCO_X_Rad2" )

MEDGE ( SELE, ID, WIND = 1 )

201

MEDGE ( MESH, .MAP, ENTI = "MCO_X_Rad3" )

MEDGE ( SELE, ID, WIND = 1 )

189

192

MEDGE ( MESH, MAP, ENTI = "MCO_X_Rad4" )

MEDGE ( SELE, ID, WIND $=1$ )

227

MEDGE ( MESH, MAP, ENTI = "MCO_X_Rad5" )

MEDGE ( SELE, ID, WIND $=1$ )

233

MEDGE( MESH, MAP, ENTI = "MCO X Rad6" )

MEDGE ( SELE, ID, WIND = I)

221

224

MEDGE ( MESH, MAP, ENTI = "MCO_X_Rad7" )

MEDGE（SELE, ID, WIND = 1 ) 
MEDGE ( MESH, MAP, ENTI = "MCO_X_Syml")

MEDGE ( SELE, ID, WIND = 1 )

195

MEDGE ( MESH, MAP, ENTI = "MCO_X_Sym2" )

MEDGE ( SELE, ID, WIND = 1 )

201

MEDGE ( MESH, MAP, ENTI $=$ "MCO_X_Sym3" )

MEDGE ( SELE, ID, WIND = 1 )

189

192

MEDGE (MESH, MAP, ENTI $=$ "MCO X_Sym4" )

MEDGE ( SELE, ID, WIND $=1$ )

227

MEDGE ( MESH, MAP, ENTI = "MCO_X_Sym5" )

MEDGE ( SELE, ID, WIND = 1 )

233

MEDGE ( MESH, MAP, ENTI = "MCO_X_Sym6" )

MEDGE ( SELE, ID, WIND = 1 )

221

224

MEDGE ( MESH, MAP, ENTI = "MCO_X_Sym7" )

MEDGE ( SELE, ID, WIND = 1 )

256

257

258

259

264

MEDGE ( MESH, MAP, ENTI = "MCO_Y_Radl")

MEDGE ( SELE, ID, WIND = 1 )

105

MEDGE( MESH, MAP, ENTI = "MCO_Y_Rad2" )

MEDGE ( SELE, ID, WIND = 1 )

99

MEDGE ( MESH, MAP, ENTI = "MCO_Y_Rad3" )

MEDGE ( SELE, ID, WIND = 1 )

96

93

MEDGE ( MESH, MAP, ENTI = "MCO_Y_Rad4" )

MEDGE ( SELE, ID, WIND = 1 )

137

MEDGE ( MESH, MAP, ENTI = "MCO_Y_Rad5" )

MEDGE ( SELE, ID, WIND = 1 )

131

MEDGE ( MESH, MAP, ENTI = "MCO_Y_Rad6" )

MEDGE ( SELE, ID, WIND = 1 ) 128 125

MEDGE ( MESH, MAP, ENTI = "MCO_Y Rad7" )

MEDGE ( SELE, ID, WIND = 1 )

MEDGE( MESH, MAP, ENTI = "MCO_Y_Rad8" ) 


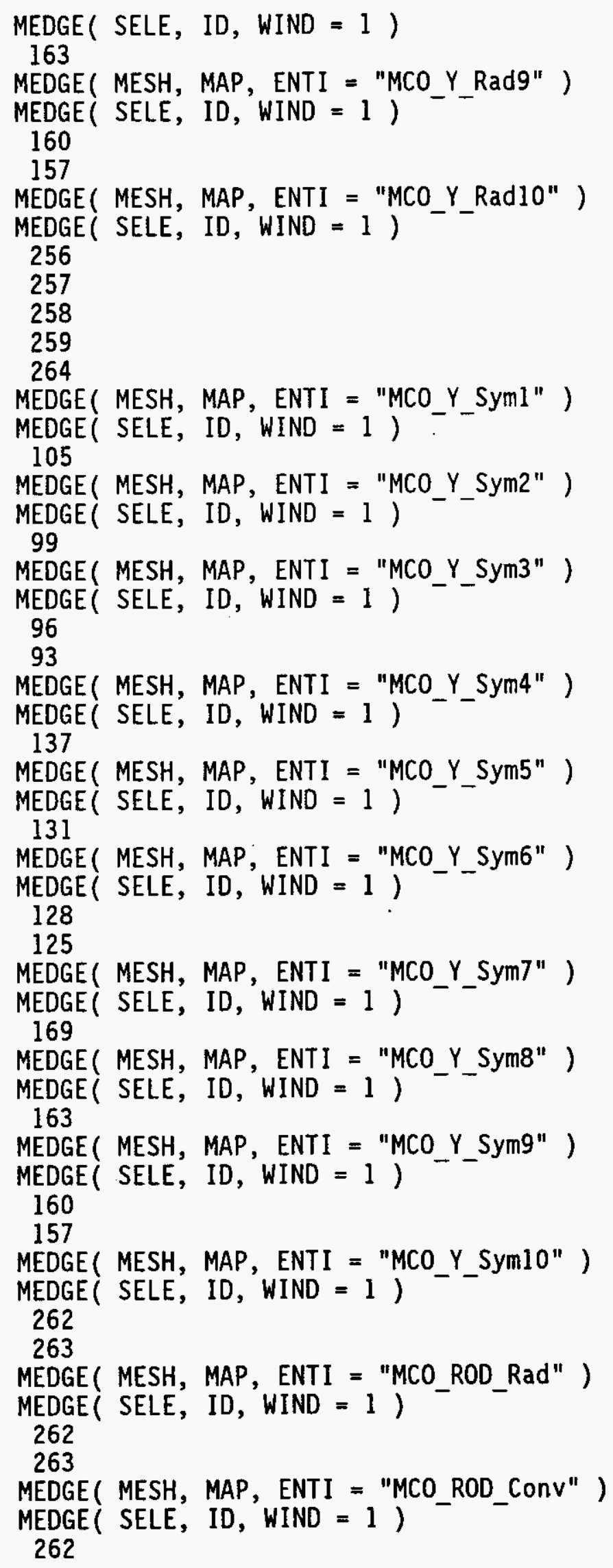




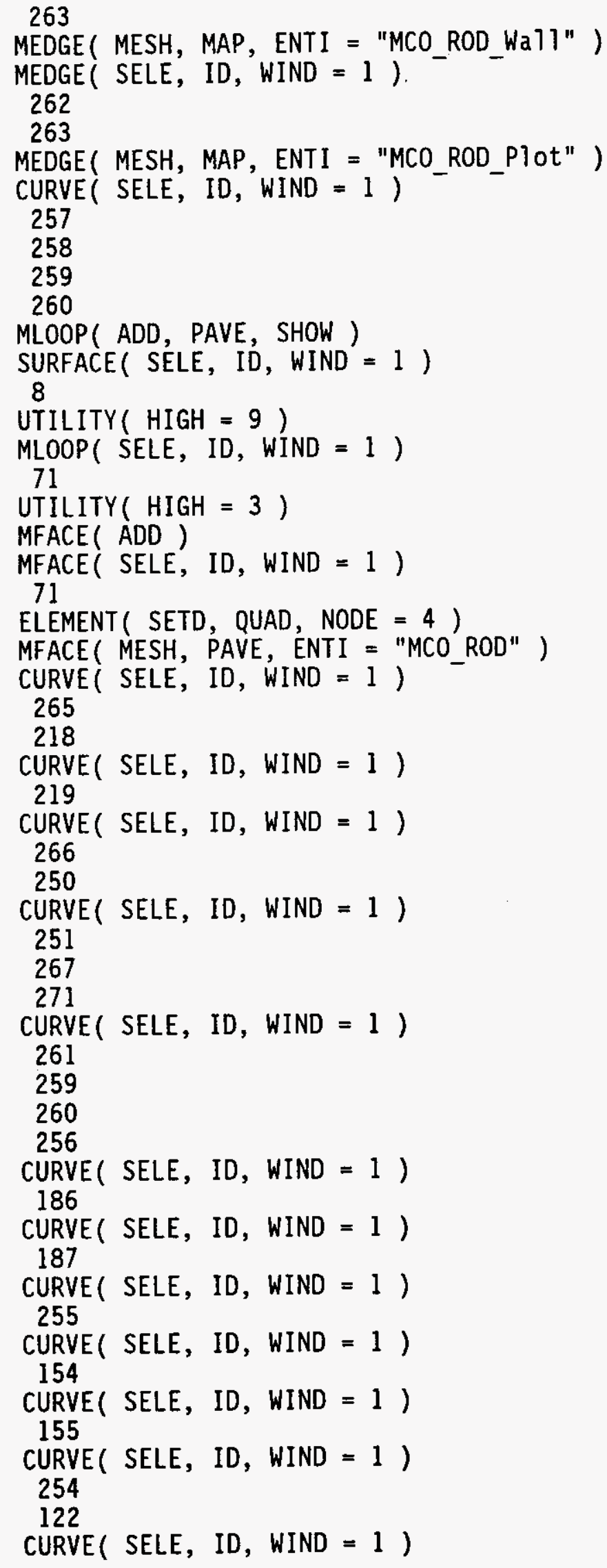




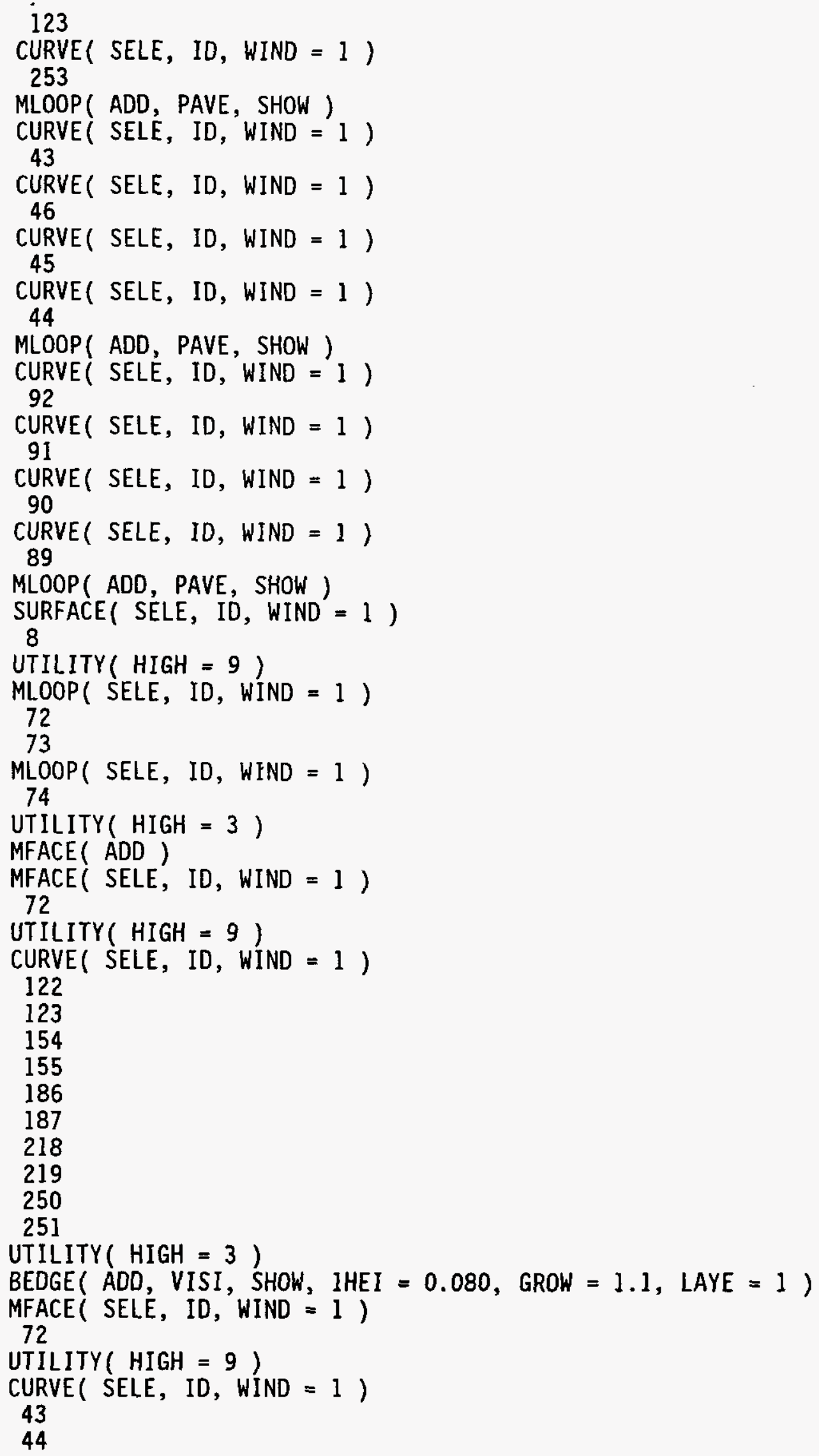




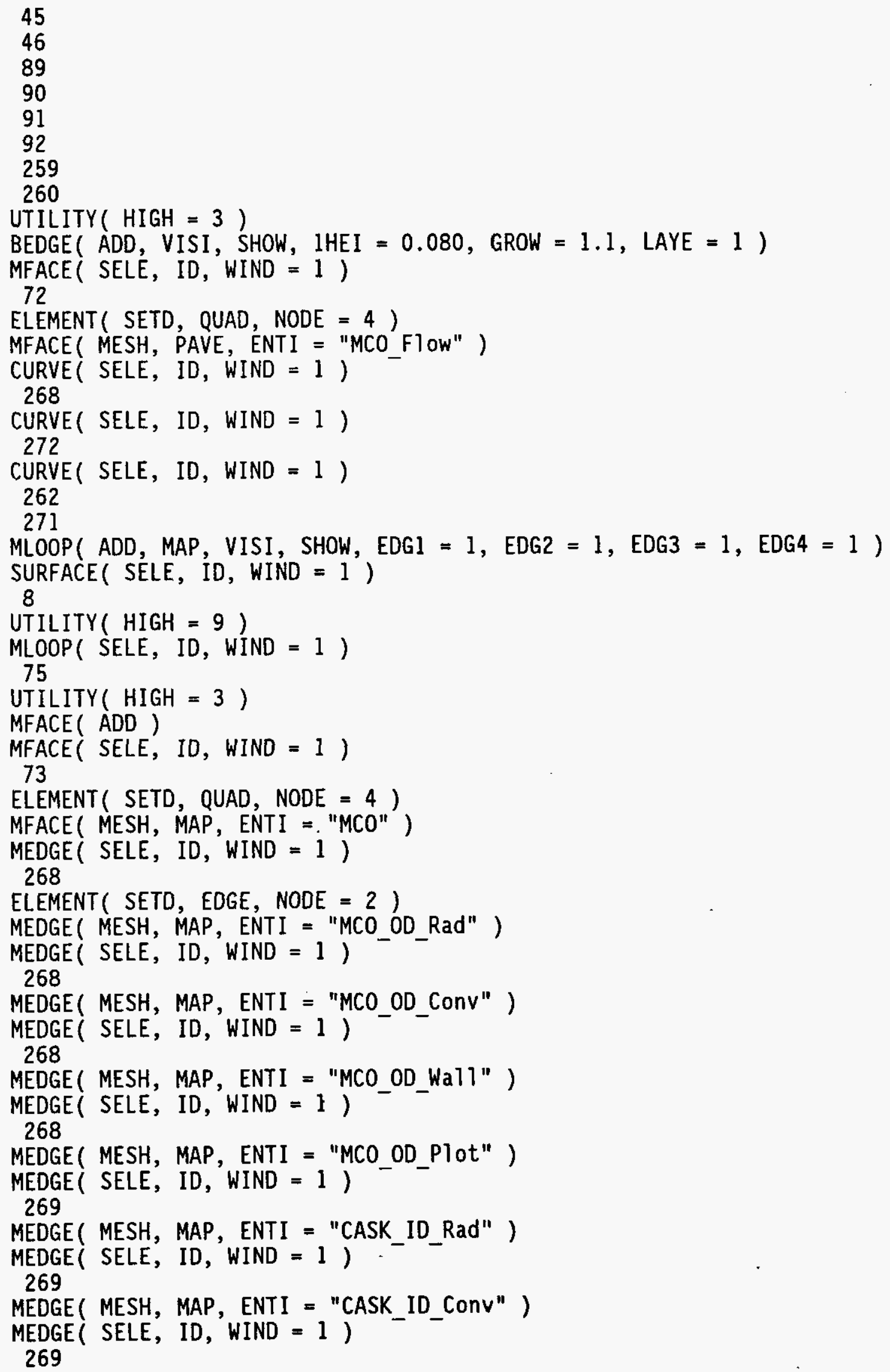


MEDGE ( MESH, MAP, ENTI = "CASK_ID_Wal 1")

MEDGE( SELE, ID, WIND = 1 )

269

MEDGE ( MESH, MAP, ENTI = "CASK ID_Plot" )

MEDGE ( SELE, ID, WIND = 1 )

266

MEDGE ( MESH, MAP, ENTI = "GAP_Y_Rad" )

MEDGE ( SELE, ID, WIND = 1 )

266

MEDGE ( MESH, MAP, ENTI = "GAP_Y_Sym" )

MEDGE ( SELE, ID, WIND $=1$ )

273

MEDGE ( MESH, MAP, ENTI = "GAP_X_Rad" )

MEDGE ( SELE, ID, WIND = 1 )

273

MEDGE ( MESH, MAP, ENTI = "GAP X_Sym" )

MEDGE ( SELE, ID, WIND $=1$ )

270

271

MEDGE ( MESH, MAP, ENTI = "CASK_OD_Rad" )

MEDGE（ SELE, ID, WIND $=1$ )

270

271

MEDGE ( MESH, MAP, ENTI = "CASK_OD_Conv" )

MEDGE ( SELE, ID, WIND $=1$ )

270

271

MEDGE ( MESH, MAP, ENTI = "CASK_OD_Wal1" )

MEDGE ( SELE, ID, WIND = 1 )

270

271

MEDGE ( MESH, MAP, ENTI $\approx$ "CASK_OD_Plot")

CURVE( SELE, ID, WIND $=1$ )

269

273

CURVE( SELE, ID, WIND = 1 )

263

272

MLOOP( ADD, MAP, VISI, SHOW, EDGI = 1, EDG2 $=1, E D G 3=1, E D G 4=1$ )

SURFACE ( SELE, ID, WIND = 1)

8

UTILITY ( HIGH $=9$ )

MLOOP ( SELE, ID, WIND $=1$ )

76

UTILITY( HIGH $=3$ )

MFACE ( ADO)

MFACE（ SELE, ID, WIND = 1 )

74

ELEMENT( SETD, QUAD, NODE = 4)

MFACE ( MESH, MAP, ENTI = "GAP FTOW" )

CURVE（ SELE, ID, WIND = 1 )

270

275

274 
WHC-SD-WM-ER-525

Rev. 0

264

CURVE ( SELE, ID, WIND = 1 )

273

MLOOP ( ADD, MAP, VISI, SHOW, EDG1 = 1, EDG2 = 2, EDG3 = 1, EDG4 = 1)

SURFACE ( SELE, ID, WIND = 1 )

8

UTILITY( HIGH = 9)

MLOOP ( SELE, ID, WIND = 1 )

77

UTILITY( HIGH $=3$ )

MFACE ( ADD, SHOW)

MFACE ( SELE, ID, WIND = 1 )

75

MFACE( MESH, MAP, ENTI = "CASK" )

I

WINDOW (CHANGE $=1$, MATRIX )

1.000000

.000000

.000000

.000000

1.000000

.000000

.000000

$.000000 \quad .000000$

.000000

.000000

.000000

$-1.92606$

24.52182

45.000000

45.000000

1.000000

.000000

.000000

1.000000

$-9.23830$

10.59761

$-23.73077$

23.73077

I

END

/

/ Merge your geometry if your copies share surfaces

I

MERGE( EXECUTE , PROXIMITY $=(3 * \$$ tole $))$

I

FIPREP

/SI UNITS - INCHES TO METERS

SCALE $(X=0.0254, Y=0.0254)$

/DATAPRINT (NORMAL, PAGE, NODES, ELEMENTS, CONSTRAINED, FLUX, INITIAL , GENERAL)

DATAPRINT (NONE)

/COMPRESSIBLE (PRESSURE $=101325.0$, GASCONSTANT $=8314.34, \mathrm{DELAY}=20$ )

EXECUTION(NEWJOB)

/ GRAVITY (MAGNITUDE $=9.8066352$, THETA=0)

POSTPROCESS(RESIDUAL)

PRESSURE (PENALTY $=1.0 E-8$, DISCONTINUOUS)

/PRINTOUT(ALL)

PRINTOUT (NONE)

PROBLEM (INCOMPRESS IBLE, TRANS I ENT, NONL INEAR, NEWTONIAN, 2-D, NOMOMENTUM, ENERGY)

$/ T I M E(B A C K, N S T E=100$, VARIABLE $=0.001$, NOF IXE $=3, \mathrm{DT}=1.0, \mathrm{TEND}=30.0, \mathrm{UCHA}=20.0$,

/ $V C H A=20.0, T C H A=1000.0, K C H A=200.0, E C H A=20000.0, W I N D O W=0.99$, TSTART $=0.0$,

/ INCMAX =3)

TIME (BACK, NSTE $=300$, VARIABLE $=0.001$, NOF IXE $=5, D T=1.0, T E N D=1296000, T C H A=10.0$, INCSTEADY $=100$, DTMAX $=10800$ )

/SOLUTION ( $S E G R=1500$, VELCONV $=0.00001, C R=2000, C G S=2000, N C G C=1 E-6, S C G C=1 E-6$,

/ PRECON=21)

SOLUTION $(S . S .=100$, VELCONV $=0.001, \operatorname{RESCONV}=0.001)$

CLIPPING (MINIMUM)

$0,0,0,0,283.16,0,0,0,1 E-20,1 E-20,1 E-20,1 E-20,1 E-20,1 E-20$,

$0,0,0,0,0,0,0,0,0,0,0,0,0,0$ 
CLIPPING(MAXIMUM)

$0,0,0,0,800.0,0,0,0,0.8641,0.0248,0.3814,0.7552,0.0836,0.2448$,

$0,0,0,0,0,0,0,0,0,0,0,0,0,0$

RELAXATION(RESIDUAL, MAXIMUM, RADIATION=0.90)

$0.2,0.2,0.0,0.75,0.90,0.0,0.15,0.15,0.05,0.05,0.05,0.05,0.05,0.05$,

$0.0,0.0,0.0,0.0,0.0,0.0,0.0,0.0,0.0,0.0,0.0,0.0,0.0,0.0$

RELAXATION(MINIMUM)

$0.2,0.2,0.0,0.75,1.0 E-5,0.0,0.15,0.15,0.05,0.05,0.05,0.05,0.05,0.05$,

$0.0,0.0,0.0,0.0,0.0,0.0,0.0,0.0,0.0,0.0,0.0,0.0,0.0,0.0$

OPTIONS (UPWINDING, CDYNAMIC)

UPWINDING (MAXIMUM)

$1.0,1.0,0.0,0.0,3.0,0.0,5.0,5.0,1.0,1.0,1.0,1.0,1.0,1.0,1.0,0.0,0.0,0.0,0.0$, $0.0,0.0,0.0,0.0,0.0,0.0,0.0,0.0,0.0$

UPWINDING(MINIMUM)

$1.0,1.0,0.0,0.0,1.0,0.0,1.0,1.0,1.0,1.0,1.0,1.0,1.0,1.0,1.0,0.0,0.0,0.0,0.0$, $0.0,0.0,0.0,0.0,0.0,0.0,0.0,0.0,0.0$

/MOLECULARWEIGHTS (SET $=1$, CONSTANT, CARRIER $=31.999$ )

$/ 44.013,2.016,18.015,28.013,17.030,31.999,0.0,0.0,0.0,0.0,0.0,0.0,0.0,0.0,0.0$ /TURBOPTIONSS (EXTENDED, REVISED)

$/ 1.35,1.9,0.09,0.75,1.15,0.9,0.41,26,0.8,0.9,0.9,0.9,0.9,0.9,0.9,0.9,0.9,0.9$, /0.9,0.9,0.9,0.9,0.9,0.9,0.9,0.05

/EDDYVISCOSITY (BOUSSINESQ, DELAY $=5$, RAMP =5)

/

/ENTITY NAMES AND ATTRIBUTES

I

/ FLUIDS, LIQUIDS, AND VACUUMS

/

ENTITY (NAME=" Inner Flow Channel1", SOLID, PROPERTY="AIR")

ENTITY (NAME = "Inner ${ }^{-}$Flow Channe 12" , SOLID, PROPERTY= "AIR")

ENTITY (NAME=" Inner Flow-Channe13" , SOLID, PROPERTY="AIR")

ENTITY (NAME=" Inner-Fl ow Channe 14", SOLID, PROPERTY= "AIR")

ENTITY (NAME=" Inner ${ }^{-}$Flow Channel5" , SOLID, PROPERTY="AIR")

ENTITY(NAME=" Inner -Flow Channe 16", SOLID, PROPERTY= "AIR")

ENTITY (NAME="Inner Flow Channel7" , SOLID, PROPERTY = "AIR")

ENTITY (NAME="Outer ${ }^{-F}$ low ${ }^{-}$ChannelU1" , SOL ID, PROPERTY="AIR")

ENTITY (NAME= "Outer ${ }^{-}$Flow ${ }^{-}$ChannelL1" ", SOLID, PROPERTY="AIR")

ENTITY (NAME= "Outer ${ }^{-}$Fl ow ChannelU2" , SOL ID, PROPERTY="AIR")

ENTITY (NAME="Outer Flow ChannelL2", SOL ID, PROPERTY="AIR")

ENTITY (NAME="Outer Fl ow-Channe13", SOL ID, PROPERTY="AIR")

ENTITY (NAME="Outer -Flow Channe14" , SOLID, PROPERTY="AIR")

ENT ITY (NAME="Outer Flow Channe 15" , SOL ID, PROPERTY="AIR")

ENTITY (NAME="Outer Flow-Channe16", SOLID, PROPERTY="AIR")

ENTITY(NAME="Outer "Flow-Channel7", SOLID, PROPERTY="AIR")

ENT ITY (NAME = "MCO FTOW", SOLID, PROPERTY="AIR")

ENT ITY (NAME= "GAP_Flow", SOLID, PROPERTY="AIR", MCOND="AIR")

$/$

/ SOLIDS

/

ENTITY (NAME="Inner Fuel CladidU1 ", SOLID, PROPERTY="ZIRC2")

ENT ITY (NAME =" Inner Fuel"CladidL1", SOL ID, PROPERTY="ZIRC2")

ENT ITY (NAME=" Inner Fue IU1" , SOL ID, PROPERTY= "UMETAL")

ENTITY (NAME=" Inner ${ }^{-}$Fue lL1 ", SOL ID, PROPERTY= "UMETAL")

ENTITY (NAME="Inner Fuel CladodU1", SOL ID, PROPERTY="ZIRC2")

ENTITY (NAME="Inner_Fuel_Cl adodL1", SOLID, PROPERTY="ZIRC2") 
WHC-SD-WM-ER-525

Rev. 0

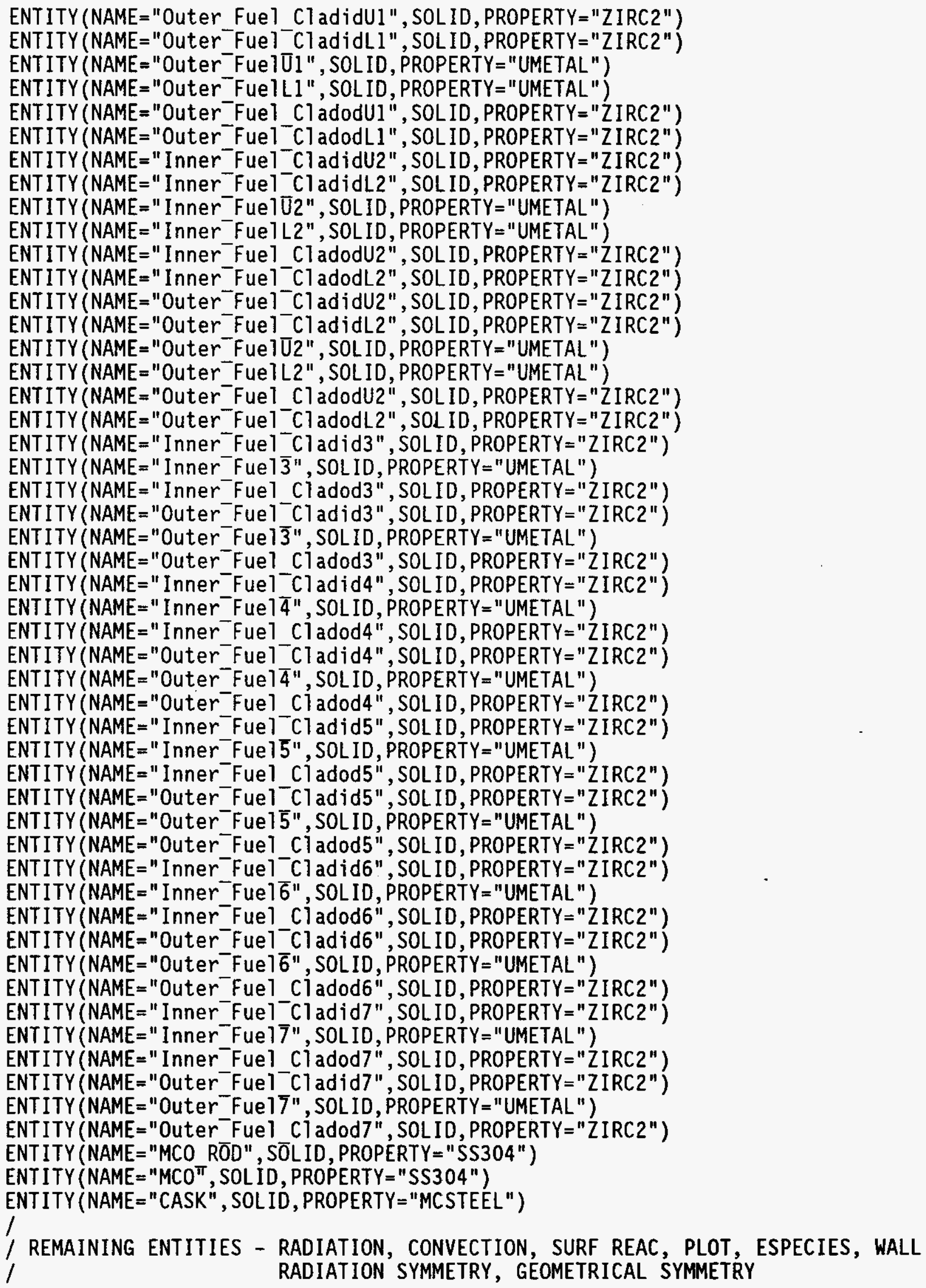


I

ENTITY (NAME="Inner Flow_Radl", ATTACH="Inner_Flow_Channell", RADIATION, $M E M S V=5, G R E \bar{Y})$

ENTITY (NAME = "Inner_Flow_Conv1" ,ATTACH="Inner_Flow_Channel1",PLOT)

ENTITY (NAME ="Inner Flow Sreacl", ATTACH="Inner Flow Channel1", PLOT)

ENTITY(NAME= "Inner-Flow-Plot]", ATTACH="Inner Flow Channel l", PLOT)

ENTITY (NAME = "Inner-Flow Espl ", ATTACH = "Inner Flow_Channel1", PLOT)

ENTITY (NAME= "Outer Flowĩd RadI", ATTACH= "Outēer Flöw Channelul",

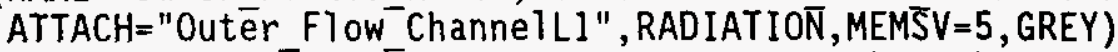

ENTITY(NAME= "Outer FTowid Conv1", ATTACH="Outer_Flow_ChannelU1", ATTACH $=$ "Outēr Flow ChannelL]", PLOT)

ENTITY (NAME="Outer_FTowid_Sreacl", ATTACH="Outer_Flow_Channelul", ATTACH= "Outer Flow Channe1L1", PLOT)

ENTITY (NAME="Outer_FTowid_Plotl", ATTACH="Outer_Flow_ChannelU1", ATTACH= "Outēr Flow ChannelL1", PLOT)

ENTITY (NAME $=$ "Outer_FTowid_Espl",ATTACH="Outer_Flow_ChannelU1", ATTAGH= "Outèr Flow ChannelL1", PLOT)

ENTITY (NAME ="Outer FTowod Radl ", ATTACH="Outer Flow ChannelU1", ATTACH= "Outer Flow" ChannelLl", RADIATION, MEMS̄V =5, GREY)

ENTITY(NAME="Outer FTowod_Convl", ATTACH="Outer_Flow_ChannelU1", ATTACH="Outer Flow ChannelL1", PLOT)

ENTITY (NAME ="Outer FTowod_Sreacl", ATTACH= "Outer_Flow_ChannelU1", ATTACH="Outer Flow-ChannelL1", PLOT)

ENTITY (NAME ="Outer_FTowod_Plot1", ATTACH="Outer_Flow_ChannelU1", ATTACH= "Outer Flow ChannelL1", PLOT)

ENTITY (NAME ="Outer FTowod"Espl", ATTACH="Outer Flow ChannelU1", ATTACH $=$ "Outer Flow ChannelLI", PLOT)

ENTITY (NAME = "Cl adod Radl", ATTACH="MCO Flow", RADIATION, MEMSV=5, GREY)

ENTITY (NAME = "Cl adod Conv1", ATTACH = "MCD̄ Fl OW" , PLOT)

ENTITY (NAME $=$ "Cladod Sreac]" " ATTACH $=$ "MCD Flow", PLOT)

ENT ITY (NAME $=$ "Cl adod"Pl ot 1", ATTACH = "MCO Flow", PLOT)

ENTITY(NAME $=$ "Cladod Espl ", ATTACH = "MCO Flow", PLOT)

ENTITY (NAME $=$ "Cladod Wa $111 ", A T T A C H=" M C \bar{O}$ Flow", PLOT)

ENTITY(NAME=" Inner Flow_Rad2", ATTACH= "Inner_Flow_Channel2", RADIATION, MEMSV $=5$, GREY)

ENTITY (NAME $=$ "Inner Flow Conv2", ATTACH = Inner Flow Channel2", PLOT)

ENTITY (NAME = "Inner-Flow Sreac2", ATTACH= "Inner Flow Channel2", PLOT)

ENT ITY (NAME = "Inner Fl ow Pl ot2", ATTACH=" Inner Flow Channel2", PLOT)

ENTITY(NAME = "Inner-Flow-Esp2", ATTACH= "Inner Flow Channel2", PLOT)

ENTITY (NAME="Outer Flowĩd Rad2" , ATTACH="Outèr Flow ChannelU2", ATTACH="Outēer Flow-ChannelL2", RADIATION , MEMSV $=5$, GREY)

ENTITY (NAME="Outer_FTowid_Conv2", ATTACH="Outer_Flow_Channelu2", ATTACH= "Outēr Flow" Channe1L2", PLOT)

ENTITY (NAME="Outer FTowid_Sreac2", ATTACH="Outer_Flow_ChannelU2", ATTACH="Outër Flow ChanneTL2", PLOT)

ENTITY(NAME="Outer FTowid"Plot2", ATTACH="Outer Flow Channelu2", ATTACH $=$ "Outèr Flow Channe1L2", PLOT)

ENTITY(NAME= "Outer_FTowid_Esp2" , ATTACH="Outer_Flow_ChannelU2", ATTACH= "Outēr Flow' ChannelL2", PLOT)

ENTITY (NAME="Outer FTowod Rad2", ATTACH="Outer Flow ChannelU2", ATTACH="Outēer Flow-ChannelL2", RADIATION, MEMSV $=5$, GREY)

ENTITY (NAME="Outer FTowod Conv2", ATTACH="Outer Flow_ChannelU2", ATTACH= "Outer FIow ChanneiL2", PLOT)

ENTITY(NAME="Outer_FTowod_Sreac2",ATTACH="Outer_Flow_ChannelU2", 
ATTACH= "Outer Flow ChannelL2", PLOT)

ENTITY(NAME $=$ "Outer_FTowod_Plot2", ATTACH="Outer_Flow_ChannelU2", ATTACH $=$ "Outēr Flow'Channe1L2", PLOT)

ENTITY(NAME= "Outer_FTowod_Esp2", ATTACH="Outer_Flow_ChannelU2", ATTACH="Outēr Flow (hannelL2", PLOT)

ENTITY (NAME = "Cladod $\bar{R}$ ad2", ATTACH="MCO Fl ow", RADIATION, MEMSV =5, GREY)

ENTITY (NAME $=$ "Cladod Conv2" , ATTACH="MCD Fl ow", PLOT)

ENTITY (NAME $=$ "Cladod Sreac2", ATTACH="MCD Flow", PLOT)

ENTITY (NAME $=$ "Cl adod Plot2" , ATTACH="MCO Flow", PLOT)

ENTITY (NAME = "Cladod Esp2", ATTACH="MCO Flow", PLOT)

ENTITY (NAME = "Cladod Wal 12", ATTACH = "MCD Flow", PLOT)

ENTITY (NAME=" Inner Flow_Rad3", ATTACH="Inner_Flow_Channel3", RADIATION, MEMSV $=5$, GREY)

ENTITY (NAME ="Inner Flow Conv3", ATTACH="Inner Flow Channe13", PLOT)

ENTITY (NAME=" Inner Flow Sreac3", ATTACH="Inner Flow Channe13", PLOT)

ENTITY(NAME = "Inner Flow Plot3", ATTACH= "Inner Flow Channe13", PLOT)

ENTITY (NAME="Inner Flow Esp3", ATTACH="Inner Flow_Channel3", PLOT)

ENTITY (NAME ="Outer Flowid_Rad3", ATTACH="Outer_Flö_Channe13", RADIATION, MEMSV $=5$, GRE $\bar{Y}$ )

ENTITY (NAME="Outer Flowid Conv3", ATTACH="Outer Flow Channel3", PLOT)

ENTITY(NAME="Outer-Flowid Sreac3", ATTACH $=$ "Outer Flow Channel3", PLOT)

ENTITY (NAME="Outer Flowid Plot3", ATTACH="Outer Flow Channe13", PLOT)

ENTITY (NAME ="Outer-Flowid_Esp3", ATTACH="Outer Flow_Channel3", PLOT)

ENTITY (NAME = "Outer Flowod_Rad3", ATTACH="Outer_Flow_Channe13", RADIATION, MEMSV $=5$, GREY)

ENTITY (NAME="Outer Flowod Conv3", ATTACH="Outer Flow Channe13", PLOT)

ENT ITY (NAME = "Outer Flowod Sreac3", ATTACH = "Outer Flow Channe13", PLOT)

ENTITY (NAME ="Outer-Flowod Plot3", ATTACH="Outer Flow Channel3",PLOT)

ENTITY (NAME="Outer-Flowod Esp3", ATTACH="Outer Flow Channel3", PLOT)

ENTITY (NAME $=$ "Cl adod Rad3",ATTACH = "MCO Fl OW", RADDIATION, MEMSV =5, GREY)

ENTITY (NAME $=$ "Cladod Conv3", ATTACH $=$ "MCD̄ Flow",PLOT)

ENTITY (NAME $=$ "Cl adod Sreac3", ATTACH="MCD̄ Flow", PLOT)

ENTITY (NAME = "Cl adod Plot3", ATTACH= "MCO Flow", PLOT)

ENTITY (NAME $=" C l$ adod Esp3", ATTACH="MCO Flow",PLOT)

ENTITY (NAME $=$ "Cladod Wal13", ATTACH= "MCD̄ FTow", PLOT)

ENTITY(NAME =" Inner Flow Rad4" , ATTACH="Inner Flow_Channe14", RADIATION, MEMSV $=5$, GREY)

ENTITY(NAME = "Inner Flow Conv4", ATTACH="Inner Flow Channel4", PLOT)

ENTITY (NAME = "Inner-Flow_Sreac4", ATTACH= "Inner Flow Channel4", PLOT)

ENTITY (NAME = "Inner-Flow-Plot4", ATTACH= "Inner Flow Channel4", PLOT)

ENTITY (NAME $=$ "Inner Flow Esp4", ATTACH= "Inner Flow Channe14", PLOT)

ENTITY (NAME ="Outer Flowid_Rad4", ATTACH="Outër_Flöw_Channel4", RADIATION, MEMSV $=5$, GREY)

ENTITY (NAME="Outer Flowid Conv4", ATTACH="Outer Flow Channel4", PLOT)

ENTITY (NAME = "Outer Flowid Sreac4", ATTACH="Outer Flow Channel4", PLOT)

ENTITY (NAME="Outer Flowid Plot4", ATTACH="Outer Flow Channel4", PLOT)

ENTITY(NAME="Outer_Flowid"Esp4", ATTACH="Outer_Flow_Channel4", PLOT)

ENTITY (NAME="Outer Flowod_Rad4" , ATTACH="Outer_Flow_Channel4", RADIATION, MEMSV $=5$, GREY)

ENTITY (NAME= "Outer Flowod Conv4", ATTACH="Outer Flow Channe14", PLOT)

ENTITY(NAME = "Outer-Flowod Sreac4", ATTACH="Outer Flow Channe14", PLOT)

ENTITY (NAME= "Outer Flowod P1 ot4", ATTACH="Outer Flow Channe14", PLOT)

ENTITY (NAME="Outer "Flowod"Esp4", ATTACH="Outer Flow Channel4", PLOT)

ENTITY (NAME $=$ "Cladod_Rad4",ATTACH="MCO_Fl ow", RADDIATION, MEMSV=5, GREY) 
ENTITY (NAME $=$ "Cladod Conv4", ATTACH= "MCO Flow", PLOT)

ENTITY (NAME $=" C l$ adod Sreac4" ATTACH $=$ "MCŌ Flow" , PLOT)

ENTITY (NAME $=$ "Cladod"Plot4", ATTACH="MCO F1ow",PLOT)

ENTITY (NAME $=" C l$ adod Esp4", ATTACH $=$ "MCO Flow", PLOT)

ENTITY (NAME $=$ "Cl adod "Wa114", ATTACH = "MCD Flow", PLOT)

ENTITY(NAME ="Inner Flow_Rad5", ATTACH="Inner_Flow_Channel5", RADIATION, $M E M S V=5, G R E \bar{Y}$ )

ENTITY (NAME="Inner Flow Conv5", ATTACH="Inner Flow Channel5", PLOT)

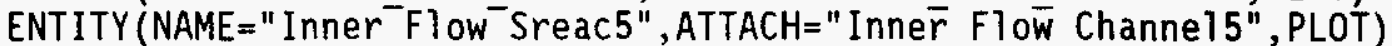

ENTITY(NAME="Inner-Flow"Plot5", ATTACH="Inner Flow Channe15", PLOT)

ENTITY (NAME $=$ "Inner-Flow Esp5",ATTACH="Inner Flow Channel 5",PLOT)

ENTITY(NAME="Outer Flowīd_Rad5", ATTACH="Outēr_Flow_Channel5", RADIATION, MEMSV $=5$, GREY)

ENTITY (NAME="Outer_Flowid_Conv5", ATTACH="Outer_Flow_Channe15", PLOT)

ENTITY (NAME ="Outer ${ }^{-F l}$ owid Sreac5", ATTACH="Outer Flow Channel5",PLOT)

ENTITY (NAME="Outer Flowid Plot5", ATTACH="Outer Flow Channe15", PLOT)

ENT ITY(NAME ="Outer-Flowid-Esp5", ATTACH="Outer Flow_Channe15", PLOT)

ENTITY (NAME="Outer Flowod_Rad5", ATTACH="Outer_Flow_Channe15", RADIATION, MEMSV $=5$, GRE $\bar{Y}$ )

ENTITY (NAME="Outer Flowod Conv5", ATTACH="Outer Flow Channe15", PLOT)

ENTITY (NAME = "Outer Flowod"Sreac5", ATTACH="Outer $\bar{r}$ Flow Channel5", PLOT)

ENTITY (NAME="Outer Flowod Plot5", ATTACH="Outer Flow Channe15", PLOT)

ENTITY (NAME="Outer Flowod-Esp5", ATTACH="Outer Flow Channe15", PLOT)

ENTITY (NAME $=" C 1$ adod Rad5", ATTACH = "MCO Flow", RAADIATION, MEMSV =5, GREY)

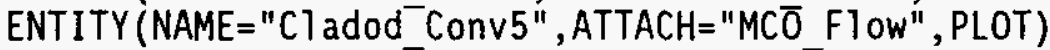

ENTITY (NAME $=" C 1$ adod Sreac5", ATTACH $=$ "MCO Flow", PLOT)

ENTITY (NAME ="Cladod"Plot5", ATTACH $=$ "MCO Flow", PLOT)

ENTITY (NAME $=" C l$ adod Esp5", ATTACH $=" M C O F \bar{F} 10 w ", P L O T)$

ENTITY (NAME $=$ "Cladod $" W a 115 "$, ATTACH $=" M C \overline{0}$ Flow", PLOT)

ENTITY(NAME="Inner F F ow_Rad6" ,ATTACH= "Inner_Flow_Channel6", RADIATION, $M E M S V=5, G R E \bar{Y})$

ENTITY(NAME="Inner Flow Conv6", ATTACH="Inner Flow Channe16", PLOT)

ENTITY(NAME = "Inner ${ }^{-}$Flow Sreac6", ATTACH $=$"Inner Flow Channel6", PLOT)

ENTITY (NAME=" Inner-Flow-Plot6", ATTACH="Inner Flow Channe16",PLOT)

ENTITY (NAME =" Inner Flow"Esp6", ATTACH= "Inner Flow Channe 16", PLOT)

ENTITY (NAME="Outer Flowid_Rad6", ATTACH="Outēr_Flow_Channel6", RADIATION, MEMSV $=5$, GREY)

ENTITY(NAME= "Outer Flowid Conv6", ATTACH="Outer Flow Channe16", PLOT)

ENTITY (NAME = "Outer_Flowid_Sreac6", ATTACH="Oute $\bar{r}$ Flow Channel6", PLOT)

ENTITY (NAME="Outer-Flowid"Plot6", ATTACH="Outer Flow Channe16", PLOT)

ENTITY (NAME ="Outer_Flowid_Esp6", ATTACH="Outer_Flow_Channe16", PLOT)

ENTITY (NAME="Outer-Flowod_Rad6", ATTACH="Outer_Flow_Channe16", RADIATION, MEMSV $=5$, GREY)

ENTITY (NAME="Outer Flowod Conv6" , ATTACH="Outer Flow Channe16", PLOT)

ENTITY(NAME="Outer Flowod Sreac6", ATTACH="Outer Flow Channe16", PLOT)

ENTITY (NAME="Outer Flowod"Plot6", ATTACH="Outer Flow Channel6",PLOT)

ENTITY (NAME ="Outer"Flowod_Esp6", ATTACH="Outer Flow Channel6", PLOT)

ENTITY (NAME = "Cladod_Rad6", ATTACH="MCO Flow", RĀDIATION, MEMSV=5, GREY)

ENTITY (NAME $=$ "Cladod CONv6", ATTACH $=$ "MCŌ Flow", PLOT)

ENTITY (NAME $=" \mathrm{Cl}$ adod Sreac6", ATTACH $=" M C \overline{0}$ Flow", PLOT)

ENT ITY (NAME $=$ "Cl adod"Plot6", ATTACH ="MCO Flow", PLOT)

ENTITY (NAME = "Cladod Esp6", ATTACH="MCO Flow", PLOT)

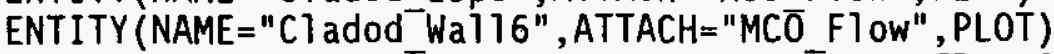

ENTITY (NAME="Inner_Flow_Rad7", ATTACH="Inner_Flow_Channe17", RADIATION, 
WHC-SD-WM-ER-525

Rev. 0

MEMSV $=5$, GREY)

ENTITY (NAME="Inner Flow Conv7", ATTACH="Inner Flow Channel7", PLOT)

ENTITY (NAME="Inner Flow Sreac7", ATTACH="Inner Flow Channel7", PLOT)

ENTITY (NAME = "Inner Flow ${ }^{-}$Plot 7" , ATTACH="Inner Flow Channe17", PLOT)

ENTITY (NAME = "Inner Flow Esp7", ATTACH="Inner Flow Channel7", PLOT)

ENTITY (NAME="Outer-Flowid_Rad7", ATTACH="Outēr_Flōw_Channel7", RADIATION, MEMSV $=5$, GREY)

ENTITY (NAME="Outer Flowid Conv7", ATTACH="Outer Flow Channel7", PLOT)

ENTITY (NAME="Outer-Flowid Sreac7", ATTACH="Outer $\bar{r}$ Flow Channel7", PLOT)

ENTITY (NAME ="Outer Flowid Plot7", ATTACH="Outer Flow Channel7", PLOT)

ENTITY(NAME="Outer Flowid"Esp7", ATTACH="Outer Flow_Channel7", PLOT)

ENTITY (NAME ="Outer Flowod"Rad7" , ATTACH="Outer_Flow_Channel7" , RADIATION, MEMSV $=5$, GREY)

ENTITY(NAME="Outer Flowod Conv7", ATTACH= "Outer Flow_Channel7", PLOT)

ENTITY (NAME $=$ "Outer - Flowod Sreac7", ATTACH $=$ "Outer Flow Channe 17",PLOT)

ENTITY(NAME="Outer Flowod Plot7", ATTACH="Outer Flow Channel7", PLOT)

ENTITY (NAME ="Outer Flowod"Esp7", ATTACH="Outer Flow Channel7", PLOT)

ENT ITY (NAME = "Cl adod_Rad7", ATTACH= "MCO Fl OW", RĀDIAT İON, MEMSV =5, GREY)

ENTITY (NAME $=$ "Cladod Conv7", ATTACH= "MCD̄ Flow", PLOT)

ENTITY (NAME $=" \mathrm{Cl}$ adod Sreac7", ATTACH $=$ "MCD̄ Flow", PLOT)

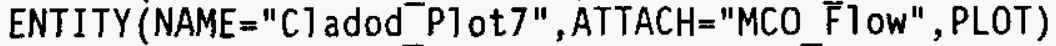

ENTITY (NAME $=$ "Cl adod Esp7", ATTACH = "MCO Flow", PLOT)

ENTITY (NAME $=$ "Cl adod Wal17", ATTACH $=$ "MCD̄ Flow", PLOT)

ENTITY (NAME $=$ "MCO_ROD_Rad", ATTACH = "MCO F Flow", RADIATION, MEMSV =l, GREY)

ENTITY (NAME $=$ "MCO- ROD CONV", ATTACH="MCD̄ FTOW", PLOT)

ENTITY (NAME = "MCO-ROD-Wa $11 "$ " ATTACH="MCO-Fl OW", PLOT)

ENTITY (NAME = "MCO-ROD-PIot", ATTACH= "MCO-FTOW", PLOT)

ENTITY (NAME $=$ "MCO ${ }^{-}$ID Rad" , ATTACH $=$"MCO FTOW", RADIATION , MEMSV $=1$, GREY)

ENTITY (NAME $=$ "MCO ${ }^{-}$ID $^{-}$CONV", ATTACH $=$"MCD $\overline{0}$ Flow" , PLOT)

ENTITY (NAME $=$ "MCO ID ${ }^{-}$Wa 11 ", ATTACH $=" M C 0^{-}$Fl OW", PLOT)

ENTITY (NAME $=$ "MCO ${ }^{-}$ID $^{-}$Pl ot ", ATTACH $=" M C 0^{-}$Fl OW", PLOT)

ENTITY (NAME $=$ "MCO' $X$ Radl ", ATTACH = "MCO Flow", RADIATION, MEMSV=2, GREY)

ENTITY (NAME ="MCO $X-$ Rad2", ATTACH="Outēer Flow Channe16", RADIATION, MEMSV=2, GREY)

ENT ITY (NAME = "MCO ${ }^{-}{ }^{-}$Rad3" , ATTACH="Outer ${ }^{-}$Fl ow Channe16", RADIATION, MEMSV =2, GREY)

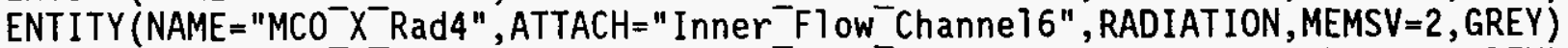

ENT ITY (NAME = "MCO ${ }^{-}{ }^{-}$Rad5" , ATTACH="Outer ${ }^{-}$Flow Channe 17", RADIATION, MEMSV =2, GREY)

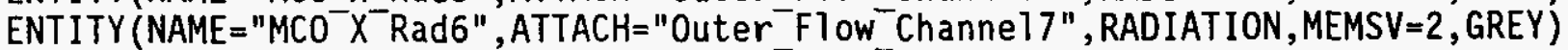

ENT ITY (NAME = "MCO- $X^{-}$Rad7", ATTACH= "Inner - Flow-Channe 17", RADIATION, MEMSV=2, GREY)

ENTITY (NAME $=$ "MCO- $X$ Syml ", ATTACH = "MCO FTOW" , PLOT)

ENTITY(NAME $=$ "MCO $X^{-}$Sym2", ATTACH="Outēr_Flow_Channel6",PLOT)

ENTITY(NAME $=" M C 0^{-} X^{-}$Sym3", ATTACH $="$ Outer Flow-Channe16", PLOT)

ENTITY (NAME $=$ "MCO- $X^{-}$Sym4" , ATTACH =" Inner ${ }^{-}$Flow ${ }^{-}$Channe 16"

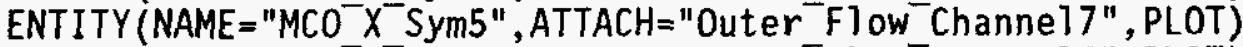

ENTITY (NAME $=$ "MCO ${ }^{-}$- Sym6", ATTACH="0uter ${ }^{-}$Flow-Channe 17", PLOT)

ENTITY (NAME $=$ "MCO- $X^{-}$Sym7" , ATTACH $="$ Inner ${ }^{-}$Flow Channel7", PLOT)

ENTITY (NAME $=$ "MCO ${ }^{-}$Rad1 " , ATTACH $=$"MCO FTOW" , RADIATION, MEMSV $=2$, GREY)

ENTITY (NAME = "MCO-Y Rad2", ATTACH= "Outēer Flow Channe13", RADIATION, MEMSV=2, GREY)

ENT ITY (NAME = "MCO-Y Rad3", ATTACH="Outer-Flow-Channel3", RADIATION, MEMSV=2, GREY)

ENT ITY (NAME $=$ "MCO-Y Rad4", ATTACH = "Inner Flow_Channe 13", RADIATION, MEMSV =2, GREY)

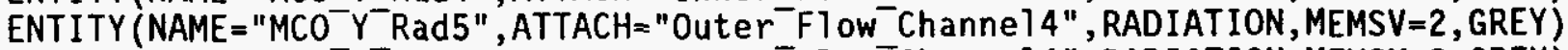

ENTITY (NAME= "MCO-Y Rad6", ATTACH="Outer-Flow_Channel4", RADIATION, MEMSV=2, GREY)

ENTITY (NAME = "MCO-Y Rad7" ", ATTACH=" Inner - Flow-Channe14" , RADIATION, MEMSV=2, GREY)

ENTITY (NAME="MCO-Y-Rad8", ATTACH ="Outer Flow_Channe15", RADIAT ION, MEMSV=2, GREY)

ENTITY (NAME = "MCO-Y Rad9", ATTACH="Outer_Flow_Channe15", RADIATION, MEMSV=2, GREY) 
WHC-SD-WM-ER-525

Rev. 0

/BCFLUX (ENTITY="Inner Flow Plot1", HEAT, FSUBROUTINE)

/BCFLUX (ENTITY="Outer Flowid PI ot 1", HEAT, FSUBROUTINE)

/BCFLUX (ENTITY="Outer Flowod Plot I", HEAT, FSUBROUTINE)

/BCFLUX (ENTITY="Cladod Plot ${ }^{\pi}$, HEAT, FSUBROUTINE)

/BCFLUX (ENTITY=" Inner Flow PTot2" , HEAT, FSUBROUTINE)

/BCFLUX (ENTITY="Outer Flowĩd Plot2", HEAT, FSUBROUTINE)

/BCFLUX (ENTITY="Outer Flowod Pl ot2" , HEAT, FSUBROUT INE)

/BCFLUX (ENTITY $=$ "Cladod Plot2" ${ }^{\pi}$, HEAT, FSUBROUTINE)

/BCFLUX (ENTITY="Inner Flow Plot3", HEAT, FSUBROUTINE)

/BCFLUX (ENTITY="Outer Flowīd_Plot3", HEAT, FSUBROUTINE)

/BCFLUX (ENTITY="Outer Flowod Plot3", HEAT, FSUBROUTINE)

/BCFLUX (ENTITY="Cladod Plot3", HEAT, FSUBROUTINE)

/BCFLUX (ENTITY=" Inner Flow Plot4", HEAT, FSUBROUTINE)

/BCFLUX (ENTITY="Outer Flowid P1 ot4", HEAT, FSUBROUTINE)

/BCFLUX (ENTITY="Outer Flowod"Plot4" , HEAT, FSUBROUTINE)

/BCFLUX (ENTITY = "Cladod Plot 4" ${ }^{\pi}$, HEAT, FSUBROUTINE)

/BCFLUX (ENTITY=" Inner Flow Pl ot5", HEAT, FSUBROUTINE)

/BCFLUX (ENTITY="Outer-Flowīd_Plot5", HEAT, FSUBROUTINE)

/BCFLUX (ENTITY="Outer Flowod Pl ot5", HEAT, FSUBROUTINE)

/BCFLUX (ENTITY="Cladod Plot5", HEAT, FSUBROUTINE)

/BCFLUX (ENTITY="Inner Flow Plot6", HEAT, FSUBROUTINE)

/BCFLUX (ENTITY="Outer ${ }^{-F 1}$ owid Plot6", HEAT, FSUBROUT INE)

/BCFLUX (ENTITY="Outer Flowod-P1 ot6", HEAT, FSUBROUTINE)

/BCFLUX (ENTITY $=" C$ ladod Plot $6 \overline{ }$, HEAT, FSUBROUTINE)

/BCFLUX (ENTITY=" Inner Flow Plot7", HEAT, FSUBROUTINE)

/BCFLUX (ENTITY="Outer-Flowid Plot7", HEAT, FSUBROUTINE)

/BCFLUX (ENTITY="Outer Flowod Plot7", HEAT, FSUBROUTINE)

/BCFLUX (ENTITY $=$ "Cladod Plot $7 "$, HEAT, FSUBROUTINE)

I

/ VOLUMETRIC CHEMICAL HEAT SOURCE

/ VOLUMETRIC SOURCE $=$ PLANAR HEAT FLUX $X$ SURFACE AREA/VOLUME

I

/ PROP(1) = TYPE OF REACTION WITH U; 1 = WATER (TYFIELD)

I

/

2 = MOIST AIR (MCGILLIVARY) $\operatorname{PROP}(8)=1 ;$ WITH 02

PROP $(8)=2 ;$ WITHOUT 02

$3=$ MOIST AIR (RITCHIE)

$\operatorname{PROP}(8)=1$; WITH 02

$\operatorname{PROP}(8)=2 ;$ WITHOUT 02

$4=$ CONDON

$\operatorname{PROP}(8)=1 ;$ WITH 02

PROP $(8)=2$; WITHOUT 02

PROP (2) = NORMALIZED REACTION SURFACE AREA MULTIPLIER

/ PROP (3) = SURFACE TO VOLUME CORRECTION FACTOR TYPE

/ PROP $(4)=$ PARTIAL PRESSURE OF WATER VAPOR IN $\mathrm{KPa}$

/ MUST BE ENTERED IF PROP $(1)=2,3$, OR 4

/ $\operatorname{PROP}(5)=1=$ REACTANT LIMITED; 2 = NOT REACTANT LIMITED

/ PROP $(6)=$ CROSS SECTIONAL AREA OF AVG ELEMENT FOR EACH ENTITY

/ USED DURING REACTANT LIMITED CALCULATIONS

/ $\operatorname{PROP}(7)=$ MAX ENERGY IN JOULES FOR LIMITED REACTANT CALC

$/$ PROP $(8)=1$ OXYGEN ATMOSPHERE; $=2$ OXYGEN FREE ATMOSPHERE

/ PROP(9) $=$ RELATIVE HUMIDITY; ZERO $=0.0$ AND $100 \%=1.0$

/

/SOURCE(ENTITY="Inner_Fuel_CladidU1", HEAT, SUBROUTINE=9) 
$/ 4,1,1,2.000,1,8.4282344 E-7,1.0496831 E+6,2,1$ / SOURCE (ENTITY = "Inner Fuel CladidLI", HEAT, SUBROUTINE=9) $/ 4,1,1,2.000,1,8.4282 \overline{3} 44 \mathrm{E}-\overline{7}, 1.0496831 \mathrm{E}+6,2,1$ /SOURCE (ENTITY=" Inner Fuel CladodUI", HEAT, SUBROUTINE=9) $/ 4,1,2,2.000,1,1.1866 \overline{4} 56 \mathrm{E}-\overline{6}, 1.0496831 \mathrm{E}+6,2,1$ /SOURCE (ENTITY =" Inner Fuel CladodL1", HEAT, SUBROUTINE=9) $/ 4,1,2,2.000,1,1.1866 \overline{4} 56 \mathrm{E}-\overline{6}, 1.049683 \mathrm{IE}+6,2,1$

/ SOURCE (ENTITY="Outer Fuel CladidU1", HEAT, SUBROUTINE=9) $/ 4,1,3,2.000,1,1.0900545 \mathrm{E}-\overline{6}, 1.0496831 \mathrm{E}+6,2,1$

/SOURCE (ENTITY $=$ "Outer Fuel CladidL1", HEAT, SUBROUTINE=9) $/ 4,1,3,2.000,1,1.0900545 \mathrm{E}-\overline{6}, 1.0496831 \mathrm{E}+6,2,1$ /SOURCE (ENTITY= "Outer Fuel CladodU1", HEAT, SUBROUTINE=9) $14,1,4,2.000,1,1.2667 \overline{6} 87 \mathrm{E}-\overline{6}, 1.0496831 \mathrm{E}+6,2,1$

/SOURCE (ENTITY $=$ "Outer Fuel CladodL1" , HEAT, SUBROUT INE=9) $/ 4,1,4,2.000,1,1.2667 \overline{6} 87 \mathrm{E}-\overline{6}, 1.0496831 \mathrm{E}+6,2,1$

/SOURCE (ENTITY=" Inner Fuel CladidU2" , HEAT, SUBROUTINE=9) $/ 4,1,1,2.000,1,8.4282 \overline{3} 44 E-\overline{7}, 1.0496831 E+6,2,1$

/ SOURCE (ENTITY=" Inner Fuel CladidL2" , HEAT, SUBROUTINE=9) $/ 4,1,1,2.000,1,8.4282 \overline{3} 44 \mathrm{E}-\overline{7}, 1.0496831 \mathrm{E}+6,2,1$ /SOURCE (ENTITY=" Inner Fuel Cl adodU2", HEAT, SUBROUTINE=9) $/ 4,1,2,2.000,1,1.1866 \overline{4} 56 \mathrm{E}-\overline{6}, 1.0496831 \mathrm{E}+6,2,1$ /SOURCE (ENTITY="Inner Fuel CladodL2", HEAT, SUBROUTINE=9) $/ 4,1,2,2.000,1,1.1866 \overline{4} 56 \mathrm{E}-\overline{6}, 1.0496831 \mathrm{E}+6,2,1$

/SOURCE (ENTITY="Outer Fuel CladidU2", HEAT, SUBROUTINE=9) $14,1,3,2.000,1,1.0900545 \mathrm{E}-\overline{6}, 1.0496831 \mathrm{E}+6,2,1$

/ SOURCE (ENTITY="Outer Fuel CladidL2", HEAT, SUBROUTINE=9) $14,1,3,2.000,1,1.0900545 E-\overline{6}, 1.0496831 \mathrm{E}+6,2,1$ / SOURCE (ENTITY="Outer Fuel Cl adodU2", HEAT, SUBROUTINE=9) $14,1,4,2.000,1,1.2667 \overline{6} 87 \mathrm{E}-\overline{6}, 1.0496831 \mathrm{E}+6,2,1$ /SOURCE (ENTITY="Outer Fuel Cl adodL2", HEAT, SUBROUTINE=9) $/ 4,1,4,2.000,1,1.2667 \overline{6} 87 \mathrm{E}-\overline{6}, 1.0496831 \mathrm{E}+6,2,1$

/ SOURCE (ENTITY=" Inner Fuel Cladid3", HEAT, SUBROUTINE=9) $/ 4,1,1,2.000,1,8.4282 \overline{3} 44 \mathrm{E}-\overline{7}, 1.0496831 \mathrm{E}+6,2,1$ /SOURCE (ENTITY=" Inner Fue 1 C T adod3", HEAT, SUBROUTINE=9) $14,1,2,2.000,1,1.1866 \overline{4} 56 \mathrm{E}-\overline{6}, 1.0496831 \mathrm{E}+6,2,1$ / SOURCE (ENTITY="Outer Fuel Cladid3", HEAT, SUBROUTINE=9) $/ 4,1,3,2.000,1,1.0900545 \mathrm{E}-\overline{6}, 1.0496831 \mathrm{E}+6,2,1$ / SOURCE (ENTITY="Outer Fuel Cladod3", HEAT, SUBROUTINE=9) $14,1,4,2.000,1,1.2667 \overline{6} 87 \mathrm{E}-\overline{6}, 1.0496831 \mathrm{E}+6,2,1$ / SOURCE (ENTITY=" Inner Fuel Cladid4", HEAT, SUBROUTINE=9) $14,1,1,2.000,1,8.4282344 E-7,1.0496831 \mathrm{E}+6,2,1$ /SOURCE (ENTITY=" Inner Fuel Cladod4", HEAT, SUBROUTINE=9) $/ 4,1,2,2.000,1,1.1866 \overline{4} 56 \mathrm{E}-\overline{6}, 1.0496831 \mathrm{E}+6,2,1$ /SOURCE (ENTITY="Outer Fuel Cladid4", HEAT, SUBROUTINE=9) $14,1,3,2.000,1,1.0900 \overline{5} 45 \mathrm{E}-\overline{6}, 1.0496831 \mathrm{E}+6,2,1$ / SOURCE (ENTITY="Outer Fuel Cladod4", HEAT, SUBROUTINE=9) $/ 4,1,4,2.000,1,1.2667 \overline{6} 87 \mathrm{E}-\overline{6}, 1.0496831 \mathrm{E}+6,2,1$ / SOURCE (ENTITY=" Inner Fuel Cladid5", HEAT, SUBROUT INE=9) $/ 4,1,1,2.000,1,8.4282 \overline{3} 44 \mathrm{E}-\overline{7}, 1.0496831 \mathrm{E}+6,2,1$ /SOURCE (ENTITY=" Inner Fuel C 7 adod5", HEAT, SUBROUTINE=9) $/ 4,1,2,2.000,1,1.1866 \overline{4} 56 \mathrm{E}-\overline{6}, 1.0496831 \mathrm{E}+6,2,1$ /SOURCE (ENTITY="Outer FueI CTadid5", HEAT, SUBROUTINE=9) $/ 4,1,3,2.000,1,1.0900545 \mathrm{E}-\overline{6}, 1.0496831 \mathrm{E}+6,2,1$

/SOURCE (ENTITY="Outer_Fuel_C1adod5", HEAT, SUBROUTINE=9) 
WHC-SD-WM-ER-525

Rev. 0

$14,1,4,2.000,1,1.2667687 \mathrm{E}-6,1.0496831 \mathrm{E}+6,2,1$

/ SOURCE (ENTITY="Inner Fuel Cladid6", HEAT, SUBROUTINE=9)

$/ 4,1,1,2.000,1,8.4282 \overline{3} 44 \mathrm{E}-7,1.0496831 \mathrm{E}+6,2,1$

/ SOURCE (ENTITY="Inner Fuel Cladod6", HEAT, SUBROUT INE=9)

$14,1,2,2.000,1,1.1866 \overline{4} 56 \mathrm{E}-\overline{\bar{\sigma}}, 1.0496831 \mathrm{E}+6,2,1$

/ SOURCE (ENTITY="Outer Fuel Cladid6", HEAT, SUBROUT INE=9)

$/ 4,1,3,2.000,1,1.0900545 E-\overline{6}, 1.0496831 \mathrm{E}+6,2,1$

/ SOURCE (ENTITY="Outer Fuel Cladod6", HEAT, SUBROUTINE=9)

$/ 4,1,4,2.000,1,1.2667 \overline{6} 87 \mathrm{E}-\overline{6}, 1.0496831 \mathrm{E}+6,2,1$

/ SOURCE (ENTITY="Inner Fuel Cladid7", HEAT, SUBROUTINE=9)

$/ 4,1,1,2.000,1,8.4282 \overline{3} 44 \mathrm{E}-\overline{7}, 1.0496831 \mathrm{E}+6,2,1$

/ SOURCE (ENTI ITY=" Inner Fuel Cladod7" , HEAT, SUBROUTINE $=9$ )

$14,1,2,2.000,1,1.1866 \overline{4} 56 \mathrm{E}-\overline{6}, 1.0496831 \mathrm{E}+6,2,1$

/ SOURCE (ENTITY="Outer Fuel C 7 adid7", HEAT, SUBROUTINE=9)

$14,1,3,2.000,1,1.0900545 E-\overline{6}, 1.0496831 E+6,2,1$

/SOURCE (ENTITY="Outer Fuel Cladod7", HEAT, SUBROUTINE=9)

$/ 4,1,4,2.000,1,1.2667 \overline{6} 87 \mathrm{E}-\overline{6}, 1.0496831 \mathrm{E}+6,2,1$

/

/ WATER

SPECIFICHEAT (SET = "WATER" , CURVE $=15$, TEMPERATURE, SPATIAL)

$273.16,288.72,299.83,310.94,338.72,366.49,367.05$,

$367.60,394.27,422.05,477.60,533.16,588.72,810.94,1088.72$,

$4228.4,4186.6,4182.4,4182.4,4186.6,4228.4,4228.4$,

$4228.4,4270.3,4312.2,4521.5,4982.0,6321.7,6321.7,6321.7$

DENSITY (SET $=$ "WATER", CONSTANT $=994.7466)$

CONDUCTIVITY (SET = "WATER", CURVE $=15$, TEMPERATURE, ISOTROPIC)

$273.16,288.72,299.83,310.94,338.72,366.49,367.05$,

$367.60,394.27,422.05,477.60,533.16,588.72,810.94,1088.72$,

$0.5521,0.5884,0.6109,0.6299,0.6628,0.6784,0.6784$,

$0.6784,0.6836,0.6836,0.6611,0.6040,0.5071,0.5071,0.5071$

CONDUCTIVITY (SET $=$ "HCWATER" , CONSTANT $=1000.0$ )

CONDUCTIVITY (SET = "WATERGAP1" , CURVE =15, TEMPERATURE, ISOTROPIC)

$273.16,288.72,299.83,310.94,338.72,366.49,367.05$,

$367.60,394.27,422.05,477.60,533.16,588.72,810.94,1088.72$,

$0.5521,0.5884,0.6109,0.6299,0.6628,0.6784,0.6784$,

$0.6784,0.6836,0.6836,0.6611,0.6040,0.5071,0.5071,0.5071$

CONDUCTIVITY (SET= "WATERGAP5" , CURVE $=9$, TEMPERATURE, ISOTROPIC)

$273.16,313.72,316.49,322.05,327.60,333.16,338.72,366.49,810.94$,

$94.62,94.62,119.21,150.19,171.93,189.23,203.84,256.81,522.30$

/ WATER VAPOR

SPECIFICHEAT (SET $=$ "VAPOR" , CURVE $=11$, TEMPERATURE, SPATIAL)

$380.0,400.0,450.0,500.0,550.0,600.0,650.0,700.0,750.0,800.0,850.0$,

$2060.0,2014.0,1980.0,1985.0,1997.0,2026.0,2056.0,2085.0,2119.0$,

$2152.0,2186.0$

DENSITY (SET $=$ "VAPOR" , CONSTANT $=0.5863$ )

CONDUCT IVITY (SET = "VAPOR" , CURVE $=11$, TEMPERATURE, ISOTROPIC)

$380.0,400.0,450.0,500.0,550.0,600.0,650.0,700.0,750.0,800.0,850.0$, $0.0246,0.0261,0.0299,0.0339,0.0379,0.0422,0.0464,0.0505,0.0549$,

$0.0592,0.0637$

/ AIR

SPECIFICHEAT (SET="AIR" , CURVE $=14$, TEMPERATURE, SPATIAL)

$100.00,288.72,299.83,310.94,338.72,366.49,394.27$,

$422.05,477.60,533.16,588.72,699.83,810.94,1088.72$,

$1004.8,1004.8,1004.8,1004.8,1009.0,1009.0,1013.2$, 
$1017.3,1025.7,1034.1,1050.8,1076.0,1101.1,1159.7$

DENSITY (SET $=$ "AIR" , CONSTANT $=1.137310873$ )

CONDUCTIVITY (SET = "AIR" , CURVE $=14$, TEMPERATURE, ISOTROPIC)

$100.00,288.72,299.83,310.94,338.72,366.49,394.27$,

$422.05,477.60,533.16,588.72,699.83,810.94,1088.72$,

$0.022844,0.025267,0.026306,0.026998,0.028902,0.030979,0.033055$,

$0.035132,0.038939,0.042574,0.046727,0.052438,0.058323,0.070610$

CONDUCTIVITY (SET = "HCAIR" , CONSTANT $=10.0$ )

CONDUCTIVITY (SET="AIRGAP1", CONSTANT=0.10961)

CONDUCTIVITY (SET="AIRGAP5" , CURVE $=9$, TEMPERATURE, ISOTROPIC)

$100.0,273.16,316.49,322.05,327.60,333.16,338.72,366.49,810.94$,

$0.23675,0.23675,0.30597,0.39542,0.45942,0.51102,0.55500,0.71726,1.61713$

/ VACUUM DUMMY PROPERTY SET

SPECIFICHEAT (SET $=$ "VACI " , CONSTANT $=0.000001$ )

DENSITY (SET $=$ "VAC $1 "$ " CONSTANT $=1.0$ )

CONDUCTIVITY(SET = "VACI" , CURVE $=14$, TEMPERATURE, ISOTROPIC)

$100.00,288.72,299.83,310.94,338.72,366.49,394.27$,

$422.05,477.60,533.16,588.72,699.83,810.94,1088.72$,

$0.022844,0.025267,0.026306,0.026998,0.028902,0.030979,0.033055$,

$0.035132,0.038939,0.042574,0.046727,0.052438,0.058323,0.070610$

/ HELIUM

SPECIFICHEAT(SET $=$ "HE" , CONSTANT $=5200.0)$

DENSITY (SET $=$ "HE" , CONSTANT $=0.13280$ )

CONDUCTIVITY (SET = "HE" , CURVE $=8$, TEMPERATURE, ISOTROPIC)

$144.0,200.0,255.0,366.0,477.0,589.0,700.0,800.0$,

$0.0928,0.1177,0.1357,0.1691,0.197,0.225,0.251,0.275$

/ ARGON

SPECIFICHEAT (SET $=$ "AR", CONSTANT $=518.8$ )

DENSITY (SET = "AR" , CONSTANT $=1.784$ )

CONDUCTIVITY (SET = "AR" , CURVE $=7$, TEMPERATURE, ISOTROPIC)

$173.16,273.16,373.16,573.16,773.16,1073.16,1473.16$,

$0.0109,0.0166,0.0214,0.0295,0.0351,0.0439,0.1285$

/ NITROGEN

SPECIFICHEAT (SET $=$ "N2" , CURVE $=11$, TEMPERATURE, SPATIAL)

$200,300,400,500,600,700,800,900,1000,1100,1200$,

$1042.9,1040.8,1045.9,1055.5,1075.6,1096.9,1122.5,1146.4$,

$1167.7,1185.7,1203.7$

DENSITY (SET $=$ "N2" , CONSTANT $=1.11056)$

CONDUCTIVITY (SET="N2" , CURVE $=11$, TEMPERATURE, ISOTROPIC)

$200,300,400,500,600,700,800,900,1000,1100,1200$,

$0.01824,0.02620,0.03335,0.03984,0.04580,0.05123,0.05609,0.06070$,

$0.06475,0.06850,0.07184$

/ OXYGEN

SPECIFICHEAT (SET $=$ "02" , CURVE $=9$, TEMPERATURE, SPATIAL)

$150.0,200.0,250.0,300.0,350.0,400.0,450.0,500.0,550.0$,

$917.8,913.1,915.7,920.3,929.1,942.0,956.7,972.2,988.1$

DENSITY (SET $=$ "02" , CONSTANT $=1.3007$ )

CONDUCTIVITY (SET $=$ "02", CURVE $=9$, TEMPERATURE, I SOTROPIC)

$150.0,200.0,250.0,300.0,350.0,400.0,450.0,500.0,550.0$, $0.01367,0.01824,0.02259,0.02676,0.03070,0.03461$,

$0.03828,0.04173,0.04517$

/ HYDROGEN

SPECIFICHEAT (SET="H2" , CURVE $=13$, TEMPERATURE, SPATIAL)

$150.0,200.0,250.0,300.0,350.0,400.0,450.0,500.0,550.0,600.0,700.0$, 
WHC-SD-WM-ER-525

Rev. 0

$800.0,900.0$,

$12602.0,13450.0,14059.0,14314.0,14436.0,14491.0,14499.0,14507.0$,

$14532.0,14537.0,14574.0,14675.0,14821.0$

DENSITY (SET $=" H 2 "$, CONSTANT $=0.07016$ )

CONDUCTIVITY (SET="H2", CURVE=13, TEMPERATURE, ISOTROPIC)

$150.0,200.0,250.0,300.0,350.0,400.0,450.0,500.0,550.0,600.0,700.0$,

$800.0,900.0$,

$12602.0,13450.0,14059.0,14314.0,14436.0,14491.0,14499.0,14507.0$,

$14532.0,14537.0,14574.0,14675.0,14821.0$

/ UMETAL

SPECIF ICHEAT (SET = "UMETAL" , CURVE $=14$, TEMPERATURE, SPATIAL)

$100.00,273.16,373.16,473.16,573.16,673.16,773.16$,

$873.16,939.16,940.16,1049.16,1050.16,1403.16,1773.16$,

$114.0843,115.1309,122.4574,131.8772,142.3437,153.6474,168.5098$,

$188.3960,206.8170,178.7669,178.7669,160.7646,160.7646,160.7646$

DENSITY (SET= "UMETAL" , CONSTANT $=19037.5$ )

CONDUCTIVITY (SET = "UMETAL" , CURVE $=14$, TEMPERATURE, ISOTROPIC)

$100.00,273.16,373.16,473.16,573.16,673.16,773.16$,

$873.16,939.16,940.16,1049.16,1050.16,1403.16,1773.16$,

$26.7968,26.9015,26.9015,29.0159,30.9838,32.9726,35.0033$,

$37.8924,39.1485,39.1485,41.4513,41.4513,50.2440,50.2440$

/ ZIRC2

SPECIFICHEAT (SET="ZIRC2" , CURVE $=15$, TEMPERATURE, SPATIAL)

$100.00,273.16,310.94,366.49,422.05,477.60,533.16$,

$588.72,644.27,699.83,755.38,810.94,922.05,1088.72,2000.0$,

$284.6873,284.6873,288.8739,293.0605,301.4336,305.2022,309.8068$,

$318.1800,322.3665,330.7397,334.9263,341.2061,360.0457,376.7921$,

376.7921

DENSITY (SET="ZIRC2" , CONSTANT $=6550.0$ )

CONDUCTIVITY (SET = "ZIRC2" , CURVE =9, TEMPERATURE, ISOTROPIC)

$273.16,373.16,473.16,573.16,673.16,773.16,873.16,973.16,1073.16$,

$12.3517,13,3984,14.4452,15.6175,17.0411,18.4228,19.8883,21.5212$,

23.0285

/ U02

SPECIFICHEAT (SET = "UO2" , CURVE =14, TEMPERATURE, SPATIAL)

$273.16,298.0,366.33,505.22,644.11,783.0,921.89$,

$1060.8,1199.7,1338.6,1477.4,1616.3,1755.2,1894.1$,

$235.62,235.62,256.80,280.36,293.26,301.99,308.78$,

$314.56,319.77,324.72,329.73,335.42,342.85,353.69$

DENSITY (SET $=$ "U02", CONSTANT $=9659.3$ )

CONDUCTIVITY (SET = "UO2" , CURVE=14, TEMPERATURE, ISOTROPIC)

$273.16,298.0,333.33,444.44,555.56,666.67,777.78,888.89,1000.0$,

$1222.2,1444.44,1666.7,1888.9,2000.0$

$8.2704,8.2704,7.3417,6.7192,5.8508,5.1601,4.5985,4.1337,3.7434,3.1276$,

$2.6761,2.3638,2.2030,2.1908$

/ $\mathrm{AL}$

SPECIFICHEAT (SET = "AL ", CONSTANT $=937.7936$ )

DENSITY (SET $=$ "AL", CONSTANT $=2700.7129$ )

CONDUCTIVITY (SET = "AL" , CURVE $=6$, TEMPERATURE, ISOTROPIC)

273.16,293.16,373.16, 573.16,699.83,1088.72,228.4449, 228.4449, 228.4449,

$230.1755,230.1755,230.1755$

ISS304

SPECIFICHEAT (SET="SS304" , CURVE $=17$, TEMPERATURE, SPATIAL)

$273.16,294.16,311.16,366.16,422.16,477.16,533.16,589.16,644.16$, 
WHC-SD-WM-ER-525

Rev. 0

$700.16,755.16,811.16,866.16,922.16,977.16,1033.16,1144.16$, $477.6,477.6,483.9,503.1,519.1,533.5,545.2,555.2,563.8,571.3$, $578.0,584.3,590.5,597.0,604.1,612.2,632.7$

DENSITY (SET $=$ "SS304", CONSTANT $=8045.0$ )

CONDUCT IVITY (SET = "SS304" , CURVE $=17$, TEMPERATURE, ISOTROPIC) 273.16,294.16,311.16,366.16,422.16,477.16,533.16, 589.16,644.16, $700.16,755.16,811.16,866.16,922.16,977.16,1033.16,1144.16$, $14.83,14.83,15.12,16.08,17.00,17.90,18.76,19.60,20.42,21.22$, $22.00,22.77,23.53,24.27,25.01,25.74,27.20$

/ SS 316

SPEC IFICHEAT (SET = "SS316" , CURVE $=14$, TEMPERATURE, SPATIAL)

$273.16,294.27,310.94,366.49,422.05,477.60,533.16$,

$588.72,644.27,699.83,810.94,922.05,1033.16,1144.27$,

$465.6,465.6,472.3,492.4,509.7,524.3,536.6$,

$547.1,556.1,563.9,577.6,590.9,606.9,628.4$

DENSITY (SET $=$ "SS316" , CONSTANT $=7962.0)$

CONDUCTIVITY (SET = "SS316" , CURVE $=14$, TEMPERATURE, ISOTROPIC)

$273.16,294.27,310.94,366.49,422.05,477.60,533.16$,

$588.72,644.27,699.83,810.94,922.05,1033.16,1144.27$,

$13.36,13.36,13.64,14.58,15.51,16.41,17.31$,

$18.18,19.04,19.88,21.51,23.06,24.55,25.96$

/ MILD CARBON STEEL

SPECIF ICHEAT(SET = "MCSTEEL" , CURVE $=14$, TEMPERATURE, SPATIAL)

$273.16,294.27,310.94,366.49,422.05,477.60,533.16$,

$588.72,644.27,699.83,810.94,922.05,1033.16,1144.27$,

$437.53,437.53,450.22,486.46,515.21,538.84,559.73$,

$580.25,602.79,629.70,706.20,828.74,1758.5,705.89$

DENSITY(SET $=$ "MCSTEEL" , CONSTANT $=7852.2506$ )

CONDUCTIVITY (SET = "MCSTEEL" , CURVE $=14$, TEMPERATURE, ISOTROPIC)

$273.16,294.27,310.94,366.49,422.05,477.60,533.16$,

$588.72,644.27,699.83,810.94,922.05,1033.16,1144.27$,

$51.733,51.733,51.510,50.574,49.368,47.930,46.298$,

$44.508,42.599,40.607,36.525,32.562,29.016,26.187$

/ SLUDGE 1 - PURE SILICON DIOXIDE (SAND)

SPECIFICHEAT(SET = "SLUDGE1" , CONSTANT $=1842.1$ )

DENSITY (SET $=$ "SLUDGEI" , CONSTANT $=1601.8463$ )

CONDUCTIVITY(SET="SLUDGEl ", CONSTANT =1 .0384)

/

/ EMISSIVITIES $1=$ SS304 (BRIGHT SURFACE) , $2=\mathrm{REFL}, 3=\mathrm{MCS}$ (BLACK), 4=AL203

$/$

$5=$ ZRO2, $6=$ MCS (DARK GREY SURFACE), $7=$ ZERO SURFACE

/

EMISSIVITY (SET $=1$, CONSTANT $=0.25$, STEFB $=5.6697 E-8$ )

EMISS IVITY (SET $=2$, CONSTANT $=1.00$, STEFB $=5.6697 \mathrm{E}-8)$

EMISSIVITY (SET $=3$, CONSTANT $=0.55$, REFTEMP $=310.94$, STEFB $=5.6697 \mathrm{E}-8$ )

EMISSIVITY (SET $=4$, CONSTANT $=0.15$, STEFB $=5.6697 \mathrm{E}-8$ )

EMISSIVITY (SET $=5$, CONSTANT $=0.40$, STEFB $=5.6697 \mathrm{E}-8$ )

EMISSIVITY (SET $=6$, CONSTANT $=0.30$, STEFB $=5.6697 \mathrm{E}-8$ )

EMISSIVITY (SET $=7$, CONSTANT $=1.0 \mathrm{E}-5, \mathrm{STEFB}=5.6697 \mathrm{E}-8$ )

/

/ INITIAL CONDITIONS

/

ICNODE (TEMPERATURE, CONSTANT $=310.94, \mathrm{ALL}$ )

/ ICNODE (TEMPERATURE, ENTITY="CASK ID_Rad" , CONSTANT=310.94)

/ ICNODE (TEMPERATURE, ENT ITY="CASK_ID_CONV", CONSTANT=310.94) 
/ ICNODE (TEMPERATURE, ENTITY= "CASK ID Wall ", CONSTANT $=310.94$ )

/ICNODE (TEMPERATURE, ENT ITY = "CASK ${ }^{-}$ID $^{-P 1}$ ot " , CONSTANT $=310.94$ )

/ ICNODE (TEMPERATURE, ENTITY = "CASK", CŌNSTANT $=310.94$ )

/ ICNODE (TEMPERATURE, ENTITY="CASK OD Rad" , CONSTANT=310.94)

/ ICNODE (TEMPERATURE, ENT ITY= "CASK OD"CONV" , CONSTANT=310.94)

/ICNODE (TEMPERATURE, ENTITY="CASKOOD Wa11" , CONSTANT =310.94)

/ ICNODE (TEMPERATURE, ENTITY = "CASK_OD_Plot ", CONSTANT=310.94)

/

/ BOUNDARY CONDITIONS FOR VACUUM CALCULATIONS

/

BCNODE (ENTITY="Inner Flow Channel1", VELOCITY,ZERO)

BCNODE (ENTITY="Inner-Flow_Channel2", VELOCITY, ZERO)

BCNODE (ENTITY="Inner FT ow Channe13", VELOCITY, ZERO)

BCNODE (ENTITY="Inner Fl ow Channel4" , VELOCITY, ZERO)

BCNODE (ENTITY= "Inner Flow-Channe 15", VELOCITY, ZERO)

BCNODE (ENTITY="Inner Flow-Channe 16", VELOCITY, ZERO)

BCNODE (ENTITY=" Inner Fl ow Channel7", VELOCITY, ZERO)

BCNODE (ENTITY="Outer Fl OW ChanneIUI", VELOCITY, ZERO)

BCNODE (ENTITY="Outer-Flow_Channe IU2", VELOCITY, ZERO)

BCNODE (ENTITY="Outer-Flow-ChannelL1", VELOCITY, ZERO)

BCNODE (ENTITY="Outer Fl ow ChannelL2", VELOCITY, ZERO)

BCNODE (ENT ITY="Outer-Flow-Channel3" , VELOCITY, ZERO)

BCNODE (ENTITY="Outer-Flow_Channel4", VELOCITY, ZERO)

BCNODE (ENTITY="Outer-Flow_Channel 5", VELOCITY, ZERO)

BCNODE (ENTITY="Outer Flow Channe 16", VELOCITY, ZERO)

BCNODE (ENTITY= "Outer Fl ow Channel7", VELOCITY, ZERO)

BCNODE (ENTITY= "MCO FTOW", VELOCITY, ZERO)

1

/ HEAT TRANSFER SETS (J/S-M2-K)

I

/ HC FROM OD SURFACE OF CASK FOR REFERENCE EXTERNAL TEMEPRATURES

/ $54,60,70,77,80,90,92,100,110,115,120,125,140,150,160$,

$/ 175,200,205$, AND $212 \mathrm{~F}$

/ BASED ON NAT CIRCULATION IN AIR FROM VERTICAL CYLINDRICAL SURFACES

/

/HTRANSFER(SET = "EXT54", CURVE $=17$, TEMPERATURE, REFTEMP $=285.38$ )

/HTRANSFER (SET $="$ EXT60" , CURVE $=17$, TEMPERATURE, REFTEMP $=288.72$ )

/HTRANSFER(SET $="$ EXT70" , CURVE $=17$, TEMPERATURE, REFTEMP $=294.27$ )

HTRANSFER (SET = "EXT77 " , CURVE $=17$, TEMPERATURE, REFTEMP=298.16)

$273.16,298.71,299.82,305.37,310.93,316.48,322.04,327.59,333.15,338.71$,

$344.26,349.82,355.37,360.93,366.48,372.04,377.59$,

$1.291,1.291,1.859,3.005,3.601,4.021,4.342,4.635,4.902,5.139,5.352$,

$5.545,5.721,5.881,6.028,6.162,6.284$

/HTRANSFER (SET = "EXT80", CURVE $=17$, TEMPERATURE, REFTEMP $=299.83$ )

/HTRANSFER(SET $="$ EXT90", CURVE $=17$, TEMPERATURE, REFTEMP $=305.38$ )

/HTRANSFER(SET $=$ "EXT92", CURVE $=17$, TEMPERATURE, REFTEMP $=306.49$ )

HTRANSFER (SET $=$ "EXT 100", CURVE $=17$, TEMPERATURE, REFTEMP $=310.94$ )

$273.16,311.48,316.48,322.04,327.59,333.15,338.71,344.26,349.82,355.37$, $360.93,366.48,372.04,377.59,383.15,388.71,394.26$,

$1.235,1.235,2.657,3.342,3.819,4.193,4.505,4.773,5.008,5.217,5.403$,

$5.570,5.720,5.855,5.977,6.085,6.180$

/HTRANSFER(SET = "EXT110", CURVE $=17$, TEMPERATURE, REFTEMP $=316.49$ )

/HTRANSFER (SET $=$ "EXT115", CURVE $=17$, TEMPERATURE, REFTEMP $=319.27$ )

HTRANSFER(SET $=$ "EXT120", CURVE $=17$, TEMPERATURE, REFTEMP $=322.05$ ) 
$273.16,322.59,327.59,333.15,338.71,344.26,349.82,355.37,360.93,366.48$, $372.04,377.59,383.15,388.71,394.26,399.82,405.37$,

$1.226,1.226,2.635,3.310,3.776,4.140,4.441,4.698,4.920,5.115,5.287$, $5.439,5.573,5.691,5.793,5.881,5.955$

HTRANSFER (SET $=$ "EXT125", CURVE $=9$, TEMPERATURE, REFTEMP $=324.83$ )

273.16, 333.], 338.7, 344.3, 349.8, 355.4, 360.9, 366.5, 477.6,

$3.002,3.002,3.547,3.952,4.278,4.552,4.787,4.991,6.917$

/HTRANSFER (SET = "EXT130" , CURVE =9, TEMPERATURE, REFTEMP $=327.60$ )

HTRANSFER (SET = "EXT140", CURVE $=17$, TEMPERATURE, REFTEMP $=333.16$ )

$273.16,333.71,338.71,344.26,349.82,355.37,360.93,366.48,372.04,377.59$, $383.15,388.71,394.26,399.82,405.37,410.93,416.48$,

$1.210,1.210,2.597,3.257,3.710,4.060,4.346,4.588,4.794,4.971,5.125$,

$5.257,5.370,5.464,5.603,5.732,5.853$

HTRANSFER ( $S E T="$ EXT150" , CURVE $=9$, TEMPERATURE, REFTEMP $=338.72$ )

$273.16,344.3,349.8,355.4,360.9,366.5,372.1,377.6,477.6$,

$2.572,2.572,3.222,3.666,4.008,4.285,4.517,4.713,6.603$

HTRANSFER(SET $="$ EXT160" , CURVE $=17$, TEMPERATURE, REFTEMP $=344.27$ )

$273.16,344.82,349.82,355.37,360.93,366.48,372.04,377.59,383.15,388.71$, $394.26,399.82,405.37,410.93,416.48,422.04,427.59$,

$1.186,1.186,2.542,3.181,3.614,3.946,4.213,4.434,4.619,4.773,4.956$,

$5.124,5.278,5.420,5.552,5.674,5.787$

HTRANSFER (SET $=$ "EXT175", CURVE $=9$, TEMPERATURE, REFTEMP $=352.60$ )

$273.16,355.4,360.9,366.5,372.1,377.6,383.2,388.7,477.6$,

$1.981,1.981,2.833,3.328,3.686,3.964,4.210,4.443,6.264$

HTRANSFER(SET $=$ "EXT200", CURVE $=11$, TEMPERATURE, REFTEMP $=366.49$ )

$273.16,372.1,377.6,383.2,388.7,394.3,399.8,405.4,410.9,416.5,477.6$, $2.383,2.383,2.996,3.423,3.758,4.038,4.278,4.489,4.677,4.845,5.895$

/HTRANSFER(SET ="EXT205", CURVE $=17$, TEMPERATURE, REFTEMP $=369.27$ )

/HTRANSFER(SET= "EXT212" , CURVE $=17$, TEMPERATURE, REFTEMP=373.16)

/

/ BOUNDARY CONDITIONS

/

BCFLUX (HEAT, CONSTANT $=1.0$, CURVE $=1$, FACTOR=1.0, ENTITY="CASK_OD_Wa $11 "$ )

1

/ SOLAR INSOLATION VALUES FOR 30 DAYS - (10CFR71 VALUES/3600)*0.5*0.30

/ ASSUMES CONSERVATIVE VALUE OF SOLAR ABSORPTIVITY FOR WHITE PAINT

/ UNITS J/M2-S

/

TMFUNCTION $(S E T=1.0$, CURVE $=722$ )

$\begin{array}{rr}0.0, & 0.00000 \\ 3600.0, & 0.00000 \\ 7200.0, & 0.00000 \\ 10800.0, & 0.00000 \\ 14400.0, & 0.00000 \\ 18000.0, & 5.39406 \\ 21600.0, & 21.15041 \\ 25200.0, & 47.64757 \\ 28800.0, & 78.92368 \\ 32400.0, & 107.64471 \\ 36000.0, & 130.92436 \\ 39600.0, & 147.29582 \\ 43200.0, & 155.48155 \\ 46800.0, & 155.05571 \\ 50400.0, & 146.20755\end{array}$




\begin{tabular}{|c|c|}
\hline 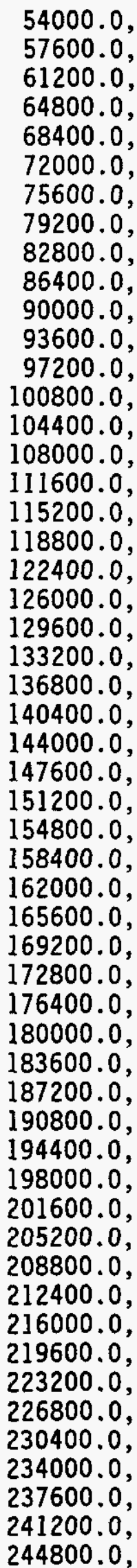 & $\begin{array}{r}130.49850 \\
107.64471 \\
80.24854 \\
50.91240 \\
24.36792 \\
6.24576 \\
0.00000 \\
0.00000 \\
0.00000 \\
0.00000 \\
0.00000 \\
0.00000 \\
0.00000 \\
0.00000 \\
5.39406 \\
21.15041 \\
47.64757 \\
78.92368 \\
107.64471 \\
130.92436 \\
147.29582 \\
155.48155 \\
155.05571 \\
146.20755 \\
130.49850 \\
107.64471 \\
80.24854 \\
50.91240 \\
24.36792 \\
6.24576 \\
0.00000 \\
0.00000 \\
0.00000 \\
0.00000 \\
0.00000 \\
0.00000 \\
0.00000 \\
0.00000 \\
5.3940\end{array}$ \\
\hline
\end{tabular}


Rev. 0

\begin{tabular}{|c|c|}
\hline $\begin{array}{l}48400.0, \\
52000.0, \\
55600.0, \\
59200.0, \\
62800.0, \\
66400.0, \\
70000.0, \\
73600.0, \\
77200.0, \\
80800.0, \\
84400.0, \\
88000.0, \\
91600.0, \\
95200.0, \\
98800.0, \\
02400.0, \\
06000.0, \\
09600.0, \\
13200.0, \\
16800.0, \\
20400.0, \\
24000.0, \\
27600.0, \\
31200.0, \\
34800.0, \\
38400.0, \\
42000.0, \\
45600.0, \\
49200.0, \\
52800.0, \\
56400.0, \\
60000.0, \\
63600.0, \\
67200.0, \\
70800.0, \\
74400.0, \\
78000.0, \\
81600.0, \\
85200.0, \\
88800.0, \\
92400.0, \\
96000.0, \\
09600.0\end{array}$ & $\begin{array}{r}0.00000 \\
0.00000 \\
0.00000 \\
0.00000 \\
0.00000 \\
0.00000 \\
0.00000 \\
0.00000 \\
5.39406 \\
21.15041 \\
47.6475 \\
78.92368 \\
107.64471 \\
130.92436 \\
147.2958 \\
155.48155 \\
155.05571 \\
146.2075 \\
130.49850 \\
107.64471 \\
80.24854 \\
50.91240 \\
24.36792 \\
6.24576 \\
0.00000 \\
0.00000 \\
0.00000 \\
0.00000 \\
0.00000 \\
0.00000 \\
0.00000 \\
0.00000 \\
5.39406 \\
21.15041 \\
47.6475 \\
78.92368 \\
107.6447 \\
130.92436 \\
147.2958 \\
155.4815 \\
155.0557 \\
146.2075 \\
130.49850 \\
107.6447 \\
80.2485 \\
50.9124\end{array}$ \\
\hline
\end{tabular}




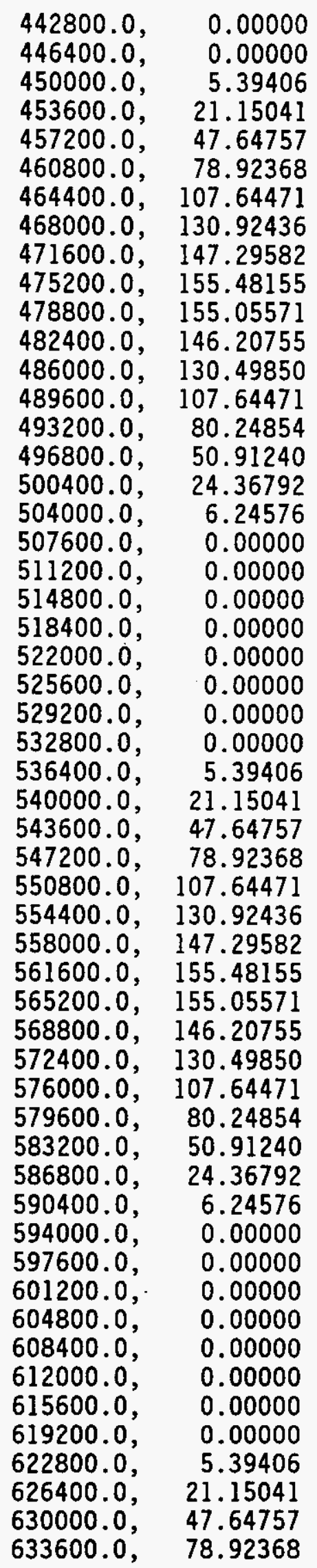




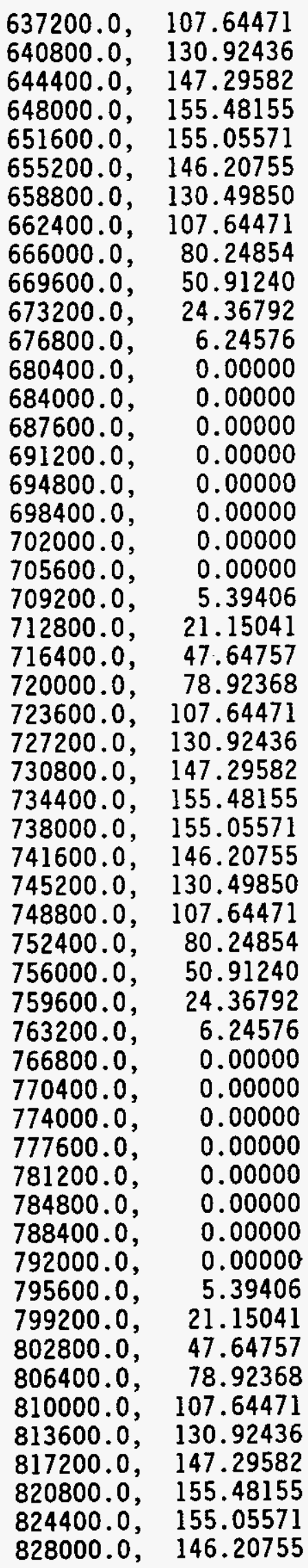




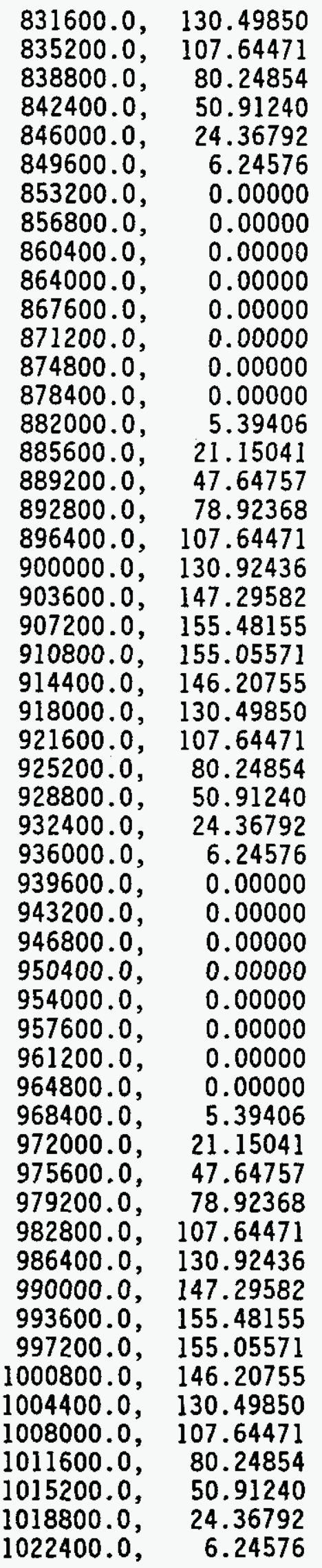




\begin{tabular}{|c|c|}
\hline 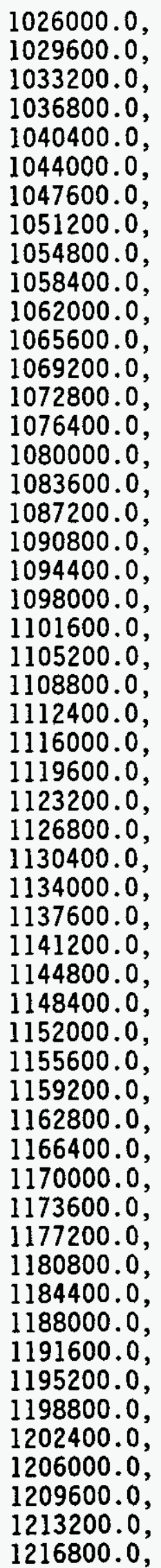 & $\begin{array}{r}0.00000 \\
0.00000 \\
0.00000 \\
0.00000 \\
0.00000 \\
0.00000 \\
0.00000 \\
0.00000 \\
5.39406 \\
21.15041 \\
47.64757 \\
78.92368 \\
107.64471 \\
130.92436 \\
147.29582 \\
155.48155 \\
155.05571 \\
146.20755 \\
130.49850 \\
107.64471 \\
80.24854 \\
50.91240 \\
24.36792 \\
6.24576 \\
0.00000 \\
0.00000 \\
0.00000 \\
0.00000 \\
0.00000 \\
0.00000 \\
0.00000 \\
0.00000 \\
5.39406 \\
21.15041 \\
47.64757 \\
78.92368 \\
107.64471 \\
130.92436 \\
147.29582 \\
155.48155 \\
155.05571 \\
146.20755 \\
130.49850 \\
107.64471 \\
80.24854 \\
50.91240 \\
24.36792 \\
6.24576 \\
0.00000 \\
0.00000 \\
0.00000 \\
0.00000 \\
0.000\end{array}$ \\
\hline
\end{tabular}




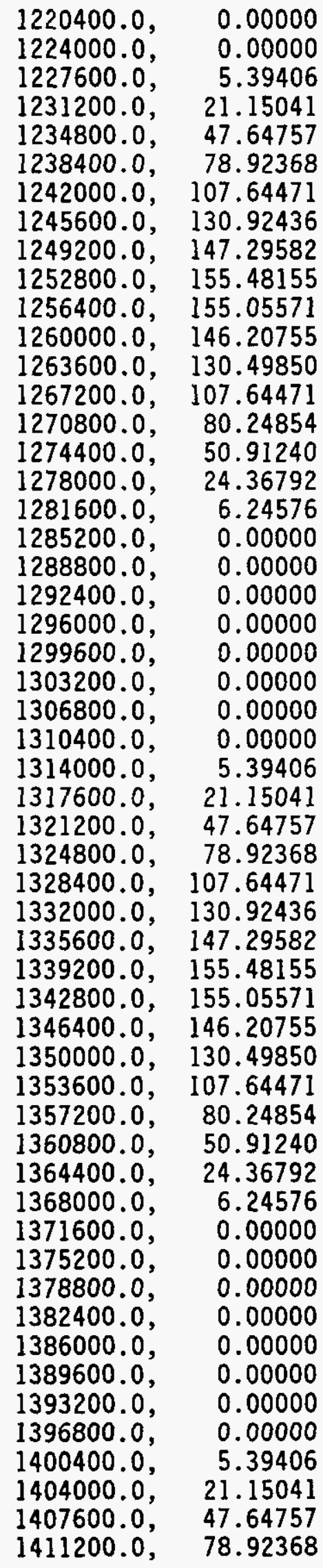




$\begin{array}{lr}1414800.0, & 107.64471 \\ 1418400.0, & 130.92436 \\ 1422000.0, & 147.29582 \\ 1425600.0, & 155.48155 \\ 1429200.0, & 155.05571 \\ 1432800.0, & 146.20755 \\ 1436400.0, & 130.49850 \\ 1440000.0, & 107.64471 \\ 1443600.0, & 80.24854 \\ 1447200.0, & 50.91240 \\ 1450800.0, & 24.36792 \\ 1454400.0, & 6.24576 \\ 1458000.0, & 0.00000 \\ 1461600.0, & 0.00000 \\ 1465200.0, & 0.00000 \\ 1468800.0, & 0.00000 \\ 1472400.0, & 0.00000 \\ 1476000.0, & 0.00000 \\ 1479600.0, & 0.00000 \\ 1483200.0, & 0.00000 \\ 1486800.0, & 5.39406 \\ 1490400.0, & 21.15041 \\ 1494000.0, & 47.64757 \\ 1497600.0, & 78.92368 \\ 1501200.0, & 107.64471 \\ 1504800.0, & 130.92436 \\ 1508400.0, & 147.29582 \\ 1512000.0, & 155.48155 \\ 1515600.0, & 155.05571 \\ 1519200.0, & 146.20755 \\ 1522800.0, & 130.49850 \\ 1526400.0, & 107.64471 \\ 1530000.0, & 80.24854 \\ 1533600.0, & 50.91240 \\ 1537200.0, & 24.36792 \\ 1540800.0, & 6.24576 \\ 1544400.0, & 0.00000 \\ 1548000.0, & 0.00000 \\ 1551600.0, & 0.00000 \\ 1555200.0, & 0.00000 \\ 1558800.0, & 0.00000 \\ 1562400.0, & 0.00000 \\ 1566000.0, & 0.00000 \\ 1569600.0, & 0.00000 \\ 1573200.0, & 5.39406 \\ 1576800.0, & 21.15041 \\ 1580400.0, & 47.64757 \\ 1584000.0, & 78.92368 \\ 1587600.0, & 107.64471 \\ 1591200.0, & 130.92436 \\ 1594800.0, & 147.29582 \\ 1598400.0, & 155.48155 \\ 1602000.0, & 155.05571 \\ 1605600.0, & 146.20755\end{array}$


$1609200.0, \quad 130.49850$

$1612800.0, \quad 107.64471$

$1616400.0, \quad 80.24854$

$1620000.0, \quad 50.91240$

$1623600.0, \quad 24.36792$

$1627200.0, \quad 6.24576$

$1630800.0, \quad 0.00000$

$1634400.0, \quad 0.00000$

$1638000.0, \quad 0.00000$

$1641600.0, \quad 0.00000$

$1645200.0, \quad 0.00000$

$1648800.0, \quad 0.00000$

$1652400.0, \quad 0.00000$

$1656000.0, \quad 0.00000$

$1659600.0, \quad 5.39406$

$1663200.0, \quad 21.15041$

$1666800.0, \quad 47.64757$

$1670400.0, \quad 78.92368$

$1674000.0, \quad 107.64471$

$1677600.0, \quad 130.92436$

$1681200.0, \quad 147.29582$

$1684800.0, \quad 155.48155$

$1688400.0, \quad 155.05571$

$1692000.0, \quad 146.20755$

$1695600.0, \quad 130.49850$

$1699200.0, \quad 107.64471$

$1702800.0, \quad 80.24854$

$1706400.0, \quad 50.91240$

$1710000.0, \quad 24.36792$

$1713600.0, \quad 6.24576$

$1717200.0, \quad 0.00000$

$1720800.0, \quad 0.00000$

$1724400.0, \quad 0.00000$

$1728000.0, \quad 0.00000$

$1731600.0, \quad 0.00000$

$1735200.0, \quad 0.00000$

$1738800.0, \quad 0.00000$

$1742400.0, \quad 0.00000$

$1746000.0, \quad 5.39406$

$1749600.0, \quad 21.15041$

$1753200.0, \quad 47.64757$

$1756800.0, \quad 78.92368$

$1760400.0, \quad 107.64471$

$1764000.0, \quad 130.92436$

$1767600.0, \quad 147.29582$

$1771200.0, \quad 155.48155$

$1774800.0, \quad 155.05571$

$1778400.0, \quad 146.20755$

$1782000.0, \quad 130.49850$

$1785600.0, \quad 107.64471$

$1789200.0, \quad 80.24854$

$1792800.0, \quad 50.91240$

$1796400.0, \quad 24.36792$

$1800000.0, \quad 6.24576$ 


\begin{tabular}{|c|c|}
\hline $\begin{array}{l}1803600 . \\
1807200 \\
1810800 . \\
1814400 \\
1818000 \\
1821600 \\
1825200 \\
1828800 \\
1832400 \\
1836000 \\
1839600 \\
1843200 \\
1846800 \\
1850400 \\
1854000 \\
1857600 \\
1861200 \\
1864800 \\
1868400 \\
1872000 \\
1875600 \\
1879200 \\
1882800 \\
1886400 \\
1890000 \\
1893600 \\
1897200 \\
1900800 \\
1904400 \\
1908000 \\
1911600 \\
1915200 \\
1918800 \\
1922400 \\
1926000 \\
1929600 \\
1933200 \\
1936800 \\
1940400 \\
1944000 \\
1947600 \\
1951200 \\
1954800 \\
1958400 \\
1962000 \\
1965600 \\
1969200 \\
1972800 \\
1976400 \\
1980000 \\
1983600 \\
1987200 \\
1990800 \\
1994400\end{array}$ & $\begin{array}{r}0.00000 \\
0.00000 \\
0.00000 \\
0.00000 \\
0.00000 \\
0.00000 \\
0.00000 \\
0.00000 \\
5.39406 \\
21.15041 \\
47.64757 \\
78.92368 \\
107.64471 \\
130.92436 \\
147.29582 \\
155.48155 \\
155.05571 \\
146.20755 \\
130.49850 \\
107.64471 \\
80.24854 \\
50.91240 \\
24.36792 \\
6.24576 \\
0.00000 \\
0.00000 \\
0.00000 \\
0.00000 \\
0.00000 \\
0.00000 \\
0.00000 \\
0.00000 \\
5.39406 \\
21.15041 \\
47.64757 \\
78.92368 \\
107.64471 \\
0.000000000 \\
130.92436 \\
0.000000 \\
147.29582 \\
155.48155 \\
155.05571 \\
146.20755 \\
130.49850 \\
107.64471 \\
80.24854 \\
50.91240 \\
24.36792 \\
0.000000\end{array}$ \\
\hline
\end{tabular}




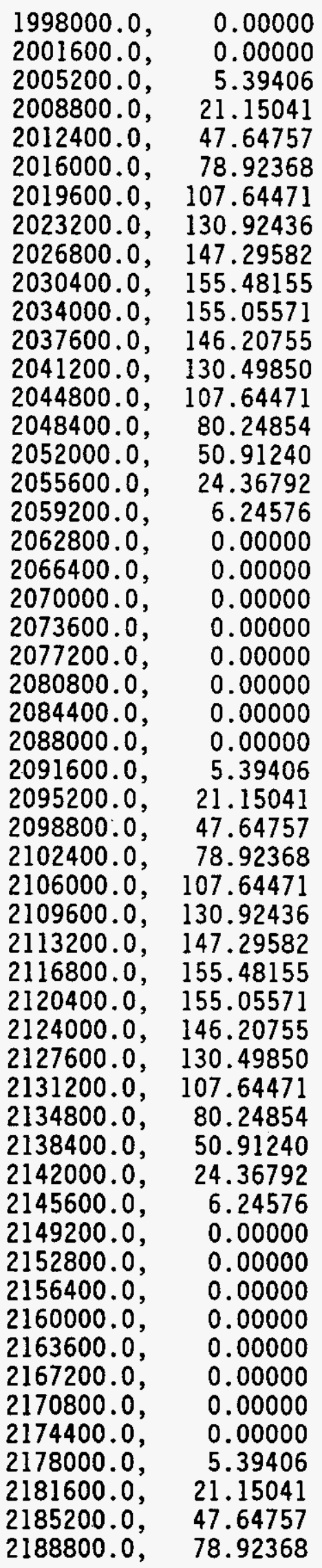


Rev. 0

$2192400.0, \quad 107.64471$

$2196000.0, \quad 130.92436$

$2199600.0, \quad 147.29582$

$2203200.0, \quad 155.48155$

$2206800.0, \quad 155.05571$

$2210400.0, \quad 146.20755$

$2214000.0, \quad 130.49850$

$2217600.0, \quad 107.64471$

$2221200.0, \quad 80.24854$

$2224800.0, \quad 50.91240$

$2228400.0, \quad 24.36792$

$2232000.0, \quad 6.24576$

$2235600.0, \quad 0.00000$

$2239200.0, \quad 0.00000$

$2242800.0, \quad 0.00000$

$2246400.0, \quad 0.00000$

$2250000.0, \quad 0.00000$

$2253600.0, \quad 0.00000$

$2257200.0, \quad 0.00000$

$2260800.0, \quad 0.00000$

$2264400.0, \quad 5.39406$

$2268000.0, \quad 21.15041$

$2271600.0, \quad 47.64757$

$2275200.0, \quad 78.92368$

$2278800.0, \quad 107.64471$

$2282400.0, \quad 130.92436$

$2286000.0, \quad 147.29582$

$2289600.0, \quad 155.48155$

$2293200.0, \quad 155.05571$

$2296800.0, \quad 146.20755$

$2300400.0, \quad 130.49850$

$2304000.0, \quad 107.64471$

$2307600.0, \quad 80.24854$

$2311200.0, \quad 50.91240$

$2314800.0, \quad 24.36792$

$2318400.0, \quad 6.24576$

$2322000.0, \quad 0.00000$

$2325600.0, \quad 0.00000$

$2329200.0, \quad 0.00000$

$2332800.0, \quad 0.00000$

$2336400.0, \quad 0.00000$

$2340000.0, \quad 0.00000$

$2343600.0, \quad 0.00000$

$2347200.0, \quad 0.00000$

$2350800.0, \quad 5.39406$

$2354400.0, \quad 21.15041$

$2358000.0, \quad 47.64757$

$2361600.0, \quad 78.92368$

$2365200.0, \quad 107.64471$

$2368800.0, \quad 130.92436$

$2372400.0, \quad 147.29582$

$2376000.0, \quad 155.48155$

$2379600.0, \quad 155.05571$

$2383200.0, \quad 146.20755$ 


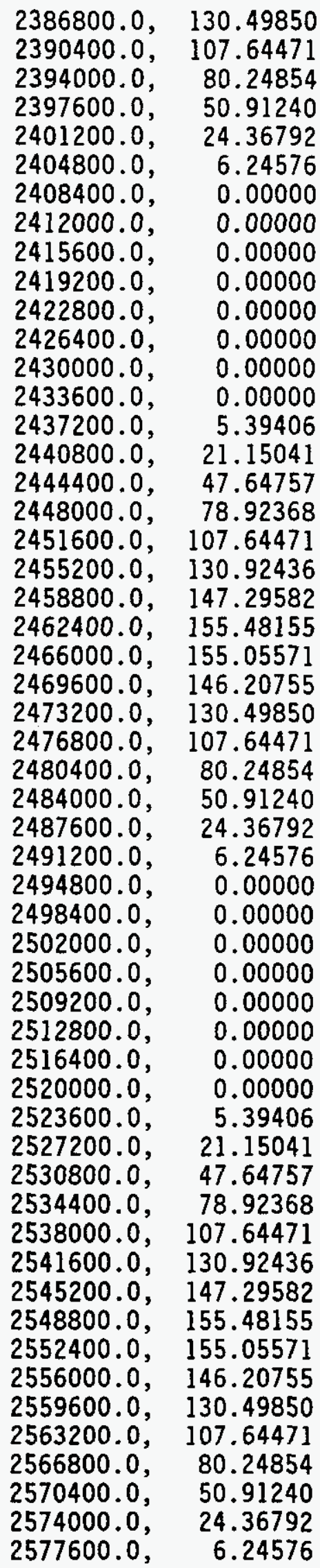


WHC-SD-WM-ER-525

Rev. 0

$\begin{array}{rr}2581200.0, & 0.00000 \\ 2584800.0, & 0.00000 \\ 2588400.0, & 0.00000 \\ 2592000.0, & 0.00000 \\ 2595600.0, & 0.00000\end{array}$

RADSURFACE (ENTITY= "MCO OD Rad", INDIVIDUAL)

RADSURFACE (ENTITY = "GAP" $\chi$ Rad", INDIVIDUAL)

RADSURFACE (ENTITY = "GAP ${ }^{-} Y^{-}$Rad", INDIVIDUAL)

RADSURFACE (ENTITY="CASK ID Rad", INDIVIDUAL)

RADSURFACE (ENTITY="MCO ID R̄ad", INDIVIDUAL)

RADSURFACE (ENTITY= "MCO-ROD Rad", INDIVIDUAL)

RADSURFACE (ENTI TY= "MCO- $X$ Ràd1", INDIVIDUAL)

RADSURFACE (ENTITY="MCO- $\chi^{-}$Rad2" , INDIVIDUAL)

RADSURFACE (ENTITY= "MCO- $\chi^{-}$Rad3", INDIVIDUAL)

RADSURFACE (ENTITY= "MCO ${ }^{-} \chi^{-}$Rad4" ", INDIVIDUAL)

RADSURFACE (ENTITY= "MCO- $\chi^{-}$Rad5" , INDIVIDUAL)

RADSURFACE (ENTI $Y=" M{ }^{-}{ }^{-}{ }^{-}$Rad6", INDIVIDUAL)

RADSURFACE (ENTITY= "MCO- $\chi^{-}$Rad7" ", INDIVIDUAL)

RADSURFACE (ENTITY= "MCO- ${ }^{-}$Radl ", INDIVIDUAL)

RADSURFACE (ENTITY= "MCO- ${ }^{-}$Rad2", INDIVIDUAL)

RADSURFACE (ENTITY="MCO- ${ }^{-}$Rad3", INDIVIDUAL)

RADSURFACE (ENTITY = "MCO- ${ }^{-}$Rad4" ", INDIVIDUAL)

RADSURFACE (ENT ITY= "MCO- $Y$-Rad5", INDIVIDUAL)

RADSURFACE (ENT ITY = "MCO- ${ }^{-}$-Rad6", INDIVIDUAL)

RADSURFACE (ENTITY= "MCO ${ }^{-}{ }^{-}$Rad7" ", INDIVIDUAL)

RADSURFACE (ENTITY= "MCO- ${ }^{-}$Rad8", INDIVIDUAL)

RADSURFACE (ENTITY= "MCO- ${ }^{-}$Rad9", INDIVIDUAL)

RADSURFACE (ENTITY= "MCO ${ }^{-} Y^{-} \operatorname{Rad} 10^{\prime}$ ", INDIVIDUAL)

RADSURFACE (ENTITY="Innēr-Flow Radl", INDIVIDUAL)

RADSURFACE (ENTITY=" Inner-Flow-Rad2", INDIVIDUAL)

RADSURFACE (ENTITY=" Inner-Flow-Rad3", INDIVIDUAL)

RADSURFACE (ENTITY=" Inner-Flow'Rad4", INDIVIDUAL)

RADSURFACE (ENTITY=" Inner-Flow'Rad5", INDIVIDUAL)

RADSURFACE (ENTITY=" Inner-Flow'Rad6", INDIVIDUAL)

RADSURFACE (ENTITY=" Inner-Fl ow-Rad7", INDIVIDUAL)

RADSURFACE (ENTITY="Outer Flowid Radl ", INDIVIDUAL)

RADSURFACE (ENTITY="Outer-Flowid-Rad2", INDIVIDUAL)

RADSURFACE (ENTITY="Outer Flowid Rad3", INDIVIDUAL)

RADSURFACE (ENTITY = "Outer Flowid Rad4", INDIVIDUAL)

RADSURFACE (ENTITY="Outer Flowid Rad5", INDIVIDUAL)

RADSURFACE (ENTITY="Outer Flowid Rad6", INDIVIDUAL)

RADSURFACE (ENTITY="0uter ${ }^{-}$Flowid Rad7", INDIVIDUAL)

RADSURFACE (ENT ITY="Outer Flowod Radl ", INDIVIDUAL)

RADSURFACE (ENTITY="Outer Flowod Rad2", INDIVIDUAL)

RADSURFACE (ENTITY="Outer ${ }^{-}$Flowod ${ }^{-R a d 3 ", ~ I N D I V I D U A L) ~}$

RADSURFACE (ENT ITY= "Outer - Flowod Rad4" , INDIVIDUAL)

RADSURFACE (ENTITY="Outer Flowod Rad5", INDIVIDUAL)

RADSURFACE (ENTITY="Outer Flowod Rad6", INDIVIDUAL)

RADSURFACE (ENTIIY="Outer Flowod Rad7", INDIVIDUAL)

RADSURFACE (ENTITY="Cladod_Radl ", INDIVIDUAL) 


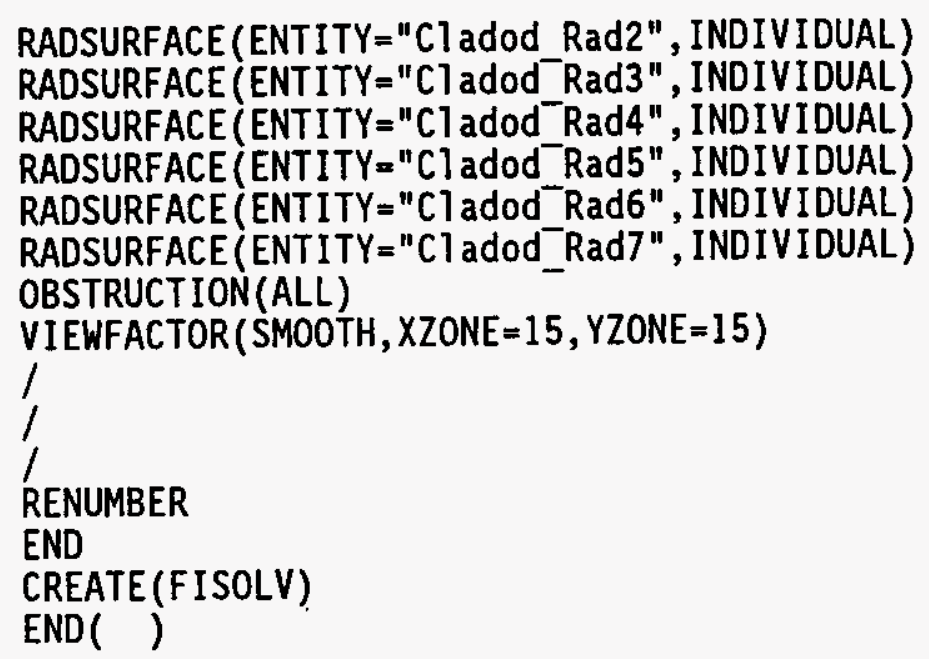


WHC-SD-WM-ER-525

Rev. 0

APPENDIX E

FIDAP MODEL SIZES

E-1 
WHC-SD-WM-ER-525

Rev. 0

Table E-1. Summary of FIDAP Model sizes.

\begin{tabular}{|c|c|c|c|c|c|}
\hline & FEC & \multicolumn{3}{|c|}{ Dense Pack } & Rubble \\
\hline & $\begin{aligned} & 90^{\circ} \mathrm{MCO}+\text { FEC } \\
&+ 7 \text { Q MKIV + Cask } \\
&\end{aligned}$ & $\begin{array}{l}30^{\circ} \text { MCO + } \\
\text { MKIV + Cask }\end{array}$ & $\begin{array}{l}30^{\circ} \mathrm{MCO}+ \\
\text { MKI a + Cask }\end{array}$ & $\begin{array}{l}30^{\circ} \mathrm{MCO}+ \\
\mathrm{MIV}+\mathrm{CSB} \\
\end{array}$ & $\begin{array}{c}30^{\circ} \mathrm{MCO}+ \\
\text { Rubble + Cask }\end{array}$ \\
\hline \# of Nodal Pts. & 7889 & 3558 & 2967 & 3690 & 1203 \\
\hline \# of El ements & 5229 & 7194 & 5906 & 7362 & 1139 \\
\hline * of Pts./Element & 9 & 4 & 4 & 4 & 4 \\
\hline \# of Element Groups & 290 & 280 & 259 & 280 & 5 \\
\hline$\#$ of Faces & 1945 & 3396 & 2818 & 3524 & 1139 \\
\hline \# of External Faces & 1945 & 3396 & 2818 & 3524 & 1139 \\
\hline \# of External Edges & 7884 & 6953 & 5784 & 7213 & 2341 \\
\hline
\end{tabular}




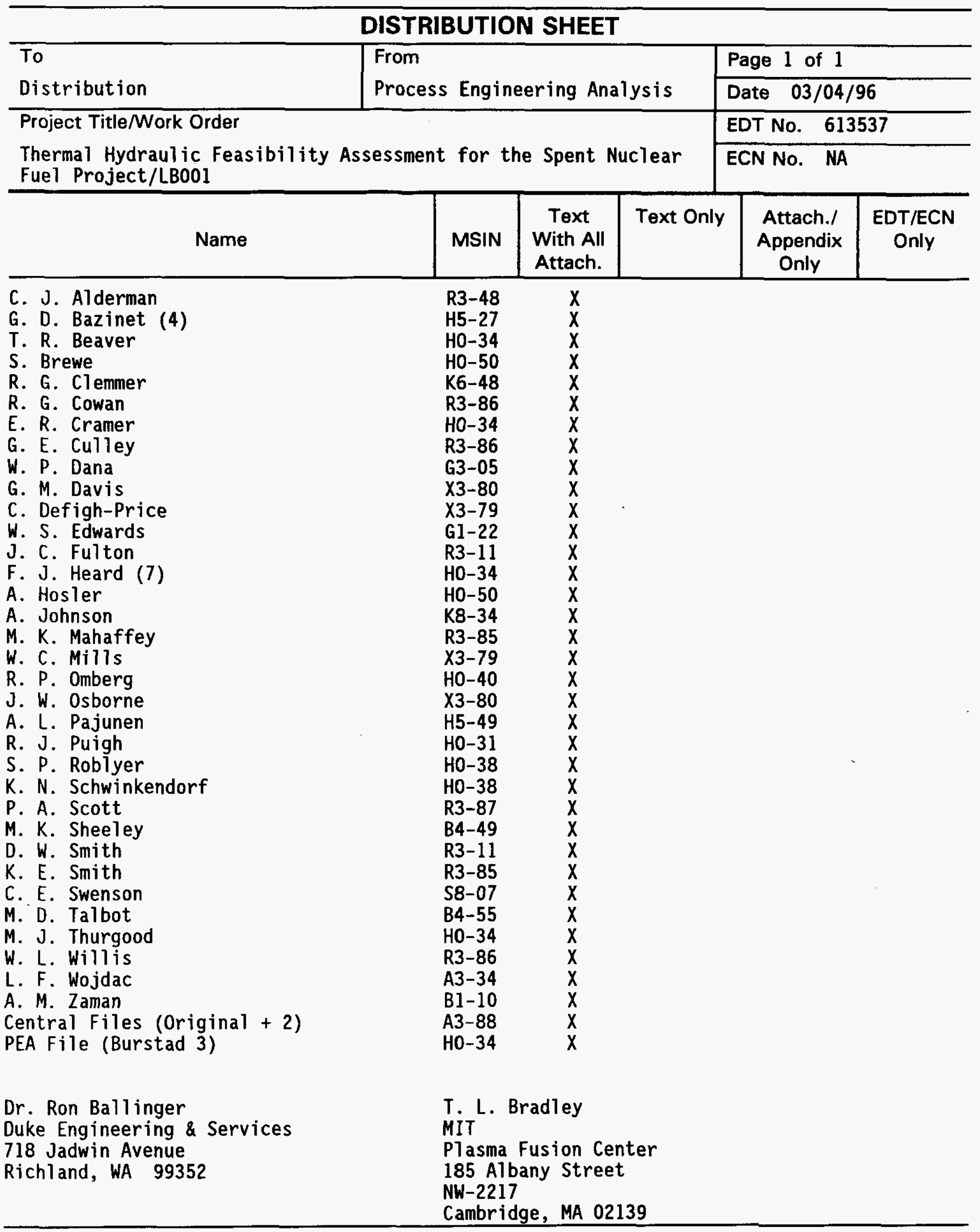

